\title{
Sustainable Process Synthesis-Intensification
}

\section{Babi, Deenesh Kavi}

Publication date:

2014

\section{Document Version}

Publisher's PDF, also known as Version of record

Link back to DTU Orbit

Citation (APA):

Babi, D. K. (2014). Sustainable Process Synthesis-Intensification. DTU Chemical Engineering.

\section{General rights}

Copyright and moral rights for the publications made accessible in the public portal are retained by the authors and/or other copyright owners and it is a condition of accessing publications that users recognise and abide by the legal requirements associated with these rights.

- Users may download and print one copy of any publication from the public portal for the purpose of private study or research.

- You may not further distribute the material or use it for any profit-making activity or commercial gain

- You may freely distribute the URL identifying the publication in the public portal

If you believe that this document breaches copyright please contact us providing details, and we will remove access to the work immediately and investigate your claim. 


\section{Sustainable Process Synthesis-} Intensification

\section{Computer-Aided Molecular Design}

From atoms to molecules

Lower Level of Aggregation

Next Lower Level of Aggregation

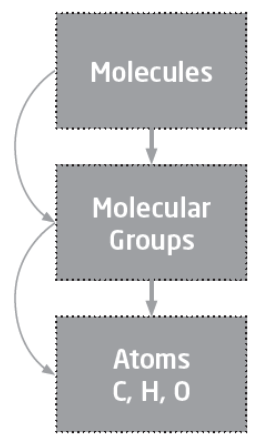

Computer-Aided Flowsheet Design

From phenomena to process
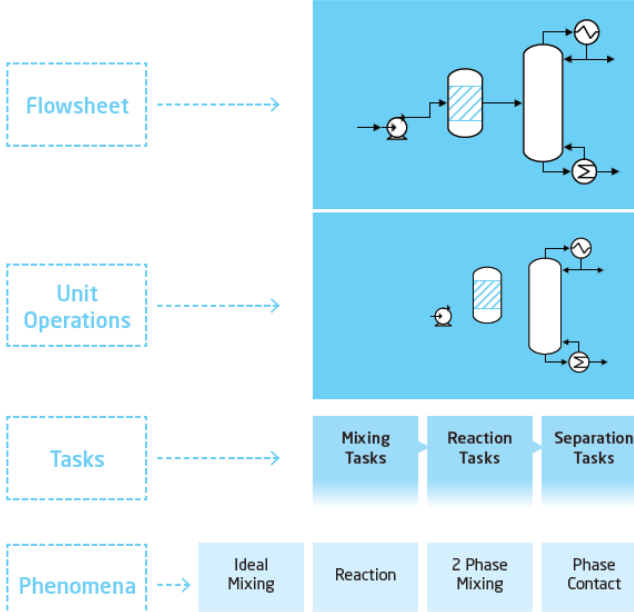
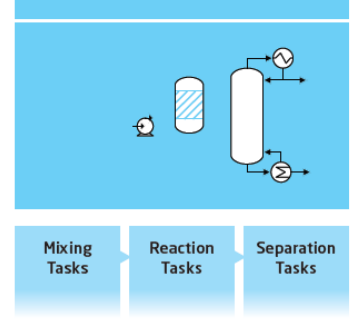
\begin{tabular}{l|l|l} 
Reaction & $\begin{array}{c}2 \text { Phase } \\
\text { Mixing }\end{array}$ & $\begin{array}{c}\text { Phase } \\
\text { Contact }\end{array}$
\end{tabular} Transition

Deenesh K. Babi

Ph.D. Thesis

September 2014 


\section{Sustainable Process}

\section{Synthesis-Intensification}

Doctor of Philosophy Thesis

By

Deenesh K. Babi

CAPEC-PROCESS Research Centre

DTU Chemical Engineering

Technical University of Denmark

Lyngby, Denmark

Tuesday, 30th September, 2014 


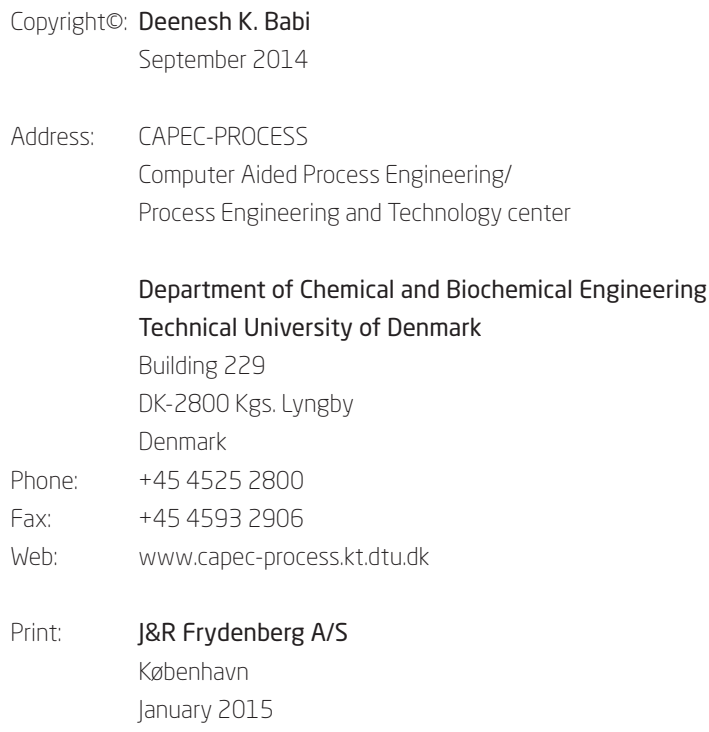


This thesis is submitted as part of the requirements for the Doctor of Philosophy (PhD) degree at the Technical University of Denmark (DTU). The PhD project was carried out at the Computer-Aided Process-Product Engineering Center, at the Department of Chemical and Biochemical Engineering from 2011 to 2014 under the supervision of Professor Rafiqul Gani and Professor John M. Woodley. The PhD project included an external stay at the Laboratory of Fluid Separations (FVT), headed by Professor Andrzej Górak at the Technical University of Dortmund.

First, I would like to thank my supervisors, Professor Rafiqul Gani and John M. Woodley, for advice, direction and interesting conversations related to the idea of process synthesis and intensification. I would like to thank Dr. Philip Lutze at FVT and whose work I have continued, which, he started while at CAPEC and for his advice and feedback on the development of the idea of synthesis and intensification. I would like to thank Johannes Holtbruegge at FVT for his knowledge sharing and provision of data for the combined case study work for the production of dimethyl carbonate.

I would like to thank all of my former and current colleagues, both academic and administrative, at CAPEC and PROCESS for their fruitful discussions, encouragement and ideas that were shared from time to time. I would like to thank Professor Emeritus John Villadsen who saw 5 years ago in the small island of Trinidad, a potential chemical engineering student who could succeed in pursuing a higher education in chemical and biochemical engineering in Denmark, for his motivational talks and career ideas.

I would like to especially thank my main supervisor, Professor Rafiqul Gani, who has taught me many things in the last 3 years related to process synthesis, design and sustainable design, for the training and opportunity in being able to disseminate my work at conferences, in papers and book chapters and for many late night fruitful conversations. I would like to thank the members, both pass and present, of the dancing class I teach (Bachata) at DTU. You have been one of my relaxation activities and I've enjoyed teaching all of you. I would like to thank my close friends for always being there and when you read this you know who you are. I would like to thank Valeria ("'egg") for always being there.

I would like to thank my family but most of all my mother, my sister, my grandmother and my uncle, to whom I dedicate this thesis. Finally I would like to thank Jesus, indeed you are my God and my Saviour.

Kongens Lyngby, September 2014

Deenesh K. Babi 

...to mammy, lee, mama and bodoe... 


\section{ABSTRACT}

The chemical and biochemical industry needs major reductions in energy consumption, and waste generation, among others, in order to, remain competitive in a global market through the construction and operating of, sustainable chemical processes. These required reductions can be addressed through process intensification, that is, the efficient use of raw materials (feedstock) and the use of sustainable technologies or processes that directly impact and improves sustainability/LCA factors. Process intensification is a concept by which processes, whether conceptual or existing, can be designed or redesigned to achieve more efficient and sustainable designs. Therefore, sustainable process design can be achieved by performing process synthesis and process intensification together.

The main contribution of this work is the development of a systematic computer-aided multi-scale, multi-level framework for performing process synthesis-intensification that aims to make a process more sustainable than a base case design that represents either a new or existing process. The framework consists of two parts. In the first part, process synthesis, design and analysis are performed (step 1 to step 8 ) and operates at the unit operation scale and task scale. In the second part, integrated task-phenomena based synthesis is performed (IT-PBS.1 to IT-PBS.4) and operates at the task scale and phenomena scale. The concept of generating more sustainable designs through the combination of phenomena provides the opportunity to innovate through the generation of novel unit operations and thereby, expands the search space of available unit operations.

At the unit operations scale a conceptual base case process is synthesized, designed and analysed, for identifying process limitations or bottlenecks (hot-spots) using a comprehensive analysis, consisting of, economic, life cycle and sustainability analyses that are translated into design targets. These hot-spots are associated with tasks that may be targeted for overall process improvement. Next, an integrated task-phenomena based synthesis method is applied, where the involved phenomena in various tasks are identified, manipulated and recombined using combination rules, in order to, generate new and/or existing unit operations that are configured into flowsheet alternatives inclusive of hybrid/intensified unit operations. The flowsheet alternatives that satisfy the performance criteria and design targets give innovative and more sustainable, non-trade off process designs that otherwise could not be found from operation at the higher scales.

The framework is tested through three case studies related to the chemical and bioprocess industry in order to test the applicability of the framework for covering a wide range of applications, showing that process intensification provides major benefits related to the generation of more sustainable process designs. 



\section{RESUMÉ PÁ DANSK}

Kemi- og biokemiindustrien har behov for en betydelig reduktion af blandt andet energiforbrug og affaldsgenerering for at forblive konkurrencedygtig på et globalt marked gennem opbygning og drift af bæredygtige kemiske processer. Disse nødvendige reduktioner kan adresseres gennem procesintensivering, det vil sige effektiv brug af råmaterialer (feedstock) og brug af bæredygtige teknologier eller processer som direkte påvirker og forbedrer bæredygtighed $\backslash$ LCA-faktorer. Procesintensivering er et koncept gennem hvilket processer, både konceptuelle og eksisterende, kan struktureres eller omstruktureres for at opnå mere effektive og bæredygtige design. Derfor kan et bæredygtigt procesdesign opnås ved processyntese og procesintensivering sideløbende.

Dette værks hovedbidrag er udviklingen af et systematisk computerbaseret, multi-scale, multi-niveau framework til at udføre processynteseintensivering, som har til sigte at gøre en proces mere bæredygtig end et base case-design, som repræsenterer enten en ny eller eksisterende proces. Framework består af to dele. I den første del, processyntese, udføres design og analyse (trin 1 til trin 8) som opererer på enheds- og opgaveniveau. I den anden del udføres integreret opgave-fænomen-baseret syntese (IT-PBS.1 to ITPBS.4) som opererer på opgave- og fænomen niveau. Skabelsen af mere bæredygtige designs gennem kombinationen af fænomener giver mulighed for at innovere gennem generation af nye enhedsoperationer og derved udvide søgerummet for tilgængelige enhedsoperationer.

På enhedsoperationsniveau syntetiseres, designes og analyseres en konceptuelt base case-proces for at identificere procesbegrænsninger eller flaskehalse (hot-spots) ved hjælp af en omfattende analyse bestående af økonomiske, livscyklus og bæredygtighedsanalyser som oversættes til designmål. Disse hot-spots er associeret med opgaver som kan målrettes til generel procesforbedring. Dernæst anvendes en integreret opgave-fænomen-baseret syntesemetode, hvor det involverede fænomen i forskellige opgaver identificeres, manipuleres og rekombineres ved hjælp af kombinationsregler for at generere nye og/eller eksisterende enhedsoperationer, som konfigureres til alternative flowdiagrammer inklusiv hybrid/intensiverede enhedsoperationer. De flowdiagramalternativer, som opfylder præstationskriterierne og designmålene, giver innovative og mere bæredygtige kompromisløse flowdiagramdesign, som ellers ikke kunne findes på de højere niveauer.

Frameworket påføres tre casestudier relateret til kemi- og biokemiindustrien for at teste anvendeligheden af frameworket på en bred vifte af formål. Dette viser at procesintensivering genererer betydelige fordele relateret til udviklingen af mere bæredygtige procesdesigns 

Contents

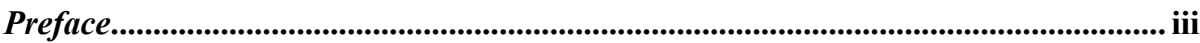

Abstract ........................................................................................................................................... vii

Resumé på Dansk .............................................................................................................

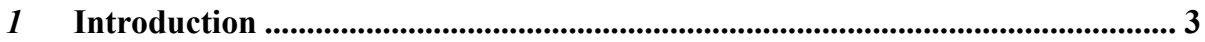

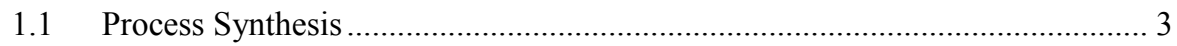

1.2 State of the Art: Process Synthesis and Process Intensification Methods ......... 5

1.3 Sustainable Process Synthesis, Design and Sustainable Design........................ 8

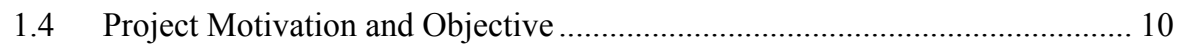

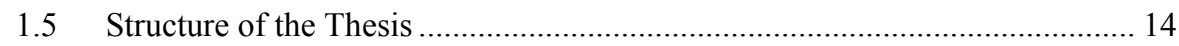

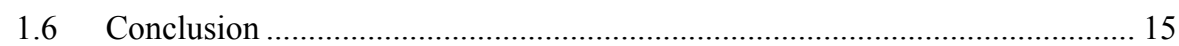

2 Framework for Sustainable Process Synthesis-Intensification: Solution Approach \& Definitions ...................................................................................... 17

2.1 Process Synthesis-Intensification Mathematical Description .......................... 17

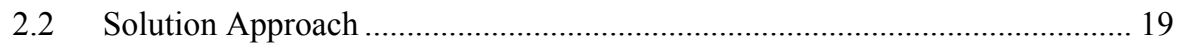

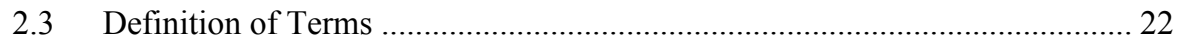

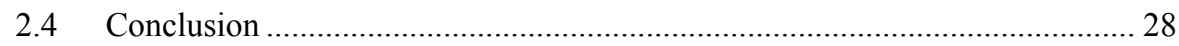

3 Framework for Sustainable Process Synthesis-Intensification: Methodology 29

$3.1 \quad$ Framework Architecture ............................................................................. 29

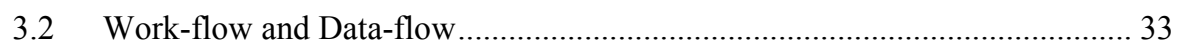

3.3 Part I-Synthesis, Design and Analysis ........................................................... 33

3.4 Part II-Sustainable Design : Integrated Task-Phenomena based Synthesis..... 47

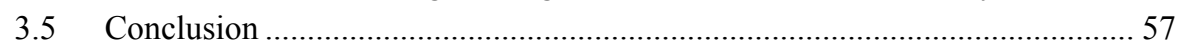

4 Framework for Sustainable Process Synthesis-Intensification: Algorithms... 59

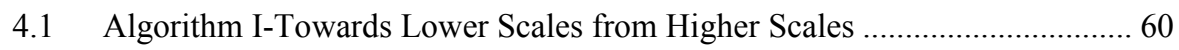

4.2 Algorithm II-Towards Higher Scales from Lower Scales ............................... 64

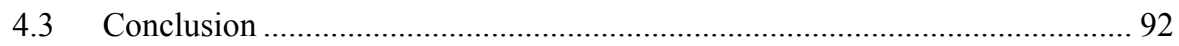

5 Framework for Sustainable Process Synthesis-Intensification: Supporting

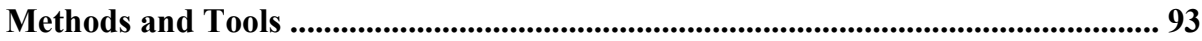

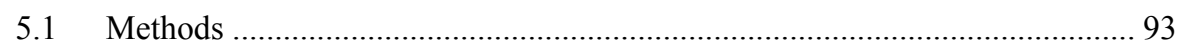

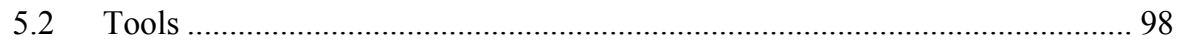

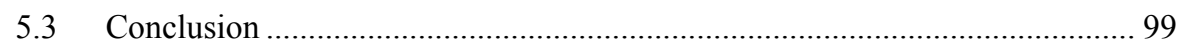

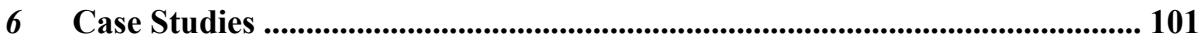

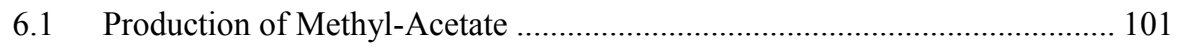

6.2 Production of Di-Methyl Carbonate ........................................................... 125

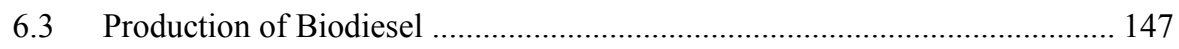

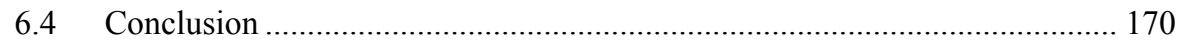


7 Conclusion and Future Perspectives.............................................................. 171

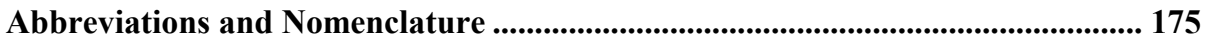

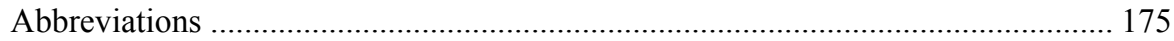

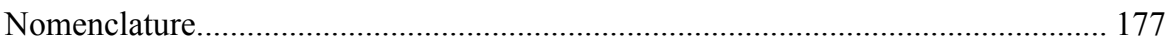

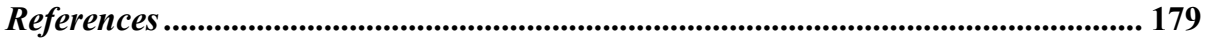

Appendices ........................................................................................................................... 189

Appendix A-Classification of Basic Structures...................................................... 190

Appendix B-Identification of Phenomena Building Blocks................................... 193

Appendix C-Identification of Desirable Task and Phenomena Building Blocks ..... 196

Appendix D-Database of Basic Structures ............................................................ 201

Appendix E-Translation of Basic Structures into Unit Operations .......................... 213

Appendix F-Membrane reactor Analysis-Methyl-Acetate ....................................... 216 


\section{$1_{\text {InTROduction }}$}

When you awake in the morning, pull the curtain and say to the world, 'Today I'm going to manage the complexity. '-John M. Woodley \& Rafiqul Gani (Lyngby, Denmark, 2013)

The general process synthesis problem is a complex problem to solve, because it involves the selection, evaluation and design of an optimal (or near optimal) processing route from among numerous alternatives. Therefore, different methods have been and continue to be, developed in order to solve it. The process synthesis problem can be solved from the application of heuristic based methods (Douglas, 1985, Rudd and Watson, 1968), optimization based methods (Papoulias and Grossmann, 1983, Quaglia et al., 2014) or hybrid methods (Papalexandri and Pistikopoulos, 1996, Lutze et al., 2014). The author, based on the current research performed in this thesis, places the current work under hybrid methods, that is, a computer-aided systematic framework for performing process synthesis (and intensification) has been developed.

In this chapter, first, an overview of process synthesis, that is, its objective and how it is performed is presented. Second, an overview of the process synthesis (inclusive of intensification) methods currently applied is presented in order to identify further developments related to process synthesis and intensification. Third, an overview of process synthesis, design and sustainable design is presented explaining the different stages associated with achieving more sustainable designs. Fourth, the project motivation and objective are presented for which this thesis has been developed to address.

\subsection{Process Synthesis}

The objective of process synthesis is to determine the best processing route (process flowsheet), from among numerous alternatives for converting given raw materials to specific desired products subject to predefined performance criteria (Gani and Babi, 2014). This is shown in Figure 1-1. Multiple scenarios of the process synthesis problem exists, for example, given a set of raw materials, determine the best chemical processes for producing a range of products, or, given a set of products, determine the best chemical processes for producing these products from multiple raw materials, among others. 


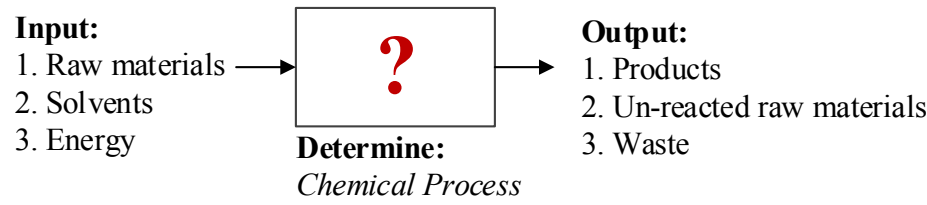

Figure 1-1: Process synthesis problem structure

In performing process synthesis, the unit operations typically considered are normally well-known (established) unit operations (Bedenik et al., 2004, Li et al., 2011). Examples of these are given in Table 1-1.

Table 1-1: A list of well-known unit operations

\begin{tabular}{|l|l|l|}
\hline $\begin{array}{l}\text { Unit Operation } \\
\text { (reaction + separa- } \\
\text { tion) }\end{array}$ & Feed Phase & Task \\
\hline Batch reactor & $\begin{array}{l}\text { Solid, gas (vapor) } \\
\text { and/or liquid }\end{array}$ & Reaction \\
\hline Semi-batch reactor & $\begin{array}{l}\text { Solid, gas (vapor) } \\
\text { and/or liquid }\end{array}$ & Reaction \\
\hline CSTR & Liquid & Reaction \\
\hline Distillation & Vapor and/or liquid & Separation \\
\hline $\begin{array}{l}\text { Extractive distilla- } \\
\text { tion }\end{array}$ & Vapor and/or liquid & Separation \\
\hline Reboiled absorption & Vapor and/or liquid & Separation \\
\hline
\end{tabular}

However, an extension of the unit operations search space is needed in order to include other types of unit operations not frequently considered during process synthesis, that is, hybrid (used interchangeably with intensified) unit operations. A hybrid/intensified unit operation, is an unit operation that enhances the function of one or more unit operations for performing a task or set of tasks, through the combination of more than one unit operation or the design of a new unit operation. Therefore, the general definition of the process synthesis problem must be expanded in order to include constraints and performance criteria that provide the opportunity, where applicable, to consider hybrid/intensified unit operations when performing process synthesis. Examples of hybrid/intensified unit operations are given in Table 1-2. 
Table 1-2: A list of hybrid/intensified unit operations

\begin{tabular}{|l|l|l|l|}
\hline Unit Operation & Novelty & Feed Phase & Task \\
\hline $\begin{array}{l}\text { Divided Wall Col- } \\
\text { umn }\end{array}$ & $\begin{array}{l}\text { Performs the } \\
\text { separation } \\
\text { equivalent to 2 } \\
\text { or more con- } \\
\text { ventional distil- } \\
\text { lation columns }\end{array}$ & $\begin{array}{l}\text { Vapor and/or liq- } \\
\text { uid }\end{array}$ & Separation \\
\hline Reactive Distillation & $\begin{array}{l}\text { Preforms the } \\
\text { reaction and } \\
\text { separation of 1 } \\
\text { or more reactors } \\
\text { and 1 or more } \\
\text { distillation col- } \\
\text { umns }\end{array}$ & Vapor and/or Liq- & Reaction+Separation \\
\cline { 3 - 5 } Reactive Divided & Vid & Reaction+Separation \\
Wall Column & \multicolumn{2}{|l}{ Liq- } & \\
\hline
\end{tabular}

\subsection{State of the Art: Process Synthesis and Process Intensifi- cation Methods}

Process synthesis methods can be classified into three main categories of methods which operate at the unit operations scale, task scale and phenomena scale. At the unit operations scale the synthesis methods can be classified into heuristic (and knowledgebased) methods, mathematical optimization methods and hybrid methods. Heuristic methods and mathematical optimization methods mainly perform process synthesis at the unit operations scale and task scale. The search space includes well-known (established) plus existing hybrid/intensified unit operations. Hybrid methods incorporates knowledge of the previous two methods, that is, heuristic and mathematical optimization and, performs process synthesis at the unit operations level, tasks level and phenomena level.

\subsubsection{Heuristic and knowledge based}

Heuristic methods utilize rules that are based on experience obtained from the knowhow of existing processes and which provide favourable results when applied (though it might not be the optimal result). However, these rules when applied should be verified for example through simulation in order to confirm that they can be used for a specific application because heuristics are not applicable to all situations.

Knowledge based methods (Douglas 1985, Brandt et al., 2000, Bayer et al., 2000, Singh et al., 2010, Gernaey and Gani, 2010) are structured around three models and usually consist of sets of heuristic rules. The first, are data models where all the available knowledge are stored in a structured framework. The second, are data mining models 
that includes the procedures and rules to obtain the necessary knowledge from the data model to be applied. The third, are application models that includes the rules and methods to apply the knowledge obtained through the data mining model.

An advantage of heuristic methods is that, it is helpful in recommending process improvements of an existing process because it is based on knowledge gained from experience, that is, it is evolutionary. Therefore, it can also be used for synthesis of new flowsheet alternatives based on existing processes which are similar in reaction and/or products.

The limitation of heuristic-based methods and methods which employ heuristics is that not all heuristic rules are of general application and therefore, careful consideration must be taken when applying these rules. For example, consider these two heuristic rules:

1. Remove the most plentiful component first

2. Perform the most difficult separation last

A problem arises if the most plentiful component is involved in the most difficult separation.

\subsubsection{Mathematical programming}

Mathematical programming methods require the generation of a superstructure which contains a finite number of processing units with their corresponding interconnections (Papoulias and Grossmann, 1983, Hostrup et al., 2001, Grossmann, 2012, Baliban et al., 2012, Quaglia et al., 2014). The superstructure is commonly derived by making use of engineering judgement, heuristics and/or thermodynamic considerations. The process synthesis optimization problem is solved by using equations that describe the equipment within the superstructure and their connectivity, together with the constraints for the operating conditions. The objective function to be minimized/maximized is specified such as cost minimization or profit maximization and is subject to linear and non-linear constraints. Since different choices are possible among equipment, discrete variables are used to represent these choices and therefore, the overall synthesis model to be solved is a mixed integer non-linear programming (MINLP) problem. The solution of the MINLP problem is difficult due to the non-convexity of the system of equations, therefore, it can be solved by reformulating the synthesis problem into an MILP problem for example operating conditions, such as temperature and pressure, can be fixed and linear equations, such as mass and energy balances, can be derived for evaluating the performance of each unit (Quaglia et al., 2014).

The advantage of mathematical programming methods is that they perform simultaneous optimization of the flowsheet structure and operating conditions which has been shown to provide better results than the sequential approach, used by, for example, heuristic methods (Biegler, Grossmann and Westerberg, 1997).

The limitations with mathematical programming methods are as follows (Barnicki and Siirola, 2004): 
1. Generation of an adequate superstructure- In order to find the best path through the superstructure for generating the optimal flowsheet, the optimal pathway must be embedded into the original search space which constitutes the superstructure

2. Solution of the optimization problem- Since the optimization problem consists of a number of non-linear equations to be solved and is discontinuous and nonconvex in nature, solution to such the optimization problem is difficult. Therefore the models need to be simplified, hence if it were possible to solve the rigorous models compared to the simple models, new solutions may be possible

\subsubsection{Hybrid}

Hybrid methods consist of knowledge based on the two previous approaches among others. Instead of using heuristics, physical (thermodynamic) insights based on pure component, mixture properties and process phenomena, are used which can be linked to separation techniques (Lutze et al., 2013). It can be said that hybrid methods keep the simple structure of heuristic/knowledge-based methods, but replace the fixed rules with guidelines based on physical insights, generated through analysis of the behaviour of the chemicals (D'Anterroches, 2006). Hybrid methods (Lutze and Gorak, 2013, Kobus et al., 2001) move beyond the well-used unit operations scale and operate at different scales for performing process synthesis, design and sustainable design (Siirola et al., 1971, Papalexandri and Pistikopoulos, 1996).

From the information gained by the physical insights, the search space of flowsheet alternatives can be narrowed by removing from the search space infeasible solutions. Therefore, the final mathematical programming problem to be solved is a smaller MINLP or NLP problem because of the removal of a large portion of the infeasible part of the search space (Karunanithi et al., 2005).

\subsubsection{Heuristic -Process Intensification}

A heuristic approach for process intensification of an entire process, similar to that proposed by Douglas (1985), has not yet been proposed. However, heuristics for application of specification hybrid/intensified unit operations, for example, reactive distillation and reactive dividing wall columns, have been proposed (Bessling et al., 1997, Kiss et al., 2007).

\subsubsection{Mathematical programming-Process Intensification}

Mathematical programming methods for process intensification of an entire process, have not yet been proposed. However, mathematical programming methods for reactive distillation coupled with membrane separation (Amte, 2011), for dividing wall columns (Caballero and Grossmann, 2004) and for reactive distillation (Urselmann et al., 2011), have been proposed. 


\subsubsection{Hybrid-Process Intensification}

A hybrid method for systematically achieving process intensification has been proposed by Lutze et al. (2012). Lutze et al. (2012) proposed an innovative systematic computeraided methodology for performing process synthesis (and design) at the unit operations scale and phenomena scale (Papalexandri and Pistikopoulos, 1996) for the intensification of entire processes. In performing process synthesis at the phenomena scale, not only is the search space of unit operations expanded to include hybrid/intensified unit operations but, also the opportunity to innovate is provided (Lutze et al., 2012), that is, the generation of novel hybrid/intensified unit operations. Hybrid methods have also been proposed for intensifying specific parts of a process or for the intensification of an entire process through the use of expert knowledge.

Peschel et al., 2012 proposed a method for generating novel intensified reactor networks based on elementary process functions. Siirola (1996) proposed the means-ends analysis that identifies tasks (based on expert knowledge) that satisfy a set of process specifications. Seifert et al. (2012) proposed a modular concept for process design where sections of a process are modularized in order to generate flexible process designs. Rong et al. $(2004,2008)$ proposed a phenomena-based concept where the process phenomena are represented by phases, variables that affect the phases, energy sources and geometry, among others. When these phenomena are identified for a specific unit operation that has the potential for improvement/replacement, the process phenomena are manipulated in order to achieve a better design, using a trial and error approach.

This thesis employs a hybrid method that operates at three different scales: unit operations, tasks and phenomena, that is, multi-scale (and multi-level) synthesisintensification is performed.

\subsection{Sustainable Process Synthesis, Design and Sustainable Design}

Westerberg (2004) states that there is an important need during process synthesis and design, that is, a need for inovation which can be achieved if one operates at lower scales. The method of finding the best processing route, the design and analysis of such a route and further investigation of that route for generating other more sustainable routes, can be categorized into three main stages, (1) synthesis, (2) design and analysis, and (3) sustainable design (Kongpanna et al., 2014). Each stage works sequentially and interchangeably for example if one performs synthesis followed by design and the design does not satisfy all the constraints of the synthesis-design problem, then one returns to the synthesis stage.

The problem definition defined at each stage is defined as follows:

- Synthesis: Given- raw materials and products. Find- the processing route

- Design and analysis: Given- the processing route. Find- the design 
- Sustainable design: Given: the design. Find- alternative sustainable processing routes

The objective of design and analysis is to calculate the design variables, for example, equipment parameters, for describing the unit operations in the processing route and the evaluation of processing route for identification of process hot-spots which are translated into design targets for improvement. A process hot-spot is a limitation/bottleneck in a process that affects its performance and if improved/eliminated increases the overall performance of the process. A design target is defined as a target that must be satisfied in order to claim a process improvement, that is, it is the improvement or elimination of a process hot-spot.

The objective of sustainable design is to generate more sustainable processing alternatives that have improvements in economic, sustainability and LCA factors. For evaluating whether a more sustainable design has been achieved, different performance metrics can be plotted on a radar diagram (used in this thesis), where in principle, the outer axis is the base case design and any value within the diagram shows an improvement. If all metrics fall within the diagram for new process designs, then nontrade off process alternatives have been generated. An example is shown in Figure 1-2 where economic (operational cost, utility cost, energy usuage and profit) and sustainability/LCA factors (GWP, HTPI and carbon footprint) are included in the diagram as performance metrics (criteria). A more detailed list of the performnace metrics, that is, both economic and sustainbaility/LCA related, are presented in chapter 6. 


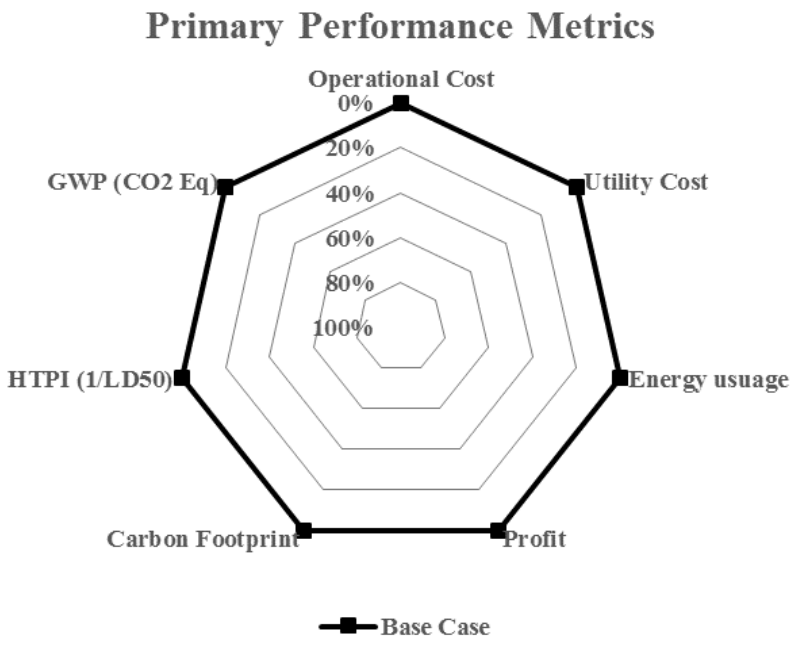

Figure 1-2: Graphical representation for evaluating sustainable synthesis-design. All metrics are presented as per kiligram of product. GWP- Global Warming Potential HTPI- Human Toxicity Potential by Ingestion

For achieving synthesis, design and sustainable design, different methods that require specific input and output information/data are required. This overall scope of this project lies within the interface of design and sustainability, however the developed multi-level, multi-scale framework, can operate at all three stages that is synthesis, design and sustainable design.

\subsection{Project Motivation and Objective}

In the chemical industry, process improvements have mainly been performed via an evolutionary approach where, over time knowledge about the process is used to provide valuable information for identifying recommendations for process improvements. However, with the inclusion of process intensification into process synthesis, not only can the traditional way of performing process synthesis be achieved but also the potential use of hybrid/intensified equipment, whether novel or mature, can be explored that can provide major improvements in the design of new processes or the retrofitting of existing processes. Process intensification (PI) can be defined as the improvement of a process through: (1) the integration of operations, (2) the integration of tasks, (3) the integration of phenomena and/or (4) the targeted enhancement of phenomena of a given operation (Lutze et al., 2010). Therefore, it is more beneficial to perform process synthesis and PI together, compared to performing process synthesis and then exploring an existing design for the use of hybrid/intensified unit operations. This is shown in Figure 1-3. 


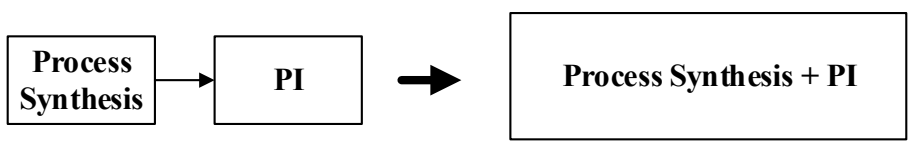

Sequential Approach

Simultaneous Approach

Figure 1-3: Moving towards a simultaneous approach for Process Synthesis inclusive of PI

In looking at the chemical/bio-chemical industry four major needs can be identified (Moulijn et al., 2008, Harmsen, 2010):

1. Energy consumption- The efficient use of energy in operating a chemical process is necessary because the cost of utilities (mainly heating) can be high which, has an overall impact on the operating cost of the process

2. Waste generation- In nearly all chemical processes waste of some form; for example solvent loss or by product production; is generated. Therefore, the process should be designed in such a way that it minimizes waste production, because this has an overall effect on the environmental impact of the process

3. Number of equipment- Not all new or retrofit processes will employ hybrid/intensified unit operations. However in order to achieve PI, a new or retrofit process should have a reduction in the number of equipment as compared to the original (base case) design. This has an overall impact on the equipment size to production capacity ratio

4. Capital/Operational cost- The three aforementioned reductions, if considered directly, has an impact on the capital and investment cost that is lower energy consumption and waste generation can reduce the yearly operational cost and a reduction in the number of equipment can reduce the overall capital investment

From the four major identified needs, three major improvements should be accomplished in addressing these needs:

1. Sustainable technologies/processes- In developing new processes the use of technologies/processes which employ hybrid/intensified unit operations should be considered because new process designs can be found that are more sustainable, for example, lower carbon footprint and global warming potential, that cannot otherwise be generated from current synthesis methods that do not employ the use of these technologies within their search space of unit operations. Reductions are achieved in: energy consumption, waste generation, number of equipment and capital/operational cost. In Figure 1-2 this is evaluated, for example, using the following metrics: energy usage (economic) and GWP (sustainability/LCA).

2. Efficient use of raw materials- The efficient use of raw materials is important because of the following factors:

a. Competing demand from competitors who produce the same product 
b. Competing demand from other processes that utilize the same raw materials

c. The dwindling of a given raw material resource

Reductions are achieved in: Waste generation and operational cost. In Figure 1-2 this is evaluated, for example, using the following metrics: profit (economic) and HTPI (sustainability/LCA).

3. Sustainability/LCA factors- In order to quantify sustainable design, new as well as existing processes must not only show improvements economically but also with respect to sustainability metrics and LCA factors (Carvalho et al., 2013, Babi et al., 2014 (a, b)). This provides an indicator for the improvements in environmental impacts due to, for example, reductions in waste generation. In Figure 1-2 this is evaluated, for example, using the following metrics: carbon footprint and GWP.

The identified needs for the chemical and bio-chemical industry, can be addressed through the identified reductions in energy consumption, waste generation, number of equipment and capital/operational cost, by performing process synthesis and intensification together, as presented in this thesis.

Therefore, a flexible, systematic and efficient method is needed for accomplishing the improvements related to the use of sustainable technologies (hybrid/intensified unit operations), the efficient use of raw materials and sustainability factors. Based on the previous work of Lutze (2012), the framework must be multi-level because it should be able to perform synthesis, design and more sustainable design and multi-scale, since it performs synthesis-intensification at different scales, the unit operations scale, task scale and phenomena scale. The objective of this thesis is as follows:

To develop a systematic, computer-aided, multi-level, multi-scale framework, for performing process synthesis-intensification, which operates at the unit operations scale, task scale and phenomena scale for generating more sustainable flowsheet designs, inclusive (where possible) of well-known plus existing/novel intensified/hybrid unit operations.

A first version of a framework for performing process synthesis at the phenomena scale has been developed previously by Lutze (2012). The framework has been further developed as follows:

1. Flowsheet generation, phenomena based synthesis- An integrated taskphenomena based approach has been developed based on the method proposed by Lutze (2012), for systematically (hierarchal and rule-based) generating flowsheet alternatives (more sustainable designs) from the phenomena scale to the unit operations scale. To go beyond the current search space of unit operations (established plus intensified) and to find truly innovative and predictive solutions, process synthesis must be performed at lower scales, that is the phenome- 
na scale, where in principle flowsheet alternatives can be generated employing well known and existing/novel hybrid/intensified unit operations. This is shown in Figure 1-4. In Figure 1-4 the major needs, explained previously, are used as criteria in order to quantify the improvements obtained from the use of, for example, sustainable technologies/processes. If process synthesis is performed, then the search space of unit operations consists of well-known unit operations. This search space can be expanded through the performance of process and intensification together, that is, the search space of unit operations consists of, both well-known and hybrid/intensified unit operations. The search space can be expanded even further, by performing process synthesis-intensification at the phenomena level (Lutze, 2012, Babi et al., 2014(b)), that is, the search space of unit operations consists of, well-known unit operations, existing hybrid/intensified unit operations plus innovative (generated through a phenomena based method) unit operations. At the phenomena scale new unit operations can be designed for example the design of a rectangular plate-frame-flow reactorpervaporator (Lutze et al., 2013)

2. The development and inclusion of the phenomena based synthesis method into a generic process synthesis-intensification methodology for performing process synthesis and/or intensification together

3. Process hot-spot identification: To identify process limitations/bottlenecks (process hot-spots) of a reference (base case) process, three comprehensive analyses are employed, that is, economic, sustainability and LCA analyses. These three analyses are employed because the developed framework seeks to achieve sustainable process designs and therefore, this requires the design of efficient, cost effective processes with minimum resource utilization and environmental impacts (Gani, 2004). The process hot-spots are translated into design targets that, if satisfied, generate more sustainable designs 


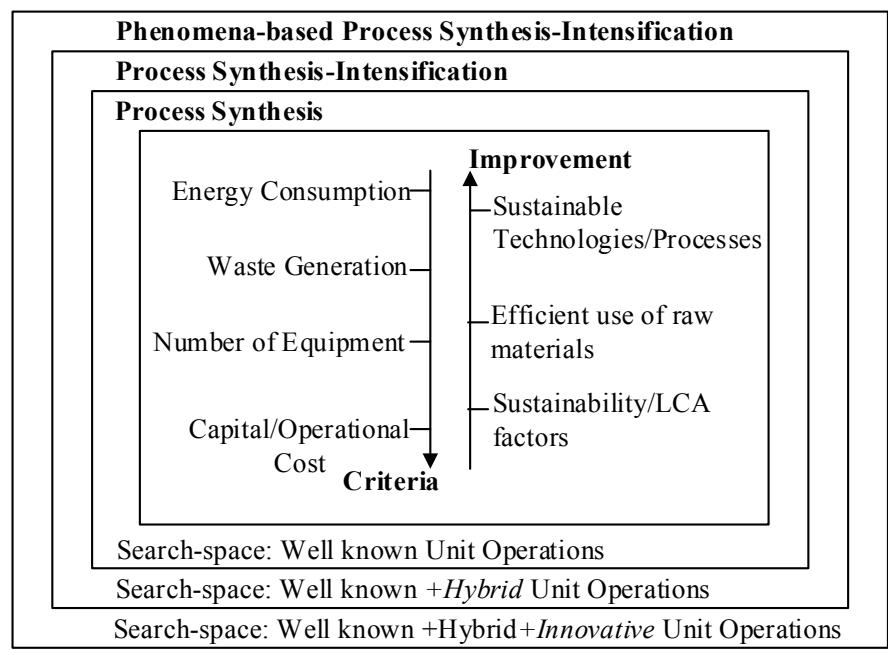

Figure 1-4: The role of phenomena-based process intensification for achieving more sustainable designs

The developed framework is multi-level: In level 1, process synthesis is performed where a reference design (base case) is synthesized. In level 2, the base case is designed and analyzed using economic, sustainability and LCA analyses for identifying process hot-spots that are translated into design targets. In level 3, phenomena based synthesis for achieving more sustainable designs is performed in order to, select the best intensified flowsheet alternatives that match the design targets and thereby, eliminate/minimize the process hot-spots.

Therefore, based on the project motivation and objective, the synthesis-intensification problem definition is as follows:

Generate more sustainable designs inclusive of well-known plus existing/novel hybrid/intensified unit operations that, provide improvements related to the use of sustainable technologies, efficient use of raw materials, improvements related to sustainability/LCA factors and reductions in the total number of unit operations, compared to a base case (reference) design.

\subsection{Structure of the Thesis}

This thesis consists of 7 chapters and has the following sequential outline. In chapter 1 , an overview of, the concept of process synthesis and, of the current methods for performing process synthesis, are presented. The concept of process synthesis, design and 
more sustainable is explained and, the project motivation and objective that this thesis seeks to achieve, is presented.

In chapter 2, the mathematical formulation of the sustainable process synthesisintensification problem is stated and explained together with the solution approach that is executed in this thesis. Definitions are introduced and explained to provide understanding related to the combination of phenomena (phenomena-based synthesis) for generating more sustainable designs.

In chapter 3, the framework for achieving sustainable process synthesis-intensification is presented. The framework architecture is presented, that is, the overall structure of the framework. The detailed work-flow and data-flow are presented systematically, that is, using a hierarchal step by step approach, where, each step in the framework is explained in detail in order to, achieve the overall objective of the framework, that is, more sustainable designs.

In chapter 4, the algorithms developed for application of the different steps in the workflow of the framework are presented. These algorithms operate at different scales, that is, the unit operations scale to phenomena scale (higher scale to lower scale) and, from the phenomena scale to the unit operations scale (lower scale to higher scale).

In chapter 5 the supporting methods and tools embedded within the framework are presented. The methods are synthesis methods that operate at the unit operations or task scale and, are used, for example, for the base case generation in case one is not available. The tools presented are all computer-aided and are used for analysis, rigorous simulation and evaluation.

In chapter 6 the case studies used for testing the developed framework are presented. Three case studies are presented, of which two case studies are related to the production of industrial bulk chemicals, methyl acetate and di-methyl carbonate. The final case study is related to a bio-based chemical, biodiesel that is a promising alternative fuel source compared to conventional diesel.

In chapter 7 an overview of what has been performed/developed in this thesis and the conclusion of the entire thesis, are presented. Finally, the future perspective is presented which provides ideas for future development of sustainable process synthesisintensification for achieving more sustainable designs.

\subsection{Conclusion}

In this chapter the overall concept of process synthesis and the current methods by which process synthesis is performed, has been presented. Process synthesis can be performed through, the application of heuristics which are based on defined rules from process know-how and knowledge based methods. It can be performed through, the application of mathematical programming, where in principle all possible combination of flowsheet alternatives are considered and the best is selected through the optimization of an objective function subject to constraints. Process synthesis can also be performed through the application of hybrid methods that go beyond the well-known unit 
operations scale for generating flowsheet designs and uses the know-how of the previous two methods, heuristics and mathematical programming, that is, models are used to provide physical insights that aid in reducing the search space of alternatives and therefore, the final problem to be solved is smaller. In this approach, the search of unit operations consist of well-known unit operations, mature and novel, hybrid/intensified unit operations. It has been discussed the identification the best/optimal route that is more sustainable, can be categorized into 3 main stages, synthesis, design and sustainable design.

The project motivation and objective has been explained, that is, opportunities for process intensification should be investigated during process synthesis instead of, performing process synthesis (and design) followed by process intensification. The objective of the thesis has been presented and how it has further developed/expanded the previous work by Lutze (2012). 


\section{FRAMEWORK FOR SUSTAINABLE PROCESS SYNTHESIS-INTENSIFICATION: SOLUTION APPROACH \& DEFINITIONS}

In this chapter, first, the process synthesis-intensification problem is defined mathematically and explained. Second, the solution approach used in this thesis is presented and explained conceptually. Third, definition of the terms used in the methods embedded in the framework is introduced and explained. These are used in the integrated taskphenomena based method for, performing phenomena-based synthesis, embedded in the framework for generating more sustainable designs. It is compared to computer-aided molecular design (CAMD) because these two methods are multi-level (and multi-scale) and inherently analogous to each other, that is, they both operate at different levels of aggregation.

\subsection{Process Synthesis-Intensification Mathematical Descrip- tion}

In selecting the best (optimal) sustainable design, the process synthesis-intensification mathematical problem must be formulated and solved. It consists of an objective function to be optimized, subject to a set of pre-defined constraints that are a set of linear and non-linear equations and different discrete choices must be made from among raw materials, among others. Therefore, the process synthesis-intensification problem to be solved becomes a mixed integer non-linear programming (MINLP) problem because the objective function and constraints can be linear and non-linear and discrete choices must be made.

The process synthesis-intensification problem for achieving more sustainable/design is formulated mathematically, Equation 2.1 to Equation 2.8, and covers 3 scales of operations: unit operations scale, task scale and phenomena scale. The system of equations is explained as follows.

$$
\min / \max f_{o b j}^{o}=f_{o b j}^{o}(\underline{X}, \underline{Y}, \underline{d}, \underline{z}, \underline{\theta})
$$

subject to:

$$
\begin{aligned}
& g(\underline{X}, \underline{z}, \underline{\theta})=0 \\
& f(\underline{X}, \underline{Y}, \underline{d}, \underline{z}, \underline{\theta})=0 \\
& b^{L} \leq b_{1} \underline{X}+b_{2} \underline{Y} \leq b^{U} \\
& h^{L} \leq h(\underline{X}, \underline{Y}, \underline{d}, \underline{\theta}) \leq h^{U}
\end{aligned}
$$




$$
\begin{aligned}
& v^{L} \leq v(\underline{X}, \underline{Y}, \underline{d}, \underline{\theta}) \leq v^{U} \\
& w^{L} \leq w(\underline{X}, \underline{Y}, \underline{d}, \underline{\theta}) \leq w^{U} \\
& \underline{Y}^{O}=0 / 1, i=1,2 \ldots n_{y^{o}}, \underline{X}^{O} \geq 0
\end{aligned}
$$

The objective function (Equation 2.1) is subject to a set of design/optimization variables $\underline{X}$, a set of binary $(0,1)$ decision integer variables $\underline{Y}$, a set of equipment variables $\underline{d}$, a set of thermodynamic variables $\underline{z}$, and a set of process specifications $\underline{\theta}$.

Equation 2.1 represents the objective function to be minimized/maximized subject to a set of constraints. Equation 2.2 and Equation 2.3 represent a system of linear and nonlinear equations for example the steady state process model which consists of phenomena as well as mass and energy algebraic equations, respectively. Equation 2.4 and Equation 2.5 represent physical constraints and design specifications for example flowsheet structure and equipment parameters, respectively. Equations 2.6 and Equation 2.7 represents PI constraints that is intensification design specifications and performance criteria that the feasible flowsheet alternatives must satisfy (using design targets) for example, the inclusion of intensified equipment within the search space of available unit operations and the improvement of sustainability/LCA factors respectively. Equation 2.8 represents the decision variables $\underline{Y}^{O}$ that are binary-integer.

The MINLP optimization problem described by Equation 2.1 to Equation 2.8 can be difficult to solve, for example, if the process model together with its constitutive equations are highly non-linear. The size of the MINLP problem is an issue because generating flowsheet alternatives using a phenomena-based synthesis method, where, phenomena are combined is complex, due, to the large number of possible combinations (Lutze et al., 2013). Therefore, in order to manage this complexity, an efficient and systematic solution approach is used where the problem is decomposed into a set of sub-problems that are solved according to a pre-defined calculation order. This method is referred to as the decomposition based solution strategy method (Karunanithi et al., 2005). Most of the sub-problems require bounded solution of a sub-set of equations. The final subproblem is solved as a set of NLP or MILP.

Feasible flowsheet alternatives are identified by simultaneously solving the process model equations (Equation 2.2 to Equation 2.3) subject to the constraints defined in Equation 2.4 to Equation 2.6. The feasible alternatives are then evaluated using a set of PI performance criteria (Equation 2.7). For the remaining flowsheet alternatives, the objective function (Equation 2.1) is calculated and ordered. Therefore, the flowsheet alternative(s) that give the best objective function are selected as the more sustainable designs. A global optimal solution cannot be guaranteed with this method, however, the generated sustainable designs are the best according to the problem definition, the selected performance criteria, constraints, availability of data, parameters and models (Lutze et al., 2013). 


\subsection{Solution Approach}

To manage the complexity of the synthesis-intensification MINLP problem, an efficient and systematic solution approach is used, where, the problem is decomposed into a set of sub-problems that are solved according to a pre-defined calculation order (Karunanithi et al., 2005). This solution approach is called the decomposition-based solution strategy (DBSS) and has been adopted for solution of the process synthesis problem (D'Anterroches, 2006, Lutze, 2012). The DBBS has the following properties and advantages:

1. Properties:

a. The problem is decomposed into manageable sub-problems.

b. Each sub-problem, except for the final, requires only the solution of a subset of constraints from the original problem formulation.

c. The final sub-problem is the solution of the objective function with the remaining constraints.

2. Advantages:

a. The decomposing of the problem into manageable sub-problems

b. The solution of the decomposed problem is equivalent to solution of the original MINLP problem (this will be illustrated by an example).

c. The MINLP problem is decomposed into manageable sub-problems from which the final MINLP is solvable, the solution approach is more flexible in managing complexity.

d. Solution of each sub-problem acts as a screening step within the search space and therefore, infeasible solutions are removed, while, each subproblem is solved.

e. Since the solution of the sub-problems satisfies the constraints defined in the original problem, the finding of a global optimal solution from solution of the reduced MINLP can be guaranteed as long as a global optimization algorithm is used to solve it.

\subsubsection{Conceptual example}

The application of the DBSS is highlighted through the following MINLP problem. Consider, the minimization of the objective function in Equation 2.9 subject to, the constraints defined in Equation 2.10 to Equation 2.17.

$$
\begin{aligned}
& \min z=2 x_{1}+3 x_{2}+1.5 y_{1}+2 y_{2}-0.5 y_{3} \\
& \text { s.t } \\
& x_{1}^{2}+y_{1}=1.25 \\
& x_{2}^{1.5}+1.5 y_{2}=3 \\
& x_{1}+y_{1} \leq 1.6
\end{aligned}
$$




$$
1.333 x_{2}+y_{2} \leq 3
$$

$$
-y_{1}-y_{2}+y_{3} \leq 0
$$

$$
y_{1} y_{2}=1
$$

$$
x_{1}, x_{2} \geq 0
$$

$$
y_{1}, y_{2}, y_{3}=\{0,1\}
$$

\subsubsection{Sub-problem 1}

First the enumeration of the binary variables $\left(\mathrm{y}_{1}, \mathrm{y}_{2}, \mathrm{y}_{3}\right)$ is performed. This is given in

Table 2-1.

Table 2-1: Enumeration Binary Variables

\begin{tabular}{|l|l|l|l|}
\hline $\begin{array}{l}\text { Enumeration } \\
\text { No. }\end{array}$ & $\mathbf{y 1}$ & $\mathbf{y 2}$ & $\mathbf{y 3}$ \\
\hline 1 & 0 & 0 & 0 \\
\hline 2 & 1 & 1 & 1 \\
\hline 3 & 1 & 1 & 0 \\
\hline 4 & 1 & 0 & 0 \\
\hline 5 & 1 & 0 & 1 \\
\hline 6 & 0 & 1 & 1 \\
\hline 7 & 0 & 1 & 0 \\
\hline 8 & 0 & 0 & 1 \\
\hline
\end{tabular}

\subsubsection{Sub-problem 2}

The linear constraint defined in Equation 2.14 is used for screening the feasible solutions from Table 2-1 to identify those that satisfy Equation 2.14 constraint. The feasible enumerated binary variable sets are given in Table 2-2. 
Table 2-2: Enumerated binary variables that satisfy the linear constraint of Equation 2.14

\begin{tabular}{|l|l|l|l|}
\hline $\begin{array}{l}\text { Enumeration } \\
\text { No. }\end{array}$ & $\mathbf{y 1}$ & $\mathbf{y 2}$ & $\mathbf{y 3}$ \\
\hline 1 & 0 & 0 & 0 \\
\hline 2 & 1 & 1 & 1 \\
\hline 3 & 1 & 1 & 0 \\
\hline 4 & 1 & 0 & 0 \\
\hline 5 & 1 & 0 & 1 \\
\hline 6 & 0 & 1 & 1 \\
\hline 7 & 0 & 1 & 0 \\
\hline
\end{tabular}

\subsubsection{Sub-problem 3}

The non-linear constraint defined in Equation 2.15 is used for screening the feasible solutions from Table 2-2 to identify those that satisfy Equation 2.14 to Equation 2.15. The feasible enumerated binary variable sets are given in Table 2-3.

Table 2-3: Enumerated binary variables sets that satisfy Equation 2.14 to Equation 2.15

\begin{tabular}{|l|l|l|l|}
\hline $\begin{array}{l}\text { Enumeration } \\
\text { No. }\end{array}$ & $\mathbf{y 1}$ & $\mathbf{y 2}$ & $\mathbf{y 3}$ \\
\hline 2 & 1 & 1 & 1 \\
\hline 3 & 1 & 1 & 0 \\
\hline
\end{tabular}

\subsubsection{Sub-problem 4}

The problem is now reduced to the non-linear programming (NLP) problem and can be solved for $\mathrm{x} 1$ and $\mathrm{x} 2$ to determine the optimal solution. In Table 2-4 is given the reduced NLP problem and in Table 2-5 is given the comparison of solving the reduced NLP problem using the DBSS to solving the problem as an MINLP.

Table 2-4: NLP problem for each set of the feasible solutions (see Table 2-3)

\begin{tabular}{|l|l|}
\hline $\multicolumn{1}{|c|}{y_{1}, y_{2}, y_{3}}=\{1,1,1\}$ & $\multicolumn{1}{c|}{y_{1}, y_{2}, y_{3}}=\{1,1,0\}$ \\
\hline $\min z=2 x_{1}+3 x_{2}+1.5(1)+2(1)-0.5(1)$ & $\min z=2 x_{1}+3 x_{2}+1.5(1)+2(1)-0.5(0)$ \\
s.t & s.t \\
$x_{1}^{2}+(1)=1.25$ & $x_{1}^{2}+(1)=1.25$ \\
$x_{2}^{1.5}+1.5(1)=3$ & $x_{2}^{1.5}+1.5(1)=3$ \\
$x_{1}+(1) \leq 1.6$ & $x_{1}+(1) \leq 1.6$ \\
$1.333 x_{2}+(1) \leq 3$ & $1.333 x_{2}+(1) \leq 3$ \\
$x_{1}, x_{2} \geq 0$ & $x_{1}, x_{2} \geq 0$ \\
\hline
\end{tabular}


From Table 2-5, it is seen that the DBSS provides the same result as the MINLP approach for the objective function (Fobj).

Table 2-5: Optimization results of the MINLP and NLP problems

\begin{tabular}{|l|l|l|l|l|l|}
\hline \multicolumn{2}{|l|}{ MINLP } & $\multicolumn{2}{l|}{\mathbf{y} 1, \mathbf{y} 2, \mathbf{y} 3}=\{1,1,1\}$ & $\multicolumn{2}{l|}{\mathbf{y}, \mathbf{y}, \mathbf{y 3}}=\{1,1,0\}$ \\
\hline Variable & Value & Variable & Value & Variable & Value \\
\hline y1 & 1 & y1 & 1 & y1 & 1 \\
\hline y2 & 1 & $y 2$ & 1 & $y 2$ & 1 \\
\hline y3 & 1 & $y 3$ & 1 & $y 3$ & 0 \\
\hline x1 & 0.5 & $\mathrm{x} 1$ & 0.5 & x1 & 0.5 \\
\hline x2 & 1.31 & $\mathrm{x} 2$ & 1.31 & x2 & 1.31 \\
\hline Fobj & 7.93 & Fobj & 7.93 & Fobj & 8.43 \\
\hline
\end{tabular}

Therefore, in order to manage the complexity in solving the MINLP synthesisintensification problem for, achieving more sustainable designs, the DBSS is employed.

\subsection{Definition of Terms}

In this section terms related to the combination of phenomena building blocks (PBBs) to generate flowsheet alternatives are presented. Three definitions are presented, phenomena-based synthesis and its comparison to computer-aided molecular design, phenomena building blocks (PBBs), simultaneous phenomena building blocks (SPBs) that are combinations of PBBs and basic structures that are combinations of SPBs.

\subsubsection{Phenomena-based synthesis}

For performing phenomena-based synthesis, PBBs are combined to form SPBs that are combined to form basic structures that perform a certain task in a process. The basic structures are then translated into unit operations which constitute the final flowsheet alternatives. This is shown in Figure 2-1. The combination of PBBs to basic structures is rule based and is analogous to computer-aided molecular-mixture design (CAMD) (Harper and Gani, 2000). Consider, the combination of atoms to generate functional groups which can be connected together using a set of combination rules to form molecules with a desired set of properties (performance criteria). This is shown in Figure 2-2. 
Phenomena-based Synthesis

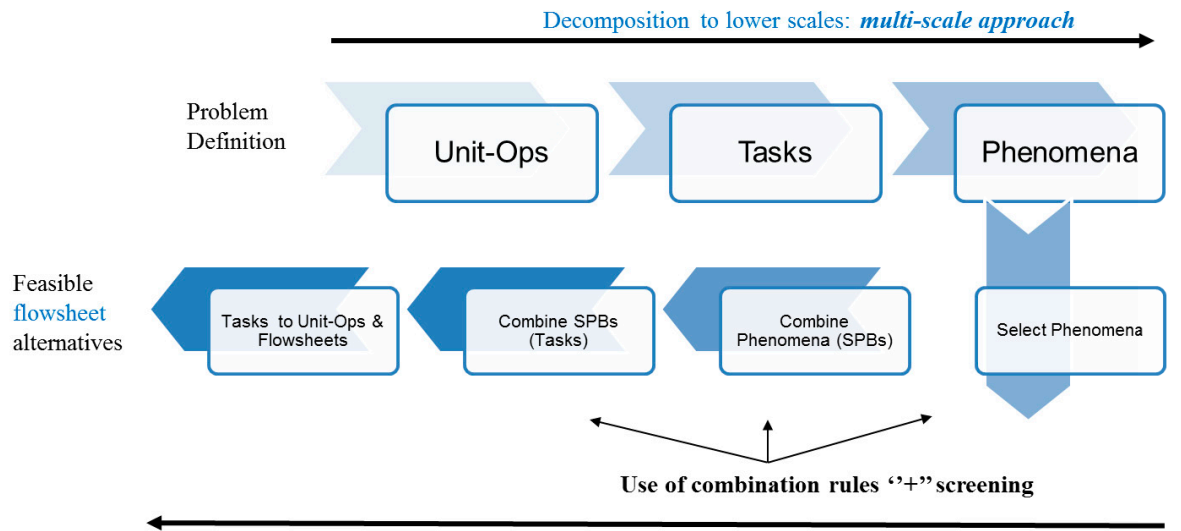

Towards higher scales-larger set of feasible alternatives

Figure 2-1: Phenomena-based synthesis

Consider Computer-Aided Molecular Design

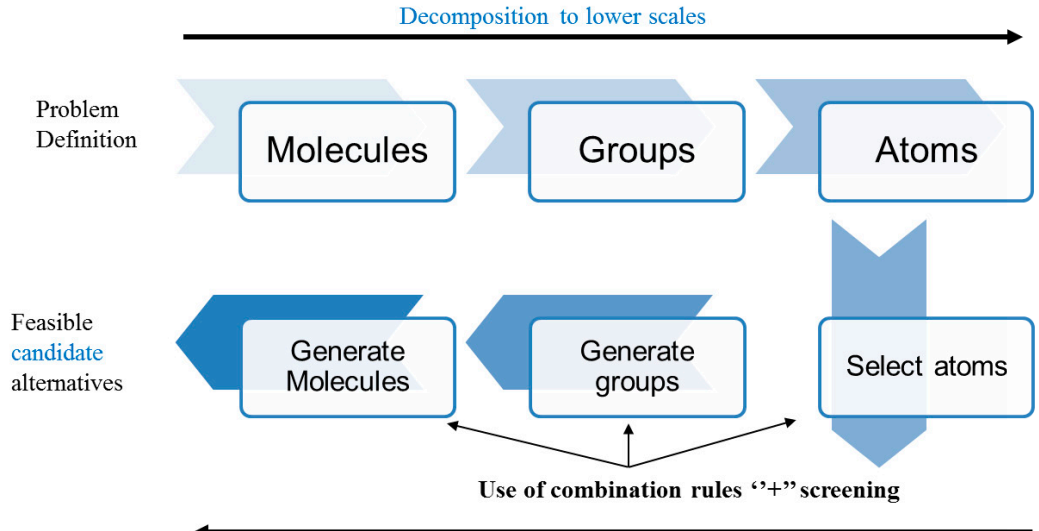

Towards higher scales-larger set of feasible candidates

Figure 2-2: Computer-Aided Molecular Design (CAMD)

\subsubsection{Phenomena building blocks}

From a study of chemical processes, it was found that most chemical and bio-chemical processes can be represented by 9 PBBs. These PBBs are classified into 5 categories consisting of, mixing, energy and mass transfer, reaction and dividing:

1. Mixing:

a. Mixing (M) - The mixing of more than one streams, for example, two liquid streams 
b. 2 phase mixing (2phM)- The mixing of two phases, for example, a liquid and gas

2. Energy Transfer:

a. Heating $(\mathrm{H})$ - Energy transfer, for example, heating of a liquid stream

b. Cooling (C)- Energy transfer, for example, the cooling of a vapour stream

3. Reaction (R)- Reaction, for example, a liquid phase reaction taking place inside a reactor

4. Mass transfer (and energy transfer):

a. Phase contact (PC)- The contact of two phases, for example, vapour and liquid

b. Phase transition (PT)- The transition of one phase to a next phase, for example, vapour condensing into a liquid

c. Phase separation (PS)- The separation of two phases, for example, the separation of a vapour phase from a liquid phase

5. Dividing (D)-The division of a stream into two or more streams

\subsubsection{Simultaneous Phenomena building blocks}

One or more PBBs can be combined according to a set of combination rules to fulfil the objectives of a task that performs an activity/action in a flowsheet. For example, by combining mixing, two-phase mixing, reaction, phase-contact, phase transition and phase separation PBBs, a reaction-separation SPB $\mathrm{M}=2 \mathrm{phM}=\mathrm{R}=\mathrm{PC}(\mathrm{VL})=\mathrm{PT}(\mathrm{VL})=\mathrm{PS}(\mathrm{VL})$ is generated, where $\mathrm{PT}(\mathrm{VL})$ is a $\mathrm{PBB}$ representing a vapor-liquid separation task. Note that, the representation of combined PBBs are similar to that of 'smiles' for, combining atoms to form molecules. SPBs are classified as initiator, intermediate and terminator SPBs as follows:

- An initiator SPB is an SPB that fulfills the main objective of a task.

- An intermediate SPB can be repeated multiple times when multiple SPBs are combined to form a basic structure then an operation.

- A terminator SPB bounds the initiator and intermediate SPBs. Note, initiator SPBs can also be intermediate SPBs. The concept is compared to CAMD as follows. Consider an alkane (propane), the terminator molecule is $\mathrm{CH} 3$ and the initiator molecule is $\mathrm{CH} 2$ which by itself is an intermediate because it can be repeated multiple times to form higher order alkanes. The concept is shown in Figure 2-3. 


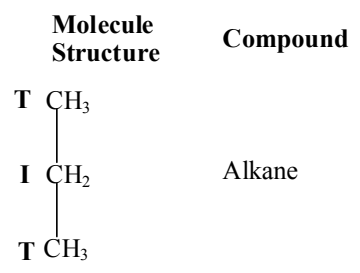

Basic

Structure

\begin{tabular}{l|c|} 
T & $\mathrm{M}=\mathrm{C}=2 \mathrm{phM}=\mathrm{PC}(\mathrm{VL})=\mathrm{PT}(\mathrm{VL})=\mathrm{PS}(\mathrm{VL})$ \\
$\mathbf{I}$ & $\mathrm{M}=2 \mathrm{phM}=\mathrm{PC}(\mathrm{VL})=\mathrm{PT}(\mathrm{VL})=\mathrm{PS}(\mathrm{VL})$ \\
$\mathbf{T}$ & $\mathrm{M}=\mathrm{H}=2 \mathrm{phM}=\mathrm{PC}(\mathrm{VL})=\mathrm{PT}(\mathrm{VL})=\mathrm{PS}(\mathrm{VL})$ \\
&
\end{tabular}

Task

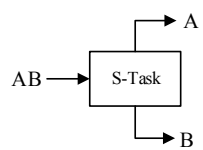

Operation

Unit Operation

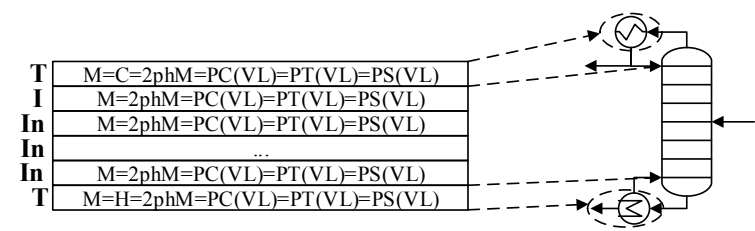

Figure 2-3: Concept of the type of SPBs. T-terminator, In-intermediate and I-initiator

\subsubsection{Basic Structures that perform Tasks}

The combination of SPBs form basic structures (Babi et al., 2014 (a, b)), that perform a task or tasks, and these tasks are connected to form task-based flowsheets which represent at the unit operations scale process flowsheets in the same way that functional groups are joined together to form molecules. A basic structure is defined as the combination of initiator and terminator SPBs. Using this basic structure another type of SPBs are added that is, intermediate SPBs because multiple intermediate SPBs may be needed in order to perform a task. A task activity is defined as the objective that a task must fulfill. Consider the two SPBs given in Table 2-6.

Table 2-6: SPBs for exothermic liquid phase reaction

\begin{tabular}{|l|l|l|l|l|}
\hline SPB Type & SPB No. & SPB & Inlet & Outlet \\
\hline Initiator/Intermediate & 1 & $\mathrm{M}=\mathrm{R}$ & $1 \ldots \mathrm{n}(\mathrm{L})$ & $1 \ldots \mathrm{n}(\mathrm{L})$ \\
\hline Terminator & 2 & $\mathrm{M}=\mathrm{C}$ & $1 \ldots \mathrm{n}(\mathrm{L})$ & $1 \ldots \mathrm{n}(\mathrm{L})$ \\
\hline
\end{tabular}

The concept of SPBs being combined to form basic structures that perform a task is given in Table 2-7. Note the rules for combining SPBs to form basic structures are presented in section 4.2.4. 
Table 2-7: The concept of a basic structure that performs a task

\begin{tabular}{|c|c|c|c|c|}
\hline SPB No. & Basic Structure & Task Activity & Task & \\
\hline \multirow{2}{*}{$\begin{array}{l}\text { SPB.1 } \\
\text { SPB.2 }\end{array}$} & $\mathrm{M}=\mathrm{R}$ & \multirow{2}{*}{$\begin{array}{l}\text {-Isothermal re- } \\
\text { action (exo- } \\
\text { thermic), liquid } \\
\text { phase } \\
\text {-Cooling }\end{array}$} & \multirow{2}{*}{$\begin{array}{l}\mathbf{R t}_{\mathbf{i}}(\mathbf{i}=\mathbf{1} . . \mathbf{n}) \longrightarrow \mathrm{R} \text {-Task } \\
\text { Rt-reactants } \\
\text { P-products }\end{array}$} & \multirow{2}{*}{ 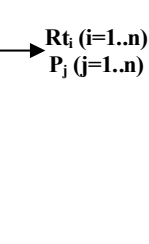 } \\
\hline & $\mathrm{M}=\mathrm{C}$ & & & \\
\hline
\end{tabular}

More than one set of tasks can be performed by one basic structure. Consider, the three SPBs given in Table 2-8 that are to be combined, to form basic structure(s) to perform the task associated with, the separation of a non-azeotropic mixture of $\mathrm{ABC}$ with, the order of boiling points as follows: $\mathrm{C}<\mathrm{B}<\mathrm{A}$. The number of separation tasks is calculated as $n-1$ which is equal to 2 , where $\mathrm{n}$ is the number of compounds.

Table 2-8: SPBs for vapor-liquid separation and, vapor and liquid contacting allowing mass and energy transfer between both phases and with/without addition of cooling and heating

\begin{tabular}{|l|l|l|l|l|}
\hline SPB Type & SPB No. & SPB & Inlet & Outlet \\
\hline Initiator/Intermediate & 1 & $\mathrm{M}=2 \mathrm{phM}=\mathrm{PC}=\mathrm{PT}=\mathrm{PS}$ & $1 \ldots \mathrm{n}(\mathrm{L}, \mathrm{V}, \mathrm{VL})$ & $1 \ldots \mathrm{n}(\mathrm{L}, \mathrm{V}, \mathrm{VL})$ \\
\hline Terminator & 2 & $\mathrm{M}=\mathrm{C}=2 \mathrm{phM}=\mathrm{PC}=\mathrm{PT}=\mathrm{PS}$ & $1 \ldots \mathrm{n}(\mathrm{L}, \mathrm{V}, \mathrm{VL})$ & $1 \ldots \mathrm{n}(\mathrm{L}, \mathrm{V}, \mathrm{VL})$ \\
\hline Terminator & 3 & $\mathrm{M}=\mathrm{H}=2 \mathrm{phM}=\mathrm{PC}=\mathrm{PT}=\mathrm{PS}$ & $1 \ldots \mathrm{n}(\mathrm{L}, \mathrm{V}, \mathrm{VL})$ & $1 \ldots \mathrm{n}(\mathrm{L}, \mathrm{V}, \mathrm{VL})$ \\
\hline
\end{tabular}

The concept that more than one set of tasks can be performed by one basic structure is given in Table 2-9. When a basic structure performs more than one tasks, the number of unit operations in a flowsheet alternative is reduced. 
Table 2-9: The concept that multiple tasks can be performed by one basic structure. Note each binary pair that represents the inlet to a task represent the two key compounds under consideration

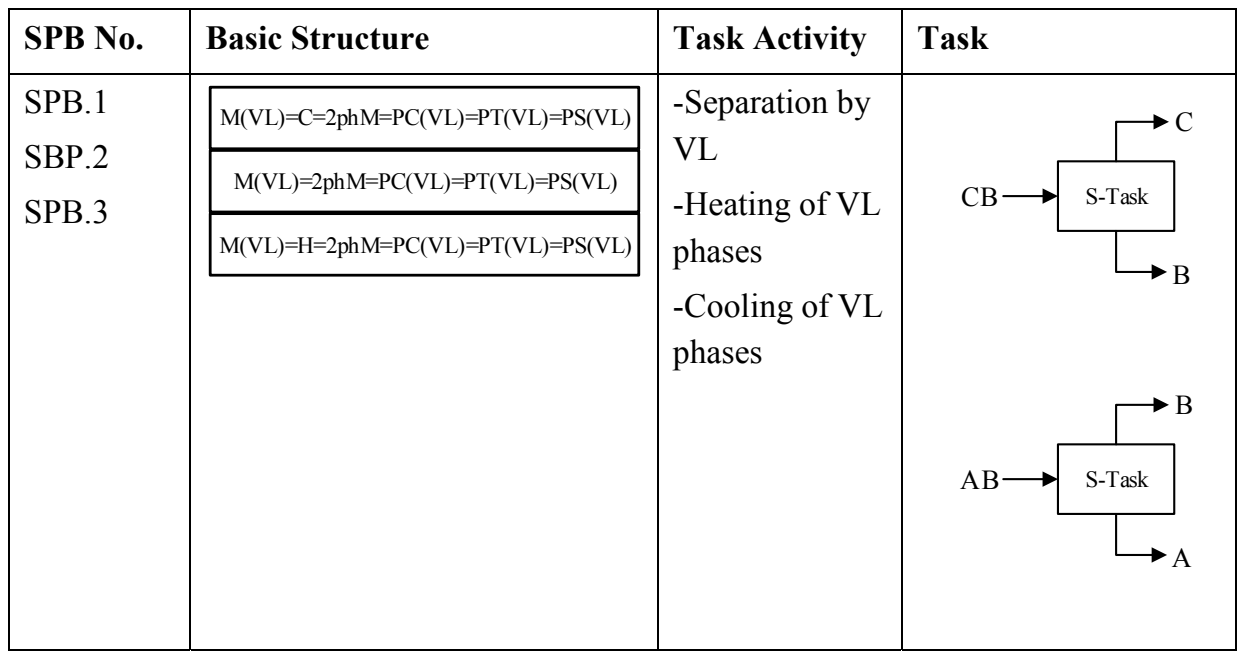

More than one basic structure can perform a task. Consider the four SPBs given in Table 2-10 that are to be combined to form basic structures to perform the task associated with the separation of an azeotropic mixture of $\mathrm{AB}$ using phenomena building blocks related to permeability/affinity. PT(VV) represents a phenomena building block that at the unit operations level translates into a vapor permeation membrane and PT(PVL) represents a phenomena building block that at the unit operations level translates into a vapor permeation membrane.

Table 2-10: SPBs for separation related to permeability/affinity: PT(VV) and PT(PVL)

\begin{tabular}{|l|l|l|l|l|}
\hline SPB Type & $\begin{array}{l}\text { SPB } \\
\text { No. }\end{array}$ & SPB & Inlet & Outlet \\
\hline Initiator/Intermediate & 1 & $\mathrm{M}=2 \mathrm{phM}=\mathrm{PC}(\mathrm{VL})=\mathrm{PT}(\mathrm{PVL})=\mathrm{PS}(\mathrm{VL})$ & $1 \ldots \mathrm{n}(\mathrm{L})$ & $1 \ldots \mathrm{n}(\mathrm{V}, \mathrm{L})$ \\
\hline Initiator/Intermediate & 2 & $\mathrm{M}=2 \mathrm{phM}=\mathrm{PT}(\mathrm{VV})=\mathrm{PS}(\mathrm{VV})$ & $1 \ldots \mathrm{n}(\mathrm{V})$ & $1 \ldots \mathrm{n}(\mathrm{V}, \mathrm{V})$ \\
\hline Terminator & 3 & $\mathrm{M}=2 \mathrm{phM}$ & $1 \ldots \mathrm{n}(\mathrm{L}, \mathrm{V})$ & $1 \ldots \mathrm{n}(\mathrm{L}, \mathrm{V})$ \\
\hline Terminator & 4 & $\mathrm{M}=\mathrm{C}$ & $1 \ldots \mathrm{n}(\mathrm{L}, \mathrm{V})$ & $1 \ldots \mathrm{n}(\mathrm{L}, \mathrm{V})$ \\
\hline
\end{tabular}


The concept that more than one basic structure can perform a task is given in Table 2-11. When more than one basic structure performs a task, the search space of unit operations is expanded, thereby, providing more options to choose and/or generate a novel hybrid/intensified unit operation. The basic structures in Table 2-11 when translated at the unit operations scale, represent pervaporation and vapor permeation membranes or the SPBs that constitute the basic structure can be arranged in a way that generates a new (novel) unit operation that employs a pervaporation/vapor permeation membrane.

Table 2-11: The concept that multiple basic structures can perform a single task. Note each binary pair that represent the inlet to a task represent the two key compounds under consideration

\begin{tabular}{|c|c|c|c|}
\hline SPB No. & Basic Structure & Task Activity & Task \\
\hline \multirow{3}{*}{$\begin{array}{l}\text { SPB.1 } \\
\text { SPB.3 } \\
\text { SPB.4 }\end{array}$} & $\mathrm{M}(\mathrm{VL})=2 \mathrm{phM}$ & \multirow{3}{*}{$\begin{array}{l}\text {-Separation } \\
\text { by V-phase } \\
\text {-Cooling }\end{array}$} & \multirow{5}{*}{$\mathrm{AB} \longrightarrow$ S-Task } \\
\hline & $\mathrm{M}(\mathrm{L})=2 \mathrm{phM}=\mathrm{PC}(\mathrm{VL})=\mathrm{PT}(\mathrm{PVL})=\mathrm{PS}(\mathrm{VL})$ & & \\
\hline & $\mathrm{M}(\mathrm{V})=\mathrm{C}$ & & \\
\hline \multirow{2}{*}{$\begin{array}{l}\text { SPB.1 } \\
\text { SPB.2 }\end{array}$} & $\mathrm{M}(\mathrm{V})=2 \mathrm{phM}$ & \multirow{2}{*}{$\begin{array}{l}\text {-Separation } \\
\text { by V-phase }\end{array}$} & \\
\hline & $\mathrm{M}(\mathrm{V})=2 \mathrm{phM}=\mathrm{PT}(\mathrm{VV})=\mathrm{PS}(\mathrm{VV})$ & & \\
\hline
\end{tabular}

Based on the presented concepts of basic structures, it can be seen that more than one set of tasks can be performed by one basic structure and more than one basic structure can perform a task. Therefore by combining PBBs at lower scales to generate SPBs and basic structures that perform tasks, flowsheet alternatives can have a reduction in the number of unit operations or the search space of unit operations can be expanded which provides the opportunity to generate new/novel process flowsheets inclusive of hybrid/intensification unit operations.

\subsection{Conclusion}

In this chapter, the mathematical formulation of the process synthesis-intensification problem, for achieving more sustainable designs, have been presented. Process intensification is included within the problem formulation through, a set of process intensification design specifications and performance criteria.

The solution approach, that is the decomposition-based solution strategy, has been presented and explained (DBSS). The DBSS method is useful for achieving more sustainable design due to the evaluation of a large number of flowsheet alternatives. Definition of terms for understanding phenomena based synthesis and its relation to computeraided molecular design has been presented. 


\section{FRAMEWORK FOR SUSTAINABLE PROCESS SYNTHESIS-INTENSIFICATION: METHODOL- OGY}

In this chapter, first the framework architecture (structure) is presented, illustrating the
various steps needed for application of the framework. Second, the framework work-
flow together with the data-flow are presented. Each step of the framework with a step
by step explanation that uses the algorithms presented in chapter 2, is presented, in or-
der to, successfully apply the framework.

\subsection{Framework Architecture}

The detailed architecture for the computer-aided, multi-level, multi-scale, framework and the different computer-aided tools embedded in it, for solving the process synthesisintensification optimization defined in chapter 1 , for achieving more sustainable designs is shown in Figure 3-1.

The developed framework consists of 8 steps (steps S1-steps S8) and 4 integrated taskphenomena-based synthesis (IT-PBS) steps. Steps 1-8 operate at the integrated operations-task outer levels, while, IT-PBS.1-IT-PBS.4 operate at the integrated taskphenomena inner level. 



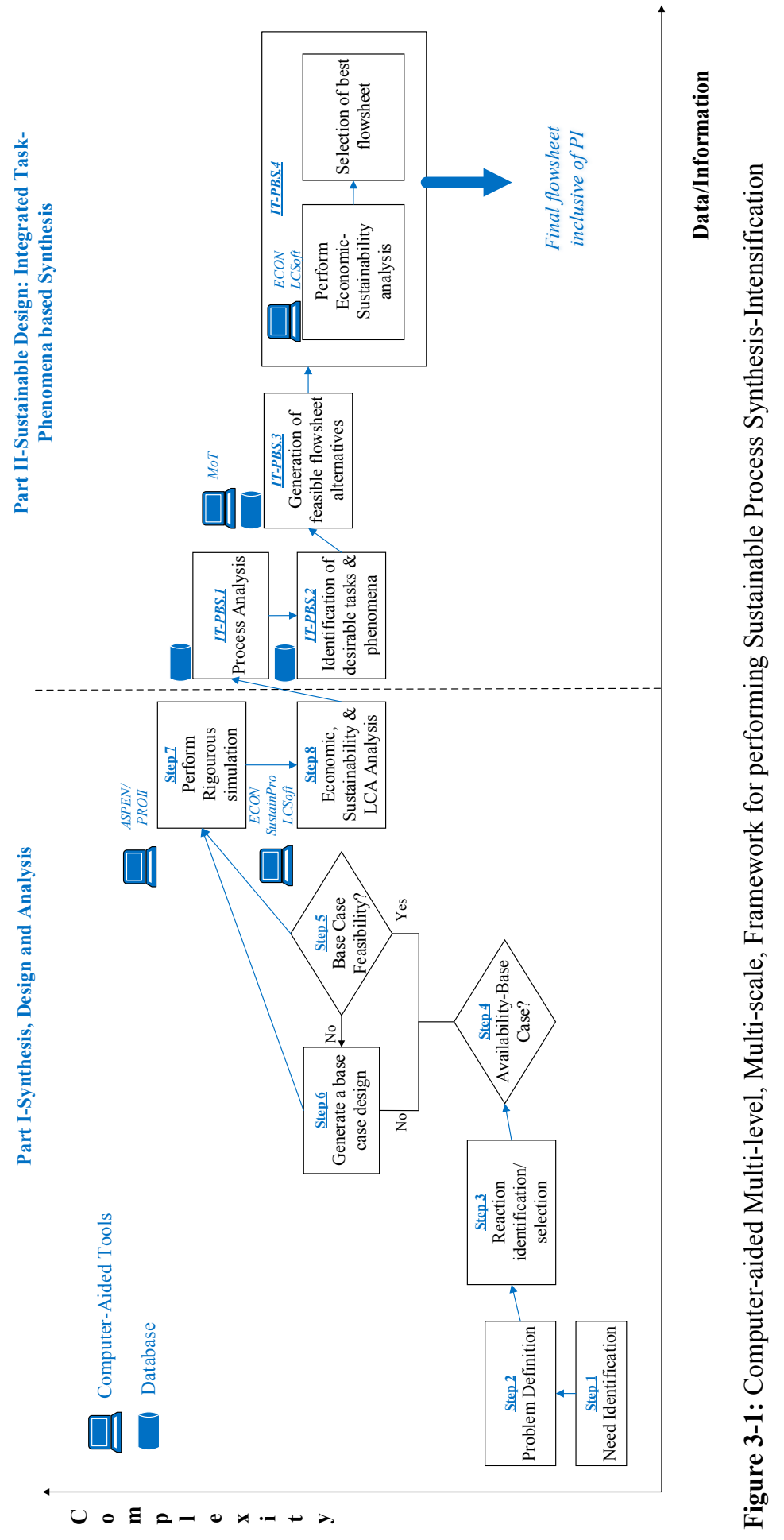





\subsection{Work-flow and Data-flow}

The work-flow and data-flow for the framework are presented and explained. The explanation of each step in the framework is divided into three parts as follows:

1. Objective- The objective to be accomplished after performing the step

2. Data-information needed- To achieve the objective certain information must be generated

3. Action/Work needed- This gives an explanation on how to obtain the information needed in order to accomplish the step objective and each type of information needed is highlighted in bold. At the end of the action/work needed, the notes explaining (where necessary) more information about the step is presented The assumptions for applying the method are:

- The product to be produced is known

- The amount of the product to be produced is known

- The type of reaction is known that is forward or reversible reaction

\subsection{Part I-Synthesis, Design and Analysis}

In this section the first 8 steps, where synthesis, design and analysis of a base case is performed, are explained. These 8 steps operate at the unit operations scale and task scale.

\subsubsection{Step 1-Need Identification}

Objective: To obtain production and cost information about the raw materials and products.

\subsubsection{Data-information needed}

The information needed to achieve the objective is as follows:

- The main uses of the product

- The total production per year of the product

- The total production per year of the raw materials

- The current or projected costs of the raw materials and products

\subsubsection{Action/Work needed}

Action 1: Perform a literature/online search to find the main uses of the product. The main uses includes products that are directly made from the product or where it is used as an important intermediate for producing other compounds

Action 2: Perform a literature/online search to find an estimate of the total production per year of the product and product purity. To collect the information apply the following steps:

1. Online search: keywords- Global production

2. Online search: keywords- Historical global production 
Note 1: The main uses of the product provides the motivation for investigating different flowsheet alternatives for its production

Note 2: The total production per year of the product provides an overview if, the demand for the product is increasing or decreasing annually

\subsubsection{Step 2-Problem (and Fobj) Definition}

Objective: To define the problem statement and objective function that explains the problem to be solved by the maximization/minimization of the objective function.

\subsubsection{Data-information needed}

The information needed for accomplishing the objective is as follows:

1. The problem statement

2. The objective function to be maximized or minimized

\subsubsection{Action/Work needed}

Action 1: To define the problem statement apply the following:

1. If a new process design or process retrofit is to be investigated then apply the following:

a. Is the reduction of the number of unit operations for the final design important?

- If yes, then include this in the problem statement; otherwise, continue

b. Is removal and/or minimal use of a solvent important?

- If yes, then include this in the problem statement; otherwise, continue

c. Is the minimization of energy consumption of the new process important?

- If yes, then include this in the problem statement; otherwise, continue

d. Is the inclusion of intensified equipment important?

- If yes, then include this in the problem statement; otherwise, continue

e. Is the minimization of any of the following costs: capital, operating and utility, important?

- If yes, then include this in the problem statement; otherwise, continue

f. Is the maximization of profit, important?

- If yes, then include this in the problem statement; otherwise, continue

g. Is the increase of reaction conversion/separation of the product important?

- If yes then include this in the problem statement 
Action 2: To define the objective function to be maximized/minimized apply the following:

1. If the problem statement includes all of or a combination of the following, define the objective function as a reduction in the operational cost or total annualized cost, per kg of product produced:

a. Reduction in the number of unit operations

b. Removal/minimal/reduction in solvent use

c. Minimization/reduction in energy consumption

d. Inclusion of hybrid/intensified equipment

e. Minimization/decrease in any of the following costs:

i. Capital

ii. Operating

iii. Utility

2. If the problem statement includes all or a combination of the following define the objective function as an increase in the profit per $\mathrm{kg}$ of product produced:

a. Maximization/increase in profit

b. Increase of reaction conversion

Action 3: To define the constraints of the optimization problem select the appropriate constraints from Table 3-1. 
Table 3-1: Constraints for the objective function. $\underline{\theta_{1}}$-Logical constraints, $\underline{\theta_{2}}$-Structural constraints, $\theta_{3}$-Operational constraints, $\varphi$-Performance criteria

\begin{tabular}{|c|c|c|c|c|}
\hline \multirow{2}{*}{ Objective } & \multicolumn{3}{|c|}{ Constraint } & \multirow{2}{*}{$\begin{array}{l}\text { Performance } \\
\text { Criteria }(\underline{\varphi})\end{array}$} \\
\hline & $\underline{\theta_{1}}$ & $\underline{\theta_{2}}$ & $\underline{\theta_{3}}$ & \\
\hline Flowsheet structure: reaction + separation & $*$ & & & \\
\hline Reaction occurs in the first unit operation & $*$ & & & \\
\hline $\begin{array}{l}\text { The product (and by-product) purity is defined } \\
\text { by the base case (reference) design }\end{array}$ & * & & & \\
\hline $\begin{array}{l}\text { PBBs are connected to form SPBs based on } \\
\text { combination rules }\end{array}$ & & * & & \\
\hline $\begin{array}{l}\text { SPBs are connected to form Basic Structures } \\
\text { based on combination rules }\end{array}$ & & $*$ & & \\
\hline $\begin{array}{l}\text { Use of a mass separating agent for reac- } \\
\text { tion/separation }\end{array}$ & & * & & \\
\hline $\begin{array}{l}\text { Do not use mass separating agents for reac- } \\
\text { tion/separation }\end{array}$ & & $*$ & & \\
\hline Recycle un-reacted raw materials & & * & & \\
\hline Do not use recycle streams if not necessary & & $*$ & & \\
\hline $\begin{array}{l}\text { Raw materials are assumed to be in their pure } \\
\text { state except if otherwise defined }\end{array}$ & & & * & \\
\hline Defined product conversion (or yield) & & & * & \\
\hline Product production target & & & * & \\
\hline $\begin{array}{l}\text { PI screening criteria for basic structures to unit } \\
\text { operations: Novel equipment feasible }\end{array}$ & & & & * \\
\hline Increase raw material conversion & & & & $*$ \\
\hline $\begin{array}{l}\text { Minimization/reduction in energy consump- } \\
\text { tion }\end{array}$ & & & & $*$ \\
\hline Inclusion of intensified equipment & & & & $*$ \\
\hline Reduction in the number of unit operations & & & & * \\
\hline Waste minimization & & & & $*$ \\
\hline $\begin{array}{l}\text { Sustainability and LCA factors must be the } \\
\text { same or better }\end{array}$ & & & & $*$ \\
\hline
\end{tabular}


Note 1: The problem statement clearly provides an overview of why the process to be synthesized/retrofitted is necessary and what should be achieved upon synthesizing the process.

Note 2: The objective function clearly shows the mathematical function that must be maximized/minimized that will provide a quantitative result that can be compared to an existing reference process (base case).

\subsubsection{Step 3-Reaction Identification/Selection}

Objective: (1) To select the reaction pathway, raw materials state and catalyst; and (2) To determine the reaction type (whether it is exothermic or endothermic).

\subsubsection{Data-information needed}

The information needed for accomplishing the objective is as follows:

1. Reaction pathway, raw materials state and catalyst

2. Reaction type

\subsubsection{Action/Work needed}

Action 1: To select the reaction pathway, raw materials state and catalyst apply the following steps:

1. Perform a literature/online search to find using keywords related to the possible reaction pathways for producing the desired product using different raw materials

2. For a selected reaction pathway retrieve the raw materials phase that is solid, liquid, vapour or a combination of these

3. For a selected reaction pathway retrieve the catalysts (if used) type, that is, heterogeneous or homogenous

4. If available, retrieve reaction equilibrium data. These are:

a. Is the reaction an equilibrium or forward reaction

b. Equilibrium constant

c. Equilibrium conversion

5. If available, retrieve the reaction kinetics data. These are:

a. Typical operating conditions of the reaction, that is, temperature and pressure

b. Rate constants and rate expression

Action 2: To determine the reaction type apply the following steps:

1. Identify the phase of the product(s) and by-product(s)

2. Calculate the heat of reaction using the following equation:

$$
\Delta H_{r x n}=\sum v_{i} H_{F i}
$$

Where $\Delta H_{r x n}$ is the heat of reaction, $v_{i}$ is the stoichiometric coefficient of the reactant/product and $H_{F i}$ is the heat of formation of the reactant/product. 
3. Reaction class. The reaction type is either one of or a combination of the following:
a. Forward reaction
b. Reversible reaction

4. State the reaction type, that is, exothermic or endothermic:

a. If $\Delta H_{r x n}<0$ then the reaction is exothermic

b. If $\Delta H_{r x n}>0$ then the reaction is endothermic

Note 1-2: The reaction information provides general information about the reaction for understanding the raw materials used to produce the raw product(s) and by-product(s). It also provides information on the phase of the reaction the reaction type based on the change of enthalpy of the reaction

\subsubsection{Step 4-Check for Availability-Base Case?}

Objective: To select a base case design based on a literature survey or based on the information on processes stored in a PI knowledge-base. Note, if a base case design has been provided, proceed to step 7 .

\subsubsection{Data-information needed}

The information needed for accomplishing the objective is as follows:

- If a base case design is available

\subsubsection{Actions/Work needed}

Action 1: To select a base case design for the production of the product from the raw materials apply the following steps:

1. Perform a literature/online search for an existing design which employs one of the reaction pathways obtained in step 3 . If a single of multiple designs are found then proceed to step 5 to test the feasibility of the design to be used as a base case

2. If no design is available, then proceed to step 6 to generate a base case design

Note 1: A literature search to obtain a base case design for the production of the product from the raw materials may or may not be found. If found then the feasibility of the flowsheet is performed (step 5), otherwise, a flowsheet must be generated (step 6) using the two synthesis methods embedded within the framework that operate at the unit operations scale and task scale.

\subsubsection{Step 5-(if the output of Step 4 is 'Yes')-Check for Base Case Feasibility}

Objective: To verify the feasibility of the base case design obtained in step 4 . 


\subsubsection{Data-information needed}

The information needed for accomplishing the objective is a set of hierarchal decisions as follows (Douglas 1985):

1. Process type: Batch vs. Continuous

2. Input/output structure of the flowsheet

3. Recycle structure of the flowsheet

4. Separation system of the flowsheet:

a. Vapour recovery system

b. Liquid separation system

5. Heat-exchanger networks

\subsubsection{Action/Work needed}

Action 1: To verify that the design obtained in step 4 is a feasible base case design, the process synthesis method by Douglas (1985) is used. The method is generally used for generating feasible process designs based on accepted heuristics formulated into specific design decisions. Therefore, the method is used in reverse where the design decisions are used to verify if the pre-selected base case design is feasible in terms of the flowsheet structure.

Note 1: The method of Douglas (Douglas 1985) is used to verify the feasibility of designs obtained in step 4 . This is important compared to directly using a design obtained from a literature search because if the design is infeasible then the starting point (reference) for generating new flowsheet alternatives is not good.

\subsubsection{Step 6-(if the output of Step 4 is 'No')-Generate a Base Case Design}

Objective: To generate a base case design for the production of the product from the raw materials. Note if this step is performed, proceed to step 8 .

\subsubsection{Data-information needed}

The information needed for accomplishing the objective is as follows:

- A base case design

\subsubsection{Action/Work needed}

Action 1: To generate a feasible base case design apply the following steps:

1. Apply the means-ends analysis (Siirola, 1996) in order to identify tasks for production and recovery of the product, and recycle of raw materials

2. Apply the method of thermodynamic insights (Jaksland et al., 1995) in order to verify the identified tasks, using analyses of pure component properties and mixture properties

3. Using the results of the property analyses, the tasks are translated into operations 
4. The set of feasible flowsheet alternatives are then rigorously simulated (step 7) and based on the calculated objective function the design that gives the best value is selected as the base case design

Note 1: The two methods used for the generation of a feasible base case design operates at the unit operations scale and task scale and do not include hybrid/intensified unit operations. Using this combined approach identified tasks can be verified through thermodynamic analyses in order to screen infeasible tasks. The objective function used for selecting the feasible design is the objective function defined in step 2 .

\subsubsection{Step 7-Perform Rigorous Simulation}

Objective: To simulate the base case design rigorously

\subsubsection{Data-information needed}

The information needed for accomplishing the objective is as follows:

1. Selection of a thermodynamic model

2. Simulation of the base case design

3. Detailed mass balance data

4. Detailed energy balance data

5. Number of streams

6. The number and type of unit operations

\subsubsection{Action/Work needed}

Action 1: To simulate the base case design follow the following steps:

1. Mass and energy balance-

a. Select a thermodynamic model using Figure 3-2 


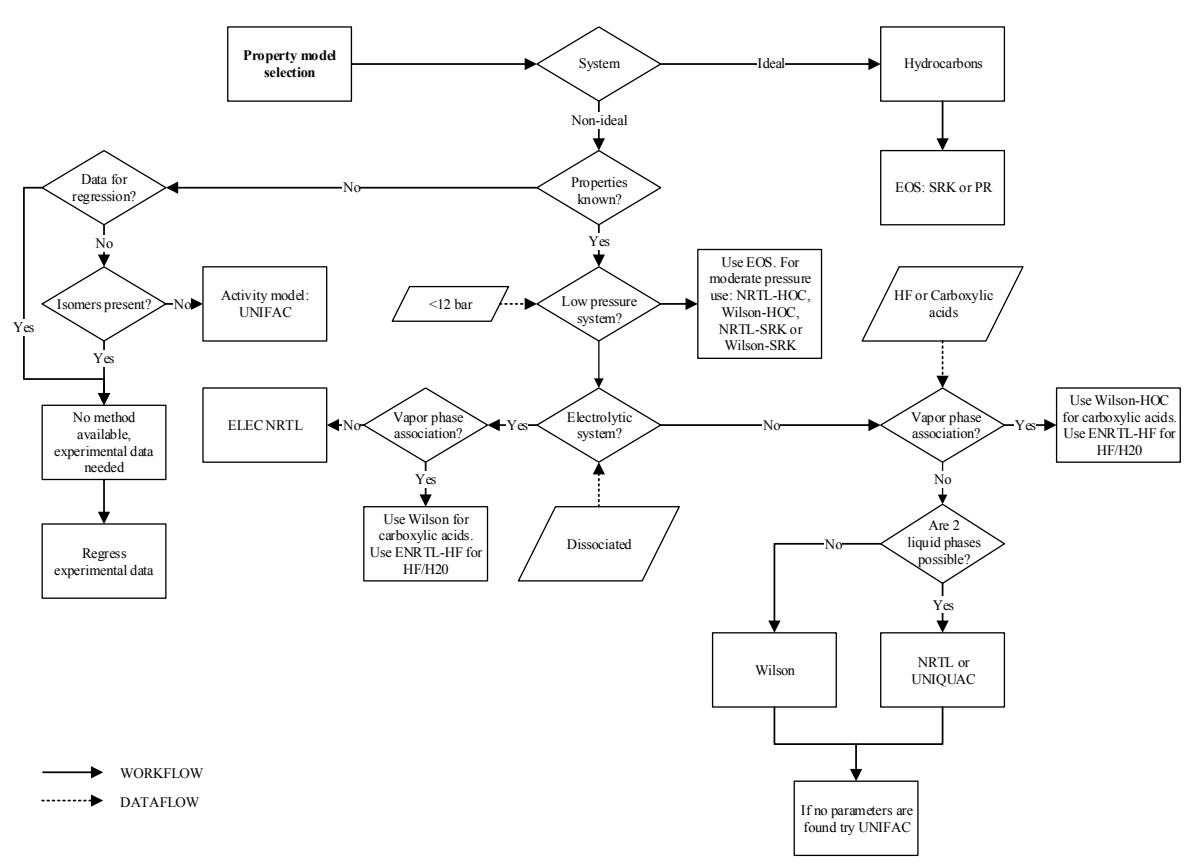

Figure 3-2: Selection of a thermodynamic model (Gani, 2010)

b. Perform a mass balance around the entire process using the selected raw materials, products, reactions and conversion (see Figure 1-1)

c. Use reaction conversion and stream calculators/splitters (in/out models) to perform the mass balance using key component separation specifications, for example, if 4 compounds are to be separated then chose the light key compound (and heavy key compound) based on boiling points and calculate the recovery of the top and bottom streams. Therefore every compound with a boiling point lower than the light key compound goes to the top, whereas, every compound with a boiling point higher than the light key compound goes to the bottom. If azetropes are present then do the following:

i. For a minimum boiling azeotrope, the maximum composition for the compounds at the top of the column consists of the azeotropic composition and the composition of every compound that has a boiling point lower than the minimum boiling azeotrope.

ii. If a binary mixture of two compounds forming a minimum boiling azeotrope is being separated then the maximum composition for the compounds at the top of the column consists of the azeotropic composition

iii. For a maximum boiling azeotrope, the maximum composition for the compounds at the bottom of the column consists of the azeo- 
tropic composition and the composition of every compound that has a boiling point higher than the minimum boiling azeotrope

iv. If a binary mixture of two compounds forming a maximum boiling azeotrope is being separated then the maximum composition for the compounds at the bottom of the column consists of the azeotropic composition

d. In the simulator, close all recycle streams as the mass balance is completed for each unit operation

e. Using the mass balance model of the base case, perform the energy balance by adding and specifying the operating conditions of unit operations that require energy.

2. Using shortcut models for estimation-

a. Replace the in/out mass balance models with shortcut calculations for estimation of equipment parameters, for example, the number of trays in a distillation column, reflux ratio and feed location

3. Rigorous simulation

a. Replace the unit operations using the shortcut models with unit operations which uses rigorous (detailed) models, for example models, based on tray by tray calculation. Use the estimates obtained from the shortcut models as estimates for rigorous simulation.

Action 2: The following information is retrieved from the detailed simulation of the base case must be performed:

1. Detailed mass balance data

2. Detailed energy balance data

3. Number of streams

4. The number and type of unit operations

Note 1: The steps provided for the simulation of the base case design is a method which is hierarchal and therefore, each step uses information from the previous step for generating the necessary information to be used in the next step.

Note 2: The number of unit operations can already be identified in step 4, however it's identified here because the flowsheet structure may change when performing rigorous simulation, for example, consider a reactor that has been built for an existing process where an equilibrium reaction and a forward reaction occur simultaneously. When this reactor is simulated in a commercial simulator the reactor is, for example, represented as follows, an equilibrium reactor followed by a conversion reactor. Therefore, the number of unit operations simulated is different from the design found in reality. Furthermore, the simulated mass and energy (unless plant data is available) data and flowsheet structure are used in step 8 for performing the sustainability analysis. However, the result generated in the analysis are reflective of an analysis on the existing (real) process. 


\subsubsection{Step 8-Economic, Sustainability and LCA Analysis}

Objective: To perform 3 analyses; economic, sustainability and LCA, in order to set the targets for sustainable design through the identification of process hot-spots.

\subsubsection{Data-information needed}

The information needed for accomplishing the objective is as follows:

1. The open and closed paths

2. Economic/Sustainability/LCA indicators

3. Process hot-spots

\subsubsection{Work/Action needed}

Action 1: Economic analysis: To calculate the economic analysis apply the following steps:

1. For the base case design, perform equipment sizing

2. Calculate and store the utility, operational and capital costs

a. Apply ECON otherwise if a computer-aided tool is not available,

b. Apply the cost estimation models presented in Peters, Timmerhaus, West (2003) or Biegler, Grossmann and Westerberg (1997)

Action 2: Perform the sustainability analysis using SustainPro and store each indicator selected. These will be translated into process hot-spots using Table 3-2

Action 3: Perform the LCA analysis using LCSoft and store the carbon footprint for each unit operation and environmental impacts of the process. The environmental impacts of the process are, for example, the global warming potential (GWP) and the human toxicity potential by ingestion (HTPI). HTPI is one of the indicators that provides a measure of the toxicity/hazard potential of the compounds (raw materials, products and by-products) in the base case design

Action 4: To translate the result of the analyses into process hot-spots use Table 3-2. 
Table 3-2: Translation of economic $(\underline{\alpha})$, sustainability $(\underline{\beta})$ and LCA $(\underline{\gamma})$ analyses into process hot-spots. MVA-mass value added, EWC-Energy to waste cost, $\mathrm{CO} 2$ eq-carbon footprint, PEI-potential environmental impact

\begin{tabular}{|c|c|c|c|}
\hline Indicator values & $\begin{array}{l}\text { Base Case prop- } \\
\text { erty }\end{array}$ & Reason & $\begin{array}{l}\text { Identified Process } \\
\text { hot-spot }\end{array}$ \\
\hline $\begin{array}{l}\alpha_{1}=\text { Raw material } \\
\text { recycle } / \text { cost } \\
\beta_{1}=\mathrm{MVA}\end{array}$ & $\begin{array}{l}\text { Un-reacted raw } \\
\text { materials }\end{array}$ & $\begin{array}{l}\text { Equilibrium reac- } \\
\text { tion }\end{array}$ & $\begin{array}{l}\text {-Activation problems } \\
\text {-Limiting equilibri- } \\
\text { um/raw material loss } \\
\text {-Contact problems of } \\
\text { raw materials/limited } \\
\text { mass transfer } \\
\text {-Limited heat trans- } \\
\text { fer }\end{array}$ \\
\hline $\begin{array}{l}\alpha_{2}=\mathrm{Utility} \text { cost } \\
\beta_{2}=\mathrm{EWC} \\
\gamma_{1}=\mathrm{CO} 2 \text { equiva- } \\
\text { lent }\end{array}$ & $\begin{array}{l}\Delta H_{r x n}>0 \text { Reactor } \\
\text { cooling }\end{array}$ & Exothermic reaction & $\begin{array}{l}\text {-Highly exothermic } \\
\text { reaction }\end{array}$ \\
\hline $\begin{array}{l}\alpha_{2}=\text { Utility cost } \\
\beta_{2}=\mathrm{EWC} \\
\gamma_{1}=\mathrm{CO} 2 \text { equiva- } \\
\text { lent }\end{array}$ & $\begin{array}{l}\Delta H_{r x n}<0 \text { Reactor } \\
\text { heating }\end{array}$ & $\begin{array}{l}\text { Endothermic reac- } \\
\text { tion }\end{array}$ & $\begin{array}{l}\text {-Highly endothermic } \\
\text { reaction }\end{array}$ \\
\hline $\begin{array}{l}\alpha_{2}=\text { Utility cost } \\
\alpha_{3}=\text { Capital cost }\end{array}$ & $\begin{array}{l}\text { Reactor operating } \\
\text { conditions }\end{array}$ & $\begin{array}{l}\text { Temperature and } \\
\text { pressure operating } \\
\text { window for the re- } \\
\text { actor }\end{array}$ & $\begin{array}{l}\text {-Explosive mixture } \\
\text {-Product degradation } \\
\text { by temperature }\end{array}$ \\
\hline $\begin{array}{l}\alpha_{4}=\text { Product sale } \\
\gamma_{2}=\text { PEI }\end{array}$ & $\begin{array}{l}\text { Formation of by- } \\
\operatorname{product}(s)\end{array}$ & $\begin{array}{l}\mathrm{NOP}=\text { number of } \\
\text { desired products } \\
\text { plus number of un- } \\
\text { desired products }\end{array}$ & $\begin{array}{l}\text {-Formation of unde- } \\
\text { sired side-products }\end{array}$ \\
\hline $\begin{array}{l}\alpha_{2}=\mathrm{Utility} \text { cost } \\
\beta_{1}=\mathrm{MVA} \\
\beta_{2}=\mathrm{EWC} \\
\gamma_{1}=\mathrm{CO} 2 \text { equiva- } \\
\text { lent } \\
\gamma_{2}=\mathrm{PEI}\end{array}$ & $\begin{array}{l}\text { Un-reacted raw } \\
\text { materials and } \\
\text { products recovery }\end{array}$ & $\begin{array}{l}\text {-Presence of azeo- } \\
\text { trope(s) } \\
\text {-High energy usage- } \\
\text { heating and/or cool- } \\
\text { ing }\end{array}$ & $\begin{array}{l}\text {-Azeotrope } \\
\text {-Difficult separation: } \\
\text { low driving force } \\
\text {-High energy con- } \\
\text { sumption and/or de- } \\
\text { mand }\end{array}$ \\
\hline
\end{tabular}


Action 5: To set the design targets use Table 3-3.

Note 1: The economic analysis is used to obtain the distribution of the utility costs for each unit operation which provides an overview of the base operational cost that is the raw material plus utility costs. The calculated capital cost is used as a comparison to the generated feasible intensified flowsheet alternatives

Note 2: The sustainability analysis is used to identify process hot-spots otherwise not evident from an economic analysis for example raw material loss in a product/waste stream. If this occurs then this is a process hot-spot and the design target would to be minimize raw material loss

Note 3: The LCA analysis serves two purposes. First, it is used to verify the economic analysis, for example, a unit operation with a high utility cost (economic analysis), will show a high availability of energy in the path where it is located in the process and therefore, will have a high carbon footprint. Second, it is used to calculate the environmental impact of the process, for example, on the process waste streams.

Note 4: The results from the analyses must be translated into process hot-spots which are used to set the design targets

Note 5: The design targets identified from Table 3-3 and those design targets which share all the process hot-spots are those defined by the performance criteria in step 2 and those defined by the base case design. 


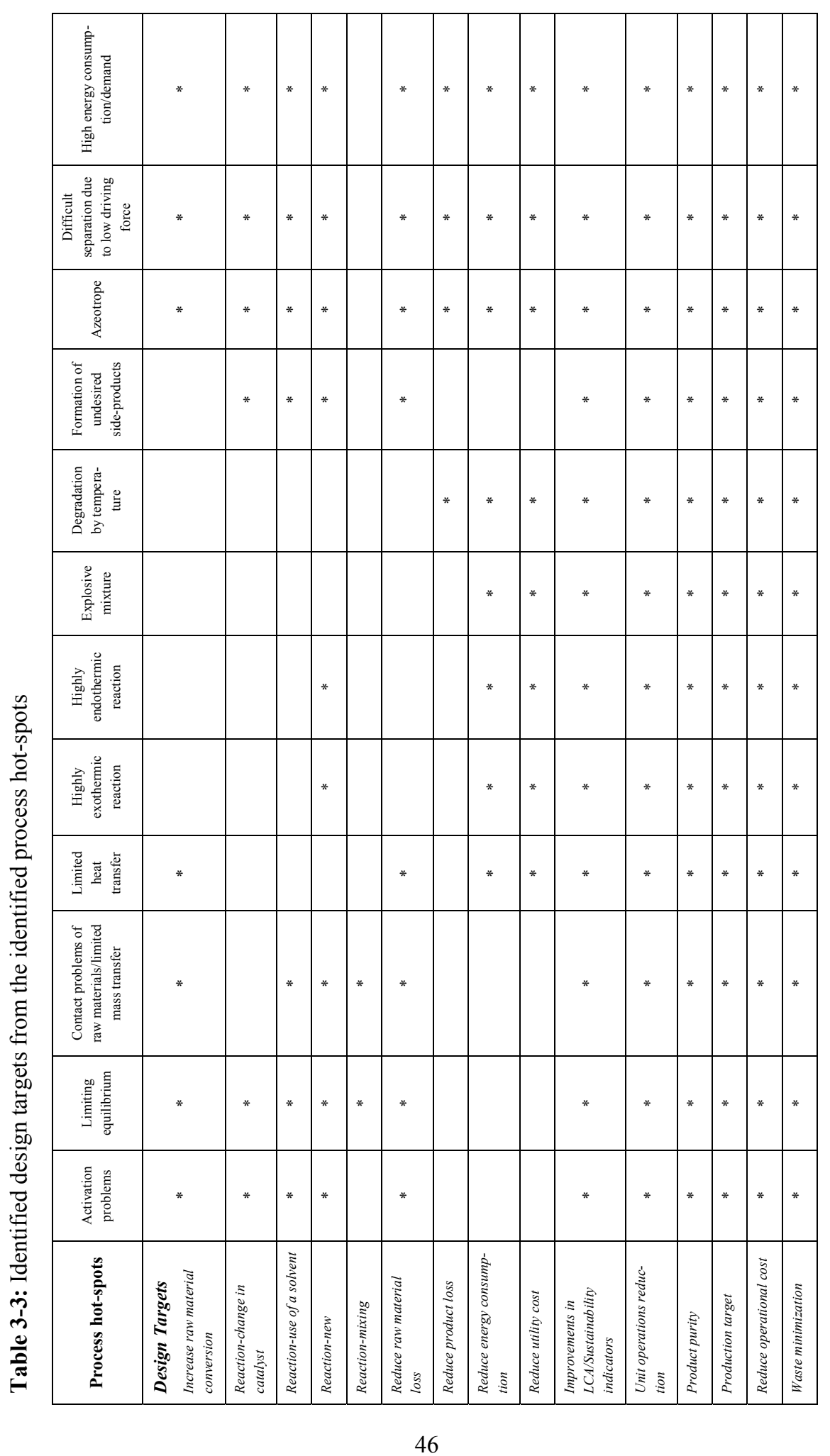




\subsection{Part II-Sustainable Design : Integrated Task-Phenomena based Synthesis}

In this section the steps of the integrated task-phenomena-based method, IT-PBS.1 to IT-PBS.4, are explained. These 4 steps operate at the task scale and unit operations scale.

\subsubsection{IT-PBS.1-Process Analysis}

Objective: To analyse the base case design for identification of tasks, PBBs and the PBBs involved in each hot-spot.

\subsubsection{Data-information needed}

The information needed for accomplishing the objective is as follows:

1. Task-based flowsheet (unless step 6 has been performed)

2. Phenomena-based flowsheet

3. Identification of the initial PBB search space

4. Mixture property analyses (unless step 6 has been performed)

\subsubsection{Action/Work needed}

Action 1: To transform the base case design to the task-based flowsheet, apply algorithm I.1 (AI.1)

Action 2: To transform the task-based flowsheet (in this case the base case design) to the phenomena based flowsheet, apply the following steps:

1. Apply algorithm I.2 (AI.2)

2. Store the identified PBBs

Action 3: The mixture property analysis performed in this section is related to the binary ratio matrix calculation based on pure component properties, an azeotrope analysis and miscibility analysis because they are the most common mixture properties that can be analysed as long as the data are available. To perform the binary ratio analysis, an azeotrope analysis and miscibility calculations, apply the following steps:

1. Generate the binary ratio matrix:

$\circ$ The binary ratio matrix represents the property differences between all binary pairs of the pure components presented. These property differences are represented in terms of property ratios for example the ratio of boiling points

○ Calculate the number binary pairs from the number of compounds using Equation 3.19

$$
p=\frac{N C(N C-1)}{2}
$$

Where $p$ is the total number of binary pairs and $N C$ is the total number of compounds in the system 
○ The binary ratio for each binary pair of compounds is calculated using Equation 3.20. Note that for each binary pair, the binary ratio of a property is always $>1$ because it is calculated by the division of the property with the lower value. Note that for the presentation of the binary ratio matrix units are not necessary because the ratio of each property (Equation 3.20) are the values that constitute the binary ratio matrix

$$
r_{i j}=\frac{p_{A j}}{p_{B j}}
$$

Where rij is the binary ratio and $\mathrm{p}$ is the pure component property

2. Identify the azeotropes in the system:

- Using the selected thermodynamic model from step 7, plot the VLE phase diagram of the compounds in the system. The number of VLE phase diagrams for NC components is calculated using Equation 3.21

$$
N_{V L E}=\frac{N C(N C-1)}{2}
$$

- For compounds where a point exist that y (vapour) composition is equal to $\mathrm{x}$ (liquid) composition, an azeotrope is identified

- Alternatively, in order to have a hint that an azeotrope is present, use the binary ratio matrix. If the ratio of the boiling point is close to unity (that is 1) then the possibility exists that an azeotrope exist between the binary pair

3. Select an increment for the pressure values for example 1 to 10 bar use increments of 1 bar

4. Calculate, plot and store the change in azeotropic composition of the lower boiling compound versus the change in pressure

- Alternatively an azeotrope database can be used in order to readily identify the pressure dependence of known azeotropes (Gani et al., 1997, Fernandez, 2012)

5. Perform a literature search for the existence of LLE of the binary pairs in the system

- If the binary ratio of the octanol-water partition coefficient is calculated and is much greater than 1 , then there is a possibility that a miscibility gap occurs

6. Use the selected thermodynamic model, perform and store LLE calculations for the following conditions:

- Keep pressure constant, vary temperature as found in literature

- Keep temperature constant, vary pressure as found in literature

Note 1: The base case design is decomposed first from the unit operations scale to the task scale 
Note 2: The base case design is decomposed second from the task scale to the phenomena scale. The PBBs identified in applying the algorithm constitute the initial PBB search space

Note 3: Further process analysis is performed because this information is used in ITPBS.3 for generating flowsheet alternatives from the combination of PBBs.

\subsubsection{IT-PBS.2-Identification of Desirable Tasks and Phenomena}

Objective: To identify desirable tasks and the corresponding PBBs for overcoming the process hot-spots.

\subsubsection{Data-information generated}

The information needed for accomplishing the objective is as follows:

- Identification of the desirable tasks to overcome the process hot-spots

- Identification of PBBs based on the identified tasks for overcoming process hotspots

- Identification of the PBB search space

- Selection of the operating window of each phenomena

\subsubsection{Action/Work needed}

Action 1: To identify the desirable tasks and PBBs apply the following steps:

1. Apply algorithm I.3 (AI.3)

2. Add the identified PBBs to the PBBs identified in IT-PBS.1. This list of PBBs constitute the PBB search space.

Action 2: To identify the PBB search space, apply the following steps:

1. Retrieve the structural constraints $\left(\underline{\theta_{2}}\right)$ and performance criteria $(\underline{\varphi})$ defined in step 2

2. If the use of a mass separating agent are not considered remove PT PBBs obtained from algorithm I.3 (AI.3) which requires the use of a mass separating agent. The constraints used are:

a. $\theta_{2}$-Do not use mass separating agents for reaction/separation

b. $\underline{\varphi}$-Waste minimization

3. If intensified/hybrid equipment is not to be included in the generation of flowsheet alternatives only keep the PT PBBs of the form PT(VL) and PT(LL). The constraints used are:

a. $\underline{\varphi}$-PI screening criteria for basic structures to unit operations: Novel equipment feasible

b. $\varphi$-Inclusion of intensified equipment

4. If no azeotropes and miscibility gaps are present only keep the PT PBBs of the form PT(VL). The constraints used are: 
a. $\underline{\theta_{2}}$-Use of a mass separating agent for reaction/separation (extractive separation) else

b. $\underline{\theta_{2}}$-Do not use mass separating agent for reaction/separation

c. $\underline{\varphi}$-PI screening criteria for basic structures to unit operations: Novel equipment feasible

d. $\underline{\varphi}$-Inclusion of intensified equipment

Action 3: To select the operating window of each identified PBB in the PBB search space use Table 3-4.

Table 3-4: Guide for choosing the operating window of the identified PBBs. NA-Not applicable

\begin{tabular}{|c|c|c|c|c|}
\hline Task & PBB & $\begin{array}{l}\text { Operating } \\
\text { variables }\end{array}$ & $\begin{array}{l}\text { Properties to } \\
\text { be checked }\end{array}$ & Example \\
\hline \multirow{3}{*}{$\begin{array}{c}\text { Reaction } \\
\text { (single phase) } \\
\text { Concentrations } \\
\text { below the dew } \\
\text { point line }\end{array}$} & \multirow{3}{*}{$\mathrm{R}$} & \multirow[t]{3}{*}{$\mathrm{T}, \mathrm{P}$} & \multirow[t]{3}{*}{$\begin{array}{l}\mathrm{T}_{\mathrm{Bi}}, \mathrm{T}_{\mathrm{Mi}}, \\
\mathrm{T} \text { of the } \\
\text { azeotrope }\end{array}$} & $\begin{array}{l}\text { Single phase is } \\
\text { liquid-P-Reaction } \\
\text { pressure (report- } \\
\text { ed in literature) }\end{array}$ \\
\hline & & & & $\begin{array}{l}\text { T-Lowest boiling } \\
\text { compound or } \\
\text { azeotrope }\end{array}$ \\
\hline & & & & $\begin{array}{l}\text { T-Lowest highest } \\
\text { melting com- } \\
\text { pound }\end{array}$ \\
\hline \multirow{3}{*}{$\begin{array}{c}\text { Reaction } \\
\text { (two phase) }\end{array}$} & \multirow{3}{*}{$\mathrm{R}$} & \multirow[t]{3}{*}{$\mathrm{T}, \mathrm{P}$} & \multirow[t]{3}{*}{$\begin{array}{l}\mathrm{T}_{\mathrm{Bi}}, \mathrm{T}_{\mathrm{Mi}}, \\
\mathrm{T} \text { of the } \\
\text { azeotrope }\end{array}$} & $\begin{array}{l}\text { Phases: Va- } \\
\text { por/Liquid } \\
\text { P-Reaction pres- } \\
\text { sure }\end{array}$ \\
\hline & & & & $\begin{array}{l}\text { T-Highest boiling } \\
\text { compound in the } \\
\text { liquid phase }\end{array}$ \\
\hline & & & & $\begin{array}{l}\text { T-Lowest melt- } \\
\text { ing compound }\end{array}$ \\
\hline \multirow{2}{*}{$\begin{array}{c}\text { Mixing } \\
\text { (single phase) } \\
\text { Concentrations } \\
\text { below the dew }\end{array}$} & \multirow[t]{2}{*}{ M } & \multirow[t]{2}{*}{$\mathrm{T}, \mathrm{P}$} & \multirow[t]{2}{*}{$\begin{array}{l}\mathrm{T}_{\mathrm{Bi}}, \mathrm{T}_{\mathrm{Mi}}, \\
\mathrm{T} \text { of the } \\
\text { azeotrope }\end{array}$} & $\begin{array}{l}\text { Ideal Mixing: T- } \\
\text { Lowest melting } \\
\text { compound }\end{array}$ \\
\hline & & & & Ideal Mixing: T- \\
\hline
\end{tabular}




\begin{tabular}{|c|c|c|c|c|}
\hline \multirow[t]{2}{*}{ point line } & & & & $\begin{array}{l}\text { Highest boiling } \\
\text { compound }\end{array}$ \\
\hline & & & & $\begin{array}{l}\text { Vapor Mixing: } \\
\text { T-Lowest boiling } \\
\text { compound or } \\
\text { minimum boiling } \\
\text { azeotrope }\end{array}$ \\
\hline \multirow{2}{*}{$\begin{array}{l}\text { Two-phase mixing } \\
\text { Concentrations in } \\
\text { V-L equilibrium } \\
\text { regions are be- } \\
\text { tween the dew and } \\
\text { bubble point line }\end{array}$} & \multirow[b]{2}{*}{$2 \mathrm{phM}$} & \multirow[t]{2}{*}{$\mathrm{T}, \mathrm{P}$} & \multirow{2}{*}{$\begin{array}{l}\mathrm{T}_{\mathrm{Bi}}, \mathrm{T}_{\mathrm{Mi}}, \\
\mathrm{T} \text { of the } \\
\text { azeotrope }\end{array}$} & $\begin{array}{l}\text { T- Lowest melt- } \\
\text { ing compound }\end{array}$ \\
\hline & & & & $\begin{array}{l}\mathrm{T}-2 \text { nd highest } \\
\text { boiling com- } \\
\text { pound or mini- } \\
\text { mum boiling } \\
\text { azeotrope }\end{array}$ \\
\hline Heating/Cooling & $\mathrm{H} / \mathrm{C}$ & $\mathrm{T}$ & - & NA \\
\hline \multirow{3}{*}{ Phase Contact } & \multirow{3}{*}{$\mathrm{PC}$} & \multirow[t]{3}{*}{-} & \multirow[t]{3}{*}{-} & VL:-NA \\
\hline & & & & LL:-NA \\
\hline & & & & SL:-NA \\
\hline \multirow{2}{*}{$\begin{array}{l}\text { Phase Transition } \\
\text { Concentrations in } \\
\text { V-L equilibrium } \\
\text { regions are be- } \\
\text { tween the dew and } \\
\text { bubble point line }\end{array}$} & \multirow{2}{*}{$\mathrm{PT}$} & $\mathrm{T}, \mathrm{P}$ & \multirow[t]{2}{*}{$\begin{array}{l}\mathrm{T}_{\mathrm{Bi}}, \mathrm{T} \text { of the } \\
\text { azeotrope }\end{array}$} & $\begin{array}{l}\text { T-Lowest boiling } \\
\text { compound or } \\
\text { minimum boiling } \\
\text { azeotrope }\end{array}$ \\
\hline & & & & $\begin{array}{l}\text { T-Highest boiling } \\
\text { compound or } \\
\text { maximum boiling } \\
\text { azeotrope }\end{array}$ \\
\hline \multirow{3}{*}{ Phase Separation } & \multirow{3}{*}{ PS } & \multirow[t]{3}{*}{-} & \multirow[t]{3}{*}{-} & VL:-NA \\
\hline & & & & LL:-NA \\
\hline & & & & SL:-NA \\
\hline
\end{tabular}

Note: NA-not applicable. T- temperature, P- pressure, TBi- boiling point of compound $i$, TMi- melting point of compound $i$

Note 1: The desirable tasks are identified followed by the PBBs that are associated with these tasks. The identified PBBs are beneficial since they expand the PBB search, therefore, providing the option to innovate and thereby, generate flowsheet alternatives that include hybrid/intensified equipment 
Note 2: To identify the PBB search space the PBBs identified in action 1 must be screened using the specified structural constraints and performance criteria.

Note 3: The operating widow of the selected PBB provides a bound for the process operating conditions that is temperature and pressure

\subsubsection{IT-PBS.3-Generation of Feasible Flowsheet Alternatives}

Objective: To generate feasible flowsheet alternatives using an integrated, taskphenomena based approach.

\subsubsection{Data-information needed}

The information needed for accomplishing the objective is as follows:

1. Generation of SPBs

2. Task-based superstructure

3. Identification of Basic structures that perform tasks

4. Task-based flowsheet sheets

5. Flowsheet alternatives

\subsubsection{Action/Work needed}

Action 1: To generate feasible SPBs, apply algorithm II.1 (AII.1)

Action 2: To generate the task-based superstructure, apply algorithm II.2 (AII.2)

Action 3: To identify the tasks that must be performed, apply algorithm II.3 (AII.3)

Action 4: To identify the basic structures that perform a task, apply algorithm II.4 (A11.4). Based on the structure of the algorithm, multiple basic structures can be generated $a$ priori for performing tasks. This has been done and can be readily used for identification of basic structures that perform specific tasks, presented in appendix D

Action 5: To identify the task-based flowsheets, apply algorithm II.5 (AII.5).

Action 6: To translate the identified basic structures that perform tasks which are combined to generate task-based flowsheets, into flowsheet alternatives at the unit operations scale, apply algorithm II.6 (AII.6)

Action 7: A model based analysis of the generated flowsheet alternatives is performed in order understand hybrid/intensified unit operations that maybe part of the flowsheet alternatives investigated in IT-PBS.4. To perform the analysis apply the following steps:

1. For hybrid/intensified equipment retrieve from the model library a suitable model for analysis of the unit operations. This is applicable to hybrid/intensified equipment related to membrane reactors, reactive distillation and reactive flash, among others. Note: The model library (Gani et al., 1997, Fedorova et al., 2014) consists of a series of developed models and are present in ICAS and ICASMoT

2. Analyse the hybrid/intensified unit operation ensuring that it meets the required set design target, for example: 
- A membrane reactor is analysed in order to investigate whether is breaks azetropes, and/or increases equilibrium conversion and/or performs in situ removal of a compound or compounds

- A reactive distillation column is analysed in order to investigate whether it overcomes the separation of azeotropes and/or increases equilibrium conversion and/or performs in situ removal of compounds, thereby, reacting all or most of a given raw material

- A reactive flash is analysed in order to investigate whether it increases equilibrium conversion and/or performs in situ removal of compounds, thereby, increasing conversion

- A divided wall column is analysed in order to investigate whether it can perform a required separation in one column as compared to using 2 distillation columns

3. Screen the flowsheet alternatives using the defined constraints set in step 2

Note 1: The identified PBBs are combined to form SPBs building blocks which are then combined to form feasible SPBs. The limitation of this forward approach is that not all possible SPB combinations are generated, however it manages the complexity instead of generating all possible SPBs and then screening them, since in principle, doing this is time consuming

Note 2: The task-based superstructure contains all possible reaction and separation tasks. From this superstructure tasked-based flowsheets are generated

Note 3: The identified task to be performed provide the overall structure of the taskbased flowsheets that can be generated

Note 4: In principle a basic structure performs a task. Multiple basic structures can perform one task, that leads to an expansion of the search space of unit operations and a basic structure can perform multiple tasks that leads to a reduction in the number of unit operations in a flowsheet alternative.

Note 5: The task based flowsheet identifies the feasible tasks that can performed for reaction and separation but does not govern the number of flowsheet alternatives that can be generated.

Note 6: The translation of the basic structures into unit operations gives rise to flowsheet alternatives consisting of well-known unit operations and existing/novel hybrid/intensified equipment

Note 7: If the models are not available in a commercial simulator then the models are either retrieved from a model library (Gani et al., 1997) or developed and stored in a model library (Fedorova et al., 2014). It should be noted that in principle, other hybrid/intensified unit operations can be analysed, for example, membrane distillation. Those mention in action 7 are those that have been analysed thus far from application of the framework. 


\subsubsection{IT-PBS.4-Comparison and Selection of the Best Flowsheet Al- ternatives}

Objective: To calculate the objective function and perform an economic, sustainability and LCA analyses for selecting the best flowsheet alternatives.

\subsubsection{Data-information needed}

The information needed for accomplishing the objective is as follows:

1. Economic/Sustainability/LCA indicators

2. Selection of the best flowsheet alternatives (more sustainable designs)

\subsubsection{Action/Work needed}

Action 1: To calculate the economic, sustainability and LCA indicators, apply action 1, action 2 and action 3 in step 8.

Action 2: Calculate the objective function and select the best flowsheet alternatives which produces the best value of the objective function while satisfying/improving the following subject to the logical constraint $\left(\underline{\theta_{1}}\right)$, structural constraint $\left(\underline{\theta_{2}}\right)$ and operational constraint $\left(\underline{\theta_{3}}\right)$ :

1. Performance criteria defined in step 2

2. Design targets defined in step 8

Note 1: The economic, sustainability and LCA indicators are calculated for each of the generated flowsheet alternatives in order to compare them to the base case design for selecting the best flowsheet alternatives (more sustainable designs)

Note 2: The flowsheet alternatives which produces the best objective function values while satisfying the performance criteria and design targets are selected as (more sustainable designs) and may or may not include hybrid equipment

\subsubsection{Tools used in each Step/IT-PBS}

Table 3-5 presents the steps and the tools applied in each step, for the sustainable process synthesis-intensification framework. The tools are categorized as databases and model-based. 


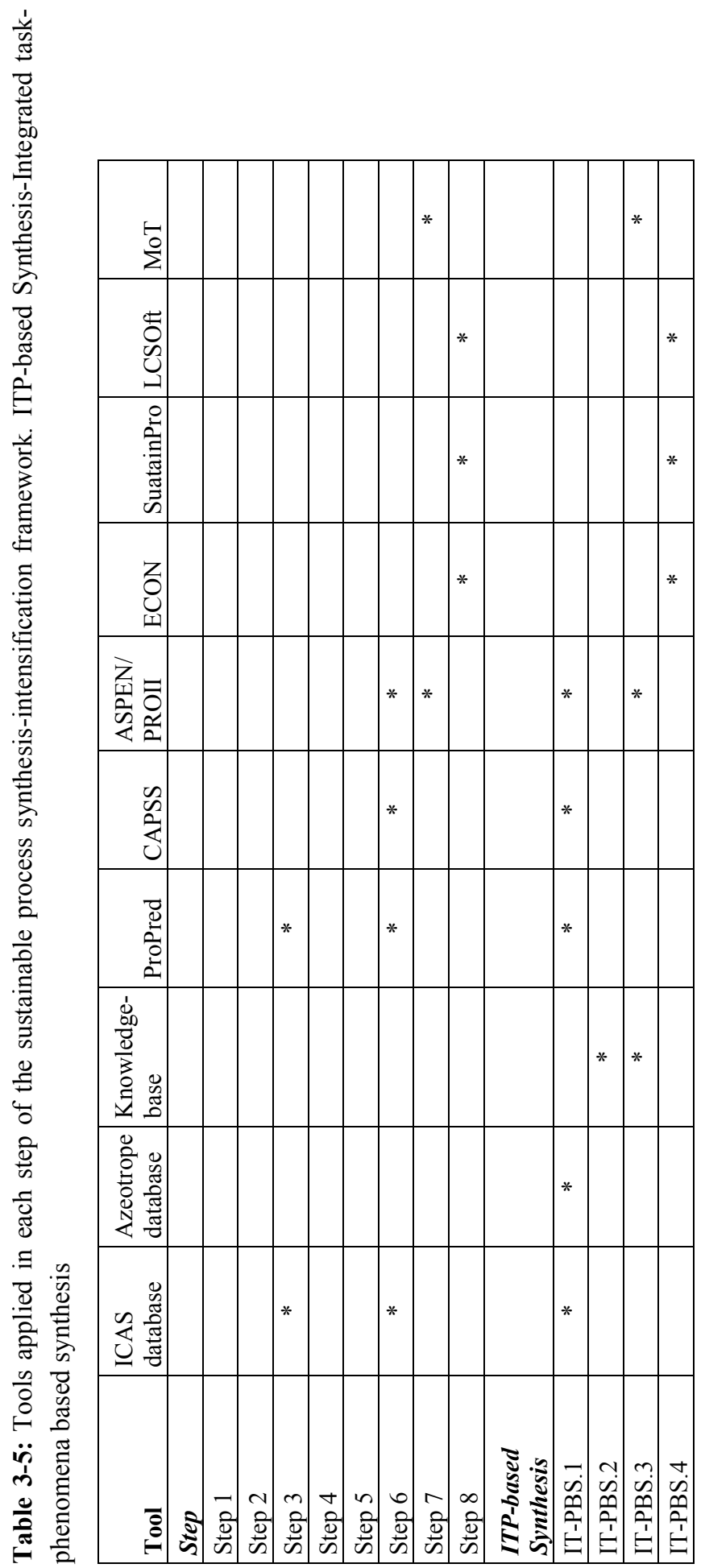





\subsection{Conclusion}

In this chapter the framework architecture for achieving sustainable process synthesisintensification has been presented. A detailed step by step explanation of each step of the framework, step 1 to step 8 and ITPBS.1 to ITPBS.4, has been presented in terms of, the step objective, data-information needed for performing the step and action/work required in order to satisfy the step objective. 



\section{FRAMEWORK fOR SUStainable PROCESS SYNTHESIS-INTENSIFICATION: ALGORITHMS}

In this chapter the steps involved in two algorithms used in the integrated taskphenomena based synthesis method are explained. First, algorithm I is presented. The objective of algorithm $I$ is to move from the highest scale (unit operation scale); to the lowest scale (phenomena scale), that is, the identification of additional tasks that are desirable for replacing a task used in the base case and, the identification of the corresponding PBBs associated with these desirable tasks.

Second, algorithm II is presented. The objective of algorithm II is to move from the lowest scale to the highest scale, that is, the combination of phenomena building blocks (PBBs) identified in algorithm I, using combination rules, into basic structures that perform a task or set of tasks. These tasks are ordered into task-based flowsheets that are translated into intensified unit operations-based flowsheet alternatives. Therefore, in algorithm II phenomena-based synthesis is performed using an integrated taskphenomena based synthesis method.

The overall concept of algorithm I and algorithm II is shown in Figure 4-1.

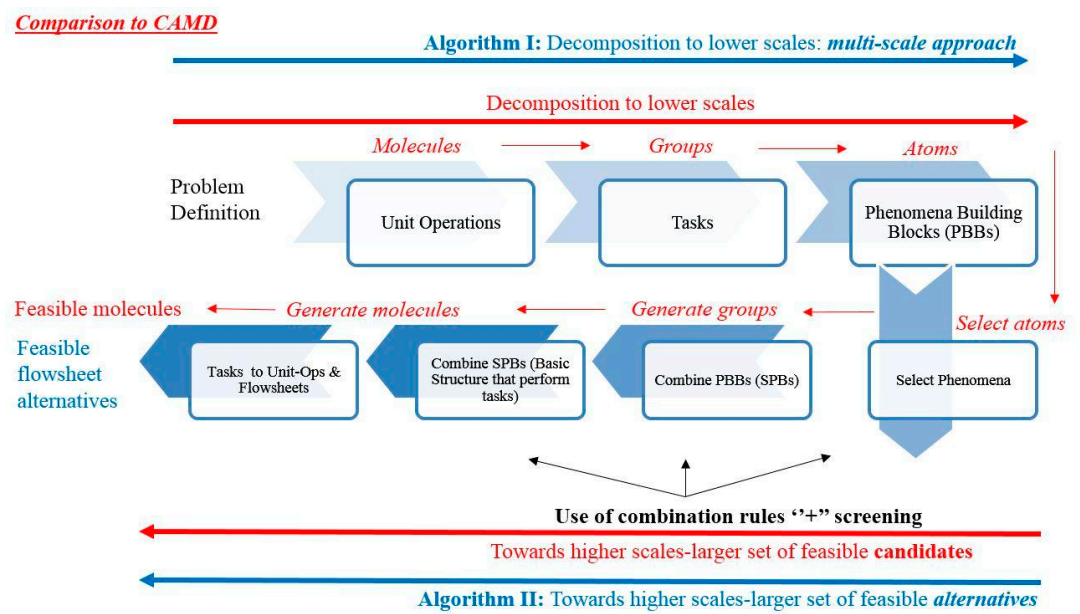

Figure 4-1: The concept of process synthesis-intensification framework compared to CAMD 


\subsection{Algorithm I-Towards Lower Scales from Higher Scales}

The problem definition for algorithm I is: Given: a base case design, process hot-spots and design targets. Identify: a set of phenomena building blocks (PBBs) that are to be combined (in algorithm II) to generate more sustainable designs.

Algorithm I employs 3 sub-algorithms. The objective and result of each algorithm is presented in Table 4-1 and each sub-algorithm is explained below.

Table 4-1: Objective and result(s) for each sub-algorithm employed in algorithm I

\begin{tabular}{|l|l|l|}
\hline Name & Objective & Result(s) \\
\hline Algorithm I.1 & $\begin{array}{l}\text {-Transform a base case } \\
\text { flowsheet to a task-based } \\
\text { flowsheet }\end{array}$ & Task-based flowsheet \\
\hline Algorithm I.2 & $\begin{array}{l}\text {-Identify PBBs in the base } \\
\text { case flowsheet } \\
\text {-Transform a task-based, } \\
\text { base case flowsheet, to a } \\
\text { phenomena-based flow- } \\
\text { sheet }\end{array}$ & $\begin{array}{l}\text {-Lhenomena-based flow- } \\
\text { case flowsheet } \\
\text { sheet }\end{array}$ \\
\hline Algorithm I.3 & $\begin{array}{l}\text {-Identify desirable task and } \\
\text { PBBs for addressing the } \\
\text { identified process hot-spots } \\
\text {-Identify final list of PBB } \\
\text { (PBB search space) }\end{array}$ & $\begin{array}{l}\text {-Identification of desirable } \\
\text { tasks for overcoming the } \\
\text { identified process hot-spots } \\
\text {-Search space of PBB }\end{array}$ \\
\hline
\end{tabular}

\subsubsection{Al.1-Transform the base case design to a task-based flowsheet}

The method for transforming a base case design at the unit operations scale to a taskbased flowsheet (TBF) at the task scale is presented.

- Step TBF.1-Classify each unit operation. Unit operations which affect a change in temperature (for example a shell and tube heat exchanger) and pressure (for example pump/compressor) are not included in the task-based flowsheet. In order to explain why these unit operations are not included in the task-based flowsheet, consider, moving from the task scale (task-based flowsheet) to the unit operations scale (unit operation-based flowsheet), then these unit operations are added during flowsheet refinement at the unit operations scale

o Step TBF.1.1- If the inlet and outlet composition of an unit operation is different and if some of or all of the inlet compounds undergo a transformation (that is reaction) to produce a new compound, then the unit 
operation is classified as a 'reactor '". Examples, CSTR, PFR, batch, semi-batch else

o Step TBF.1.2-If the inlet and outlet compositions of an unit operation are different and has a minimum of two outlet streams, then the unit operation is classified as a 'separator'. Examples, distillation column, stripper, rectifier, decanter else

o Step TBF.1.3-If there are more than one inlet streams and one outlet stream with a change in composition entering an unit operation, then the unit operation is identified as a mixer. Note that mixing here means a physical mixer and not a mixer used for combining streams/mixing them for simulation purposes

- Step TBF.2-All inlet and outlet streams connecting unit operations maintain their structural position in that task-based flowsheet (task scale) as in the unit operation-based flowsheet (unit operations scale)

- $\quad$ Step TBF.3-Generate the task-based flowsheet

o Step TBF.3.1-A reactor translated at the task scale becomes a "reaction task',

O Step TBF.3.2-A separator translated at the task scale becomes a "separation task",

o Step TBF.3.3-A mixer translated at the task scale becomes a "mixing task"

o Step TBF.3.3-Replace the classified unit operations with the identified tasks. An example is shown in Figure 4-2.

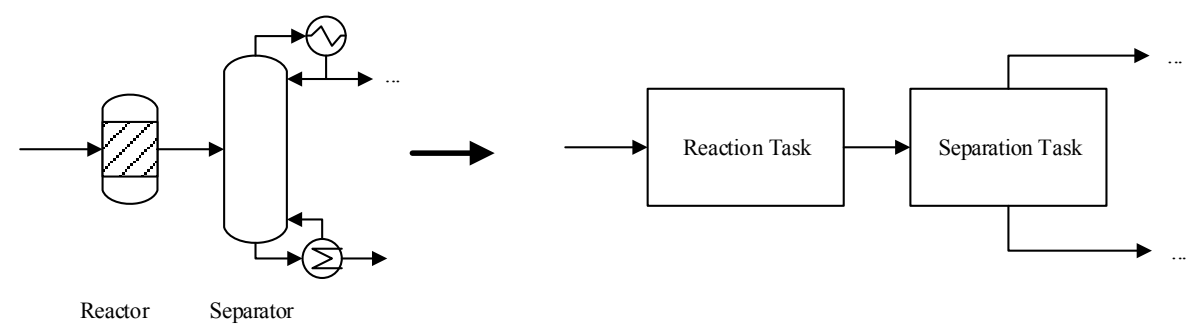

Figure 4-2: Towards lower scales: unit operations scale to tasks scale. A unit operationbased flowsheet to a task-based flowsheet

\subsubsection{Al.2-Identify the PBBs involved in performing each task}

Table 4-2 gives the PBBs that perform a given task. The method used for selection of the PBBs (SoPBB) involved in performing each task is presented. The tool used in applying the method is 'Tool 1-Selection of PBBs.xlsx", presented in appendix B. 
Table 4-2: Identification of PBBs that perform each task

\begin{tabular}{|l|l|l|l|l|l|l|l|l|l|}
\hline $\begin{array}{l}\text { PBB/ } \\
\text { Task }\end{array}$ & M & R & 2phM & PT & PC & PS & H & C & D \\
\hline Reaction & $*$ & $*$ & $*$ & & & & $*$ & $*$ & \\
\hline Separation & $*$ & & $*$ & $*$ & $*$ & $*$ & $*$ & $*$ & \\
\hline Mixing & $*$ & & $*$ & & & & & & \\
\hline
\end{tabular}

- Step SoPBB.1-Retrive the unit operations and tasks presented in the unit operations-based flowsheet and task-based flowsheet from A1.1

- Step SoPBB.2-Using the tool "Tool 1-Selection of PBBs.xlsx", select the unit operation and task that is performed. Note by default $\mathrm{M}$ is always selected for every task and for each separation task where two phases are present (except solid), 2phM is always selected.

- Step SoPBB.3-Retrieve and store the PBBs. The identified PBBs set the initial search of PBBs.

- Step SoPBB.4-Replace the tasks in the task-based flowsheet from A1.1 with the identified PBBs. Note inlet and outlet streams connecting unit operations maintain their structural position in the phenomena-based flowsheet (phenomena scale) as in the task-based flowsheet (task scale)

As an example, consider the liquid phase, exothermic reaction between $\mathrm{A}$ and $\mathrm{B}$ to produce $\mathrm{C}$, followed by the separation of $\mathrm{C}$ from $\mathrm{A}$ and $\mathrm{B}$. The order of boiling points is $\mathrm{A}<\mathrm{B}<\mathrm{C}$. The unit operation-based flowsheet and task-based flowsheet are given in Figure 4-2. Applying the method:

- Step SoPBB.1-

○ Unit operations

- Reactor

- Distillation column

○ Tasks

- Reaction task

- Separation 
- $\quad$ Step SoPBB.2-Applying the tool, a snapshot is shown in Figure 4-3.

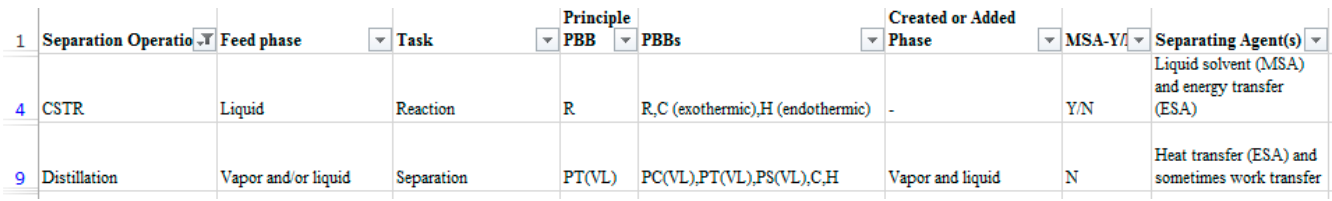

Figure 4-3: Selection of the unit operation and task that are performed

- Step SoPBB.3-The identified PBBs which constitute the initial PBB search space are:

o Reaction task: M, R, C

o Separation task: M, 2phM, PC(VL), PT(VL), PS(VL), H, C

- Step SoPBB.4-The phenomena based flowsheet is shown in Figure 4-4

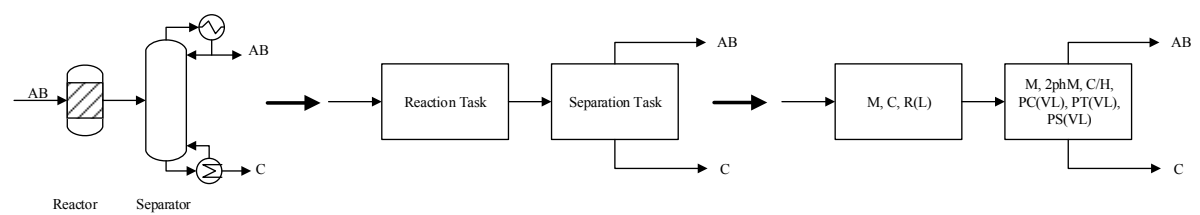

Figure 4-4: Towards lower scales: task scale to phenomena scale. A task-based flowsheet to a phenomena-based flowsheet

\subsubsection{Al.3-Identify alternative tasks and PBBs which are added to the PBB search space}

The method for identifying alternative tasks (IAT) and additional PBBs is presented. The tool used in the applying the method is "Tool 2-Selection of additional PBBs.xlsx', presented in appendix C:

- Step IAT.1-Identification of alternative task and PBB

O Step IAT.1.1-Using the tool "Tool 2-Selection of additional PBBs.xlsx", select the process hotspot and calculate the property or binary ratio

o Step IAT.1.2-Retrieve and store the PBBs for the identified alternative task

o Step IAT.1.3-Add the retrieved PBBs from step IAT.1.2 to the PBBs identified in step SoPBB.3. Note PBBs are not repeated. This set of PBBs constitute the final set of PBBs to be used in algorithm II. Note by default $\mathrm{D}$ phenomena is always added to the set of PBBs 
As an example, consider the separation of an azeotropic mixture $\mathrm{AB}$. The boiling point of $A$ is $293 \mathrm{~K}$ and $\mathrm{B}$ is $330 \mathrm{~K}$. Assume that the PBBs identified from step SoPBB.3 are M, 2phM, H, C, PC(VL), PT(VL) and PS(VL). The binary ratio for the boiling point $(\mathrm{Tb})$, vapor pressure (VP), radius of gyration (RG), Van der Waals volume (VdW), molar volume (MV) and solubility parameter (SolPar) are given in Table 4-3. Applying the method:

Table 4-3: Binary ratio for the separation of $A B$

\begin{tabular}{|l|l|l|l|l|l|l|}
\hline rij & Tb & VP & RG & VdW & VM & SolPar \\
\hline $\mathrm{A} / \mathrm{B}$ & 1.13 & 1.7 & 1.93 & 1.96 & 1.97 & 1.53 \\
\hline
\end{tabular}

- Step IAT.1-

○ Step IAT.1.1-Applying the tool, a snapshot is shown in Figure 4-5. The binary ratio is already calculated in IT-PBS 1

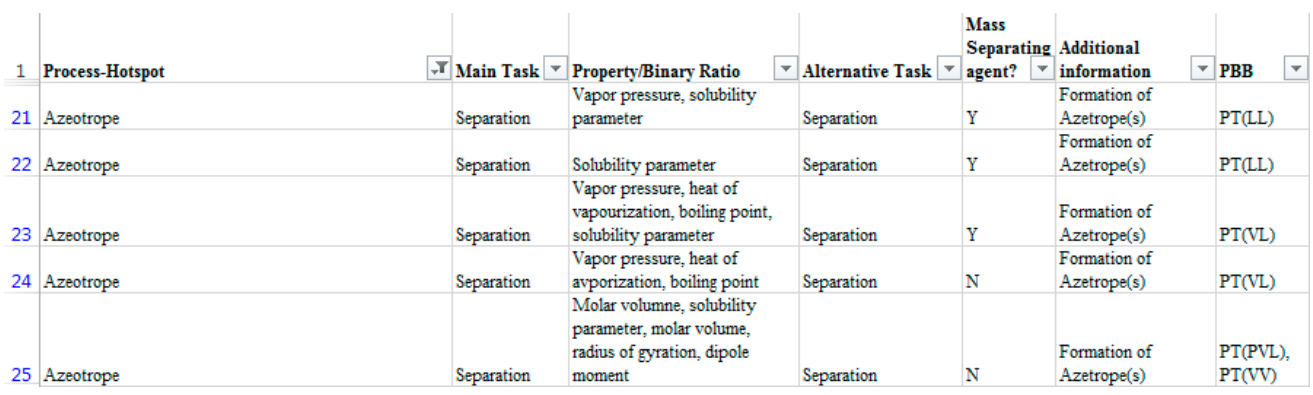

Figure 4-5: Selection of the alternative task and corresponding PBB

o Step IAT.1.2-The PBBs retrieved from the tool are PT(LL), PT(VL), PT(PVL), PT(VV)

o Step IAT.1.3-The final set of PBBs are M, 2phM, H, C, PC(VL), PT(VL), PS(VL), PT(LL), PT(VL) PT(VV) and D

\subsection{Algorithm II-Towards Higher Scales from Lower Scales}

The problem definition for algorithm II, subject to the logical constraint $\left(\theta_{1}\right)$, structural constraint $\left(\underline{\theta_{2}}\right)$ and operational constraint $\left(\underline{\theta_{3}}\right)$, is: Given: process hot-spots, design targets and PBBs. Identify: Sustainable flowsheet alternatives that eliminates the process hotspots and satisfy the design targets, identified in step 8 of the framework work-flow. Algorithm II employs 6 sub-algorithms. The objective and result of each algorithm is presented in Table 4-4 and each sub-algorithm is explained below. 
Table 4-4: Objective and result(s) for each sub-algorithm employed in algorithm II

\begin{tabular}{|c|c|c|}
\hline Name & Objective & Result(s) \\
\hline Algorithm II.1 & $\begin{array}{l}\text {-Generate feasible simulta- } \\
\text { neous phenomena building } \\
\text { blocks (SPBs) using com- } \\
\text { bination rules }\end{array}$ & $\begin{array}{l}\text {-Feasible SPBs for exam- } \\
\text { ple reaction, separation and } \\
\text { reaction-separation }\end{array}$ \\
\hline Algorithm II.2 & $\begin{array}{l}\text {-Generate a task-based } \\
\text { superstructure for identifi- } \\
\text { cation of feasible task- } \\
\text { based flowsheets }\end{array}$ & $\begin{array}{l}\text {-Task-based structure } \\
\text { comprising of feasible and } \\
\text { infeasible task-based flow- } \\
\text { sheets }\end{array}$ \\
\hline Algorithm II.3 & $\begin{array}{l}\text {-Identify tasks to be per- } \\
\text { formed }\end{array}$ & $\begin{array}{l}\text {-Tasks that must be per- } \\
\text { formed for reaction and } \\
\text { recovery of raw materials } \\
\text { (un-reacted) and products }\end{array}$ \\
\hline Algorithm II.4 & $\begin{array}{l}\text {-Generate basic structures } \\
\text { from the combination of } \\
\text { SPBs using combination } \\
\text { rules }\end{array}$ & $\begin{array}{l}\text {-Feasible basic structures } \\
\text { that perform a task }\end{array}$ \\
\hline Algorithm II.5 & $\begin{array}{l}\text {-Generation of task-based } \\
\text { flowsheets based on the } \\
\text { identification of basic } \\
\text { structures that perform a } \\
\text { task }\end{array}$ & $\begin{array}{l}\text {-Feasible task-based flow- } \\
\text { sheets obtained from the } \\
\text { task-based superstructure }\end{array}$ \\
\hline Algorithm II.6 & $\begin{array}{l}\text {-Translation of basic struc- } \\
\text { tures into unit operations } \\
\text { which constitute the final } \\
\text { flowsheet alternatives }\end{array}$ & $\begin{array}{l}\text {-Flowhseet alternatives at } \\
\text { the unit operations scale } \\
\text { inclusive (where neces- } \\
\text { sary) of hybrid/intensified } \\
\text { unit operations }\end{array}$ \\
\hline
\end{tabular}

\subsubsection{All.1-Generate feasible SPBs from the combination of PBBs}

The method used for the combination of PBBs to form SPBs that is generation of feasible SPBs (GfSPB) is presented.

- Step GfSPB.1-Calculate the maximum number of PBBs that can exist within an SPB

$\circ$ Step GfSPB.1.1-Isolate the PBBs from step IAT.2 (AI.3) into mixing and energy transfer PBBs. Note $\mathrm{M}$ phenomena in principle represents three types of mixing, ideal mixing (Mid), flow mixing (Mfl) and rectangular 
mixing (Mrect). In addition to this it can also represent vapor mixing (Mv)

O Step GfSPB.1.2-Calculate the maximum number of phenomena within an SPB using Equation 4.22

$$
n_{P B B, M a x}=n P B B-\left(n P B B_{E}-1\right)-\left(n P B B_{M}-1\right)-n P B B_{D}
$$

Where $n P B B$, max is the maximum number of PBBs within an SPB, $n P B B$ is the total number of PBBs, $n P B B E$ is the total number of energy transfer PBBs, $n P B B M$ is the total number of mixing PBBS and $n P B B D$ is the total number of dividing PBBs which is equal to 1

o Step GfSPB.1.3-Calculate all possible combinations of PBBs into SPBs with the minimum number of PBBs in an SPB equaling to 1 and the maximum equaling to $\mathrm{nPBB}$, max using Equation 4.23

$$
N S P B_{\max }=\sum_{k=1}^{n_{P B B, \max }}\left[\frac{(n P B B-1) !}{(n P B B-k-1) ! k !}\right]+1
$$

Where NSPBmax is the total number of all possible SPBs.

- Step GfSPB.2-Generate feasible SPBs from the combination of SPBs using PBB connectivity rules

$\circ$ Step GfSPB.2.1-Select from Table 4-5 the SPB building blocks that will be combined to generate feasible SPBs. A SPB building block is defined as the combination of one or more PBBs into pre-defined SPBs that can be further combined with each other to generate more SPBs. 
Table 4-5: SPB building blocks

\begin{tabular}{|l|l|l|l|}
\hline nSPB & $\begin{array}{l}\text { SPB Building } \\
\text { Block }\end{array}$ & Inlet & Rule \\
\hline 1 & $\mathrm{M}=\mathrm{C}$ & $1 \ldots \mathrm{n}(\mathrm{L}, \mathrm{V}, \mathrm{VL})$ & $\begin{array}{l}\text { Step GfSPB.2.1.1-Perform cooling } \\
\text { of a stream }\end{array}$ \\
\hline 2 & $\mathrm{M}=\mathrm{H}$ & $1 \ldots \mathrm{n}(\mathrm{L}, \mathrm{V}, \mathrm{VL})$ & $\begin{array}{l}\text { Step GfSPB.2.1.2-Perform heating } \\
\text { of stream }\end{array}$ \\
\hline 3 & $\mathrm{M}=2 \mathrm{phM}$ & $1 \ldots \mathrm{n}(\mathrm{L}, \mathrm{V}, \mathrm{VL})$ & $\begin{array}{l}\text { Step GfSPB.2.1.4-Preform a reac- } \\
\text { tion without an external energy } \\
\text { source }\end{array}$ \\
\hline 4 & $\mathrm{M}=\mathrm{R}$ & $1 \ldots \mathrm{n}(\mathrm{VL}, \mathrm{LL})$ & $\begin{array}{l}\text { Step GfSPB.2.1.3-Mixing of a } \\
\text { stream with two phases } \\
\text { contact of two phases }\end{array}$ \\
\hline 5 & $\mathrm{PC}=\mathrm{PT}$ & $1 \ldots \mathrm{n}(\mathrm{L}, \mathrm{V}, \mathrm{VL})$ & $\begin{array}{l}\text { Step GfSPB.2.1.6-Perform the } \\
\text { separation of two phases }\end{array}$ \\
\hline 6 & $\mathrm{PT}=\mathrm{PS}$ & $1 \ldots \mathrm{n}(\mathrm{VL}, \mathrm{LL})$ & $\begin{array}{l}\text { Step GfSPB.2.1.7-Preform the } \\
\text { separation of two phases }\end{array}$ \\
\hline & $\mathrm{PC}=\mathrm{PT}=\mathrm{PS}$ & &
\end{tabular}

O Step GfSPB.2.2-Combine the selected SPB building blocks to generate feasible SPBs. The rules and feasible SPBs from the combination of the SPB building blocks in Table 4-5 are given Table 4-6. Select from Table 4-6 the SPBs based on those selected from Step GfSPB.2.1. Note when SPB building blocks are combined, PBBs are not repeated. Note that the list in Table 4-6 is not exhaustive and other combinations of the SPB building blocks may exist, especially if new PBBs are incorporated 
Table 4-6: Feasible SPBs

\begin{tabular}{|c|c|c|c|}
\hline $\begin{array}{l}\text { SPB Num- } \\
\text { ber/Combinatio } \\
\text { n of } \text { nSPB }_{B B}\end{array}$ & SPB & Inlet & Rule \\
\hline $1 / 1$ & $\mathrm{M}=\mathrm{C}$ & $1 \ldots \mathrm{n}(\mathrm{L}, \mathrm{V}, \mathrm{VL})$ & $\begin{array}{l}\text { Step GfSPB.2.2.1- } \\
\text { Same as Step } \\
\text { GfSPB.2.1.1 }\end{array}$ \\
\hline $2 / 2$ & $\mathrm{M}=\mathrm{H}$ & $1 \ldots \mathrm{n}(\mathrm{L}, \mathrm{V}, \mathrm{VL})$ & $\begin{array}{l}\text { Step GfSPB.2.2.2- } \\
\text { Same as Step } \\
\text { GfSPB.2.1.2 }\end{array}$ \\
\hline $3 / 3$ & $\mathrm{M}=2 \mathrm{phM}$ & $1 \ldots \mathrm{n}(\mathrm{LL}, \mathrm{VL})$ & $\begin{array}{l}\text { Step GfSPB.2.2.3- } \\
\text { Same as Step } \\
\text { GfSPB.2.1.3 }\end{array}$ \\
\hline $4 / 4$ & $\mathrm{M}=\mathrm{R}$ & $1 \ldots \mathrm{n}(\mathrm{L}, \mathrm{V}, \mathrm{VL})$ & $\begin{array}{l}\text { Step GfSPB.2.2.4- } \\
\text { Same as Step } \\
\text { GfSPB.2.1.4 }\end{array}$ \\
\hline $5 / 1+4$ & $\mathrm{M}=\mathrm{R}=\mathrm{C}$ & $1 \ldots \mathrm{n}(\mathrm{L}, \mathrm{V}, \mathrm{VL})$ & $\begin{array}{l}\text { Step GfSPB.2.2.5- } \\
\text { Add external energy } \\
\text { source-cooling }\end{array}$ \\
\hline $6 / 1+5$ & $\mathrm{M}=\mathrm{R}=\mathrm{H}$ & $1 \ldots \mathrm{n}(\mathrm{L}, \mathrm{V}, \mathrm{VL})$ & $\begin{array}{l}\text { Step GfSPB.2.2.6- } \\
\text { Add external energy } \\
\text { source-heating }\end{array}$ \\
\hline $7 / 3+5$ & $\mathrm{M}=2 \mathrm{phM}=\mathrm{PC}=\mathrm{PT}$ & $1 \ldots \mathrm{n}(\mathrm{LL}, \mathrm{VL})$ & $\begin{array}{l}\text { Step GfSPB.2.2.7- } \\
\text { Perform the mixing } \\
\text { of two phases }\end{array}$ \\
\hline $8 / 3+7$ & $\mathrm{M}=2 \mathrm{phM}=\mathrm{PC}=\mathrm{PT}=\mathrm{PS}$ & $1 \ldots \mathrm{n}(\mathrm{LL}, \mathrm{VL})$ & $\begin{array}{l}\text { Step GfSPB.2.2.8- } \\
\text { Perform the separa- } \\
\text { tion of two phases }\end{array}$ \\
\hline $9 / 4+5$ & $\mathrm{M}=\mathrm{R}=2 \mathrm{phM}=\mathrm{PC}=\mathrm{PT}$ & $1 \ldots \mathrm{n}(\mathrm{LL}, \mathrm{VL})$ & $\begin{array}{l}\text { Step GfSPB.2.2.9- } \\
\text { Perform reaction } \\
\text { with phase creation }\end{array}$ \\
\hline $10 / 3+4+7$ & $\mathrm{M}=\mathrm{R}=2 \mathrm{phM}=\mathrm{PC}=\mathrm{PT}=\mathrm{PS}$ & $1 \ldots \mathrm{n}(\mathrm{LL}, \mathrm{VL})$ & $\begin{array}{l}\text { Step GfSPB.2.2.10- } \\
\text { Perform reaction, } \\
\text { phase creation and } \\
\text { phase separation }\end{array}$ \\
\hline $11 / 1+5$ & $\mathrm{M}=2 \mathrm{phM}=\mathrm{C}=\mathrm{PC}=\mathrm{PT}$ & $1 \ldots \mathrm{n}(\mathrm{LL}, \mathrm{VL})$ & $\begin{array}{l}\text { Step GfSPB.2.2.11- } \\
\text { Add external energy } \\
\text { source for creat- } \\
\text { ing/maintaining two } \\
\text { phases-cooling }\end{array}$ \\
\hline $12 / 2+5$ & $\mathrm{M}=2 \mathrm{phM}=\mathrm{H}=\mathrm{PC}=\mathrm{PT}$ & $1 \ldots \mathrm{n}(\mathrm{LL}, \mathrm{VL})$ & $\begin{array}{l}\text { Step GfSPB.2.2.12- } \\
\text { Add external energy } \\
\text { source for creat- }\end{array}$ \\
\hline
\end{tabular}




\begin{tabular}{|c|c|c|c|}
\hline & & & $\begin{array}{l}\text { ing/maintaining two } \\
\text { phases-heating }\end{array}$ \\
\hline $13 / 1+3+4+5$ & $\mathrm{M}=\mathrm{R}=\mathrm{C}=2 \mathrm{phM}=\mathrm{PC}=\mathrm{PT}$ & $1 \ldots \mathrm{n}(\mathrm{LL}, \mathrm{VL})$ & $\begin{array}{l}\text { Step GfSPB.2.2.13- } \\
\text { Perfom reaction } \\
\text { with two phases } \\
\text { with addition of an } \\
\text { external energy } \\
\text { source needed- } \\
\text { cooling }\end{array}$ \\
\hline $14 / 2+3+4+5$ & $\mathrm{M}=\mathrm{R}=\mathrm{H}=2 \mathrm{phM}=\mathrm{PC}=\mathrm{PT}$ & $1 \ldots \mathrm{n}(\mathrm{LL}, \mathrm{VL})$ & $\begin{array}{l}\text { Step GfSPB.2.2.13- } \\
\text { Perfom reaction } \\
\text { with two phases } \\
\text { with addition of an } \\
\text { external energy } \\
\text { source needed- } \\
\text { cooling }\end{array}$ \\
\hline $15 / 1+3+7$ & $\mathrm{M}=2 \mathrm{phM}=\mathrm{C}=\mathrm{PC}=\mathrm{PT}=\mathrm{PS}$ & $1 \ldots \mathrm{n}(\mathrm{LL}, \mathrm{VL})$ & $\begin{array}{l}\text { Step GfSPB.2.2.14- } \\
\text { Perform the separa- } \\
\text { tion of two phases } \\
\text { with the addition of } \\
\text { an external energy } \\
\text { source for creating } \\
\text { two phases-cooling }\end{array}$ \\
\hline $16 / 2+3+7$ & $\mathrm{M}=2 \mathrm{phM}=\mathrm{H}=\mathrm{PC}=\mathrm{PT}=\mathrm{PS}$ & $1 \ldots \mathrm{n}(\mathrm{LL}, \mathrm{VL})$ & $\begin{array}{l}\text { Step GfSPB.2.2.15- } \\
\text { Perform the separa- } \\
\text { tion of two phases } \\
\text { with the addition of } \\
\text { an external energy } \\
\text { source for creating } \\
\text { two phases-heating }\end{array}$ \\
\hline $17 / 1+3+4+7$ & $\mathrm{M}=\mathrm{R}=\mathrm{C}=2 \mathrm{phM}=\mathrm{PC}=\mathrm{PT}=\mathrm{PS}$ & $1 \ldots \mathrm{n}(\mathrm{LL}, \mathrm{VL})$ & $\begin{array}{l}\text { Step GfSPB.2.2.16- } \\
\text { Perform simultane- } \\
\text { ous reaction and } \\
\text { separation with two } \\
\text { phases with addition } \\
\text { of an external ener- } \\
\text { gy source-cooling }\end{array}$ \\
\hline $18 / 2+3+4+7$ & $\mathrm{M}=\mathrm{R}=\mathrm{H}=2 \mathrm{phM}=\mathrm{PC}=\mathrm{PT}=\mathrm{PS}$ & $1 \ldots \mathrm{n}(\mathrm{LL}, \mathrm{VL})$ & $\begin{array}{l}\text { Step GfSPB.2.2.17- } \\
\text { Perform simultane- } \\
\text { ous reaction and } \\
\text { separation with two } \\
\text { phases with addition } \\
\text { of an external ener- } \\
\text { gy source needed- } \\
\text { cooling }\end{array}$ \\
\hline $19 / 2+7$ & $\mathrm{M}=2 \mathrm{phM}=\mathrm{PC}=\mathrm{PT}(\mathrm{PVL})=\mathrm{PS}$ & $1 \ldots \mathrm{n}(\mathrm{L}, \mathrm{VL})$ & $\begin{array}{l}\text { Step GfSPB.2.2.18- } \\
\text { Perform the separa- }\end{array}$ \\
\hline
\end{tabular}




\begin{tabular}{|l|l|l|l|}
\hline & & & $\begin{array}{l}\text { tion of a compound } \\
\text { based on affinity }\end{array}$ \\
\hline $20 / 2+6$ & $\mathrm{M}=2 \mathrm{phM}=\mathrm{PC}=\mathrm{PT}(\mathrm{VV})=\mathrm{PS}(\mathrm{VV})$ & $1 \ldots \mathrm{n}(\mathrm{VL})$ & $\begin{array}{l}\text { Step GfSPB.2.2.19- } \\
\text { Perform the separa- } \\
\text { tion of a compound } \\
\text { based on affinity }\end{array}$ \\
\hline $21 / 3+6$ & $\mathrm{M}=2 \mathrm{phM}=\mathrm{PT}(\mathrm{VV})=\mathrm{PS}(\mathrm{VV})$ & $1 \ldots \mathrm{n}(\mathrm{V})$ & $\begin{array}{l}\text { Step GfSPB.2.2.20- } \\
\text { Perform the separa- } \\
\text { tion of a compound } \\
\text { based on affinity }\end{array}$ \\
\hline $22 / 3+4+7$ & $\mathrm{M}=2 \mathrm{phM}=\mathrm{R}=\mathrm{PC}=\mathrm{PT}(\mathrm{PVL})=\mathrm{PS}$ & $1 \ldots \mathrm{n}(\mathrm{L}, \mathrm{VL})$ & $\begin{array}{l}\text { Step GfSPB.2.2.21- } \\
\text { Perform simultane- } \\
\text { ous reaction and } \\
\text { separation of a } \\
\text { compound based on } \\
\text { affinity }\end{array}$ \\
\hline $23 / 3+4+6$ & $\mathrm{M}=2 \mathrm{phM}=\mathrm{R}=\mathrm{PT}(\mathrm{VV})=\mathrm{PS}(\mathrm{VV})$ & $1 \ldots \mathrm{n}(\mathrm{V})$ & $\begin{array}{l}\text { Step GfSPB.2.2.22- } \\
\text { Perform simultane- } \\
\text { ous reaction and } \\
\text { separation of a } \\
\text { compound based on } \\
\text { affinity }\end{array}$ \\
\hline
\end{tabular}

\subsubsection{All.2-Generate a Task-based superstructure}

The method for generating a task-based superstructure (GTbS) which consists of nonintegrated tasks (level 1) and integrated tasks (level 2) is presented.

- Step GTbS.1-Identify the reaction task

- Step GTbS.2-Calculate the minimum number of separation tasks $\left(N_{S T}\right)$ needed for separating $\mathrm{NC}$ components using Equation 4.24

$$
N_{S T}=N C-1
$$

Note: Equation 2.20 calculates the maximum number of separation tasks needed if all compounds are to be recovered separately. However scenarios will arise where, based on the design targets, not all the compounds must be recovered separately (Babi and Gani, 2014).

- Step GTbS.3-Annotate each compound with an alphabetical name that is A, B, C etc.

- Step GTbS.4-Starting with separation task 1, identify all possible separations of each compound in the system. Continue this enumeration for the subsequent remaining separation tasks and compounds, and generate the task-based superstructure

Note: Step GTbS.1 to step GTbS.4 are applicable for level 1. Step GTbS.5 to step GTbS.7 are applicable for level 2 and are performed after step ITbf.3 (A11.5) is performed. This generation of the complete task-based superstructure consisting of level 1 
and level 2 is performed in this way and not directly after step GTbS.4, in order to manage the complexity of generating a task-based superstructure consisting of a level 1 (where tasks are not combined) and a level 2 (where tasks are combined)

- Step GTbS.5-Combine reaction and all subsequent separation tasks sequentially. Note: This combination is feasible because reaction and separation SPB building blocks can be combined to for simultaneous reaction and separation SPBs

- Step GTbS.6-Add the combined reaction and separation tasks to the task-based superstructure. These new combine tasks become level 2 of the task-based superstructure

- Step GTbS.7-Starting with the combined reaction and separation tasks, identify all possible separation tasks of each compound in the system and add them to the task-based superstructure if they are not included.

- $\quad$ Step GTbS.8-Repeat step GTbS.5 to step GTbS.7 until the subsequent remaining separation tasks cannot be further combined with reaction and other separation tasks

Note: Step GTbS.5 to Step GTbS.8 are applicable for level 2

As an example consider the reaction $A+B \leftrightarrow C$. Generate a task-based superstructure for reaction and separation/recovery of the raw materials and products. Applying the method:

- Step GTbS.1-A reaction task is identified

- $\quad$ Step GTbS.2- $N_{S T}=2$

- $\quad$ Step GTbS.3-A, B, C

- Step GTbS.3-All possible identified separation tasks are:

○ Separation task 1:

- Separation task 1.1 of A from BC

- Separation task 1.2 of B from AC

- Separation task 1.3 of $\mathrm{C}$ from $\mathrm{AB}$

○ Separation task 2

- Separation task 2.1 of B from C

- Separation task 2.2 of A from C

- Separation task 2.3 of A from B. Note that if it is feasible to separate $\mathrm{C}$ from $\mathrm{AB}$ (Separation task 1.3), then there's no need to perform Separation task 2.3 because $\mathrm{AB}$ can directly be recycled

The task-based superstructure is shown in Figure 4-6. 


\begin{tabular}{|c|c|}
\hline R- Task & S- Task 1 \\
\hline $\begin{array}{c}\text { Reasible + Infeasible } \\
\text { connections }\end{array}$ & Sep. A(BC) \\
\hline $\begin{array}{c}\text { Rep. } 1 \\
\text { Sep. } \mathrm{C}(\mathrm{AB})\end{array}$ & $\mathrm{B}(\mathrm{C})$ \\
\hline $\mathrm{A}(\mathrm{C})$
\end{tabular}

Figure 4-6: Level 1 task-based superstructure for the example. R-Task-Reaction task, S-Task-Separation Task

- $\quad$ Step GTbS.5-The following tasks are combined:

$\circ$ R-Task 1 and S-Task 1:

- Reaction task + Separation task 1.1

- Reaction task + Separation task 1.2

- Reaction task + Separation task 1.3

o R-Task 1, S-Task 1 and S-Task 2:

- Reaction task + Separation task $1.1+$ Separation task 2.1

- Reaction task + Separation task $1.1+$ Separation task 2.2

- Reaction task + Separation task $1.1+$ Separation task 2.3

- Step GTbS.6 and Step GTbS.8-The task based superstructure is shown Figure 4-7. 


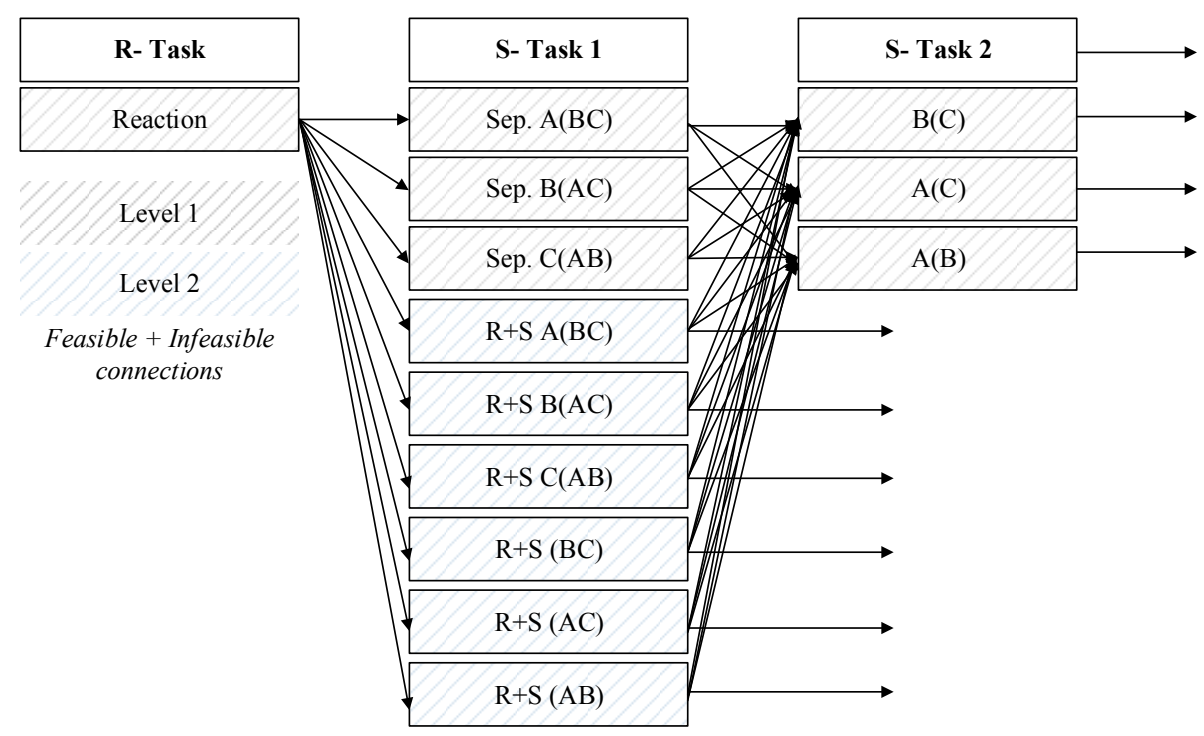

Figure 4-7: Level 1 + Level 2 task-based superstructure for the example. R-TaskReaction task, S-Task-Separation Task

\subsubsection{All.3-Identify Tasks to be Performed}

The method for identifying the main tasks to be performed (ITP) for reaction and recovery of the compounds in the system that is raw materials (for recycle) and products is presented.

- Step ITP.1-Identify the light key (lk) and heavy key (hk) components for the first separation task

- Step ITP.2-If azetropes are present identify separation tasks that isolate the azetropes in order to form binary mixture

- $\quad$ Step ITP.3-If miscibility gaps exist identify a separate task that uses the phase split for separation of a multicomponent or binary mixture

- Step ITP.2-Repeat Step ITP.1 until all separation tasks have been identified

As an example consider the reaction $A+B \leftrightarrow C$ (the level 1 task-based superstructure is shown in Figure 4-6). The boiling point order of compounds A, B and C are as follows: $C<B<A$. The following scenarios are considered: (1) No azetropes are present and (2) An azeotrope exist between B and C.

No azeotropes present

Applying the method:

- Step ITP.1-The first separation task:

o Separation task $1 \mathrm{lk}=\mathrm{C}$ and $\mathrm{hk}=\mathrm{B} \underline{\mathbf{O R}}$

$\circ$ Separation task $1 \mathrm{lk}=\mathrm{B}$ and $\mathrm{hk}=\mathrm{A}$

- $\quad$ Step ITP.4-No azetropes present

- Step ITP.3-No miscibility gaps present 
- Step ITP.4-The second separation task:

- Separation task 2 (for separation task $1 \mathrm{k}=\mathrm{C}$ and $\mathrm{hk}=\mathrm{B}$ ) $\mathrm{k}=\mathrm{B}$ and $\mathrm{hk}=\mathrm{A}$

- Separation task 2 (for separation task $1 \mathrm{lk}=\mathrm{B}$ and $\mathrm{hk}=\mathrm{A}$ ) $\mathrm{lk}=\mathrm{C}$ and $\mathrm{hk}=\mathrm{B}$ Azeotropes present

- $\quad$ Step ITP.1-The first separation task:

○ Separation task $1 \mathrm{lk}=\mathrm{B}$ and $\mathrm{hk}=\mathrm{A}$

- Step ITP.2-No azetropes present

- Step ITP.3-No miscibility gaps present

- Step ITP.4-The second separation task:

- Separation task 2 (for separation task $1 \mathrm{lk}=\mathrm{B}$ and $\mathrm{hk}=\mathrm{A}$ ) $\mathrm{lk}=\mathrm{C}$ and $\mathrm{hk}=\mathrm{B}$

\subsubsection{All.4-Identify Basic Structures that perform tasks}

The method for selecting the SPBs for generating basic structures (BS) that perform tasks is presented. The method is divided into three sections: Reaction, separation and reaction-separation.

- $\quad$ Step BS.1-Identify the task activity

○ Step BS.1.1-If in a task activity, a change of state occurs of a compound or compounds to produce other compounds then the task activity is related to a reaction task. Enter step BS.2 else

o Step BS.1.2-If in a task activity, the inlet and outlets have the same number of compounds that is no new compounds are produced, then the task activity is related to a separation task. Enter step BS.3 else

○ Step BS.1.3-If in a task activity, step BS.1.1 and step BS.1.2 are combined, then the task activity is related to a reaction-separation task. Enter step BS.4

\section{$\underline{\text { Reaction }}$}

- Step BS.2.1-Identify the reaction SPB initiator

○ Step BS.2.1.1-Identify the following properties of the reaction:

- The phase of the reaction, for example, liquid, vapor, vaporliquid

- The type of the reaction that is if the reaction is endothermic (positive $\Delta \mathrm{Hrxn}$ ) or exothermic (negative $\Delta \mathrm{Hrxn}$ )

- A set feed condition that is liquid, vapor, or vapor-liquid

○ Step BS.2.1.2-If the reaction is in the liquid phase select the SPB initiator from class 2 category 1 having the following phenomena building block (PBB), R(L) else 
○ Step BS.2.1.3-If the reaction is in the vapor phase select the SPB initiator from class 2 category 1 having the following PBB, R(V) else

○ Step BS.2.1.4-If the reaction is in the vapor-liquid phase select the SPB initiator from class 2 category 1 having the following PBB, R(VL)

○ Step BS.2.1.5-From the SPB initiators selected in step BS.2.1.2 to step BS.2.1.4, select the SPB initiator for a feed condition

- Step BS.2.2-Identify the reaction SPB terminator

○ Step BS.2.2.1-If the reaction is exothermic select the SPB terminator from class 1 category 3 having the following PBB, C else

○ Step BS.2.2.2-If the reaction is endothermic select the SPB terminator from class 1 category 3 having the following PBB, $\mathrm{H}$

\section{Separation}

- $\quad$ Step BS.3.1-Identify the separation SPB initiator

○ Step BS.3.1.1-Identify the following properties of the separation

- The presence of azeotropes

- The presence of miscibility gaps

- The set feed condition, for example, liquid, vapor, vapor-liquid

○ Step BS.3.1.2-For a non-azeotrope or azeotrope mixture, having a liquid, vapor or vapor-liquid feed condition, select the SPB initiators from class 3 category 1 having the following PBB, PS(VL)

o Step BS.3.1.3-For a azeotrope mixture, having a liquid, vapor or vaporliquid, select the SPB initiators from class 3 category 1 having the following PBB, PT(PVL) else

○ Step BS.3.1.4-For a azeotrope mixture, having a vapor feed condition, select the SPB initiators from class 3 category 1 having the following PBB, PT(VV) else

○ Step BS.3.1.5- For an azeotrope mixture having a feed condition that does not match SPB initiators having the PBBs PT(PVL) and PT(VV), a SPB terminator can be used in order to make the SPB feasible. Enter Step BS.3.2.3. Note: If this step is being applied during reaction-separation, then it is only applicable for simultaneous reaction and separation by PT(VL).

- Step BS.3.2-Identify the separation SPB terminator 
○ Step BS.3.2.1-If a SPB initiator is selected having a PS(VL) PBB, the separation is by vapor-liquid, select the SPB terminator from class 3 category 3 having the following $\mathrm{PBBs}, \mathrm{C}$ and $\mathrm{H}$

- Structural constraint-For generation of the basic structure the selected SPB terminators in step BS.3.2.1 cannot be combined together and therefore must be separated by the selected SPB initiator in step BS.3.1

○ Step BS.3.2.2-If a SPB initiator is selected having a PS(PVL) or PS(VV) $\mathrm{PBB}$, the separation is by vapor, select the SPB terminator from class 1 category 3 having the following PBB, 2phM

o Step BS.3.2.3-If step BS.3.1.4 is applied the SPB terminators from class 1 category 3 is selected as follows:

- If the feed condition is vapor and the SPB initiators from class 3 category 1 having the following PBB, PS(PVL) would like to be selected, a liquid phase must be created, select SPB terminator from class 1 category 3 having the following $\mathrm{PBB}, \mathrm{C}$ else

- If the feed condition is liquid and the SPB initiators from class 3 category 1 having the following $\mathrm{PBB}, \mathrm{PS}(\mathrm{VV})$ would like to be selected, a vapor phase must be created, select SPB terminator from class 1 category 3 having the following PBB, $\mathrm{H}$

\section{$\underline{\text { Reaction-Separation }}$}

- Step BS.4.1-Identify the reaction-separation SPB initiator

○ Step BS.4.1.1-Apply step BS.2.1 and step BS.3.1 to identify the reaction and separation initiators respectively

○ Step BS.4.1.2-The initiators from step BS.4.1.1 are combined and repeating PBBs removed. Therefore select the SPB initiators from class 4 category 1 having the PBBs representing the reaction phase (step BS.2.1) and separation (step BS.3.1)

- Step BS.4.2- Identify the reaction-separation SPB terminator

O Step BS.4.2.1-Apply step BS.2.2 and step BS.3.2 to identify the reaction and separation terminators respectively

○ Step BS.4.2.2-The terminators from step BS.4.2.1 can either be used separately or combined. If the terminators are combined repeating PBBs are 
removed. Therefore select the SPB terminators from class 1 category 3 or class 3 category 3 or both depending on if a phase needs to be created

\section{Conceptual examples}

Conceptual example for reaction

Problem definition: Generate/select an SPB basic structure for a reaction of $\mathrm{A}+\mathrm{B}$ to produce $\mathrm{C}+\mathrm{D}$ having the following properties:

1. Reaction phase- liquid

2. The reaction type: exothermic reaction

3. Set feed condition: liquid

Applying the algorithm:

- $\quad$ Step BS.1-Identify the task activity

○ Step BS.1.1-Reaction task, enter BS.2

- $\quad$ Step BS.2.1-Identify the reaction SPB initiator

○ Step BS.2.1.1-Identify the following properties of the reaction:

- The phase of the reaction-Liquid

- The type of the reaction-Exothermic

- Set feed condition-Liquid

○ Step BS.2.1.2-The selected SPB initiators are 2.1 and 2.3

- $2.1 \mathrm{M}(\mathrm{VL})=\mathrm{R}(\mathrm{L})$

- $\quad 2.3 \mathrm{M}(\mathrm{L})=\mathrm{R}(\mathrm{L})$

○ Step BS.2.1.5-The set feed condition is liquid therefore the selected SPB initiator is 2.3

- $\quad 2.3 \mathrm{M}(\mathrm{L})=\mathrm{R}(\mathrm{L})$

- Step BS.2.2- Identify the reaction SPB terminator

$\circ$ Step BS.2.2.1-The reaction is exothermic therefore SPB terminator 1.1 is selected

- $1.1 \mathrm{M}=\mathrm{C}$ 
The feasible basic structure, along with other basic structures for different reaction phase, reaction type and feed condition, is shown in Figure 4-8.

Reaction Task

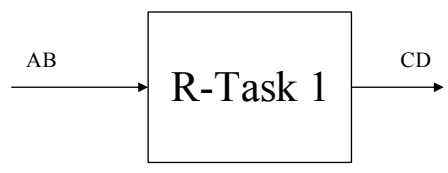

\begin{tabular}{|l|}
\hline$M(V L)=R(L)$ \\
\hline$M(V L)=C$ \\
\hline
\end{tabular}

\begin{tabular}{|c|}
\hline$M(V L)=R(L)$ \\
\hline$M(V L)=H$ \\
\hline
\end{tabular}

R-phase-L, R-Type-Exo., Feed Cond.-V-L R-phase-L, R-Type-Endo., Feed Cond.-V$\mathrm{L}$

\begin{tabular}{|c|}
\hline$M(L)=R(L)$ \\
\hline$M(L)=C$ \\
\hline
\end{tabular}

\begin{tabular}{|c|}
\hline$M(L)=R(L)$ \\
\hline$M(L)=H$ \\
\hline
\end{tabular}

\section{Feasible basic structure}

R-phase-L, R-Type-Exo., Feed Cond.-L R-phase-L, R-Type-Endo., Feed Cond.-L

Figure 4-8: The basic structure for different types of reactions in the liquid phase. The solution to the conceptual example presented is presented in italics. V-vapor. L-liquid.

Conceptual example for separation 1

Problem definition: Generate/select an SPB basic structure for the separation of a mixture containing $\mathrm{A}+\mathrm{B}$ to $\mathrm{A}$ and $\mathrm{B}$ having the following properties:

1. No azeotrope present

2. No miscibility gap present

3. Feed condition liquid

Applying the algorithm:

- $\quad$ Step BS.3.1-Identify the separation SPB initiator

○ Step BS.3.1.1-Identify the following properties of the separation

- No azeotropes present

- No miscibility gaps present

- The set feed condition that is liquid

o Step BS.3.1.2-The selected SPB initiator is 3.1 
- $\quad 3.1 \mathrm{M}(\mathrm{VL})=2 \mathrm{phM}(\mathrm{VL})=\mathrm{PC}(\mathrm{VL})=\mathrm{PT}(\mathrm{VL})=\mathrm{PS}(\mathrm{VL})$

- Step BS.3.2-Identify the separation SPB terminator

○ Step BS.3.2.1-The selected SPB terminators are:

- $3.1 \mathrm{M}(\mathrm{VL})=\mathrm{C}=2 \mathrm{phM}=\mathrm{PC}(\mathrm{VL})=\mathrm{PT}(\mathrm{VL})=\mathrm{PS}(\mathrm{VL})$

- $3.2 \mathrm{M}(\mathrm{VL})=\mathrm{H}=2 \mathrm{phM}=\mathrm{PC}(\mathrm{VL})=\mathrm{PT}(\mathrm{VL})=\mathrm{PS}(\mathrm{VL})$

The feasible basic structure is illustrated in Figure 4-9.

Separation Task

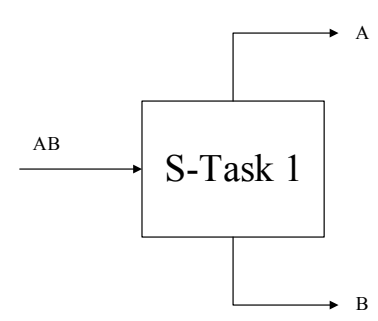

$\mathrm{M}=\mathrm{C}=2 \mathrm{phM}=\mathrm{PC}(\mathrm{VL})=\mathrm{PT}(\mathrm{VL})=\mathrm{PS}(\mathrm{VL})$

$\mathrm{M}=2 \mathrm{phM}=\mathrm{PC}(\mathrm{VL})=\mathrm{PT}(\mathrm{VL})=\mathrm{PS}(\mathrm{VL})$

$\mathrm{M}=\mathrm{H}=2 \mathrm{phM}=\mathrm{PC}(\mathrm{VL})=\mathrm{PT}(\mathrm{VL})=\mathrm{PS}(\mathrm{VL})$

S-phase-VL, Azeo-No, Feed Cond.-L

Figure 4-9: The basic structure for the separation of a non-azeotrope mixture, by vaporliquid. V-vapor, L-liquid.

Conceptual example for separation 2

Problem definition: Generate/select an SPB basic structure for the separation of a mixture containing $\mathrm{A}+\mathrm{B}$ to $\mathrm{A}$ and $\mathrm{B}$ having the following properties:

1. Azeotrope present between A and B

2. No miscibility gap present

3. Feed condition liquid

Applying the algorithm:

- $\quad$ Step BS.3.1-Identify the separation SPB initiator

○ Step BS.3.1.1-Identify the following properties of the separation

- Azeotrope present between A and B

- No miscibility gaps present 
- The set feed condition that is liquid

○ Step BS.3.1.2-The selected SPB initiator is 3.1

- $\quad 3.1 \mathrm{M}(\mathrm{VL})=2 \mathrm{phM}(\mathrm{VL})=\mathrm{PC}(\mathrm{VL})=\mathrm{PT}(\mathrm{VL})=\mathrm{PS}(\mathrm{VL})$

○ Step BS.3.1.3- The selected SPB initiator is 3.2

- $\quad 3.2 \mathrm{M}(\mathrm{L})=2 \mathrm{phM}(\mathrm{VL})=\mathrm{PC}(\mathrm{VL})=\mathrm{PT}(\mathrm{PVL})=\mathrm{PS}(\mathrm{VL})$

○ Step BS.3.1.5-Step BS.3.2.3 is applied because the following SPB initiator is also selected:

- $3.3 \mathrm{M}(\mathrm{V})=2 \mathrm{phM}(\mathrm{VL})=\mathrm{PC}(\mathrm{VL})=\mathrm{PT}(\mathrm{VV})=\mathrm{PS}(\mathrm{VV})$

- Step BS.3.2-Identify the separation SPB terminator

○ Step BS.3.2.1-The selected SPB terminators are:

- $3.1 \mathrm{M}(\mathrm{VL})=\mathrm{C}=2 \mathrm{phM}=\mathrm{PC}(\mathrm{VL})=\mathrm{PT}(\mathrm{VL})=\mathrm{PS}(\mathrm{VL})$

- $\quad 3.2 \mathrm{M}(\mathrm{VL})=\mathrm{H}=2 \mathrm{phM}=\mathrm{PC}(\mathrm{VL})=\mathrm{PT}(\mathrm{VL})=\mathrm{PS}(\mathrm{VL})$

o Step BS.3.2.2- The selected SPB terminator is:

- $1.7 \mathrm{M}(\mathrm{VL})=2 \mathrm{phM}$

○ Step BS.3.2.3-If step BS.3.1.4 is applied the SPB terminator from class 1 category 3 is selected as follows:

- The feed condition is liquid and the SPB initiators from class 3 category 1 having the following PBB, PS(VV) would like to be selected, a vapor phase must be created. The selected SPB terminator is:

- $\mathrm{M}(\mathrm{L})=\mathrm{H}$ 
The feasible basic structures are illustrated in Figure 4-10.

Separation Task

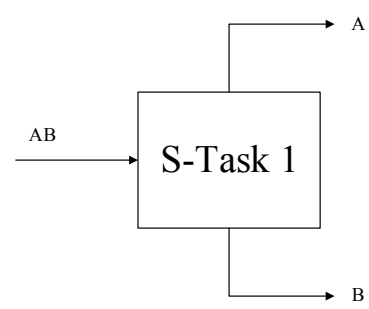

\begin{tabular}{c}
$\mathrm{M}(\mathrm{VL})=\mathrm{C}=2 \mathrm{phM}=\mathrm{PC}(\mathrm{VL})=\mathrm{PT}(\mathrm{VL})=\mathrm{PS}(\mathrm{VL})$ \\
$\mathrm{M}(\mathrm{VL})=2 \mathrm{phM}=\mathrm{PC}(\mathrm{VL})=\mathrm{PT}(\mathrm{VL})=\mathrm{PS}(\mathrm{VL})$ \\
$\mathrm{M}(\mathrm{VL})=\mathrm{H}=2 \mathrm{phM}=\mathrm{PC}(\mathrm{VL})=\mathrm{PT}(\mathrm{VL})=\mathrm{PS}(\mathrm{VL})$ \\
\hline
\end{tabular}

\begin{tabular}{|c|}
\hline $\mathrm{M}(\mathrm{VL})=\mathrm{C}=2 \mathrm{phM}=\mathrm{PC}(\mathrm{VL})=\mathrm{PT}(\mathrm{VL})=\mathrm{PS}(\mathrm{VL})$ \\
\hline $\mathrm{M}(\mathrm{VL})=2 \mathrm{phM}=\mathrm{PC}(\mathrm{VL})=\mathrm{PT}(\mathrm{VL})=\mathrm{PS}(\mathrm{VL})$ \\
$\mathrm{M}(\mathrm{L})=2 \mathrm{phM}=\mathrm{PC}(\mathrm{VL})=\mathrm{PT}(\mathrm{PVL})=\mathrm{PS}(\mathrm{VL})$ \\
\hline $\mathrm{M}(\mathrm{VL})=2 \mathrm{phM}$ \\
\hline
\end{tabular}

S-phase-V-L, Azeo-Yes, Feed Cond.-L

S-phase-V-L, Azeo-Yes, Feed Cond.-L

\begin{tabular}{c}
$\mathrm{M}(\mathrm{VL})=\mathrm{C}=2 \mathrm{phM}=\mathrm{PC}(\mathrm{VL})=\mathrm{PT}(\mathrm{VL})=\mathrm{PS}(\mathrm{VL})$ \\
$\mathrm{M}(\mathrm{VL})=2 \mathrm{phM}=\mathrm{PC}(\mathrm{VL})=\mathrm{PT}(\mathrm{VL})=\mathrm{PS}(\mathrm{VL})$ \\
$\mathrm{M}(\mathrm{V})=2 \mathrm{phM}=\mathrm{PC}(\mathrm{VL})=\mathrm{PT}(\mathrm{VV})=\mathrm{PS}(\mathrm{VV})$ \\
$\mathrm{M}(\mathrm{L})=\mathrm{H}$ \\
$\mathrm{M}(\mathrm{VL})=2 \mathrm{phM}$ \\
\hline
\end{tabular}

\begin{tabular}{|c|}
\hline $\mathrm{M}(\mathrm{V})=2 \mathrm{phM}$ \\
\hline $\mathrm{M}(\mathrm{V})=2 \mathrm{phM}=\mathrm{PT}(\mathrm{VV})=\mathrm{PS}(\mathrm{VV})$ \\
\hline $\mathrm{M}(\mathrm{VL})=2 \mathrm{phM}=\mathrm{PC}(\mathrm{VL})=\mathrm{PT}(\mathrm{VL})=\mathrm{PS}(\mathrm{VL})$ \\
\hline $\mathrm{M}(\mathrm{VL})=\mathrm{H}=2 \mathrm{phM}=\mathrm{PC}(\mathrm{VL})=\mathrm{PT}(\mathrm{VL})=\mathrm{PS}(\mathrm{VL})$ \\
\hline
\end{tabular}

S-phase-V-L, Azeo-Yes, Feed Cond.-L

S-phase-V-L, Azeo-Yes, Feed Cond.-L

\begin{tabular}{|c|}
\hline $\mathrm{M}(\mathrm{VL})=2 \mathrm{phM}$ \\
\hline $\mathrm{M}(\mathrm{V})=\mathrm{C}$ \\
\hline $\mathrm{M}(\mathrm{L})=2 \mathrm{phM}=\mathrm{PC}(\mathrm{VL})=\mathrm{PT}(\mathrm{PVL})=\mathrm{PS}(\mathrm{VL})$ \\
\hline $\mathrm{M}(\mathrm{VL})=2 \mathrm{phM}=\mathrm{PC}(\mathrm{VL})=\mathrm{PT}(\mathrm{VL})=\mathrm{PS}(\mathrm{VL})$ \\
$\mathrm{M}(\mathrm{VL})=\mathrm{H}=2 \mathrm{phM}=\mathrm{PC}(\mathrm{VL})=\mathrm{PT}(\mathrm{VL})=\mathrm{PS}(\mathrm{VL})$ \\
\hline
\end{tabular}

\begin{tabular}{|c|}
\hline $\mathrm{M}(\mathrm{V})=2 \mathrm{phM}$ \\
\hline $\mathrm{M}(\mathrm{V})=2 \mathrm{phM}=\mathrm{PT}(\mathrm{VV})=\mathrm{PS}(\mathrm{VV})$ \\
$\mathrm{M}(\mathrm{VL})=2 \mathrm{phM}=\mathrm{PC}(\mathrm{VL})=\mathrm{PT}(\mathrm{VL})=\mathrm{PS}(\mathrm{VL})$ \\
\hline $\mathrm{M}(\mathrm{L})=2 \mathrm{phM}=\mathrm{PC}(\mathrm{VL})=\mathrm{PT}(\mathrm{PVL})=\mathrm{PS}(\mathrm{VL})$ \\
\hline $\mathrm{M}(\mathrm{VL})=2 \mathrm{phM}$ \\
\hline
\end{tabular}

S-phase-V-L, Azeo-Yes, Feed Cond.-L

S-phase-V-L, Azeo-Yes, Feed Cond.-L 


\begin{tabular}{|c|}
\hline $\mathrm{M}(\mathrm{VL})=2 \mathrm{phM}$ \\
\hline $\mathrm{M}(\mathrm{V})=\mathrm{C}$ \\
\hline $\mathrm{M}(\mathrm{L})=2 \mathrm{phM}=\mathrm{PC}(\mathrm{VL})=\mathrm{PT}(\mathrm{PVL})=\mathrm{PS}(\mathrm{VL})$ \\
\hline $\mathrm{M}(\mathrm{VL})=2 \mathrm{phM}=\mathrm{PC}(\mathrm{VL})=\mathrm{PT}(\mathrm{VL})=\mathrm{PS}(\mathrm{VL})$ \\
\hline $\mathrm{M}(\mathrm{V})=2 \mathrm{phM}=\mathrm{PC}(\mathrm{VL})=\mathrm{PT}(\mathrm{VV})=\mathrm{PS}(\mathrm{VV})$ \\
\hline $\mathrm{M}(\mathrm{L})=\mathrm{H}$ \\
$\mathrm{M}(\mathrm{VL})=2 \mathrm{phM}$ \\
\hline
\end{tabular}

S-phase-V-L, Azeo-Yes, Feed Cond.-L

\begin{tabular}{|c|}
\hline $\mathrm{M}(\mathrm{V})=2 \mathrm{phM}$ \\
\hline $\mathrm{M}(\mathrm{V})=2 \mathrm{phM}=\mathrm{PT}(\mathrm{VV})=\mathrm{PS}(\mathrm{VV})$ \\
\hline $\mathrm{M}(\mathrm{VL})=2 \mathrm{phM}=\mathrm{PC}(\mathrm{VL})=\mathrm{PT}(\mathrm{VL})=\mathrm{PS}(\mathrm{VL})$ \\
\hline $\mathrm{M}(\mathrm{V})=2 \mathrm{phM}=\mathrm{PC}(\mathrm{VL})=\mathrm{PT}(\mathrm{VV})=\mathrm{PS}(\mathrm{VV})$ \\
\hline $\mathrm{M}(\mathrm{L})=\mathrm{H}$ \\
$\mathrm{M}(\mathrm{VL})=2 \mathrm{phM}$ \\
\hline
\end{tabular}

S-phase-V-L, Azeo-Yes, Feed Cond.-L

\begin{tabular}{c}
$\mathrm{M}(\mathrm{VL})=2 \mathrm{phM}$ \\
\hline $\mathrm{M}(\mathrm{V})=2 \mathrm{phM}=\mathrm{PC}(\mathrm{VL})=\mathrm{PT}(\mathrm{VV})=\mathrm{PS}(\mathrm{VV})$ \\
\hline $\mathrm{M}(\mathrm{L})=\mathrm{H}$ \\
\hline
\end{tabular}

S-phase-V, Azeo-Yes, Feed Cond.-L

\begin{tabular}{|c|}
\hline $\mathrm{M}(\mathrm{VL})=2 \mathrm{phM}$ \\
\hline $\mathrm{M}(\mathrm{V})=\mathrm{C}$ \\
\hline $\mathrm{M}(\mathrm{L})=2 \mathrm{phM}=\mathrm{PC}(\mathrm{VL})=\mathrm{PT}(\mathrm{PVL})=\mathrm{PS}(\mathrm{VL})$ \\
\hline $\mathrm{M}(\mathrm{VL})=2 \mathrm{phM}=\mathrm{PC}(\mathrm{VL})=\mathrm{PT}(\mathrm{VL})=\mathrm{PS}(\mathrm{VL})$ \\
\hline $\mathrm{M}(\mathrm{L})=2 \mathrm{phM}=\mathrm{PC}(\mathrm{VL})=\mathrm{PT}(\mathrm{PVL})=\mathrm{PS}(\mathrm{VL})$ \\
\hline $\mathrm{M}(\mathrm{VL})=2 \mathrm{phM}$ \\
\hline
\end{tabular}

S-phase-V-L, Azeo-Yes, Feed Cond.-L

\begin{tabular}{|c|}
\hline $\mathrm{M}(\mathrm{VL})=2 \mathrm{phM}$ \\
\hline $\mathrm{M}(\mathrm{L})=2 \mathrm{phM}=\mathrm{PC}(\mathrm{VL})=\mathrm{PT}(\mathrm{PVL})=\mathrm{PS}(\mathrm{VL})$ \\
\hline
\end{tabular}

S-phase-V, Azeo-Yes, Feed Cond.-L

Figure 4-10: The basic structure for the separation of an azeotrope mixture, by vapor and vapor-liquid. V-vapor. L-liquid.

\section{Conceptual example reaction-separation}

\section{Conceptual example for reaction-separation}

Problem definition: Generate/select an SPB for an equilibrium reaction of $\mathrm{A}+\mathrm{B}$ to produce $\mathrm{C}+\mathrm{D}$ having the following properties:

1. Reaction phase- liquid

2. The reaction type: exothermic reaction

3. Azeotrope present between B and D 
4. No miscibility gap present

5. Set feed condition: liquid

6. Known: removal of one of the products will shift the equilibrium and therefore increase the conversion of $A$

Applying the algorithm:

- Step BS.4.1- Identify the reaction-separation SPB initiator

○ Step BS.4.1.1-

Applying step BS.2.1-Identify the reaction SPB initiator

○ Step BS.2.1.1-Identify the following properties of the reaction:

- The phase of the reaction-Liquid

- The type of the reaction-Exothermic

- Set feed condition-Liquid

○ Step BS.2.1.2-The selected SPB initiators are 2.1 and 2.3

- $\quad 2.1 \mathrm{M}(\mathrm{VL})=\mathrm{R}(\mathrm{L})$

- $2.3 \mathrm{M}(\mathrm{L})=\mathrm{R}(\mathrm{L})$

○ Step BS.2.1.5-The set feed condition is liquid therefore the selected SPB initiator is 2.3

- $\quad 2.3 \mathrm{M}(\mathrm{L})=\mathrm{R}(\mathrm{L})$

Applying step BS.3.1-Identify the separation SPB initiator

○ Step BS.3.1.1-Identify the following properties of the separation

- Azeotrope present between B and D

- No miscibility gaps present

- The set feed condition that is liquid

○ Step BS.3.1.2-The selected SPB initiator is 3.1

- $3.1 \mathrm{M}(\mathrm{VL})=2 \mathrm{phM}(\mathrm{VL})=\mathrm{PC}(\mathrm{VL})=\mathrm{PT}(\mathrm{VL})=\mathrm{PS}(\mathrm{VL})$

○ Step BS.3.1.3- The selected SPB initiator is 3.2

- $\quad 3.2 \mathrm{M}(\mathrm{L})=2 \mathrm{phM}(\mathrm{VL})=\mathrm{PC}(\mathrm{VL})=\mathrm{PT}(\mathrm{PVL})=\mathrm{PS}(\mathrm{VL})$

○ Step BS.3.1.5-Not applicable because reaction-separation occur simultaneously

O Step BS.4.1.2-The selected SPB initiators are 4.1 and 4.4

- $4.1 \mathrm{M}(\mathrm{VL})=2 \mathrm{phM}=\mathrm{R}(\mathrm{L})=\mathrm{PC}(\mathrm{VL})=\mathrm{PT}(\mathrm{VL})=\mathrm{PS}(\mathrm{VL})$

- $\quad 4.4 \mathrm{M}(\mathrm{VL})=2 \mathrm{phM}=\mathrm{R}(\mathrm{L})=\mathrm{PC}(\mathrm{VL})=\mathrm{PT}(\mathrm{PVL})=\mathrm{PS}(\mathrm{VL})$ 
- Step BS.4.2- Identify the reaction-separation SPB terminator

o Step BS.4.2.1-

Applying step BS.2.2-Identify the reaction SPB terminator

o Step BS.2.2.1-The reaction is exothermic therefore SPB terminator 1.1 is selected

- $\quad 1.1 \mathrm{M}(\mathrm{L})=\mathrm{C}$

Applying step BS.3.2-Identify the separation SPB terminator

○ Step BS.3.2.1-The selected SPB terminators are:

- $3.1 \mathrm{M}(\mathrm{VL})=\mathrm{C}=2 \mathrm{phM}=\mathrm{PC}(\mathrm{VL})=\mathrm{PT}(\mathrm{VL})=\mathrm{PS}(\mathrm{VL})$

- $3.2 \mathrm{M}(\mathrm{VL})=\mathrm{H}=2 \mathrm{phM}=\mathrm{PC}(\mathrm{VL})=\mathrm{PT}(\mathrm{VL})=\mathrm{PS}(\mathrm{VL})$

o Step BS.3.2.2- The selected SPB terminator is:

- $1.7 \mathrm{M}(\mathrm{VL})=2 \mathrm{phM}$

○ Step BS.4.2.2-The selected SPB terminators are 1.1, 1.7, 3.1 and 3.2

- $1.1 \mathrm{M}(\mathrm{L})=\mathrm{C}$

- $1.7 \mathrm{M}(\mathrm{VL})=2 \mathrm{phM}$

- $3.1 \mathrm{M}(\mathrm{VL})=\mathrm{C}=2 \mathrm{phM}=\mathrm{PC}(\mathrm{VL})=\mathrm{PT}(\mathrm{VL})=\mathrm{PS}(\mathrm{VL})$

- $3.2 \mathrm{M}(\mathrm{VL})=\mathrm{H}=2 \mathrm{phM}=\mathrm{PC}(\mathrm{VL})=\mathrm{PT}(\mathrm{VL})=\mathrm{PS}(\mathrm{VL})$ 
The feasible basic structures are illustrated in Figure 4-11.

Reaction-Separation Task 1

Reaction-Separation Task 2
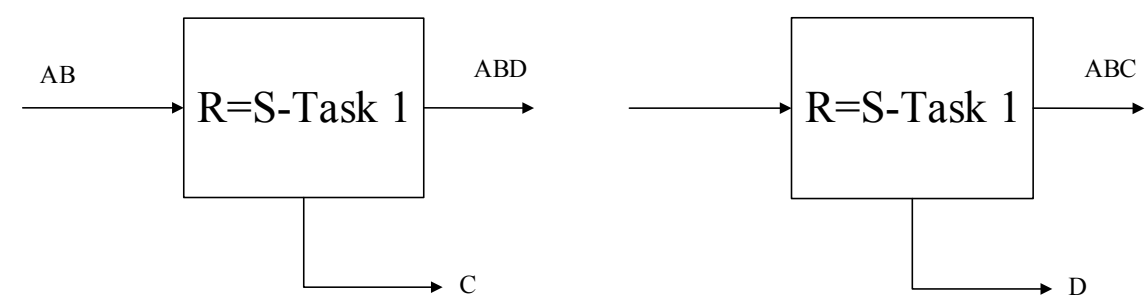

$\mathrm{M}(\mathrm{VL})=\mathrm{C}=2 \mathrm{phM}=\mathrm{PC}(\mathrm{VL})=\mathrm{PT}(\mathrm{VL})=\mathrm{PS}(\mathrm{VL})$
$\mathrm{M}(\mathrm{VL})=\mathrm{R}(\mathrm{L})=2 \mathrm{phM}=\mathrm{PC}(\mathrm{VL})=\mathrm{PT}(\mathrm{VL})=\mathrm{PS}(\mathrm{VL})$
$\mathrm{M}(\mathrm{VL})=\mathrm{H}=2 \mathrm{phM}=\mathrm{PC}(\mathrm{VL})=\mathrm{PT}(\mathrm{VL})=\mathrm{PS}(\mathrm{VL})$

R-phase-L, R-Type-Exo., S-phase-VL, Azeo-Yes, Feed Cond.-L

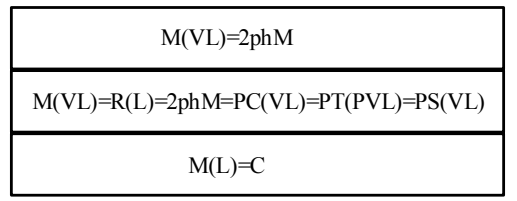

R-phase-L, R-Type-Exo., S-phase-V, Azeo-Yes, Feed Cond.-L

Figure 4-11: The basic structure for the reaction-separation of an azeotrope mixture, by vapor and vapor-liquid. V-vapor. L-liquid. Note: Two separation tasks are illustrated in Figure 4-11 where $C$ or D are removed. It would seem logical to remove D rather than $\mathrm{C}$ because $\mathrm{D}$ forms an azeotrope with $\mathrm{B}$.

\subsubsection{All.5-Identification of Task-based flowsheets}

The method for identifying task-based flowsheets (ITbf) from the task-based superstructure generated in AII.2 is presented.

- Step ITbf.1-Retrieve the tasks identified for reaction and separation from AII.3

- Step ITbf.2-Select from the task-based superstructure generated in AII.2, the tasks identified in AII.3 that are performed by the basic structures identified in AII.4

- Step ITbf.3-Apply step GTbS.5 to step GTbS.7 that is modification of the taskbased superstructure.

As an example consider the reaction (exothermic, liquid phase) $A+B \leftrightarrow C$ (the level 1 task-based superstructure is shown in Figure 4-6). The boiling order of the compounds $\mathrm{A}, \mathrm{B}$ and $\mathrm{C}$ are as follows: $C<B<A$. Additional information: The following scenarios are considered: (1) No azetropes are present and (2) An azeotrope exist between B and C.

\section{No azeotropes present}

Applying the method: 
- Step ITbf.1- All possible identified separation tasks are (Step GTbS.1, Step ITP.1, and Step ITP.4):

$\circ$ Reaction task for $A+B \leftrightarrow C$

$\circ$ The first separation task:

- Separation task $1 \mathrm{lk}=\mathrm{C}$ and $\mathrm{hk}=\mathrm{B} \underline{\mathbf{O R}}$

- Separation task $1 \mathrm{lk}=\mathrm{B}$ and $\mathrm{hk}=\mathrm{A}$

○ The second separation task:

- Separation task 2 (for separation task $1 \mathrm{lk}=\mathrm{C}$ and $\mathrm{hk}=\mathrm{B}$ ) $\mathrm{lk}=\mathrm{B}$ and $\mathrm{hk}=\mathrm{A}$

- Separation task 2 (for separation task $1 \mathrm{lk}=\mathrm{B}$ and $\mathrm{hk}=\mathrm{A}$ ) $\mathrm{lk}=\mathrm{C}$ and $\mathrm{hk}=\mathrm{B} \underline{\mathbf{O R}}$

- $\quad$ Step ITbf.2-The basic structures identified for each task are shown in Table 4-7 and obtained from the database of basic structures (presented in appendix D) in AII.4. For all identified tasks, a feasible basic structure was identified

Table 4-7: Basic structures identified for each identified task

\begin{tabular}{|c|c|c|c|}
\hline & Task & & Basic Structure \\
\hline \multirow[t]{2}{*}{ Reaction task } & \multirow{2}{*}{$\mathbf{R t}_{\mathbf{i}}(\mathbf{i}=\mathbf{1 . . n}) \longrightarrow$ R-Task } & \multirow{2}{*}{$\longrightarrow{ }_{P_{j}(j=1 . . n)}^{R t_{i}(\mathrm{i}=1 . n)}$} & $M(L)=R(L)$ \\
\hline & & & $M(L)=C$ \\
\hline Separation Task 1 & \multirow{4}{*}{$\underset{(\mathrm{i}=1,2)}{\mathrm{NC}_{\mathrm{i}}} \longrightarrow$} & \multirow{2}{*}{$\longrightarrow \begin{array}{c}\mathrm{NC}_{\mathrm{i}} \\
(\mathrm{i}=1 \text { or } 2)\end{array}$} & \multirow[b]{2}{*}{$\mathrm{M}(\mathrm{VL})=\mathrm{C}=2 \mathrm{phM}=\mathrm{PC}(\mathrm{VL})=\mathrm{PT}(\mathrm{VL})=\mathrm{PS}(\mathrm{VL})$} \\
\hline Separation Task 1 & & & \\
\hline Separation Task 2 & & \multirow[b]{2}{*}{$\begin{array}{c}N_{j} \\
(j=1 i=2 \text { or } \\
j=2 i=1)\end{array}$} & $\mathrm{M}(\mathrm{VL})=2 \mathrm{phM}=\mathrm{PC}(\mathrm{VL})=\mathrm{PT}(\mathrm{VL})=\mathrm{PS}(\mathrm{VL})$ \\
\hline Separation Task 2 & & & $\mathrm{M}(\mathrm{VL})=\mathrm{H}=2 \mathrm{phM}=\mathrm{PC}(\mathrm{VL})=\mathrm{PT}(\mathrm{VL})=\mathrm{PS}(\mathrm{VL})$ \\
\hline
\end{tabular}

The task-based flowsheets are shown in Figure 4-12. The total number of feasible taskbased flowsheets are 2 . 


\begin{tabular}{|c|c|c|}
\hline R-Task & S- Task 1 & S- Task 2 \\
\hline Reaction & Sep. $A(B C)$ & $\mathrm{B}(\mathrm{C})$ \\
\hline Level 1 & Sep. B(AC) & $\mathrm{A}(\mathrm{C})$ \\
\hline $\begin{array}{c}\text { Feasible }+ \text { Infeasible } \\
\text { connections }\end{array}$ & Sep. C(AB) & $\mathrm{A}(\mathrm{B})$ \\
\hline
\end{tabular}

Task-based flowsheet 1

Task-based flowsheet 2

Figure 4-12: Task-based flowsheets for the example (no azeotropes). R-Task-Reaction task, S-Task-Separation Task

Azeotropes present

Applying the method:

- Step ITbf.1- All possible identified separation tasks are (Step GTbS.1 and Step GTbS.3):

○ Reaction task for $A+B \leftrightarrow C$

○ Step ITP.1-The first separation task:

- Separation task $1 \mathrm{lk}=\mathrm{B}$ and $\mathrm{hk}=\mathrm{A}$

○ Step ITP.4-The second separation task:

- Separation task 2 (for separation task $1 \mathrm{lk}=\mathrm{B}$ and $\mathrm{hk}=\mathrm{A}$ ) $\mathrm{lk}=\mathrm{C}$ and $\mathrm{hk}=\mathrm{B}$

- Step ITbf.2-The basic structures identified for each task are shown in Table 4-8 and obtained from the database of basic structures (presented in appendix D) in AII.4. For all identified tasks, a feasible basic structure was identified. Note: one task based flowsheet is feasible from the task-based superstructure, however, by using the concept of basic structures, two feasible basic structures are identified for separation task 2. This will lead to the generation of 2 flowsheet alternatives at the unit operations scale compared to 1 if, one operated at the task scale. 
Table 4-8: Basic structures identified for each identified task

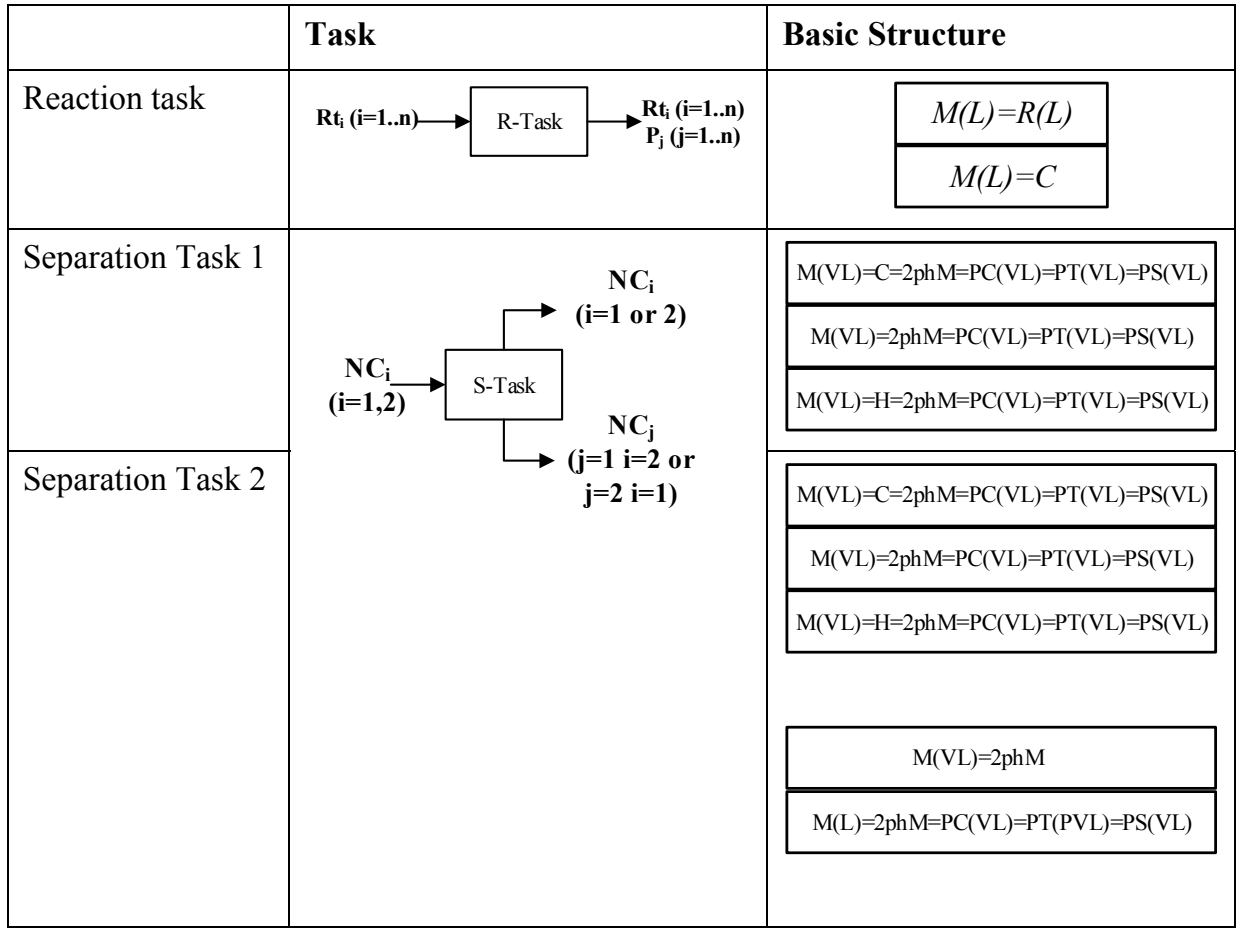

The task-based flowsheet are shown in Figure 4-13. The total number of feasible taskbased flowsheets is 1 .

\begin{tabular}{|c|c|c|}
\hline \multicolumn{1}{|c|}{ R- Task } \\
Reaction \\
$\begin{array}{c}\text { Feasible + Infeasible } \\
\text { connections }\end{array}$
\end{tabular}

Task-based flowsheet 1

Figure 4-13: Task-based flowsheet for the example (azeotropes). R-Task-Reaction task, S-Task-Separation Task

\subsubsection{All.6-Translation of Basic Structures Unit Operations}

The method for translating basic structures that performs tasks into flowsheets alternatives at the unit operations scale (TBsUo) is presented. The tool used in applying the method is "Tool 3-Selection Unit Operations.xlsx", presented in appendix E:

- Step TBsUo.1-Identification of the SPB building block and unit operations 
o Step TBsUo.1.1-Identify the initiator SPBs in the basic structures identified in AII.4

○ Step TBsUo.1.2-Using the tool "Tool 3-Selection Unit Operations.xlsx", select the SPB building block and identify the unit operations associated with the SPB initiator from Step TBsUo.1.1

- Step TBsUo.2-Screening of the identified unit operations

$\circ$ Step TBsUo.2.1-Screen the selected unit operations using the constraints, feed phase, use of a mass separating agent and azeotropes (if present)

$\circ$ Step TBsUo.2.2-If multiple unit operations are present after applying step TBsUo.2.1 then select the unit operations which perform the separation the easiest

As an example consider the conceptual examples in AII.4.

\section{Conceptual example for reaction}

Recall the reaction has the following properties:

1. Reaction phase- liquid

2. The reaction type: exothermic reaction

3. Set feed condition: liquid

Applying the method:

- Step TBsUo.1-

$\circ$ Step TBsUo.1.1-The identified SPB initiator is $\mathrm{M}=\mathrm{R}$

○ Step TBsUo.1.2-Applying the tool, a snapshot is shown in Figure 4-14

\begin{tabular}{|c|c|c|c|c|c|c|c|}
\hline & SPB building block in Basic & & & Reaction/Separation & Screening 1 : Feed & Screening 2: & Screening 3: \\
\hline 1 & Structure & Task & $\nabla$ & Operation $\quad \nabla$ & phase & MSA-Y/N $\square$ & Azeotrope \\
\hline 2 & $=\mathrm{M}=\mathrm{R}=$ & Reaction & & Batch reactor & $\begin{array}{l}\text { Solid, gas (vapor) and or } \\
\text { liquid }\end{array}$ & $\mathrm{Y} / \mathrm{N}$ & $\mathrm{N}$ \\
\hline 3 & $=\mathrm{M}=\mathrm{R}=$ & Reaction & & Semi-batch reactor & $\begin{array}{l}\text { Solid, gas (vapor) and or } \\
\text { liquid }\end{array}$ & $\mathrm{Y} / \mathrm{N}$ & $\mathrm{N}$ \\
\hline 4 & $=\mathrm{M}=\mathrm{R}=$ & Reaction & & CSTR & Liquid & $\mathrm{Y} / \mathrm{N}$ & $\mathrm{N}$ \\
\hline 5 & $=\mathrm{M}=\mathrm{R}=$ & Reaction & & Tubular Reactor (PFR) & Gas (Vapour) & $\mathrm{N}$ & $\mathrm{N}$ \\
\hline 6 & $=\mathrm{M}=\mathrm{R}=$ & Reaction & & Pack-bed reactor & Solid and or gas (vapour) & $\mathrm{N}$ & $\mathrm{N}$ \\
\hline
\end{tabular}

Figure 4-14: Identified unit operations based on the generated basic structure. MSAmass separating agent

- $\quad$ Step TBsUo.2-

$\circ$ Step TBsUo.2.1-First the unit operations in Figure 4-14 are screened using 'Screening 1: Feed phase'. In this case only one unit operations that was found shown in Figure 4-15

\begin{tabular}{|c|c|c|c|c|c|c|c|c|c|}
\hline & SPB building block in Basic & & & Reaction/Separation & & Screening 1: Feed & & Screening 2: & Screening 3: \\
\hline & Structure & 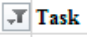 & 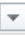 & Operation & $\checkmark$ & phase & 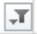 & MSA-Y/N - & Azeotrope \\
\hline & $=\mathrm{M}=\mathrm{R}=$ & Reacti & & CSTR & & Liquid & & Y/N & $\mathrm{N}$ \\
\hline
\end{tabular}

Figure 4-15: Selected unit operation from Figure 4-14 after screening. MSA-mass separating agent

Conceptual example for separation 2 
Recall the mixture to be separated has the following properties:

1. Azeotrope present between A and B

2. No miscibility gap present

3. Feed condition liquid

Applying the method:

- Step TBsUo.1-

o Step TBsUo.1.1-The identified SPB initiators are

$$
\begin{aligned}
& \mathrm{M}(\mathrm{VL})=2 \mathrm{phM}(\mathrm{VL})=\mathrm{PC}(\mathrm{VL})=\mathrm{PT}(\mathrm{VL})=\mathrm{PS}(\mathrm{VL}), \\
& \mathrm{M}(\mathrm{L})=2 \mathrm{phM}(\mathrm{VL})=\mathrm{PC}(\mathrm{VL})=\mathrm{PT}(\mathrm{PVL})=\mathrm{PS}(\mathrm{VL}), \\
& \mathrm{M}(\mathrm{V})=2 \mathrm{phM}(\mathrm{VL})=\mathrm{PC}(\mathrm{VL})=\mathrm{PT}(\mathrm{VV})=\mathrm{PS}(\mathrm{VV})
\end{aligned}
$$

\begin{tabular}{|c|c|c|c|c|c|c|c|}
\hline \multirow[b]{2}{*}{1} & \multirow{2}{*}{ SPB building block in Basic } & \multirow[b]{2}{*}{ Task } & \multirow{2}{*}{$\nabla$} & Reaction/Separation & \multirow{2}{*}{$\begin{array}{l}\text { Screening l: Feed } \\
\text { phase }\end{array}$} & Screening 2: & \multirow{2}{*}{$\begin{array}{l}\text { Screening 3: } \\
\text { Azeotrope }\end{array}$} \\
\hline & & & & Operation $\quad \nabla$ & & MSA-Y/N $\nabla$ & \\
\hline 7 & $=2 \mathrm{phM}=\mathrm{PC}(\mathrm{VL})=\mathrm{PT}(\mathrm{VL})=\mathrm{PS}(\mathrm{VL})$ & Separation & & $\begin{array}{l}\text { Partial condensation or } \\
\text { vaporization }\end{array}$ & Vapor and/or liquid & $\mathrm{N}$ & $\mathrm{N}$ \\
\hline 8 & $=2 \mathrm{phM}=\mathrm{PC}(\mathrm{VL})=\mathrm{PT}(\mathrm{VL})=\mathrm{PS}(\mathrm{VL})$ & Separation & & Flash vaporization & Liquid & $\mathrm{N}$ & $\mathrm{N}$ \\
\hline 9 & $=2 \mathrm{phM}=\mathrm{PC}(\mathrm{VL})=\mathrm{PT}(\mathrm{VL})=\mathrm{PS}(\mathrm{VL})$ & Separation & & Distillation & Vapor and/or liquid & $\mathrm{N}$ & $\mathrm{Y} / \mathrm{N}$ \\
\hline 10 & $=2 \mathrm{phM}=\mathrm{PC}(\mathrm{VL})=\mathrm{PT}(\mathrm{VL})=\mathrm{PS}(\mathrm{VL})$ & Separation & & Extractive distillation & Vapor and/or liquid & $\mathrm{Y}$ & $\mathrm{Y} / \mathrm{N}$ \\
\hline 11 & $=2 \mathrm{phM}=\mathrm{PC}(\mathrm{VL})=\mathrm{PT}(\mathrm{VL})=\mathrm{PS}(\mathrm{VL})$ & Separation & & Reboiled absorption & Vapor and or liquid & $\mathrm{Y}$ & $\mathrm{N}$ \\
\hline 13 & $=2 \mathrm{phM}=\mathrm{PC}(\mathrm{VL})=\mathrm{PT}(\mathrm{VL})=\mathrm{PS}(\mathrm{VL})$ & Separation & & Stripping & Liquid & $\mathrm{Y}$ & $\mathrm{N}$ \\
\hline 14 & $=2 \mathrm{phM}=\mathrm{PC}(\mathrm{VL})=\mathrm{PT}(\mathrm{VL})=\mathrm{PS}(\mathrm{VL})$ & Separation & & $\begin{array}{l}\text { Refluxed stripping } \\
\text { (steam distillation) }\end{array}$ & Vapor and/or liquid & $\mathrm{Y}$ & $\mathrm{N}$ \\
\hline 15 & $=2 \mathrm{phM}=\mathrm{PC}(\mathrm{VL})=\mathrm{PT}(\mathrm{VL})=\mathrm{PS}(\mathrm{VL})$ & Separation & & Reboiled stripping & Liquid & $\mathrm{N}$ & $\mathrm{N}$ \\
\hline 20 & $=2 \mathrm{phM}=\mathrm{PC}(\mathrm{VL})=\mathrm{PT}(\mathrm{VL})=\mathrm{PS}(\mathrm{VL})$ & Separation & & Evaporation & Liquid & $\mathrm{N}$ & $\mathrm{N}$ \\
\hline 24 & $=2 \mathrm{phM}=\mathrm{PC}(\mathrm{VL})=\mathrm{PT}(\mathrm{VL})=\mathrm{PS}(\mathrm{VL})$ & Separation & & Dividing Wall Column & Vapor and or liquid & $\mathrm{N}$ & $\mathrm{N}$ \\
\hline 26 & $=2 \mathrm{phM}=\mathrm{PC}(\mathrm{VL})=\mathrm{PT}(\mathrm{VL})=\mathrm{PS}(\mathrm{VL})$ & Separation & & Supercritical Extraction & Liquid & $\mathrm{Y}$ & $\mathrm{N}$ \\
\hline 27 & $=\mathrm{PC}(\mathrm{VL})=\mathrm{PT}(\mathrm{PVL})=\mathrm{PS}(\mathrm{VL})$ & Separation & & $\begin{array}{l}\text { Membrane- } \\
\text { Pervaporation }\end{array}$ & Vapor & $\mathrm{N}$ & $\mathrm{Y}$ \\
\hline 28 & $=\mathrm{PC}(\mathrm{VL})=\mathrm{PT}(\mathrm{VV})=\mathrm{PS}(\mathrm{VV})$ & Separation & & $\begin{array}{l}\text { Membrane-Vapor- } \\
\text { permeation }\end{array}$ & Vapor & $\mathrm{N}$ & $\mathrm{Y}$ \\
\hline
\end{tabular}

○ Step TBsUo.1.2-Applying the tool, a snapshot is shown in Figure 4-16

Figure 4-16: Identified unit operations based on the generated basic structure. MSAmass separating agent

- $\quad$ Step TBsUo.2-

o Step TBsUo.2.1-First, the unit operations in Figure 4-16 are screened using 'Screening 1: Feed phase'". In this scenario, either of the feed conditions are possible therefore, the unit operations in Figure 4-16 remain unchanged. Second, the unit operations are screened using ' Screening 2: MSA-Y/N'. In this case the number of unit operations was screened from 13 to 8 and is shown in Figure 4-17. Third, the unit operations are screened using 'Screening 3: Azeotrope'. In this case the number of unit operations was screened from 8 to 3 and is shown in Figure 4-18. 


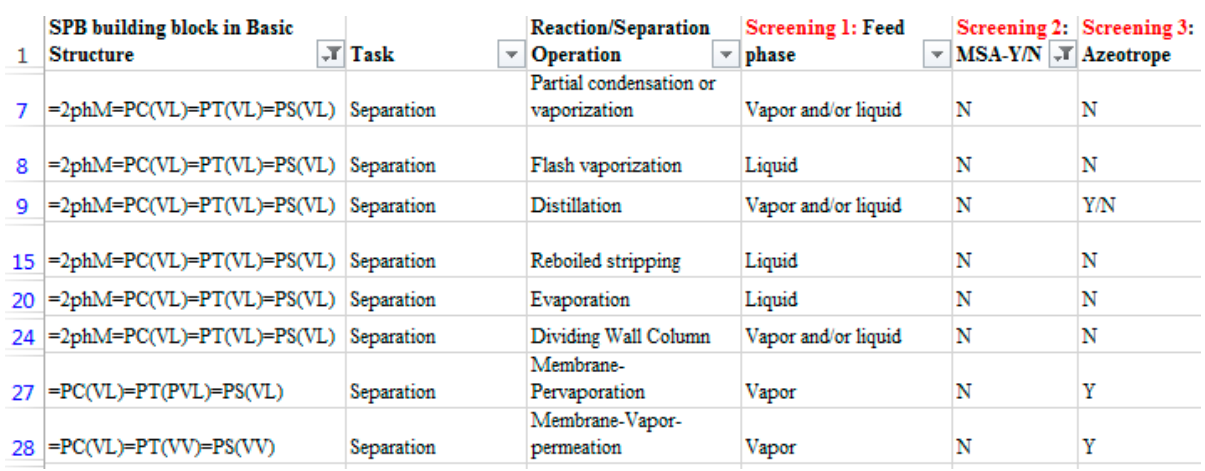

Figure 4-17: Selected unit operation from Figure 4-16 after screening. MSA-mass separating agent

\begin{tabular}{|c|c|c|c|c|c|c|}
\hline & SPB building block in Basic & & Reaction/Separation & Screening 1: Feed & Screening 2: & Screening 3: \\
\hline 1 & Structure & Task & Operation $\quad \nabla$ & phase & MSA-Y/N & Azeotrope $\pi$ \\
\hline 9 & $=2 \mathrm{phM}=\mathrm{PC}(\mathrm{VL})=\mathrm{PT}(\mathrm{VL})=\mathrm{PS}(\mathrm{VL})$ & Separation & Distillation & Vapor and/or liquid & $\mathrm{N}$ & Y/N \\
\hline 27 & $=\mathrm{PC}(\mathrm{VL})=\mathrm{PT}(\mathrm{PVL})=\mathrm{PS}(\mathrm{VL})$ & Separation & $\begin{array}{l}\text { Membrane- } \\
\text { Pervaporation }\end{array}$ & Vapor & $\mathrm{N}$ & $\mathrm{Y}$ \\
\hline 28 & $=\mathrm{PC}(\mathrm{VL})=\mathrm{PT}(\mathrm{VV})=\mathrm{PS}(\mathrm{VV})$ & Separation & $\begin{array}{l}\text { Membrane-Vapor- } \\
\text { permeation }\end{array}$ & Vapor & $\mathrm{N}$ & $\mathrm{Y}$ \\
\hline
\end{tabular}

Figure 4-18: Selected unit operation from Figure 4-17 after screening. MSA-mass separating agent

\section{Conceptual example for reaction-separation}

Recall the reaction-separation mixture to be separated has the following properties:

1. Reaction phase- liquid

2. The reaction type: exothermic reaction

3. Azeotrope present between B and D

4. No miscibility gap present

5. Set feed condition: liquid

6. Known: removal of one of the products will shift the equilibrium and therefore increase the conversion of $\mathrm{A}$

Applying the method:

- Step TBsUo.1-

o Step TBsUo.1.1-The identified SPB initiators are

$$
\begin{aligned}
& \mathrm{M}(\mathrm{VL})=2 \mathrm{phM}(\mathrm{VL})=\mathrm{R}=\mathrm{PC}(\mathrm{VL})=\mathrm{PT}(\mathrm{VL})=\mathrm{PS}(\mathrm{VL}), \\
& \mathrm{M}(\mathrm{L})=2 \mathrm{phM}(\mathrm{VL})=\mathrm{R}=\mathrm{PC}(\mathrm{VL})=\mathrm{PT}(\mathrm{PVL})=\mathrm{PS}(\mathrm{VL})
\end{aligned}
$$

o Step TBsUo.1.2-Applying the tool, a snapshot is shown in Figure 4-19 


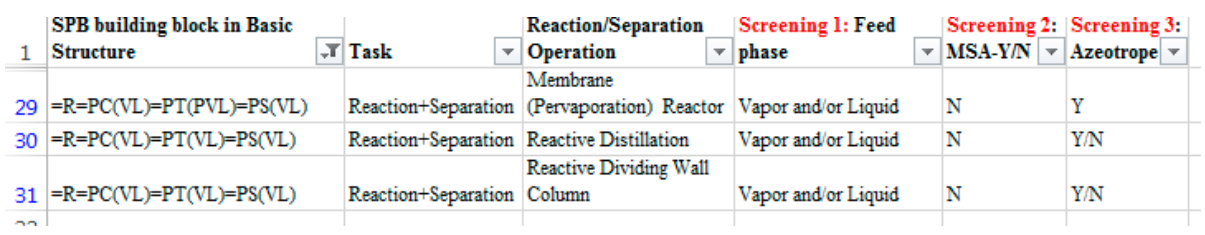

Figure 4-19: Identified unit operations based on the generated basic structure

- $\quad$ Step TBsUo.2-

$\circ$ Step TBsUo.2.1-The unit operations in Figure 4-19 are screened cannot be reduced further using the constraints, since, they are already satisfied. Therefore all three options can be evaluated or further reduced

\subsection{Conclusion}

In this chapter the problem definition and the algorithms that operate at different scales, used in the application of the framework have been presented and explained. These algorithms operate from the unit operations scale to phenomena scale and, from the phenomena scale; where phenomena are combined to generate flowsheet alternatives; to the unit operations scale. 


\section{FRAMEWORK FOR SUSTAINABLE PROCESS SYNTHESIS-INTENSIFICATION: SUPPORTING METHODS AND TOOLS}

In this chapter the different methods and tools used within the framework are presented. First, the methods used for analysis at the unit operations scale, task scale and phenomena scale are presented with an explanation of the synthesis methods that operate at the unit operations scale and task scale embedded within the framework. Second, the model-based tools based on methods that are used in the framework are presented.

\subsection{Methods}

Table 5-1 provides an overview of these methods with supporting information on inputs, outputs and models used for solving (computer-aided) the sustainable process synthesis-intensification problem. 
Table 5-1: Methods and supporting information for performing synthesis, design and sustainable design

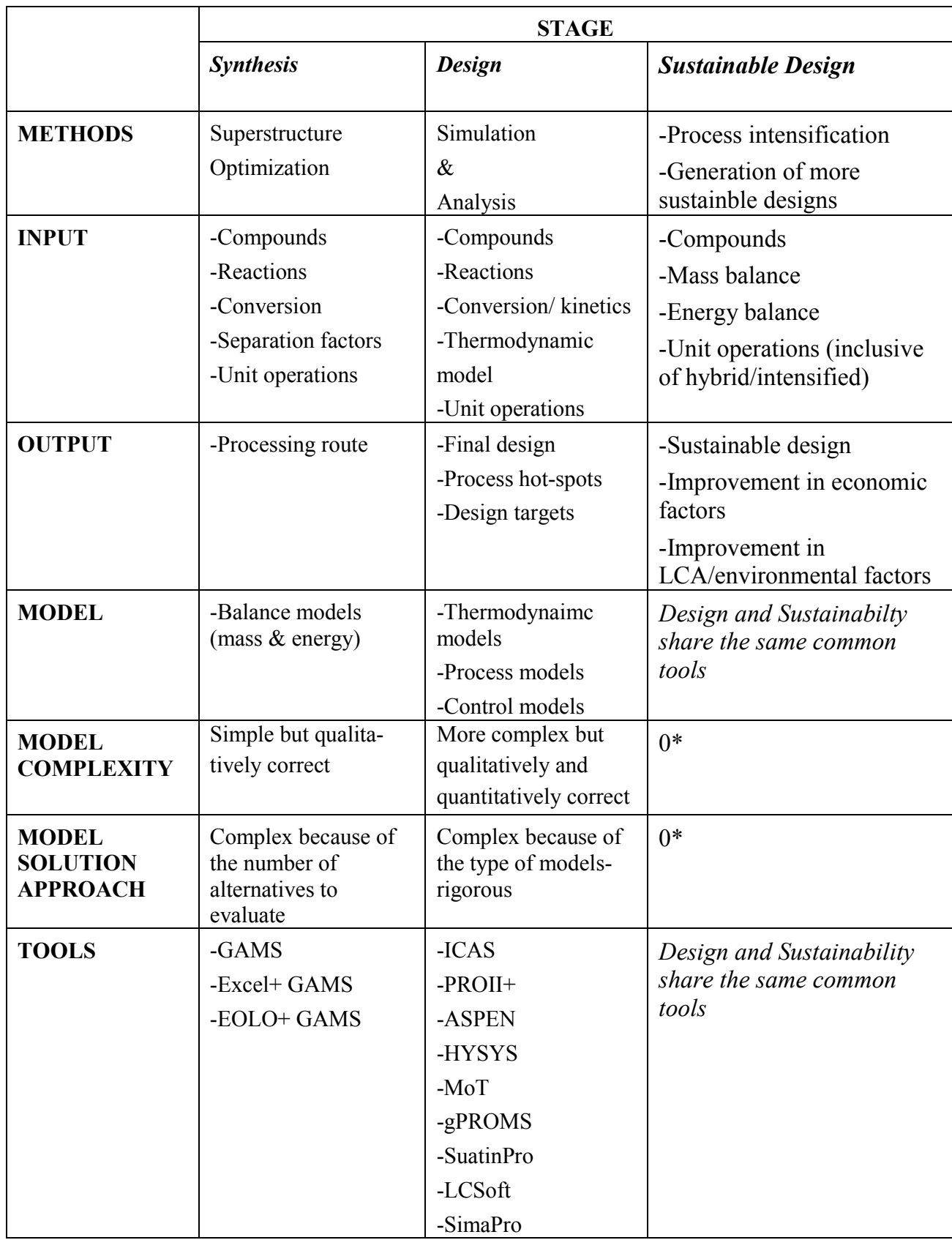

Note: " $0 *$ "' used as the reference for comparing model complexity and solution strategy. Either of these two can be more or less complex for the synthesis stage and design stage respectively 
From Table 5-1, it can be seen that different methods are used at the process synthesis stage, design stage and sustainable design stage. Multiple inputs are required for each stage and provide the generation of multiple outputs, of which, the most detailed set of inputs are required for the design stage. The model and model complexity varies for each stage and is the most complex for the design stage, because in this stage, rigorous simulation is performed. This is corroborated with the framework architecture presented in Figure 3-1, where, the complexity is the highest for step 8. The model solution strategy is more complex for the synthesis stage and design stage even though the model and model complexity for the synthesis stage can be less complex. This is the case because in the synthesis stage a large number of alternatives must be simultaneously evaluated whereas in the design stage the models themselves are complex.

Three methods explained in this section are, (1) the means-ends analysis (step 6), (2) the method of thermodynamic insights (step 6 and IT-PBS 3) and (3) the sustainability analysis (step 8). Table 5-2 gives a list of the methods and sub-methods used within the framework.

Table 5-2: Methods and sub-methods available in the Process Synthesis-Intensification Framework

\begin{tabular}{|c|c|c|}
\hline Objective & Method & Source \\
\hline $\begin{array}{l}\text { Feasibility of a particular } \\
\text { identified task }\end{array}$ & Thermodynamic Insights & Jaksland et al. (1995) \\
\hline Task-based synthesis & Means-ends Analysis & Siirola (1996) \\
\hline $\begin{array}{l}\text { Phenomena-based } \\
\text { synthesis }\end{array}$ & $\begin{array}{l}\text { Innovative Synthesis } \\
\text { Methodology } \\
\text { for Process Intensification }\end{array}$ & $\begin{array}{l}\text { Lutze et al. (2013), Babi et } \\
\text { al. (2014 (b)) }\end{array}$ \\
\hline $\begin{array}{l}\text { Base case design verifica- } \\
\text { tion }\end{array}$ & Process Synthesis Method & Douglas (1989) \\
\hline $\begin{array}{l}\text { Analysis of Pure com- } \\
\text { pound properties and mix- } \\
\text { ture } \\
\text { properties }\end{array}$ & Thermodynamic Insights & Jaksland et al. (1995) \\
\hline Sustainability analysis & $\begin{array}{l}\text { Hybrid Heuristic and Indi- } \\
\text { cator Method }\end{array}$ & Carvalho et al. (2009) \\
\hline
\end{tabular}

\subsubsection{Means-ends analysis}

The means-ends analysis is an operator-based state transformation method, often used in automated goal-oriented problem solving (Rudd and Watson, 1968). The means-ends paradigm has been modified by Siirola (1996) for process synthesis and is based on reducing/eliminating property differences between an initial state (for example, raw materials) and goal state (for example, products). 
The method consists of analysis and synthesis steps, where the analysis steps provide the data for performing the synthesis steps. The analysis and synthesis steps range from selection of the reaction path to the design of the separation synthesis, using a taskbased approach. Starting with the initial state and identifying property differences, transformation operators, that is tasks, are applied to reduce/eliminate these differences in order to produce intermediate states with fewer and fewer differences until the goal state (objective) is achieved (Siirola 1996).

\subsubsection{The method of Thermodynamic Insights}

The methodology consists of two levels (Jaksland et al., 1995), where the analysis of pure component and mixture properties are essential for identifying feasible separation tasks, separation techniques and the ordering these tasks for feasible flowsheet generation. The degree of complexity increases from one level to the next. The method is iterative and therefore, one can use the knowledge gained at the lower level in order to make decisions at the higher level. In level 1 , the pure component and mixture properties are analysed, for example, calculation of the binary ration matrix. Using this information, separation techniques and tasks are identified. In level 2, the separation techniques/tasks identified in level 1 are screened and, where applicable, mass separating agents for a particular separation technique/task is identified. The tasks/separation techniques are combined to generate task-based/unit operations-based flowsheets and the operating conditions of these unit operations are estimated in order to perform rigorous simulation.

\subsubsection{Sustainability Analysis}

The sustainability analysis uses an indicator-based methodology where a set of calculated closed- and open-path indicators are used to identify the process hot-spots within any process flowsheet. The method calculates and ranks a set of mass and energy indicators, from data obtained from steady-state process simulation or plant real-time data. Having performed the analysis, one can then identify from the sustainability indicators the process hot-spots because the indicators are ordered in such a way as to show which parts of the process has the highest potential for improvement (Carvalho et al., 2009). A brief explanation of the sustainability indicators and what should be done in order to improve the process are presented:

1. Material value added (MVA) - This indicator gives the value added between the entrance and the exit of a given compound that is the value generated between the start and the end point of the path. Negative values of this indicator show that the component has lost its value in this open-path and therefore. point to potential for improvements

2. Energy and waste cost (EWC) - This indicator is applied to both open- and closed-paths. It takes into account the energy costs (EC) and the costs related with the compound treatment (WC). The value of EWC represents the maximum 
theoretical, amount of energy that can be saved in each path within the process. High values of this indicator show high consumption of energy and waste costs and therefore these paths should be considered in order to reduce the indicator value

3. Total value added (TVA) - This indicator describes the economic influence of a compound in a given path and is the difference between MVA and EWC. Negative values of this indicator show high potential for improvements in terms of decrease in the variable costs 


\subsection{Tools}

Table 5-3 gives a selected list of the tools and its source, used for various calculations for solving the synthesis-intensification problem.

Table 5-3: Tools used in the Synthesis-Intensification Framework. HDS-Hybrid Distillation Scheme(s)

\begin{tabular}{|c|c|c|c|}
\hline Objective & Method & $\begin{array}{l}\text { Tool-name/ } \\
\text { Tool-type }\end{array}$ & Features \\
\hline $\begin{array}{l}\text { Phase diagram } \\
\text { generation }\end{array}$ & $\begin{array}{l}\text { Property } \\
\text { model based }\end{array}$ & $\begin{array}{l}\text { ICAS-utility*/ } \\
\text { Analysis }\end{array}$ & $\begin{array}{l}\text { Group contribution based property } \\
\text { models used for VLE, LLE, SLE, } \\
\text { distillation boundary, residue curve, } \\
\text { etc., calculations }\end{array}$ \\
\hline $\begin{array}{l}\text { Solvent selec- } \\
\text { tion }\end{array}$ & $\begin{array}{l}\text { CAMD; Da- } \\
\text { tabase search }\end{array}$ & $\begin{array}{l}\text { ProCAMD*/ } \\
\text { Selection }\end{array}$ & $\begin{array}{l}\text { Searches for solvents for various } \\
\text { types of solvent based separation } \\
\text { processes }\end{array}$ \\
\hline $\begin{array}{l}\text { Economic } \\
\text { Analysis }\end{array}$ & $\begin{array}{l}\text { Model/ } \\
\text { Heuristic } \\
\text { based }\end{array}$ & $\begin{array}{l}\text { ECON*/ } \\
\text { Analysis }\end{array}$ & $\begin{array}{l}\text { Cost calculation based on the model } \\
\text { from Peters, Timmerhaus, West } \\
(2003)\end{array}$ \\
\hline $\begin{array}{l}\text { Sustainability } \\
\text { Analysis }\end{array}$ & Model based & $\begin{array}{l}\text { SustainPro*/ } \\
\text { Analysis }\end{array}$ & $\begin{array}{l}\text { Indicator-based method using mass } \\
\text { and energy balance data from rigor- } \\
\text { ous simulation (Carvalho et al., 2009, } \\
\text { Carvalho et al. 2013) }\end{array}$ \\
\hline $\begin{array}{l}\text { Life Cycle } \\
\text { Assessment }\end{array}$ & Model based & LCSoft* & $\begin{array}{l}\text { Indicator based method using cradle } \\
\text { to the gate concept for LCA analysis } \\
\text { (Kalakul et al., 2014) }\end{array}$ \\
\hline $\begin{array}{l}\text { Pure compo- } \\
\text { nent properties } \\
\text { Analysis }\end{array}$ & Model based & $\begin{array}{l}\text { CAPSS*/ } \\
\text { Analysis }\end{array}$ & $\begin{array}{l}\text { Calculated from the pure component } \\
\text { properties from the system com- } \\
\text { pounds (Jaksland et al., 1995) }\end{array}$ \\
\hline $\begin{array}{l}\text { Pure compo- } \\
\text { nent property } \\
\text { Prediction }\end{array}$ & Model based & ProPred* & $\begin{array}{l}\text { Group contribution based property } \\
\text { models (Marrero and Gani 2001) }\end{array}$ \\
\hline $\begin{array}{l}\text { Distillation } \\
\text { (with or with- } \\
\text { out reaction) }\end{array}$ & $\begin{array}{l}\text { Driving force } \\
\text { based; Equi- } \\
\text { librium based }\end{array}$ & $\begin{array}{l}\text { PDS*/ } \\
\text { Design, Anal- } \\
\text { ysis }\end{array}$ & $\begin{array}{l}\text { Based on generated phase diagrams } \\
\text { and driving force diagrams design of } \\
\text { distillation columns }\end{array}$ \\
\hline Modelling & $\begin{array}{l}\text { Equation ori- } \\
\text { ented prob- } \\
\text { lem solution }\end{array}$ & $\begin{array}{l}\text { MoT*/ } \\
\text { Analysis }\end{array}$ & $\begin{array}{l}\text { Process and property models can be } \\
\text { quickly generated and solved without } \\
\text { spending time on programming. }\end{array}$ \\
\hline $\begin{array}{l}\text { Process simu- } \\
\text { lation }\end{array}$ & $\begin{array}{l}\text { Model based } \\
\text { calculations }\end{array}$ & $\begin{array}{l}\text { Aspen Plus, } \\
\text { PROII/ } \\
\text { Analysis }\end{array}$ & $\begin{array}{l}\text { Models for distillation and reactive } \\
\text { distillation are available for use in } \\
\text { analysis of HDS (Babi and Gani, } \\
\text { 2014) }\end{array}$ \\
\hline
\end{tabular}

Note: *Part of ICAS (Gani et al., 1997) 


\subsection{Conclusion}

In this chapter the methods used in the framework and the computer-aided tools used have been presented. The methods which are used for either base case design generation or for acquiring physical insights, are explained, that is, the means-ends analysis and the method of thermodynamic insights. The sustainability analysis is also explained because it is the method (made available through a computer-aided tool) that provides the means by which the sustainability analysis is directly performed for process hot-spot identification (together with an economic and LCA analyses). Finally, an overview of the computer-aided tools and their source (some of which can be made readily available upon request) has been given. 



\section{CASE STUDIES}

In this chapter, three case studies are presented, highlighting each step of the sustainable process synthesis-intensification framework. The case studies are related to 2 chemical processes and a bio-process. The case studies are presented as follows, the production of methyl acetate, di-methyl carbonate and fatty-acid methyl esters (FAME, biodiesel).

\subsection{Production of Methyl-Acetate}

\subsubsection{Step 1-Need Identification}

Action 1: Methyl-acetate (MeOAc) is an important chemical used as a solvent for glues, paints and nail polish removers, among others.

Action 2: The total production per year of MeOAc could not be found directly, however from two main producers that is Eastman Chemical Company located in the USA and Hunan Xiangwei Co. in China, their production rates are $149 \times 10^{3}$ tons/year (Huss et al., 2003) and $150 \times 10^{3}$ tons/year (Hunan Xiangwei Co.) respectively. Therefore, the set production target is chosen to be $17009 \mathrm{~kg} / \mathrm{hr}$. The purity of the product should be greater than or equal to $99 \mathrm{~mol} \% \mathrm{MeOAc}$.

\subsubsection{Step 2-Problem Definition}

Action 1: Problem statement: Identification of process flowsheet alternatives for the production of MeOAc subject to constraints and performance criteria and achieving an optimal conversion of HOAc.

Action 2: The objective function is defined in terms of maximizing the profit, Equation 6.25 subject to constraints and performance:

$$
\operatorname{Max} F_{\text {obj }}=\left(\sum m_{j} C_{\mathrm{Pr} o d, j}-\sum m_{j} C_{R M, j}-\sum E_{j} C_{U t, j}\right) / m_{\text {prod }}
$$

Action 3: The constraints considered are given in Table 6-1. 
Table 6-1: Defined constraints for process synthesis-intensification of MeOAc production

\begin{tabular}{|c|c|c|c|c|}
\hline \multirow{2}{*}{ Objective } & \multicolumn{3}{|c|}{ Constraint } & \multirow{2}{*}{$\begin{array}{l}\text { Performance } \\
\text { Criteria }(\underline{\varphi})\end{array}$} \\
\hline & $\underline{\theta_{1}}$ & $\underline{\theta_{2}}$ & $\underline{\theta_{3}}$ & \\
\hline Flowsheet structure: reaction + separation & $*$ & & & \\
\hline Reaction occurs in the first unit operation & $*$ & & & \\
\hline $\begin{array}{l}\text { The product purity of MeOAc and } \mathrm{H} 2 \mathrm{O} \text { is } \\
\text { defined is } \geq 99 \mathrm{~mol} \%\end{array}$ & $*$ & & & \\
\hline $\begin{array}{l}\text { PBBs are connected to form SPBs based } \\
\text { on combination rules }\end{array}$ & & * & & \\
\hline $\begin{array}{l}\text { SPBs are connected to form Basic Struc- } \\
\text { tures based on combination rules }\end{array}$ & & * & & \\
\hline $\begin{array}{l}\text { Do not use mass separating agents for re- } \\
\text { action/separation }\end{array}$ & & * & & \\
\hline Recycle un-reacted raw materials & & $*$ & & \\
\hline $\begin{array}{l}\text { Do not use recycle streams if not neces- } \\
\text { sary }\end{array}$ & & * & & \\
\hline $\begin{array}{l}\text { Raw materials, methanol and acetic acid } \\
\text { are assumed to be in their pure state }\end{array}$ & & & * & \\
\hline $\begin{array}{l}\text { The equilibrium conversion is defined as } \\
71.4 \% \text { (is to be increased) }\end{array}$ & & & $*$ & \\
\hline $\begin{array}{l}\text { Production target of MeOAc is set at } \\
122 \times 10^{3} \text { tons/year }\end{array}$ & & & $*$ & \\
\hline $\begin{array}{l}\text { PI screening criteria for basic structures to } \\
\text { unit operations: Novel equipment feasible }\end{array}$ & & & & $*$ \\
\hline Increase HOAc conversion is explored & & & & $*$ \\
\hline $\begin{array}{l}\text { Minimization/reduction in energy con- } \\
\text { sumption }\end{array}$ & & & & * \\
\hline Inclusion of intensified equipment & & & & $*$ \\
\hline Reduction in the number of unit operations & & & & $*$ \\
\hline Waste minimization & & & & $*$ \\
\hline $\begin{array}{l}\text { Sustainability and LCA factors must be the } \\
\text { same or better }\end{array}$ & & & & $*$ \\
\hline
\end{tabular}




\subsubsection{Step 3-Reaction Identification/Selection}

Action 1: The raw materials are methanol $(\mathrm{MeOH})$ and acetic acid (HOAc) and are in the liquid phase for the reaction. The reaction is catalyzed using an acidic based catalyst, Amberlyst 15 . The reaction is an equilibrium reaction and the reaction kinetic data is obtained from Pöpken et al. (2000). The reaction is shown in Equation 6.26.

$$
\mathrm{MeOH}+\mathrm{HOAc} \leftrightarrow \mathrm{MeOAc}+\mathrm{H} 2 \mathrm{O}
$$

Action 2: State of the products and by-products from Equation 5.26 is in the liquid phase. The heat of reaction is calculated to be $-5.42 \mathrm{~kJ} / \mathrm{mol}$, with an equilibrium conversion of $71.4 \%$ using the adsorption-based model (Pöpken et al., 2000). The reaction is an equilibrium reaction and therefore, it is reversible and exothermic because the heat of reaction, $\Delta H_{r x n}<0$.

\subsubsection{Step 4-Check for Availability-Base Case}

Action 1: From a literature survey, a known base case design (Agreda et al., 1990) was pre-selected and is shown in Figure 6-1. The base case consists of 10 unit operations: 1 reactor (R1), 6 distillation columns (T1, T2, T3, T4, T5 and T6), 1 liquid-liquid extractor (LL) and 1decanter (D1).

A brief description about the process: The raw materials are fed at a mole ratio of 2:1, with $\mathrm{MeOH}$ in excess, to the reactor where, the esterification reaction occurs to produce $\mathrm{MeOAc}$ and $\mathrm{H} 2 \mathrm{O}$. The reactor effluent consists of a mixture of $\mathrm{MeOH}, \mathrm{HOAc}, \mathrm{MeOAc}$ and $\mathrm{H} 2 \mathrm{O}$. Three minimum boiling azeotropes exist in this mixture, $\mathrm{MeOAc} / \mathrm{H} 2 \mathrm{O}$, Me$\mathrm{OAc} / \mathrm{MeOH}$ and $\mathrm{HOAc} / \mathrm{H} 2 \mathrm{O}$. The first distillation column (T1) separates HOAc and $\mathrm{H} 2 \mathrm{O}$ (bottom of T1) from the reactor effluent with $\mathrm{MeOH}$ and $\mathrm{MeOAc}$ (top of T1). However, $\mathrm{H} 2 \mathrm{O}$ forms an azeotrope with $\mathrm{MeOAc}$ and is therefore, found in the top as well as the bottom products of T1. The top stream of T1 contains $\mathrm{MeOH}, \mathrm{MeOAc}$ and $\mathrm{H} 2 \mathrm{O}$ and is separated by extractive distillation (T2) using di-methyl sulfoxide (DMSO) as a solvent. In $\mathrm{T} 3$ the solvent is recovered from a mixture with $\mathrm{MeOH}$ and $\mathrm{T} 4$ separates $\mathrm{MeOH}$ from $\mathrm{H} 2 \mathrm{O}$. The unreacted $\mathrm{MeOH}$ is recycled to the reactor. $\mathrm{HOAc}$ and $\mathrm{H} 2 \mathrm{O}$ forms an azeotrope and are separated using liquid-liquid extraction (LL), where ethylacetate (EthOAc) is used as the solvent, followed by azeotropic distillation (T5). The decanter (D1) separates a two phase mixture to recover the solvent, EthOAc and T6 separates $\mathrm{H} 2 \mathrm{O}$ from a mixture of HOAc and EthOAc. The unreacted HOAc is recycled to the reactor. 


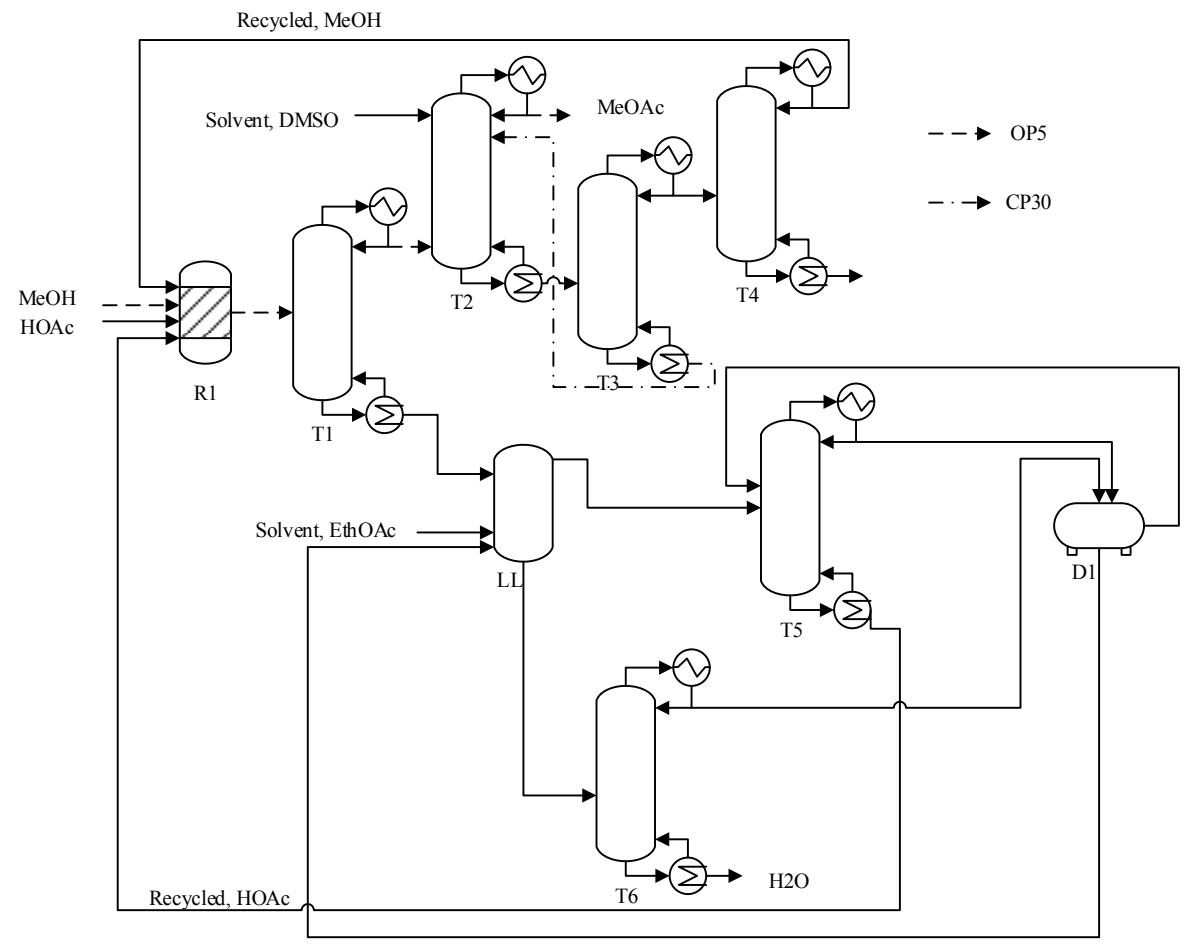

Figure 6-1: Base case design for the production of MeOAc. The open and closed paths $(\mathrm{OP}, \mathrm{CP})$ are also highlighted which are outputs of Step 8

\subsubsection{Step 5-Check for Base Case Feasibility}

The pre-selected base design is verified using the process synthesis method of Douglas (1985) in order to verify if it is feasible to be used as a base case design. From the analysis the pre-selected design satisfied the synthesis method of Douglas (1985), therefore, it is selected to be used as a feasible design. 


\subsubsection{Step 7-Perform Rigorous Simulation}

Action 1: The selected thermodynamic model is the UNIQUAC using Figure 3-2 and data from Pöpken et al. (2000). The base case design is rigorously using equilibrium based models for the reactor and separators using Aspen Plus. Information for the equilibrium constant for the reaction is obtained from Song et al. (1998). $\mathrm{MeOH}$ is fed in excess in order to achieve close to the equilibrium conversion. An overview of the simulation results is given in Table 6-2.

Table 6-2: Highlighted results from the simulation of the base case design

\begin{tabular}{|l|l|}
\hline & Value \\
\hline Feed Mole ratio (MeOH:HOAc) & $2: 1$ \\
\hline MeOAc product $(\mathrm{kg} / \mathrm{hr})$ & 17,009 \\
\hline Energy usage $(\mathrm{MJ} / \mathrm{hr})$ & 372,198 \\
\hline Utility Cost $(\$ / \mathrm{yr})$ & $12,343,384$ \\
\hline
\end{tabular}

Action 2: The detailed mass and energy balance data, number of streams and unit operations of the base case based on the rigorous simulation is retrieved, which is to be used for the analyses in step 8.

\subsubsection{Step 8-Economic, Sustainability and LCA analysis}

Action 1-3: The economic, sustainability and LCA analysis are performed. The economic and LCA analysis results are shown in Figure 6-2 and the sustainability analyses is shown in Table 6-3. In Table 6-3 the two most critical streams (paths) in the process are listed with the paths highlighted in Figure 6-1. 

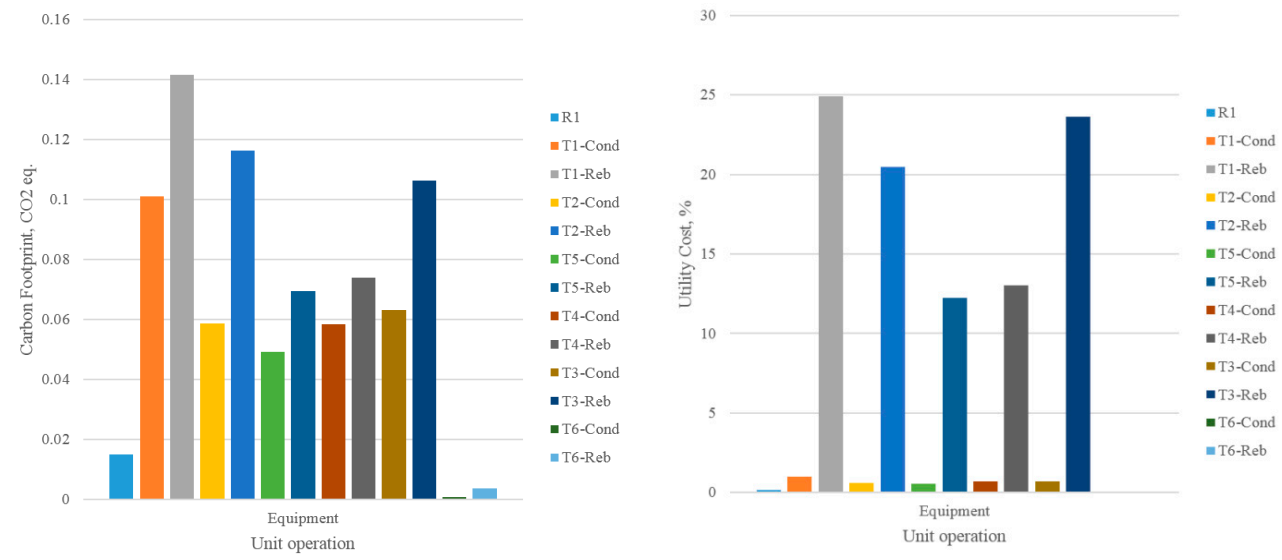

Figure 6-2: Economic analysis and LCA analysis for the base case design. Carbon footprint and Utility cost are compared. Note: Cond $=$ condenser, $R e b=$ reboiler

Table 6-3: The 2 most critical paths in the base case design that have the highest potentials for improvement. Note: OP-open path, CP-closed path

\begin{tabular}{|l|l|l|l|l|l|}
\hline Path & Compound & $\begin{array}{l}\text { Flowrate } \\
\mathbf{( k g / h r})\end{array}$ & $\begin{array}{l}\text { MVA } \\
\left(\mathbf{1 0}^{\mathbf{3}} \text { \$/year }\right)\end{array}$ & $\begin{array}{l}\text { TVA } \\
\left(\mathbf{1 0}^{\mathbf{3}} \text { \$/year }\right)\end{array}$ & $\begin{array}{l}\text { EWC } \\
\left(\mathbf{1 0}^{\mathbf{3}} \text { \$/year }\right)\end{array}$ \\
\hline OP5 & MeOH & 166 & -477 & - & - \\
\hline CP30 & DMSO & 78133 & - & - & 4440 \\
\hline
\end{tabular}

From Table 6-3, OP5 which follows the raw material MeOH, has a negative MVA value. This means that $\mathrm{MeOH}$ is losing its value as it exits the process through this path that is raw material is being lost in this path. The achieved MeOAc purity in T2 is 99 mol $\%$, and therefore, the remaining $1 \mathrm{~mol} \%$ is $\mathrm{MeOH}$. CP30 which follows the path of DMSO, has a high EWC. This means that a high flow of DMSO is being recycled resulting in high loads of energy and waste/use of utilities for solvent recovery. Therefore referring to Figure 6-2, the unit operations belonging to this closed-path, for example, column-T3, where DMSO is recovered, has a high carbon footprint and accounts for $24 \%$ of the utility costs.

Action 4: The identified process hot-spots are given in Table 6-4. 
Table 6-4: Identified process hot-spots in the base case design for the production of $\mathrm{MeOAc}$

\begin{tabular}{|c|c|c|c|}
\hline Indicator values & $\begin{array}{l}\text { Base Case prop- } \\
\text { erty }\end{array}$ & Reason & $\begin{array}{l}\text { Identified Process } \\
\text { hot-spot }\end{array}$ \\
\hline $\begin{array}{l}\alpha_{1}=\text { Raw material } \\
\text { recycle } / \text { cost } \\
\beta_{1}=\mathrm{MVA}\end{array}$ & $\begin{array}{l}\text { Un-reacted raw } \\
\text { materials }\end{array}$ & $\begin{array}{l}\text { Equilibrium reac- } \\
\text { tion }\end{array}$ & $\begin{array}{l}\text {-Limiting equilibri- } \\
\text { um/raw material loss }\end{array}$ \\
\hline $\begin{array}{l}\alpha_{2}=\text { Utility cost } \\
\beta_{1}=\mathrm{MVA} \\
\beta_{2}=\mathrm{EWC} \\
\gamma_{1}=\mathrm{CO} 2 \text { equiva- } \\
\text { lent } \\
\gamma_{2}=\mathrm{PEI}\end{array}$ & $\begin{array}{l}\text { Un-reacted raw } \\
\text { materials and } \\
\text { products recovery }\end{array}$ & $\begin{array}{l}\text {-Presence of azeo- } \\
\text { trope(s) } \\
\text {-High energy usage- } \\
\text { heating and/or cool- } \\
\text { ing }\end{array}$ & $\begin{array}{l}\text {-Azeotrope } \\
\text {-Difficult separation: } \\
\text { low driving force } \\
\text {-High energy con- } \\
\text { sumption and/or de- } \\
\text { mand }\end{array}$ \\
\hline
\end{tabular}

Action 5: Using Table 3-3, the design targets to be set/met are:

1. Increase raw material conversion

2. Reduce raw material loss

3. Reduce energy consumption

4. Reduce utility cost

5. Improvements in LCA/Sustainability indicators

6. Unit operations reduction

7. Product purity (kept as the base case)

8. Production target (kept as the base case)

9. Reduce operational cost

10. Waste minimization 


\subsubsection{IT-PBS.1-Process Analysis}

Action 1: The task based flowsheet of the base case design is shown in Figure 6-3.

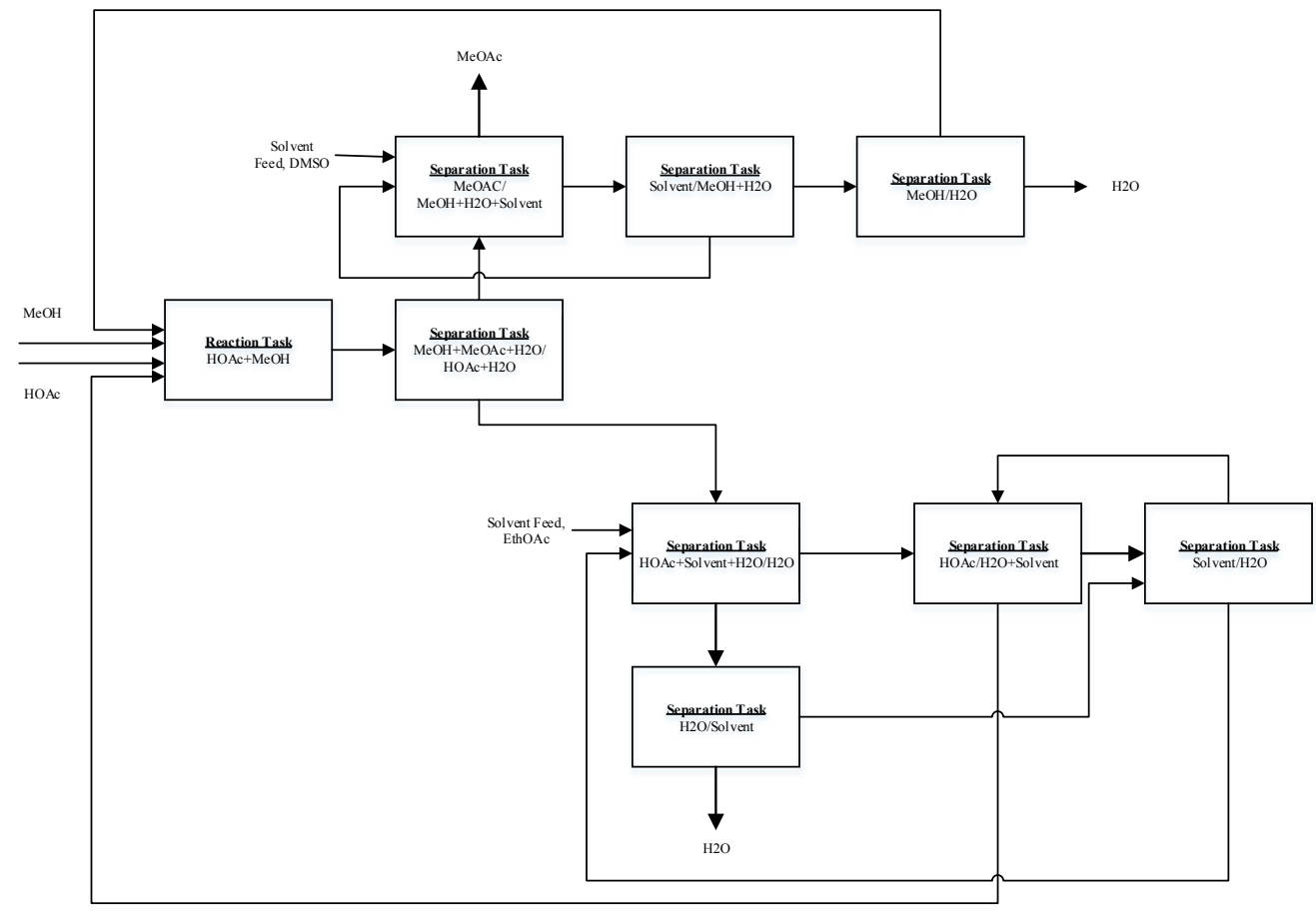

Figure 6-3: Task based flowsheet of the base case design

Action 2: The phenomena based flowsheet of the base case design is shown in Figure 6-4. The identified PBBs are:

- Reaction task: M, R, C

- Separation task:
○ VL-M, 2phM, C/H, PC(VL), PT(VL), PS(VL)
$\circ$ LL-M, 2phM, PC(LL), PS(LL) 


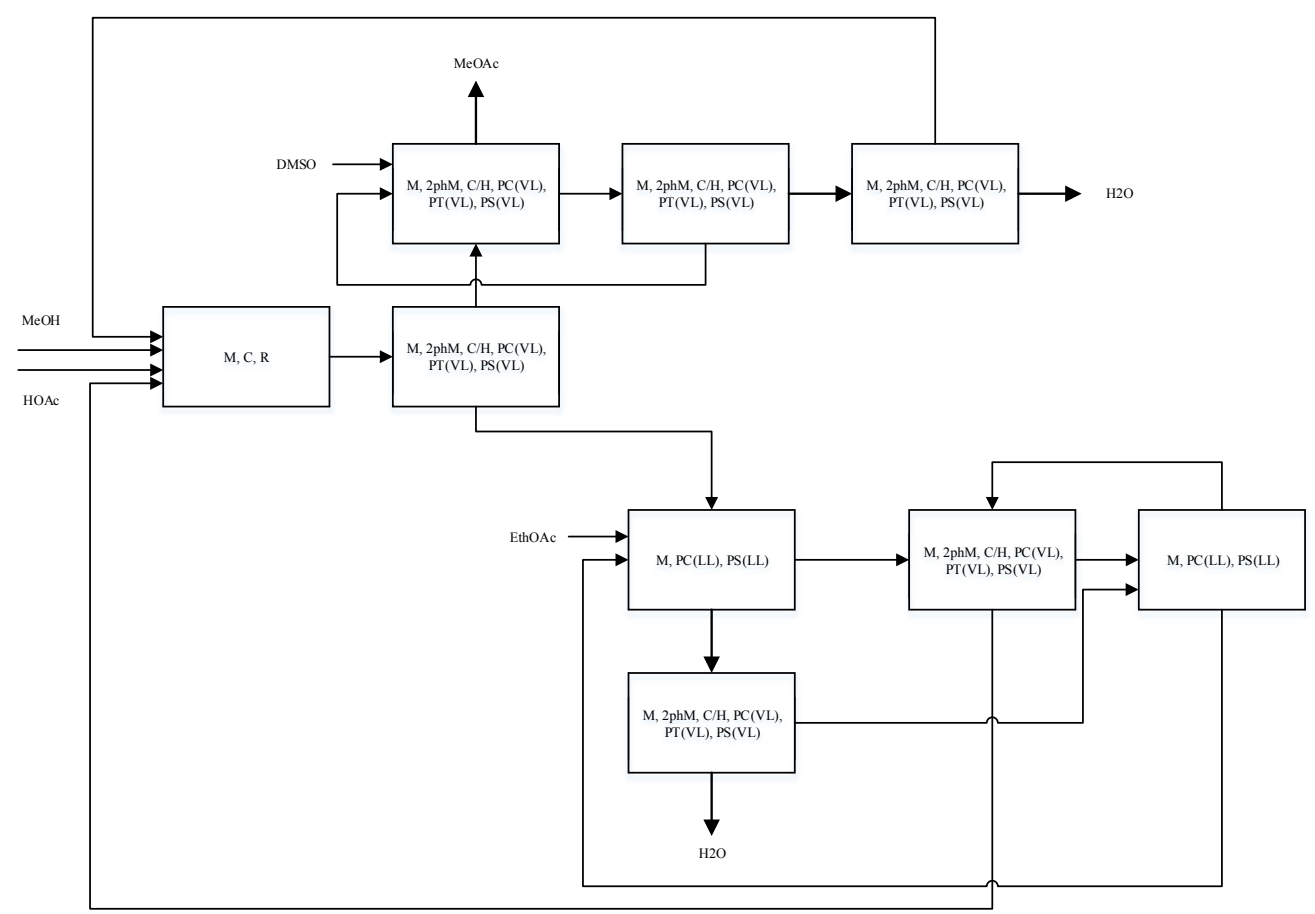

Figure 6-4: Phenomena based flowsheet of the base case design

Action 3: The binary ratio matrix (highlighted results) and the azeotrope analysis are presented in Table 6-5 and Figure 6-5.

Table 6-5: Binary ratio matrix for a selected set of properties. MW- molecular weight, $\mathrm{Tb}$ - normal boiling point, RG- radius of gyration, Tm- normal melting point, VM- molar volume, SolPar- solubility parameter, VDW- Van der Waals volume, VP- vapor pressure

\begin{tabular}{|l|l|l|l|l|l|l|l|l|}
\hline rij & Mw & Tm & Tb & RG & SolPar & VdW & VM & VP \\
\hline $\mathrm{MeOH} / \mathrm{HOAc}$ & 1.87 & 1.65 & 1.16 & 1.68 & 1.56 & 1.53 & 1.42 & 8.1 \\
\hline $\mathrm{MeOH} / \mathrm{MeOAc}$ & 2.31 & 1 & 1.02 & 1.93 & 1.53 & 1.96 & 1.97 & 1.7 \\
\hline $\mathrm{MeOH} / \mathrm{H} 2 \mathrm{O}$ & 1.78 & 1.56 & 1.1 & 2.52 & 1.62 & 1.76 & 2.25 & 5.31 \\
\hline $\mathrm{HOAc} / \mathrm{MeOAc}$ & 1.23 & 1.65 & 1.18 & 1.15 & 1.02 & 1.28 & 1.39 & 13.76 \\
\hline $\mathrm{HOAc} / \mathrm{H} 2 \mathrm{O}$ & 3.33 & 1.06 & 1.05 & 4.24 & 2.52 & 2.69 & 3.19 & 1.52 \\
\hline $\mathrm{MeOAc} / \mathrm{H} 2 \mathrm{O}$ & 4.11 & 1.56 & 1.13 & 4.87 & 2.47 & 3.44 & 4.42 & 9.02 \\
\hline
\end{tabular}




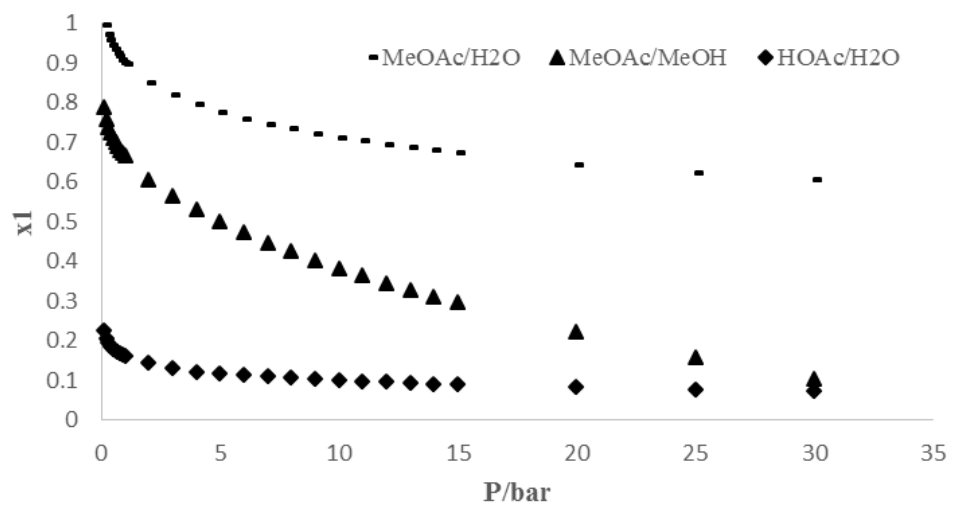

Figure 6-5: Pressure dependence analysis of the 3 minimum boiling azeotropes

From Figure 6-5 3 minimum boiling binary azeotropes are found: $\mathrm{HOAc} / \mathrm{H} 2 \mathrm{O}$, $\mathrm{MeOH} / \mathrm{MeOAc}$ and $\mathrm{MeOAc} / \mathrm{H} 2 \mathrm{O}$. This is hinted from the binary ratio matrix looking at the ratio of the boiling points for each pair. The azeotropes are further analyzed for pressure dependence as this information may be useful for the flowsheet generation using the integrated task-phenomena based approach in IT-PBS.33. It can be seen that all the azeotropes are pressure dependent with the $\mathrm{MeOAc} / \mathrm{MeOH}$ and $\mathrm{HOAc} / \mathrm{H} 2 \mathrm{O}$ being the most and least dependent, respectively. At low pressures $\mathrm{MeOAc} / \mathrm{H} 2 \mathrm{O}$ azeotrope disappears whereas the $\mathrm{MeOAc} / \mathrm{MeOH}$ azeotrope reaches a purity of $\mathrm{MeOAc}$ of approximately $80 \mathrm{~mol} \%$.

\subsubsection{IT-PBS.2-Identification of Desirable Tasks and Phenomena}

Action 1: The additional PBBs selected are PT(PVL), PT(VV), and PS(VV). Therefore the total list of PBBs are: R, M, 2phM, C, H, PT(VL), PT(PVL), PT(VV), PC(VL), PC(LL), PS(VL), PS(LL), PS(VV), D

Action 2: The remaining PBBs from applying the constraints defined in step 2 are R, M (assuming four types: ideal liquid, flow, rectangular, ideal vapor), 2phM, C, H, PT(VL), PT(PVL), PT(VV), PC(VL), PS(VL), PS(VV), D

Action 3: The operating window for each PBB is given in Table 6-6. 
Table 6-6: Operating window of the identified PBBs in the base case design. All concentrations are below the dew point line and above the bubble point line.

\begin{tabular}{|c|c|}
\hline Phenomena & Operating Window \\
\hline \multirow[b]{2}{*}{$\mathrm{R}$} & $\mathrm{T}_{\text {low }}=175.15 \mathrm{~K}$ (Lowest Melter) \\
\hline & $\begin{array}{c}\mathrm{T}_{\text {high }}=378.15 \mathrm{~K} \text { (Maximum T for reactor } \\
\text { operation) }\end{array}$ \\
\hline \multirow{2}{*}{$\mathrm{MV}_{\mathrm{V}}$} & $\mathrm{T}_{\text {low }}=330.05 \mathrm{~K}$ (Lowest boiler) \\
\hline & $\mathrm{T}_{\text {high }}=391.05 \mathrm{~K}$ (Highest Boiler) \\
\hline \multirow{2}{*}{$M_{l d}$} & $\mathrm{~T}_{\mathrm{low}}=175.55 \mathrm{~K}$ (Lowest Melter) \\
\hline & $\mathrm{T}_{\text {high }}=391.05 \mathrm{~K}$ (Highest Boiler) \\
\hline $\mathrm{M}_{\mathrm{V}}, 2 \mathrm{phM}$ & $\mathrm{T}_{\text {low }}=326.41 \mathrm{~K}$ (Lowest boiling azeotrope) \\
\hline $\mathrm{PC}(\mathrm{VL})$ & V-L present \\
\hline \multirow{2}{*}{ PT(VL) } & $\mathrm{T}_{\mathrm{low}}=326.41 \mathrm{~K}$ (Lowest boiling azeotrope) \\
\hline & $\mathrm{T}_{\text {high }}=391.05 \mathrm{~K}$ (Highest Boiler) \\
\hline PS(VL) & V-L present \\
\hline $\mathrm{PT}(\mathrm{PVL})$ & Component affinity - \\
\hline PT(VV) & Component affinity \\
\hline PS(VV) & $\begin{array}{l}\mathrm{V}-\mathrm{V} \text { present (all compounds in the va- } \\
\text { pour phase) }\end{array}$ \\
\hline $\mathrm{H}$ & - \\
\hline $\mathrm{C}$ & - \\
\hline $\mathrm{D}$ & - \\
\hline
\end{tabular}

\subsubsection{IT-PBS.3-Generation of Feasible Flowsheet Alternatives}

Action 1: The maximum number of phenomena that can be combined to form an SPB, $\mathrm{n}_{\text {PBB,Max }}$, is calculated to be 11 (Equation 4.22). The total number of SPBs that can be generated, having a maximum of 11 SPBs is 16278 (Equation 4.23). A list of feasible SPBs is presented in Table 6-7 assuming three types of mixing for each SPB in the liquid phase that is ideal liquid, flow and rectangular. 
Table 6-7: Partial list of feasible SPBs. Mix.-mixing, Cool.-cooling, Heat.-heating, React.-reaction, Sep.-Separation, Ph. Cr.-phase creation, Div.-dividing

\begin{tabular}{|c|c|c|c|c|}
\hline SPB & Connected PBB & In & Out & $\begin{array}{l}\text { Task they } \\
\text { may per- } \\
\text { form }\end{array}$ \\
\hline SPB.1 & $\mathrm{M}$ & 1..n $(\mathrm{L}, \mathrm{VL}, \mathrm{V})$ & $1(\mathrm{~L}, \mathrm{VL}, \mathrm{V})$ & Mix. \\
\hline SPB.2 & $\mathrm{M}=2 \mathrm{phM}$ & 1..n $(\mathrm{L}, \mathrm{VL}, \mathrm{V})$ & $1(\mathrm{~L}, \mathrm{VL}, \mathrm{V})$ & Mix. \\
\hline SPB.3 & $\mathrm{M}=\mathrm{R}$ & 1..n $(\mathrm{L}, \mathrm{VL}, \mathrm{V})$ & 1(L,VL,V) & Mix.+React. \\
\hline SPB.4 & $\mathrm{M}=\mathrm{H}$ & $1 . \mathrm{n}(\mathrm{L}, \mathrm{VL}, \mathrm{V})$ & 1(L,VL,V) & Mix.+Heat. \\
\hline SPB.5 & $\mathrm{M}=\mathrm{C}$ & 1..n $(\mathrm{L}, \mathrm{VL}, \mathrm{V})$ & $1(\mathrm{~L}, \mathrm{VL}, \mathrm{V})$ & Mix.+Cool. \\
\hline SPB.6 & $\mathrm{M}=\mathrm{R}=\mathrm{H}$ & 1..n $(\mathrm{L}, \mathrm{VL}, \mathrm{V})$ & $1(\mathrm{~L}, \mathrm{VL}, \mathrm{V})$ & React.+Heat. \\
\hline SPB.7 & $\mathrm{M}=\mathrm{R}=\mathrm{C}$ & 1..n $(\mathrm{L}, \mathrm{VL}, \mathrm{V})$ & $1(\mathrm{~L}, \mathrm{VL}, \mathrm{V})$ & React.+Cool. \\
\hline SPB.8 & $\mathrm{M}=\mathrm{R}=\mathrm{H}=\mathrm{PC}(\mathrm{VL})=\mathrm{PT}(\mathrm{VL})$ & 1..n $(\mathrm{L}, \mathrm{VL}, \mathrm{V})$ & $1(\mathrm{~L}, \mathrm{VL}, \mathrm{V})$ & React.+Heat. \\
\hline SPB.9 & $\mathrm{M}=\mathrm{R}=\mathrm{C}=\mathrm{PC}(\mathrm{VL})=\mathrm{PT}(\mathrm{VL})$ & 1..n $(\mathrm{L}, \mathrm{VL}, \mathrm{V})$ & $1(\mathrm{~L}, \mathrm{VL}, \mathrm{V})$ & React. + Cool. \\
\hline SPB.10 & $\mathrm{M}=\mathrm{R}=2 \mathrm{phM}=\mathrm{PC}(\mathrm{VL})=\mathrm{PT}(\mathrm{VL})$ & $1 . . \mathrm{n}(\mathrm{L}, \mathrm{VL})$ & $2(\mathrm{~V} / \mathrm{L})$ & React.+Sep. \\
\hline SPB.11 & $\mathrm{M}=\mathrm{R}=2 \mathrm{phM}=\mathrm{PC}(\mathrm{VL})=\mathrm{PT}(\mathrm{VL})=\mathrm{PS}(\mathrm{VL})$ & 1..n(L,VL) & $2(\mathrm{~V} ; \mathrm{L})$ & React. + Sep. \\
\hline SPB.12 & $\mathrm{M}=\mathrm{R}=2 \mathrm{phM}=\mathrm{PC}(\mathrm{VL})=\mathrm{PT}(\mathrm{PVL})=\mathrm{PS}(\mathrm{VL})$ & 1..n(L,VL) & $2(\mathrm{~V} ; \mathrm{L})$ & React.+Sep. \\
\hline SPB.13 & $\mathrm{M}=\mathrm{R}=\mathrm{H}=2 \mathrm{phM}=\mathrm{PC}(\mathrm{VL})=\mathrm{PT}(\mathrm{PVL})=\mathrm{PS}(\mathrm{VL})$ & 1..n(L,VL) & $2(\mathrm{~V} ; \mathrm{L})$ & React.+Sep. \\
\hline SPB.14 & $\mathrm{M}=\mathrm{R}=\mathrm{C}=2 \mathrm{phM}=\mathrm{PC}(\mathrm{VL})=\mathrm{PT}(\mathrm{PVL})=\mathrm{PS}(\mathrm{VL})$ & $1 . . \mathrm{n}(\mathrm{L}, \mathrm{VL})$ & $2(\mathrm{~V} ; \mathrm{L})$ & React.+Sep. \\
\hline SPB.15 & $\mathrm{M}=2 \mathrm{phM}=\mathrm{PC}(\mathrm{VL})=\mathrm{PT}(\mathrm{VL})$ & $1 . . \mathrm{n}(\mathrm{L}, \mathrm{VL})$ & $2(\mathrm{~V} ; \mathrm{L})$ & Mix.+Ph. Cr. \\
\hline SPB.16 & $\mathrm{M}=2 \mathrm{phM}=\mathrm{PC}(\mathrm{VL})=\mathrm{PT}(\mathrm{VL})=\mathrm{PS}(\mathrm{VL})$ & 1..n(L,VL) & $2(\mathrm{~V} ; \mathrm{L})$ & Mix.+Sep. \\
\hline SPB.17 & $\mathrm{M}=\mathrm{C}=2 \mathrm{phM}=\mathrm{PC}(\mathrm{VL})=\mathrm{PT}(\mathrm{VL})=\mathrm{PS}(\mathrm{VL})$ & 1..n(L,VL) & $2(\mathrm{~V} ; \mathrm{L})$ & Cool.+Sep. \\
\hline SPB.18 & $\mathrm{M}=\mathrm{H}=2 \mathrm{phM}=\mathrm{PC}(\mathrm{VL})=\mathrm{PT}(\mathrm{VL})=\mathrm{PS}(\mathrm{VL})$ & $1 . . \mathrm{n}(\mathrm{VL})$ & $2(\mathrm{~V} ; \mathrm{L})$ & Heat.+Sep. \\
\hline SPB.19 & $\mathrm{M}=2 \mathrm{phM}=\mathrm{PC}(\mathrm{VL})=\mathrm{PT}(\mathrm{PVL})=\mathrm{PS}(\mathrm{VL})$ & $1 . . \mathrm{n}(\mathrm{VL})$ & $2(\mathrm{~V} ; \mathrm{L})$ & Mix.+Sep. \\
\hline SPB.20 & $\mathrm{M}=2 \mathrm{phM}=\mathrm{PC}(\mathrm{VL})=\mathrm{PT}(\mathrm{VV})=\mathrm{PS}(\mathrm{VV})$ & 1..n $(\mathrm{L}, \mathrm{VL}, \mathrm{V})$ & $2(\mathrm{~V} ; \mathrm{V})$ & Mix.+Sep. \\
\hline SPB.21 & $\mathrm{M}=2 \mathrm{phM}=\mathrm{PT}(\mathrm{VV})=\mathrm{PS}(\mathrm{VV})$ & $1 . . \mathrm{n}(\mathrm{V})$ & $2(\mathrm{~V} ; \mathrm{V})$ & Mix.+Sep. \\
\hline SPB... & $\ldots$ & $\ldots$ & $\ldots$ & \\
\hline SPB.64 & $\mathrm{D}$ & $1(\mathrm{~L} ; \mathrm{VL}, \mathrm{V})$ & $\begin{array}{l}1 . \mathrm{n}(\mathrm{L} ; \mathrm{V} ; \\
\mathrm{VL})\end{array}$ & Stream Div. \\
\hline
\end{tabular}


Action 2: The generated task based superstructure is shown in Figure 6-6. A brief explanation of the task based superstructure is as follows: Raw materials HOAc (A) and $\mathrm{MeOH}(\mathrm{B})$ react to produce product $\mathrm{MeOAc}$ (C) and by-product $\mathrm{H} 2 \mathrm{O}$ (D). In principle all SPBs which contain PBBs having PC, PT or PS or a combination of these are able to perform a separation task. A processing path within the superstructure is obtained as follows. Consider S-Task 1, the separation of $\mathrm{AB}$ from $\mathrm{CD}$ (highlighted blue); Followed by S-Task 2 that separates A from B that is $A(B)$ and S-Task 3 that separates C from D that is $C(D)$.

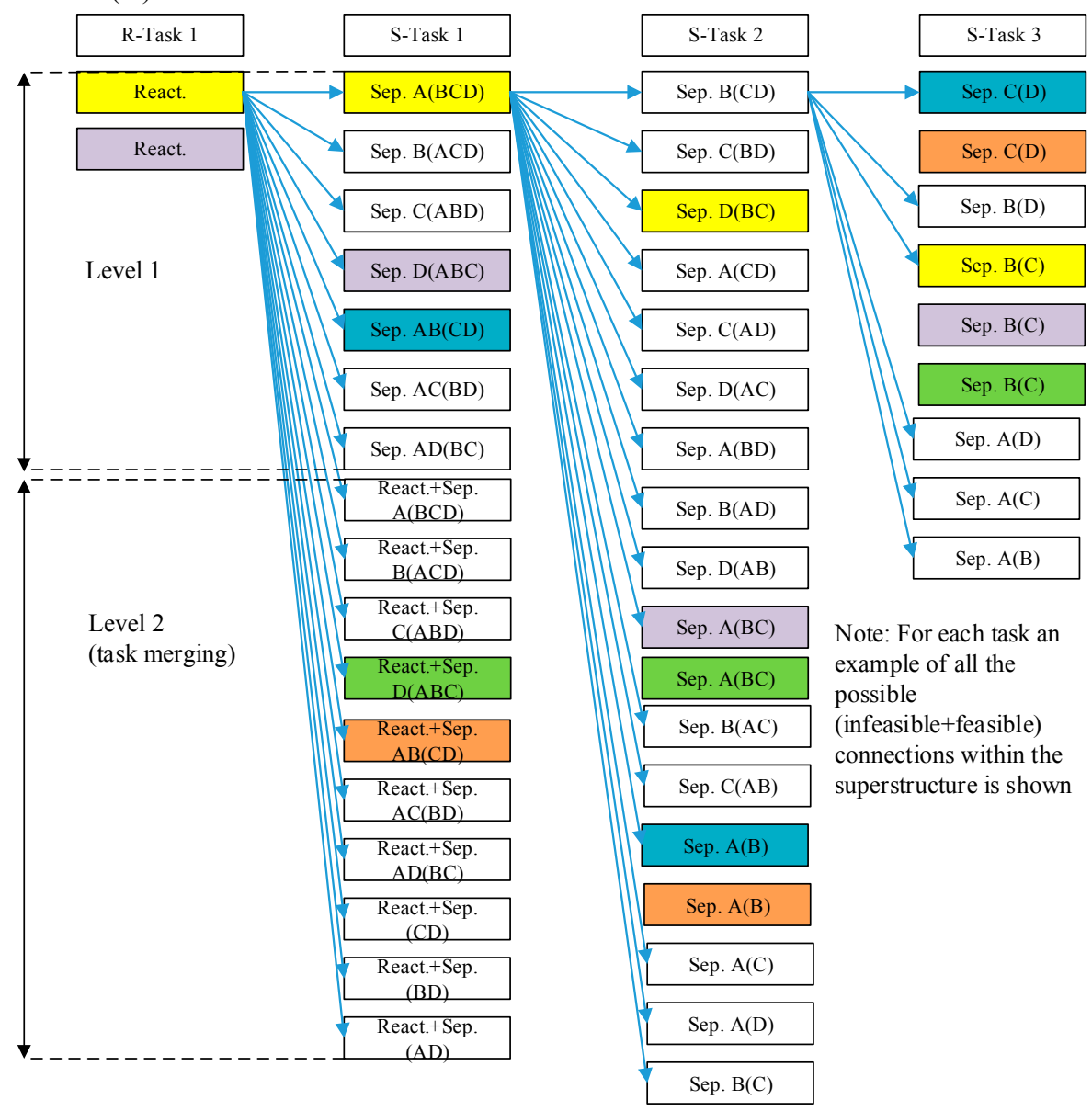

Figure 6-6: Task-based superstructure for the production of MeOAc. Task-based superstructure including task-merging. Explanation of the superstructure (highlighted blue), Flowsheet alternatives 1-2 (highlighted in yellow), Flowsheet alternatives 3-4 (highlighted in green) and Flowsheet alternatives 6-9 (highlighted in orange). A-HOAc, B$\mathrm{MeOH}, \mathrm{C}-\mathrm{MeOAc}, \mathrm{D}-\mathrm{H} 2 \mathrm{O}$

Action 4: Table 6-8 gives the identified basic structures that perform reaction and separation tasks. 
Table 6-8: Identified basic structures that perform single or multiple tasks for conversion of HOAc and $\mathrm{MeOH}$ to $\mathrm{MeOAc}$ and $\mathrm{H} 2 \mathrm{O}$. Note each binary pair that represent the inlet to a task represent the two key compounds under consideration

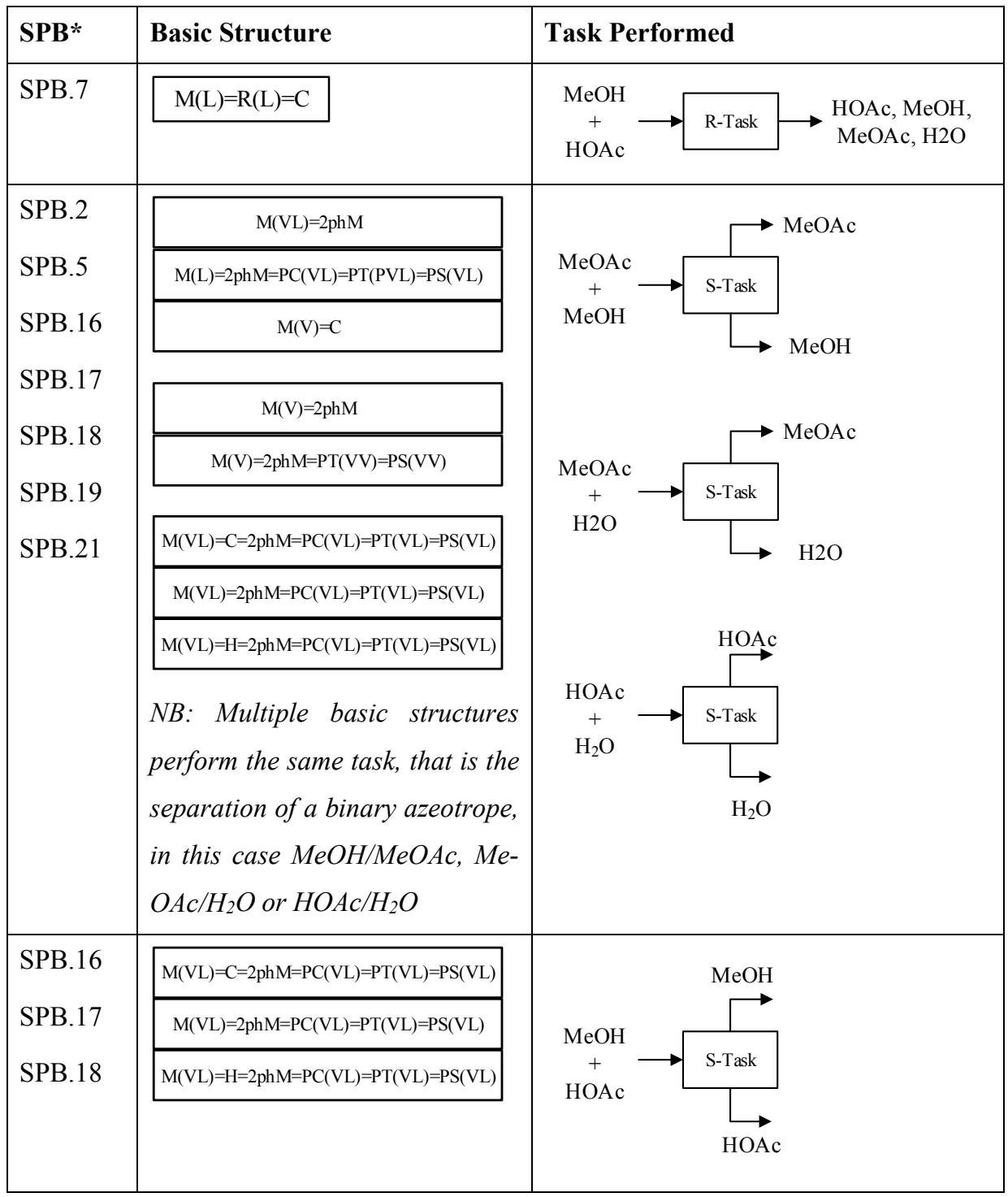

Note: *The SPB number corresponds to the SPB given in Table 6-7. For combined basic structures, only the SPBs present in the combined basic structure are presented

Action 5: The identified task based flowsheets highlighted in level 1 and level 2 of the task based superstructure shown in Figure 6-6 is explained as follows: Level 1Flowsheet alternative 1-2, highlighted yellow and purple in Figure 6-6: 
- Flowsheet alternative 1: A reactor feed (as in the base case) of a 2:1 mole ratio of $\mathrm{MeOH}$ to HOAc is used. It is generated as follows. The reaction is a reversible liquid phase reaction, therefore, the reactor outlet contains a mixture of raw materials and products. A basic structure containing a $\mathrm{R}(\mathrm{L}) \mathrm{PBB}$ is selected to perform the reaction task.

Based on the mixture analysis, 3 minimum boiling, pressure dependent azeotropes are present. From the basic structures identified in Table 6-8, a basic structure containing a PT(VL) PBB is selected to separate $\mathrm{MeOH}$ and $\mathrm{MeOAc}$ from HOAc. Note that since $\mathrm{HOAc}$ and $\mathrm{H} 2 \mathrm{O}$ also forms an azeotrope, $\mathrm{H} 2 \mathrm{O}$ will be present in the two output streams of this S-Task.

The stream from S-Task 1, contains $\mathrm{MeOH}, \mathrm{MeOAc}$ and $\mathrm{H} 2 \mathrm{O}$. Two azeotropes are present, $\mathrm{MeOH} / \mathrm{MeOAc}$ and $\mathrm{MeOAc} / \mathrm{H} 2 \mathrm{O}$. From the basic structures identified in Table 6-8, 3 basic structures are feasible to perform the task of separation of a binary azeotrope. Therefore a basic structure containing a PT(VV) PBB is selected to break the $\mathrm{MeOAc} / \mathrm{H} 2 \mathrm{O}$ azeotrope.

The stream from S-Task 2, contains $\mathrm{MeOH}$ and $\mathrm{MeOAc}$ and 1 azeotrope is present, $\mathrm{MeOH} / \mathrm{MeOAc}$. From the basic structures identified in Table 6-8 a basic structure containing a PT(VL) PBB is selected to break the $\mathrm{MeOH} / \mathrm{MeOAc}$ azeotrope. Note, the same basic structure is applied for the HOAc/H2O azeotrope. At this point all recovered unreacted raw materials are recycled, thereby, closing the task based flowsheet.

- Flowsheet alternative 2: Is similar to flowsheet alternative 1 however S-Task 1 is now the separation of $\mathrm{H} 2 \mathrm{O}$ from a multicomponent mixture with $\mathrm{HOAc}, \mathrm{MeOH}$ and $\mathrm{MeOAc}$ after the reactor. This is beneficial because of the 3 identified minimum boiling azeotropes, H2O is present in two of them. Therefore the separation sequence of tasks afterwards simplifies because no azeotropes exist between the pairs $\mathrm{HOAc} / \mathrm{MeOH}$ and $\mathrm{HOAc} / \mathrm{MeOAc}$.

- Flowsheet alternative 5-Not shown due to confidential agreements

Level 2: Flowsheet alternatives 3-9, highlighted green in Figure 6-6: 
- Flowsheet alternative 3-In level 2 the merging of tasks is considered which is feasible because PBBs can be combined that perform reaction and separation together. The concept of merging tasks also reduces the overall number of tasks that must be performed in meeting a desired design target. Therefore, the merging of the R-Task and S-Task 1 (where $\mathrm{H} 2 \mathrm{O}$ is removed) is considered. A reactor feed (as in the base case) of a 2:1 mole ratio of $\mathrm{MeOH}$ to HOAc is used. Therefore the basic structures can be combined in order to perform the R-Task and S-Task together, based on the system properties: (1) esterification reaction, (2) azeotropes are present and (3) $\mathrm{H} 2 \mathrm{O}$ is a by-product. This is given in Table 6-9.

- Flowsheet alternative 4-Is similar to flowsheet alternative 3 however a reactor feed 1:1 mole ratio of $\mathrm{MeOH}$ to $\mathrm{HOAc}$ is used. Therefore there is no need for $\mathrm{MeOH}$ to be fed in excess because the PT(PVL) PBB in the combined reaction and separation basic structure (see Table 6-9) allows in situ removal of $\mathrm{H} 2 \mathrm{O}$, thereby, improving the equilibrium of the reaction.

Table 6-9: Identified basic structures for flowsheet alternatives 3-4. Note each binary pair that represent the inlet to a task represent the two key compounds under consideration

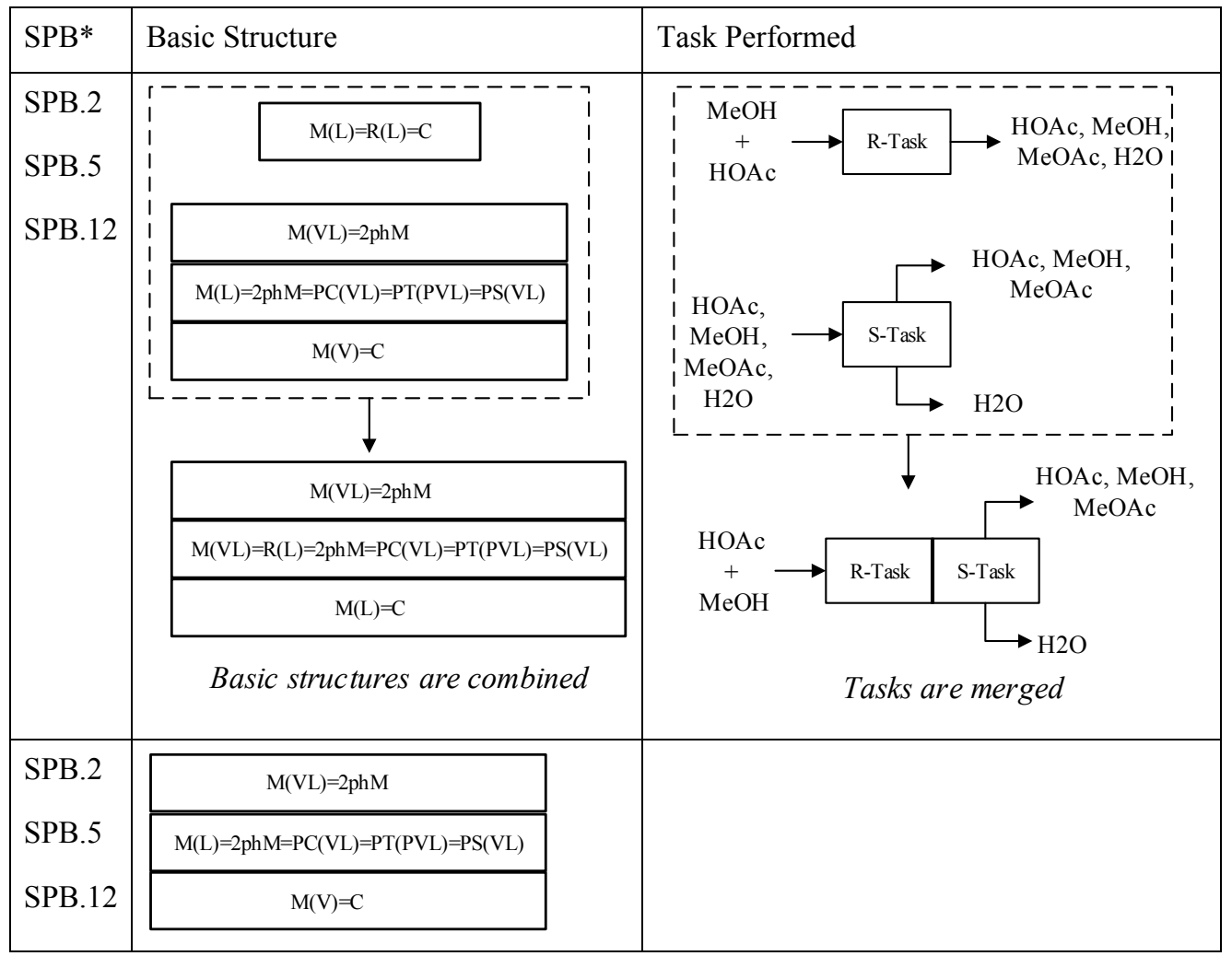




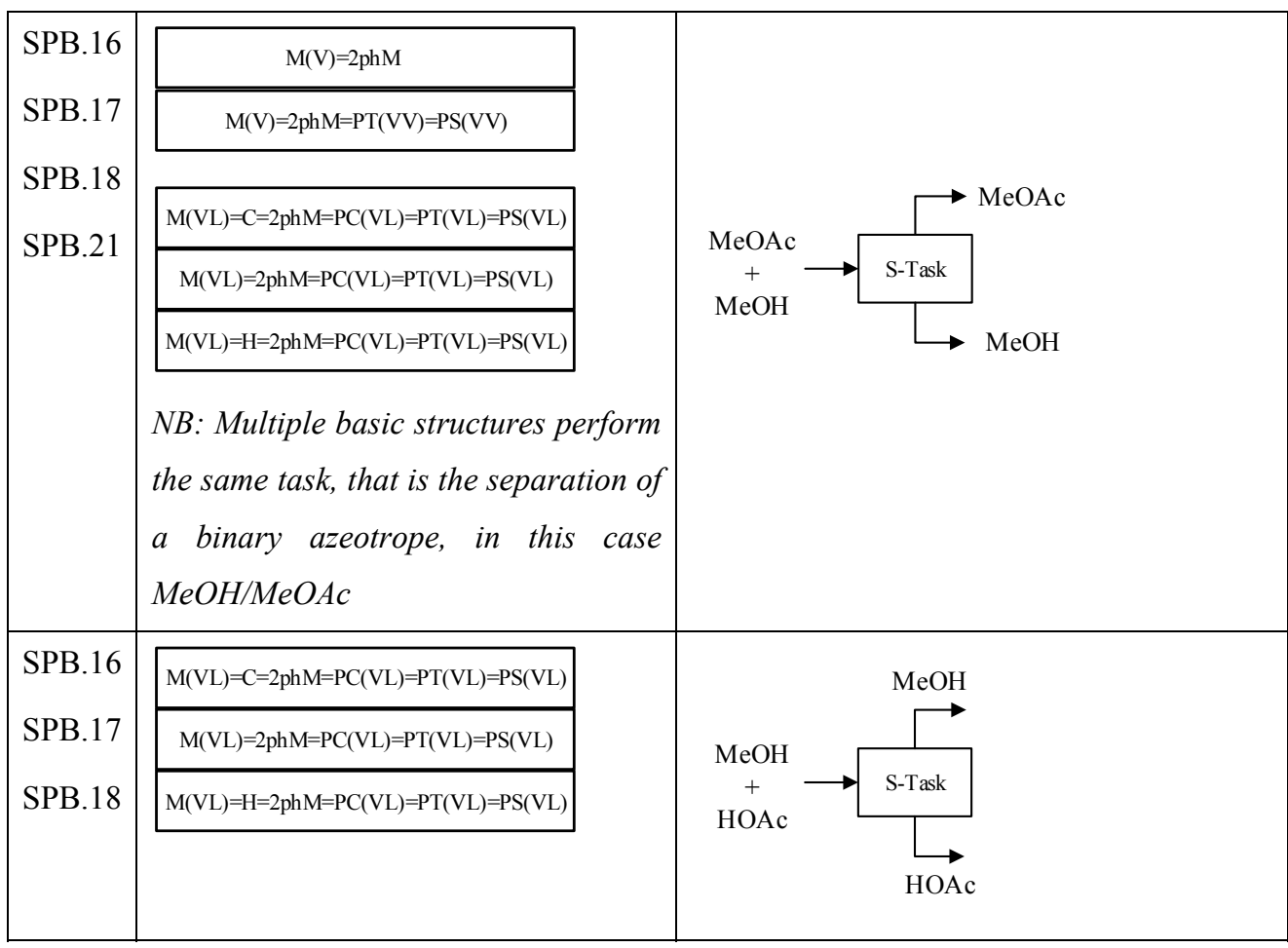

Note: *The SPB number corresponds to the SPB given in Table 6-7. For combined basic structures, only the SPBs present in the combined basic structure are presented 
- Flowsheet alternatives 6-9-The merging of R-Task, S-Task 1, S-Task 2 and $\mathrm{S}$-Task 3 is considered. This is possible based on the system properties previously mentioned with the addition of one more system property, that is the reaction occurs in the liquid phase. Therefore the basic structures can be combined in order to perform the $\mathrm{R}=\mathrm{S}$ Task together and this is given in Table 6-10. Different configurations of such a structure exist that is only reaction, reaction- separation with single or double inlet feed.

Table 6-10: Identified basic structures for flowsheet alternatives 6-9

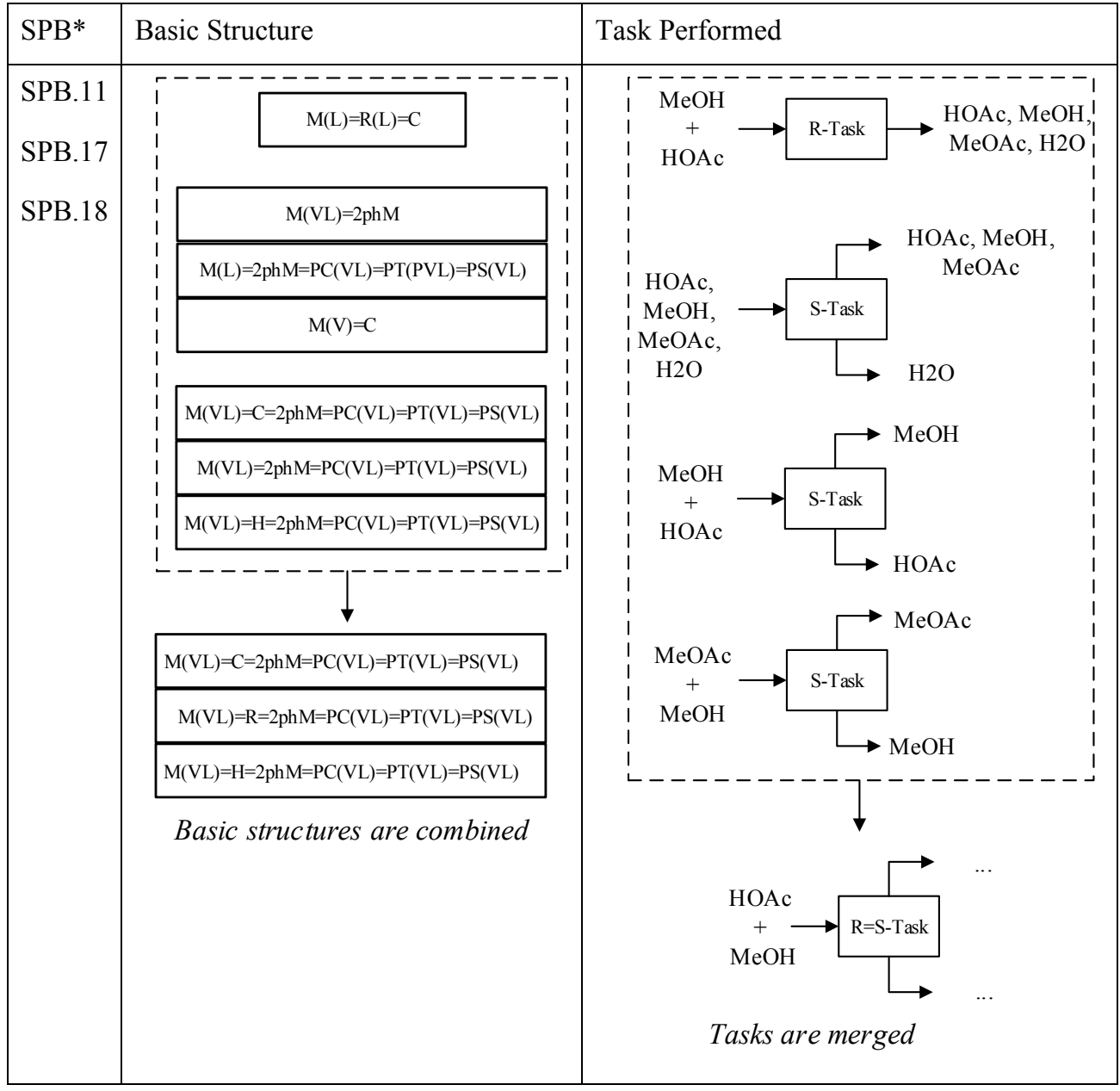

Action 6: The basic structures that perform the different identified tasks are translated into unit operations. The final flowsheet alternatives are shown in Figure 6-7. 


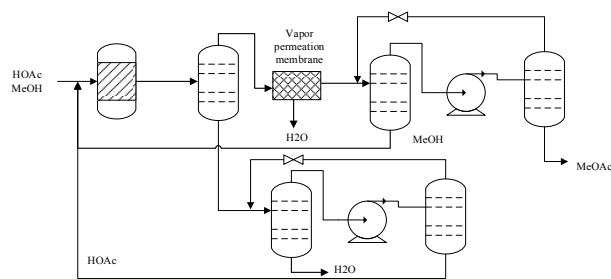

Figure 6-7 (a)

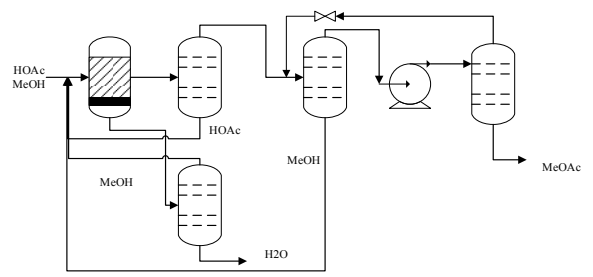

Figure 6-7 (c)

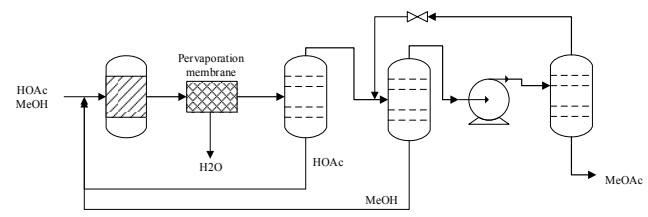

Figure 6-7 (b)

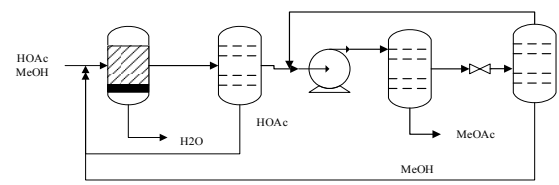

Figure 6-7 (d)

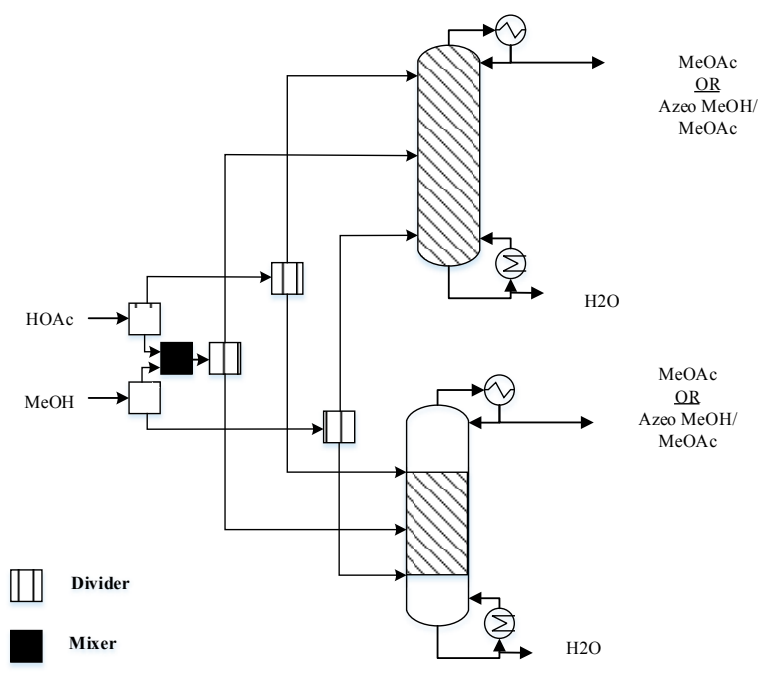

Figure 6-7 (e)

Figure 6-7: The generated flowsheet alternatives for the production of MeOAc

Action 7: The flowsheet alternatives are analyzed and screened in order to select the feasible alternatives for IT-PBS.4.

1. The flowsheet alternatives are analyzed using the following models while maintaining the following logical $\left(\theta_{1}\right)$ and operational constraints $\left(\theta_{3}\right)$ defined in step 2, $\underline{\theta_{1}}$-The product purity of MeOAc is defined is $\geq 99 \mathrm{~mol} \%, \underline{\theta_{3}}$-The equi- 
librium conversion is defined as $71.4 \%$ (is to be increased), $\underline{\theta_{3}}$-Production target of MeOAc is set at $17009 \mathrm{~kg} / \mathrm{hr}$ :

- Flowsheet alternatives 1-5-For the flowsheet alternatives containing a membrane reactor, a semi-batch membrane reactor model with in situ removal of a compound was investigated, in order to, test the feasibility of the membrane reactor (Inoue et al., 2007). The membrane chosen is a PVA membrane produced by Sulzer Chemtech, PERVAP 2201 (Assabumrungrat et al., 2003, Van Baelen et al., 2005). The semi-batch model was analyzed and solved using ICAS-MoT (Gani et al., 1997) in order to study the feasibility of achieving a HOAc conversion greater than the equilibrium conversion. From the model based membrane reactor analysis it was found that a conversion of HOAc of $92 \%$ can be achieved. The calculation details are given in appendix F.Van Baelen et al. (2005) has studied the effect of PERVAP 2201 for $\mathrm{MeOH} / \mathrm{H} 2 \mathrm{O}$ mixtures. According to the weight $\%$ of $\mathrm{H} 2 \mathrm{O}$ in the feed to the membrane, both $\mathrm{MeOH}$ and $\mathrm{H} 2 \mathrm{O}$ can permeate through the membrane or $\mathrm{H} 2 \mathrm{O}$ alone (see appen$\operatorname{dix} \mathrm{F}$ ).

- Flowsheet alternatives 6-9-Reactive distillation (RD) model. The reactive VLE phase diagram (Figure 6-8) and residue curve map (RCM) (Figure 6-9) are generated using the element-based method of Daza et al. (2004). The 4-compound system for the production of MeOAc is represented by three elements (see appendix F). From Figure 6-9, the RCM shows that if reaction-separation are performed simultaneously, the $\mathrm{MeOH} / \mathrm{MeOAc}$ azeotrope is obtained as a top product and $\mathrm{HOAc} / \mathrm{H} 2 \mathrm{O}$ as the bottom product. To investigate the feasibility of the $\mathrm{RD}$ alternatives, the $\mathrm{RD}$ flowsheet alternatives were rigorously simulated. It is found that for RD columns with single feed, the $\mathrm{MeOH} / \mathrm{MeOAc}$ azeotrope is obtained at the top of the column and, at the bottom of the column, a mixture of $\mathrm{H} 2 \mathrm{O}$ and HOAc is obtained (Huss et al., 2003). This can be seen from the RCM in Figure 6-9. The starting point of the residue curves are from the $\mathrm{MeOH} / \mathrm{MeOAc}$ azeotrope. However, for the RD columns with double feed, H2O (almost pure) is obtained at the bottom of the column and $\mathrm{MeOAc}$ at the top of the column. Furthermore, it can be said that the double feed RD column with both reactive and non-reactive sections is preferred to a column with only reactive sections due to the difference in catalyst cost, assuming that the column specifications are the same. 


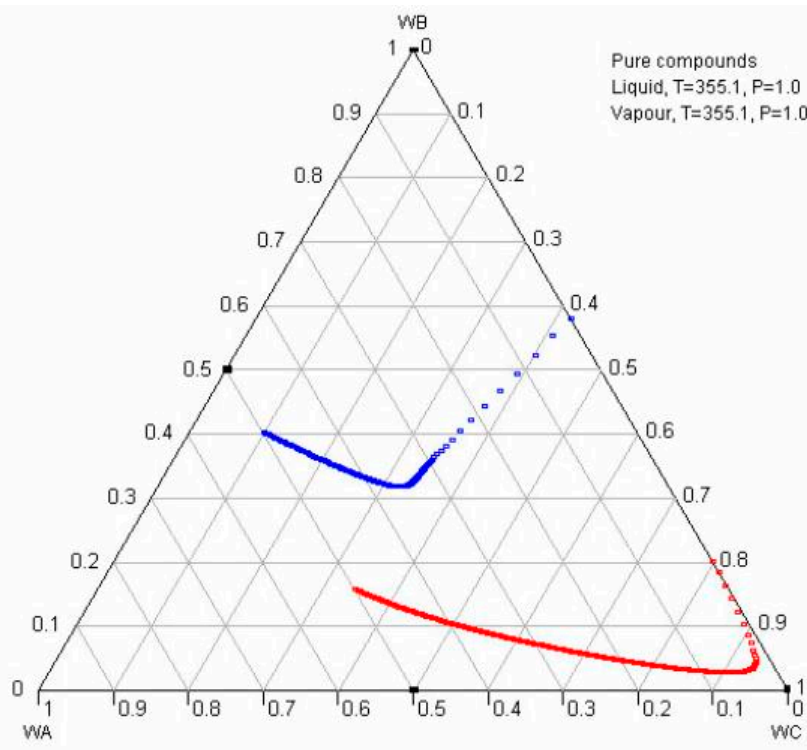

Figure 6-8: Reactive VLE phase diagram for the methyl acetate system represented by 3 elements

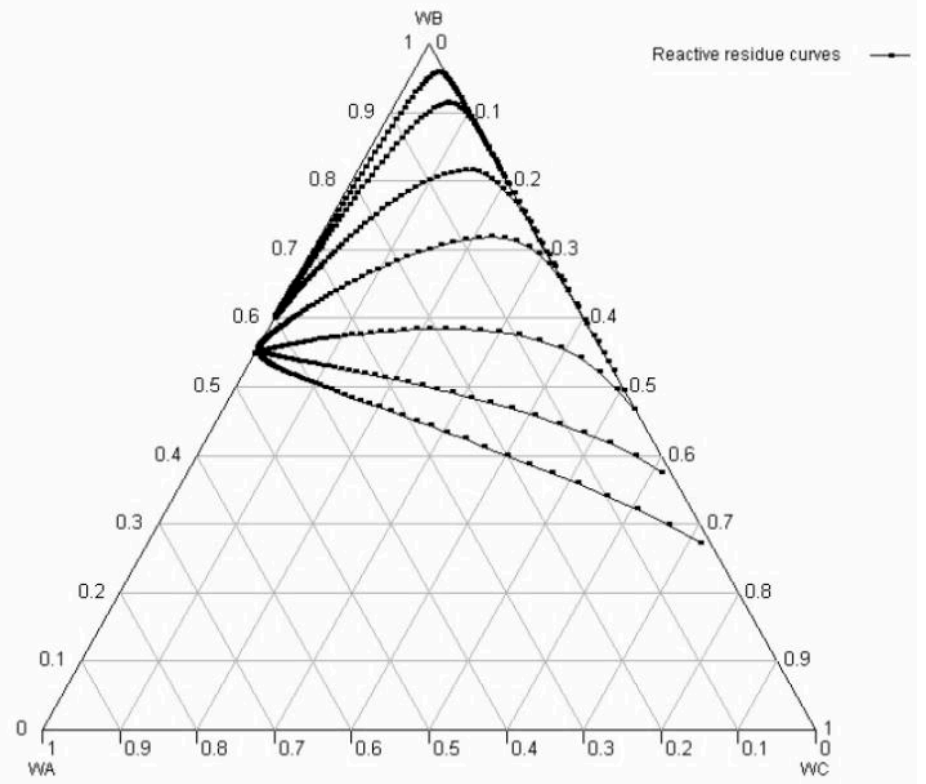

Figure 6-9: Reactive residue curves for the methyl acetate system represented by 3 elements 
2. Explained in point 1

3. The screening of the flowsheet alternatives is given in Figure 6-10.

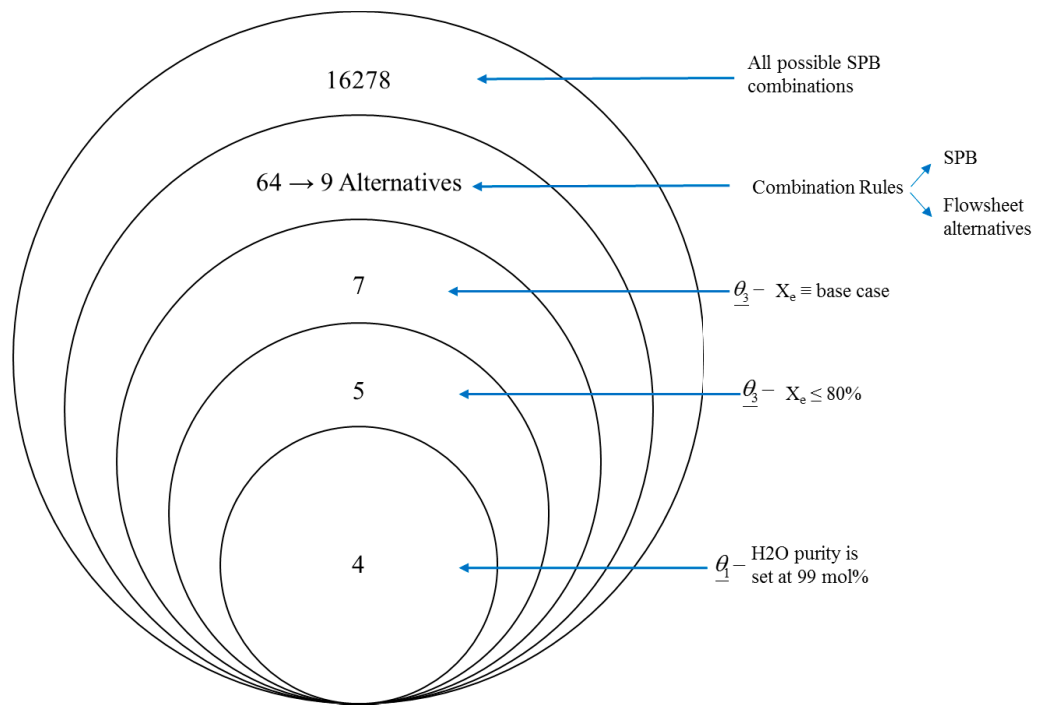

Figure 6-10: Screening of the SPBs and generated flowsheet alternatives

The four feasible flowsheet alternatives selected for further analysis in IT-PBS 4 are flowsheet alternative 3 (see Figure 6-7(c)), flowsheet alternative 4 (see Figure 6-7(d)), flowsheet alternative 5 (not shown) and flowsheet alternative 9 (see Figure 6-7, double feed $\mathrm{RD}$ column with both reactive and non-reactive stages). 


\subsubsection{IT-PBS.4-Comparision and Selection of the Best Flow- sheet Alternatives}

The results of the economic, sustainability and LCA analysis for the 4 more sustainable designs are given in Table 6-11. The prices used for different utilities are: cooling water at $0.35 \$ / G J$, LP Steam at $7.78 \$ / G J$ and electricity at $16.80 \$ / G J$ (Peters, Timmerhaus, West, 2003).

Table 6-11: Economic, sustainability and LCA analysis for the 4 feasible flowsheet alternatives generated for the production of MeOAc

\begin{tabular}{|c|c|c|c|c|c|c|}
\hline \multirow{8}{*}{ 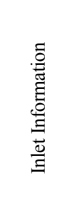 } & \begin{tabular}{|r|} 
Measures of Comparison (units) \\
\end{tabular} & Base Case & Alternative 3 & Alternative 4 & Alternative 5 & Alternative 9 \\
\hline & Feed mole Ratio (MeOH:HOAc) & 2 to 1 & 2 to 1 & 2 to 1 & 1 to 1 & 1 to 1 \\
\hline & Mole Feed to reactor $(\mathrm{kmol} / \mathrm{hr})$ & $560: 280$ & $499.13: 249.57$ & $499.13: 249.57$ & $249.57: 249.57$ & $230.15: 230.15$ \\
\hline & Mole Feed Make-up (kmol/hr) & $234.81: 229.66$ & $229.64: 229.6$ & $229.62: 229.64$ & $229.72: 229.61$ & \\
\hline & HOAc conversion & $\begin{array}{r}0.82 \\
\end{array}$ & 0.92 & 0.92 & $\begin{array}{r}0.92 \\
\end{array}$ & 0.98 \\
\hline & Input-MeOH (kg/h) & 7,524 & 7,358 & 7,357 & 7,361 & 7,379 \\
\hline & Input-HOAc (kg/h) & 13,792 & 13,788 & 13,790 & 13,789 & 13,829 \\
\hline & Input-Total $(\mathrm{kg} / \mathrm{h})$ & 21,315 & 21,146 & 21,148 & 21,150 & 21,208 \\
\hline \multirow{7}{*}{ 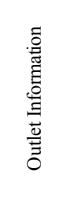 } & MeOAc product $(\mathrm{kg} / \mathrm{h})$ & 17,009 & 17,008 & 17,008 & 17,009 & 17,009 \\
\hline & Operating Days & 300 & 300 & 300 & 300 & 300 \\
\hline & Product purity (MeOAc, $\%)$ & 99.02 & 99.99 & 99.99 & 99.97 & 99.91 \\
\hline & By-product purity (H2O,\%) & 99.9 & 99.50 & 1.00 & 1.00 & 98.67 \\
\hline & Raw Material loss- $\mathrm{MeOH}(\mathrm{kg} / \mathrm{hr})$ & 166.78 & 0.00 & 0.54 & 3.75 & 14.77 \\
\hline & Raw Material loss-HOAc (kg/hr) & 3.72 & 0.00 & 2.19 & 0.87 & 40.79 \\
\hline & Raw Material loss-Total (kg/hr) & 170.49 & 0.00 & 2.72 & 4.62 & 55.56 \\
\hline \multirow{4}{*}{ 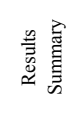 } & Energy usage (MJ/ hr) & 372,198 & 349,862 & 325,215 & 61,295 & 38,210 \\
\hline & Utility Cost (\$/year) & $12,343,384$ & $11,162,783$ & $9,866,031$ & $1,479,538$ & 959,945 \\
\hline & Raw Material Cost $(\$ / y r)$ & $107,653,098$ & $106,834,774$ & $106,842,343$ & $106,850,799$ & $107,144,908$ \\
\hline & Operating Cost (\$/year) & $119,996,482$ & $117,997,557$ & $116,708,374$ & $108,330,337$ & $108,104,853$ \\
\hline \multirow{5}{*}{ 兽兽兽 } & Raw Material usage (kg Raw Material/kg MeOAc Product) & 1.25 & 1.24 & 1.24 & 1.24 & 1.25 \\
\hline & Energy usage per kg of product (MJ/ kg of MeOAc product) & 21.88 & 20.57 & 19.12 & 3.60 & 2.25 \\
\hline & Raw Material Cost per kg of product ( $\$ / \mathrm{kg}$ of MeOAc product) & 0.88 & 0.87 & 0.87 & 0.87 & 0.87 \\
\hline & Utility Cost per $\mathrm{kg}$ of product ( $\$ / \mathrm{kg}$ of MeOAc product) & 0.10 & 0.09 & 0.08 & 0.01 & 0.01 \\
\hline & Fobj-Profit (\$/kg of MeOAc product)-max & 2.06 & 2.08 & 2.09 & 2.16 & 2.16 \\
\hline \multirow{6}{*}{ 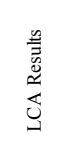 } & Total Carbon Footprint ( $\mathrm{kg} \mathrm{CO} 2 / \mathrm{kg}$ of MeOAc product) & 0.647 & 0.558 & 0.517 & 0.088 & 0.055 \\
\hline & HTPI (1/LD 50) & $9.19 \mathrm{E}-04$ & $1.36 \mathrm{E}-03$ & $2.93 \mathrm{E}-04$ & $2.92 \mathrm{E}-04$ & $7.52 \mathrm{E}-03$ \\
\hline & HTPE (1/TWA ) & $1.31 \mathrm{E}-05$ & $1.16 \mathrm{E}-05$ & $1.16 \mathrm{E}-05$ & $1.16 \mathrm{E}-05$ & $1.16 \mathrm{E}-05$ \\
\hline & GWP (CO2 eq.) & 2.060 & 1.783 & 1.741 & 1.313 & 1.284 \\
\hline & HTC (kg benzen eq) & $5.90 \mathrm{E}-05$ & $5.09 \mathrm{E}-05$ & $5.09 \mathrm{E}-05$ & $5.02 \mathrm{E}-05$ & $5.03 \mathrm{E}-05$ \\
\hline & HTNC ( $\mathrm{kg}$ toluen eq.) & $1.34 \mathrm{E}-02$ & $2.23 \mathrm{E}-02$ & $1.66 \mathrm{E}-03$ & $1.20 \mathrm{E}-03$ & $1.41 \mathrm{E}-01$ \\
\hline
\end{tabular}

The results of the objective function (Equation 6.25) is given in Table 6-11. Flowsheet alternative 5 and flowsheet alternative 9, consisting of a membrane reactor and reactive distillation column respectively, show the best values of the objective function. These two alternatives also have the lowest carbon footprint (see LCA results in Table 6-11). The interesting conclusion from Table 6-11 is that flowsheet alternative 5 is a feasible alternative compared to the well-known reactive distillation process for MeOAc production (Agreda et al., 1990). 
The results presented in Table 6-11 can be represented in terms of a radar plot where the boundary represents the base case while the feasible flowsheet alternatives (more sustainable solutions) lie inside this boundary (within the radar). Such a plot is good in providing a graphical approach to whether a tradeoff solution is achieved or whether all design targets are met. For example if any value of a variable lies outside the diagram then a tradeoff solution is obtained however if no variable lies outside the diagram then a non-tradeoff solution is obtained. For each variable plotted in this figure, the ratio (multiplied by 100) of the value of a specific variable for an alternative and the corresponding value for the base case have been used. In this way, it is possible to see that for all the considered criteria, the alternatives are better or the same (lie at the boundary). Therefore from Figure 6-11 it can be seen that for all the considered criteria, the alternatives are better than the base case design.

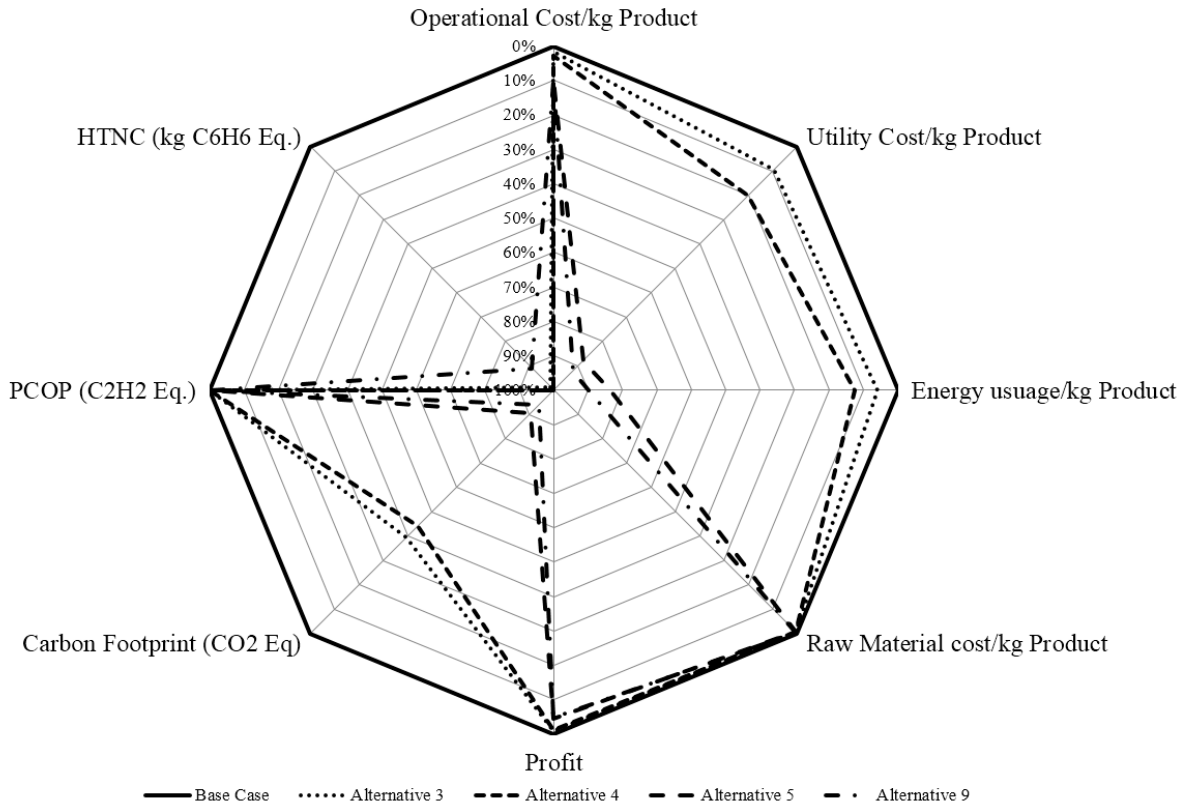

Figure 6-11: Economic and LCA improvements relative to the base case design. PCOPPhotochemical Oxidation Potential, HTNC- Human toxicity (non-carcinogenic impacts) From the results presented in Table 6-11 and the design targets set in step 8 the following can be concluded:

1. Increase raw material conversion-yes, $>90 \%$

2. Reduce raw material loss-yes

3. Reduce energy consumption-yes

4. Reduce utility cost-yes

5. Improvements in LCA/Sustainability indicators-yes, all variables within Figure 6-11 
6. Unit operations reduction-yes, 9 (base case), 5 (flowsheet alternative 3, see Figure 6-7(c)), 4 (flowsheet alternative 4, see Figure 6-7(d)), 1 (flowsheet alternative 9, see Figure 6-7(e))

7. Product purity (kept as the base case)-yes

8. Production target (kept as the base case)-yes

9. Reduce operational cost-yes

10. Waste minimization (raw material)-yes

\subsection{Production of Di-Methyl Carbonate}

\subsubsection{Step 1-Need Identification}

Action 1: Di-methyl carbonate (DMC) is an important, environmentally friendly, chemical used as a fuel additive and is being considered as an alternative to methyl tert-butyl ether (MTBE) (Bilde et al., 1997). The by-product of the reaction considered in this case study is also a valuable product that is propylene glycol (PG). Propylene glycol is used as a building block for making plastics and resins, aircraft deicer mixtures and heat transfer fluids, among others (CEFIC, 2008).

Action 2: The total production per year of DMC could not be found directly, however from three of the main producers Henan Zhongyuan Dahua Group located in the China and UBE and HighChem located in Japan, have a joint venture where their production rate is $100 \times 10^{3}$ tons/year (World of Chemicals, 2008). Therefore the specified production target is $1700 \mathrm{~kg} / \mathrm{hr}$ (Holtbruegge et al., 2013 (a)). The purity of the product and byproduct should be greater than or equal to $99.9 \mathrm{wt} \%$ and $99 \mathrm{wt} \%$, for DMC and PG respectively.

\subsubsection{Step2-Problem Definition}

Action 1: Problem statement: Identification of process flowsheet alternatives for the production of DMC subject to constraints and performance criteria and achieving an optimal conversion of propylene carbonate (PC).

Action 2: The objective function is defined in terms of minimizing the total annualized cost, Equation 6.27 subject to constraints and performance criteria:

$$
\operatorname{Max} F_{o b j}=\left(\sum E_{i} C_{U t, i}+\frac{C_{E q u i p}}{t_{\text {proj }}}\right) / m_{\text {prod }}
$$

Action 3: The constraints considered are given in Table 6-12. 
Table 6-12: Defined constraints for process synthesis-intensification of DMC production

\begin{tabular}{|c|c|c|c|c|}
\hline \multirow{2}{*}{ Objective } & \multicolumn{3}{|c|}{ Constraint } & \multirow{2}{*}{$\begin{array}{l}\text { Performance } \\
\text { Criteria }(\underline{\varphi})\end{array}$} \\
\hline & $\underline{\theta_{1}}$ & $\underline{\theta_{2}}$ & $\underline{\theta_{3}}$ & \\
\hline Flowsheet structure: reaction + separation & $*$ & & & \\
\hline Reaction occurs in the first unit operation & $*$ & & & \\
\hline $\begin{array}{l}\text { The product purity of DMC and Propylene } \\
\text { glycol is defined is } \geq 99 \mathrm{wt} \%\end{array}$ & $*$ & & & \\
\hline $\begin{array}{l}\text { PBBs are connected to form SPBs based } \\
\text { on combination rules }\end{array}$ & & * & & \\
\hline $\begin{array}{l}\text { SPBs are connected to form Basic Struc- } \\
\text { tures based on combination rules }\end{array}$ & & * & & \\
\hline $\begin{array}{l}\text { Do not use mass separating agents for re- } \\
\text { action/separation }\end{array}$ & & * & & \\
\hline Recycle un-reacted raw materials & & * & & \\
\hline $\begin{array}{l}\text { Do not use recycle streams if not neces- } \\
\text { sary }\end{array}$ & & * & & \\
\hline $\begin{array}{l}\text { Raw materials, methanol and acetic acid } \\
\text { are assumed to be in their pure state }\end{array}$ & & & $*$ & \\
\hline $\begin{array}{l}\text { The equilibrium conversion is defined as } \\
54 \% \text { (is to possibly be increased) }\end{array}$ & & & $*$ & \\
\hline $\begin{array}{l}\text { Production target of DMC is set at } \\
122 \times 10^{2} \text { tons/year }\end{array}$ & & & $*$ & \\
\hline $\begin{array}{l}\text { PI screening criteria for basic structures to } \\
\text { unit operations: Novel equipment feasible }\end{array}$ & & & & $*$ \\
\hline Increase $\mathrm{MeOH}$ conversion is explored & & & & $*$ \\
\hline $\begin{array}{l}\text { Minimization/reduction in energy con- } \\
\text { sumption }\end{array}$ & & & & $*$ \\
\hline Inclusion of intensified equipment & & & & $*$ \\
\hline Reduction in the number of unit operations & & & & $*$ \\
\hline Waste minimization & & & & * \\
\hline
\end{tabular}


Sustainability and LCA factors must be the same or better

\subsubsection{Step 3-Reaction Identification/Selection}

Action 1: The raw materials are methanol (MeOH) and propylene carbonate (PC) and are in the liquid phase for the reaction. The reaction is catalyzed using a basic catalyst, for example, Amberlite IRA-68 (Holtbruegge et al., 2013 (b)). The reaction is an equilibrium reaction and the reaction is shown in Equation 6.28.

$$
2 \mathrm{MeOH}+\mathrm{PC} \leftrightarrow \mathrm{DMC}+\mathrm{PG}
$$

Action 2: State of the products and by-products from Equation 5.28 is in the liquid phase. The heat of reaction is calculated to be $-41.67 \mathrm{~kJ} / \mathrm{mol}$, with an equilibrium conversion of $54 \%$. The reaction is an equilibrium reaction and therefore, it is reversible and exothermic because the heat of reaction, $\Delta H_{r x n}<0$.

\subsubsection{Step 4-Check for Availability-Base case}

Action 1: From a literature survey, a known base case design (Schlosberg et al., 2002) was pre-selected and is shown in Figure 6-12. The base case consists of 5 unit operations: 1 reactor (R1) and 4 distillation columns (T1, T2, T3 and T4). 
A brief description about the process: The raw materials are fed at a mole ratio of 5:1, with $\mathrm{MeOH}$ in excess, to the reactor where, the trans-esterification reaction occurs to produce DMC and PG. The reactor effluent consists of a mixture of $\mathrm{MeOH}, \mathrm{PC}, \mathrm{DMC}$ and PG. One minimum boiling azeotrope exist in this mixture that is between $\mathrm{MeOH} / \mathrm{DMC}$. The first distillation column (T1) separates PC and PG (bottom of T1) from the reactor effluent with $\mathrm{MeOH}$ and $\mathrm{DMC}$ (top of $\mathrm{T} 1$ ). The top stream of $\mathrm{T} 1$ contains $\mathrm{MeOH}$ and $\mathrm{DMC}$ and is separated using pressure swing distillation (T2 and $\mathrm{T} 3$ ). In $\mathrm{T} 2$, the feed composition at the column pressure ( 10 bar) is to the left hand side of the azeotrope therefore, DMC is obtained as the bottom product and the top product is the $\mathrm{MeOH} / \mathrm{DMC}$ azeotrope. In T3 the feed composition at the column pressure (1 bar) is to the right hand side of the azeotrope therefore $\mathrm{MeOH}$ is obtained as the bottom product which is recycled to the reactor and the top product is the $\mathrm{MeOH} / \mathrm{DMC}$ azeotrope. T4 separates PG from PC. The unreacted PC is recycled to the reactor.

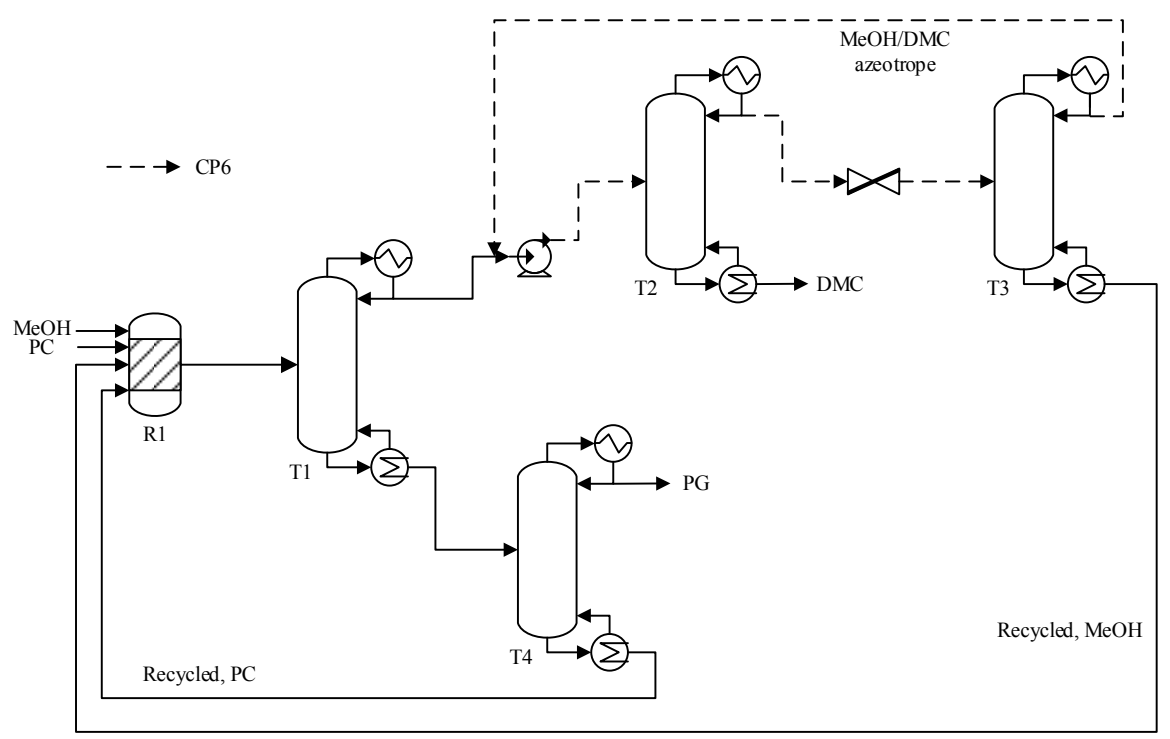

Figure 6-12: Base case design for the production of DMC. The closed path $(\mathrm{CP})$ is also highlighted which is the output of Step 8

\subsubsection{Step 5-Check for Base Case Feasibility}

The pre-selected base design is verified using the process synthesis method of Douglas (1985) in order to verify if it is feasible to be used as a base case design. From the analysis the pre-selected design satisfied the synthesis method of Douglas (1985), therefore, it is selected to be used as a feasible design. 


\subsubsection{Step 7-Perform Rigorous Simulation}

Action 1: The selected thermodynamic model is the UNIQUAC using Figure 3-2 and data from Holtbruegge et al. (2013). The base case design is rigorously using equilibrium based models for the reactor and separators using Aspen Custom Modeler (ACM). $\mathrm{MeOH}$ is fed in excess in order to achieve close to the equilibrium conversion. An overview of the simulation results is given in Table 6-13.

Table 6-13: Highlighted results from the simulation of the base case design

\begin{tabular}{|l|l|}
\hline & Value \\
\hline Feed Mole ratio (MeOH:PC) & $5: 1$ \\
\hline DMC product (kg/hr) & 1,700 \\
\hline Energy usage (MJ/ hr) & 133,563 \\
\hline Utility Cost (\$/yr) & $4,393,537$ \\
\hline
\end{tabular}

Action 2: The detailed mass and energy balance data, number of streams and unit operations of the base case based on the rigorous simulation is retrieved, which is to be used for the analyses in step 8.

\subsubsection{Step 8-Economic, Sustainability and LCA analysis}

Action 1-3: The economic, sustainability and LCA analysis are performed. The economic and LCA analysis results are shown in Figure 6-13 and the sustainability analyses is shown in Table 6-14. In Table 6-14 the most critical stream (path) in the process is listed with the path highlighted in Figure 6-12. 

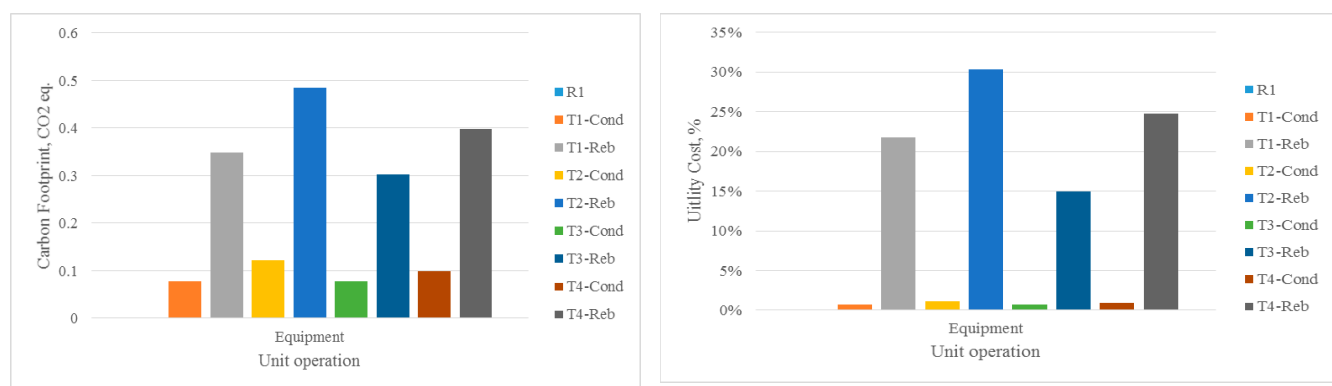

Figure 6-13: Economic analysis and LCA analysis for the base case design. Carbon footprint and Utility cost are compared. Note: Cond=condenser, $\mathrm{Reb}=$ reboiler

Table 6-14: The most critical path in the base case design that have the highest potentials for improvement. Note: CP-closed path

\begin{tabular}{|l|l|l|l|l|l|}
\hline Path & Compound & $\begin{array}{l}\text { Flowrate } \\
(\mathbf{k g} / \mathbf{h r})\end{array}$ & $\begin{array}{l}\text { MVA } \\
\left(\mathbf{1 0}^{\mathbf{3}} \mathbf{\$} / \text { year }\right)\end{array}$ & $\begin{array}{l}\text { TVA } \\
\left(\mathbf{1 0}^{\mathbf{3}} \mathbf{\$} / \text { year }\right)\end{array}$ & $\begin{array}{l}\text { EWC } \\
\left(\mathbf{1 0}^{\mathbf{3}} \mathbf{\$} / \text { year }\right)\end{array}$ \\
\hline $\mathrm{CP6}$ & $\mathrm{MeOH}$ & 761.83 & - & - & 10253 \\
\hline
\end{tabular}

From Table 6-14, CP6 which follows the raw material $\mathrm{MeOH}$, has a high EWC. This means that a high flow of $\mathrm{MeOH}$ is being recycled resulting in high loads of energy and waste/use of utilities. Therefore referring to Figure 6-13, the unit operations belonging to this closed-path that is T2 and T3, have high carbon footprints and accounts for $30 \%$ and $15 \%$ of the utility costs with respect to the reboilers, respectively.

Action 4: The identified process hot-spots are given in Table 6-15.

Table 6-15: Identified process hot-spots in the base case design for the production of $\mathrm{DMC}$

\begin{tabular}{|c|c|c|c|}
\hline Indicator values & $\begin{array}{l}\text { Base Case prop- } \\
\text { erty }\end{array}$ & Reason & $\begin{array}{l}\text { Identified Process } \\
\text { hot-spot }\end{array}$ \\
\hline $\begin{array}{l}\alpha_{1}=\text { Raw material } \\
\text { recycle } / \text { cost } \\
\beta_{1}=\mathrm{MVA}\end{array}$ & $\begin{array}{l}\text { Un-reacted raw } \\
\text { materials }\end{array}$ & $\begin{array}{l}\text { Equilibrium reac- } \\
\text { tion }\end{array}$ & $\begin{array}{l}\text {-Limiting equilibri- } \\
\text { um/raw material loss }\end{array}$ \\
\hline $\begin{array}{l}\alpha_{2}=\text { Utility cost } \\
\beta_{1}=\mathrm{MVA} \\
\beta_{2}=\mathrm{EWC} \\
\gamma_{1}=\mathrm{CO} 2 \text { equiva- } \\
\text { lent } \\
\gamma_{2}=\mathrm{PEI}\end{array}$ & $\begin{array}{l}\text { Un-reacted raw } \\
\text { materials and } \\
\text { products recovery }\end{array}$ & $\begin{array}{l}\text {-Presence of azeo- } \\
\text { trope(s) } \\
\text {-High energy usage- } \\
\text { heating and/or cool- } \\
\text { ing }\end{array}$ & $\begin{array}{l}\text {-Azeotrope } \\
\text {-Difficult separation: } \\
\text { low driving force } \\
\text {-High energy con- } \\
\text { sumption and/or de- } \\
\text { mand }\end{array}$ \\
\hline
\end{tabular}


Action 5: Using Table 3-3, the design targets to be set/met are:

1. Reduce energy consumption

2. Reduce utility cost

3. Improvements in LCA/Sustainability indicators

4. Unit operations reduction

5. Product purity (kept as the base case)

6. Production target (kept as the base case)

7. Reduce operational cost

8. Waste minimization

\subsubsection{IT-PBS.1-Process Analysis}

Action 1: The task based flowsheet of the base case design is shown in Figure 6-14.

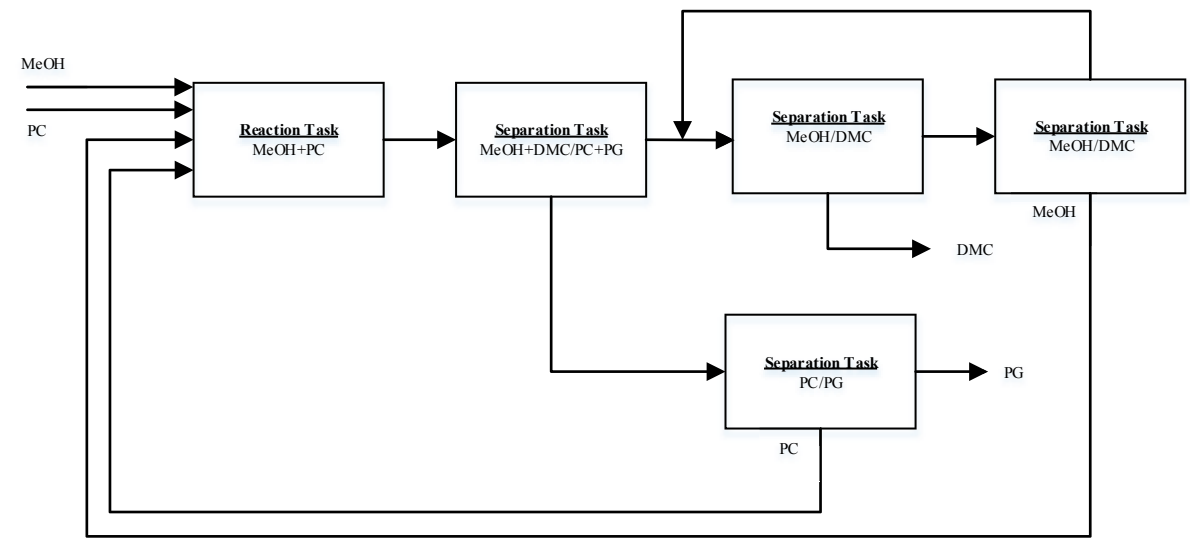

Figure 6-14: Task based flowsheet of the base case design 
Action 2: The phenomena based flowsheet of the base case design is shown in Figure 6-15. The identified PBBs are:

- Reaction task: M, R, C

- Separation task:

○ VL-M, 2phM, C/H, PC(VL), PT(VL), PS(VL)

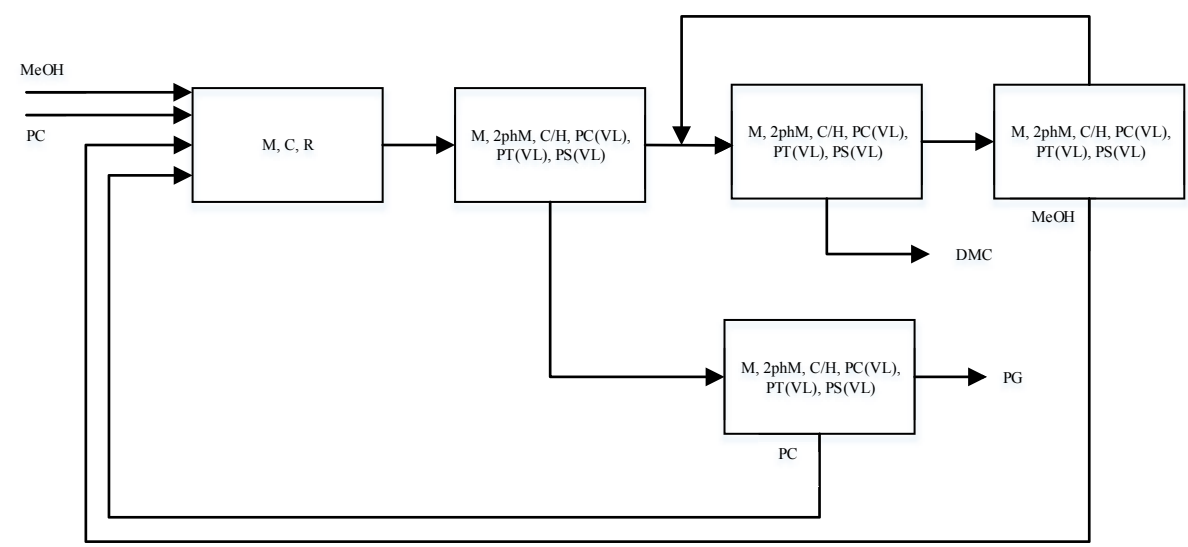

Figure 6-15: Phenomena based flowsheet of the base case design

Action 3: The binary ratio matrix (highlighted results) and the azeotrope analysis are presented in Table 6-16 and Figure 6-16.

Table 6-16: Binary ratio matrix for a selected set of properties. MW- molecular weight, Tb- normal boiling point, RG- radius of gyration, Tm- normal melting point, VM- molar volume, SolPar- solubility parameter, VDW- Van der Waals volume, VP- vapor pressure

\begin{tabular}{|l|l|l|l|l|l|l|l|l|}
\hline rij & Mw & Tm & Tb & RG & SolPar & VdW & VM & VP \\
\hline $\mathrm{MeOH} / \mathrm{PC}$ & 3.19 & 1.28 & 1.52 & 2.2 & 1.13 & 2.08 & 2.1 & 2736.13 \\
\hline $\mathrm{MeOH} / \mathrm{DMC}$ & 2.81 & 1.56 & 1.08 & 2.09 & 1.46 & 2.13 & 2.09 & 2.28 \\
\hline $\mathrm{MeOH} / \mathrm{PDO}$ & 2.37 & 1.21 & 1.36 & 2.03 & 1 & 2.15 & 1.82 & 980.63 \\
\hline $\mathrm{PC} / \mathrm{DMC}$ & 1.13 & 1.22 & 1.42 & 1.05 & 1.3 & 1.02 & 1.01 & 1198.69 \\
\hline $\mathrm{PC} / \mathrm{PDO}$ & 1.34 & 1.05 & 1.12 & 1.08 & 1.12 & 1.03 & 1.16 & 2.79 \\
\hline $\mathrm{DMC} / \mathrm{PDO}$ & 1.18 & 1.28 & 1.27 & 1.03 & 1.46 & 1.01 & 1.15 & 429.61 \\
\hline
\end{tabular}




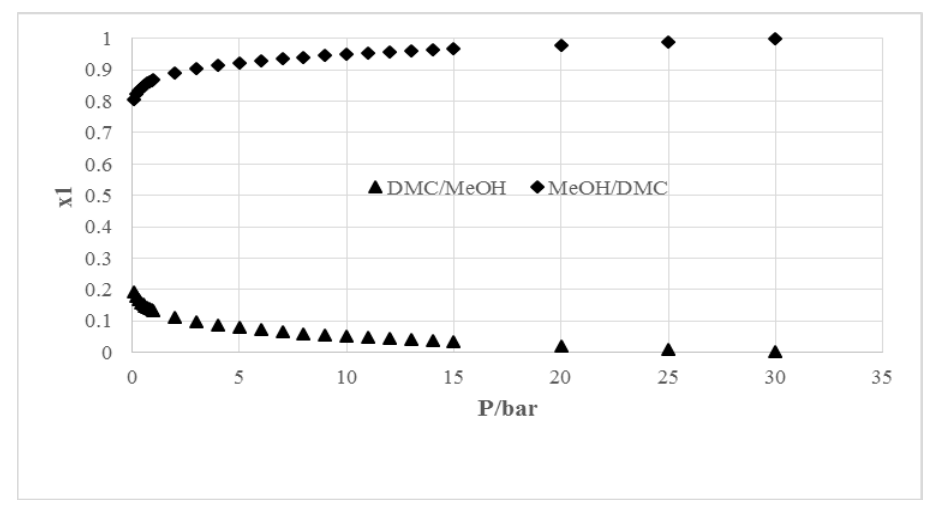

Figure 6-16: Pressure dependence analysis of the 3 minimum boiling azeotropes

From Figure 6-15 1 minimum boiling binary azeotrope is found: $\mathrm{MeOH} / \mathrm{DMC}$. This is hinted from the binary ratio matrix looking at the ratio of the boiling points for the pair and it is also the only binary pair that has a value close to unity. The azeotrope is further analyzed for investigating its pressure dependence as this information may be useful for the flowsheet generation IT-PBS 3. It can be seen that the azeotrope is pressure dependent. At low pressures the $\mathrm{MeOH} / \mathrm{DMC}$ azeotrope reaches a $\mathrm{MeOH}$ purity of approximately $80 \mathrm{~mol} \%$ and at high pressure the azeotrope disappears.

\subsubsection{IT-PBS.2-Identification of Desirable Tasks and Phenomena}

Action 1: The additional PBBs selected are PT(PVL), PT(VV), and PS(VV). Therefore the total list of PBBs are: R, M, 2phM, C, H, PT(VL), PT(PVL), PT(VV), PC(VL), PS(VL), PS(VV), D

Action 2: The remaining PBBs from applying the constraints defined in step 2 are R, M (assuming four types: ideal liquid, flow, rectangular, ideal vapor), 2phM, C, H, PT(VL), PT(PVL), PT(VV), PC(VL), PS(VL), PS(VV), D

Action 3: The operating window for each $\mathrm{PBB}$ is given in Table 6-17 
Table 6-17: Operating window of the identified PBBs in the base case design. All concentrations are below the dew point line and above the bubble point line.

\begin{tabular}{|c|c|}
\hline Phenomena & Operating Window \\
\hline \multirow[b]{2}{*}{$\mathrm{R}$} & $\mathrm{T}_{\text {low }}=175.15 \mathrm{~K}$ (Lowest Melter) \\
\hline & $\begin{array}{c}\mathrm{T}_{\text {high }}=313.15 \mathrm{~K} \text { (Maximum } \mathrm{T} \text { for reactor } \\
\text { operation) }\end{array}$ \\
\hline \multirow{2}{*}{$\mathrm{M}_{\mathrm{V}}$} & $\mathrm{T}_{\text {low }}=337.70 \mathrm{~K}$ (Lowest boiler) \\
\hline & $\mathrm{T}_{\text {high }}=514.70$ (Highest Boiler) \\
\hline \multirow{2}{*}{$M_{l d}$} & $\mathrm{~T}_{\text {low }}=175.15 \mathrm{~K}$ (Lowest Melter) \\
\hline & $\mathrm{T}_{\text {high }}=514.70 \mathrm{~K}$ (Highest Boiler) \\
\hline $\mathrm{M}_{\mathrm{V}}, 2 \mathrm{phM}$ & $\mathrm{T}_{\mathrm{low}}=336.66 \mathrm{~K}$ (Lowest boiling azeotrope) \\
\hline $\mathrm{PC}(\mathrm{VL})$ & V-L present \\
\hline \multirow{2}{*}{ PT(VL) } & $\mathrm{T}_{\text {low }}=336.66 \mathrm{~K}$ (Lowest boiling azeotrope) \\
\hline & $\mathrm{T}_{\text {high }}=514.70 \mathrm{~K}$ (Highest Boiler) \\
\hline PS(VL) & V-L present \\
\hline PT(PVL) & Component affinity - \\
\hline PT(VV) & Component affinity \\
\hline PS(VV) & $\begin{array}{l}\mathrm{V}-\mathrm{V} \text { present (all compounds in the va- } \\
\text { pour phase) }\end{array}$ \\
\hline $\mathrm{H}$ & - \\
\hline $\mathrm{C}$ & - \\
\hline $\mathrm{D}$ & - \\
\hline
\end{tabular}

\subsubsection{IT-PBS.3-Generation of Feasible Flowsheet Alternatives}

Action 1: The maximum number of phenomena that can be combined to form an SPB, $\mathrm{n}_{\text {PBB,Max }}$, is calculated to be 11 (Equation 4.22). The total number of SPBs that can be generated, having a maximum of 11 SPBs is 16278 (Equation 4.23). A list of feasible SPBs is presented in Table 6-18 assuming three types of mixing for each SPB in the liquid phase that is ideal liquid, flow and rectangular. 
Table 6-18: Partial list of feasible SPBs. Mix.-mixing, Cool.-cooling, Heat.-heating, React.-reaction, Sep.-Separation, Ph. Cr.-phase creation, Div.-dividing

\begin{tabular}{|c|c|c|c|c|}
\hline SPB & Connected PBB & In & Out & $\begin{array}{l}\text { Task they } \\
\text { may per- } \\
\text { form }\end{array}$ \\
\hline SPB.1 & $\mathrm{M}$ & 1..n $(\mathrm{L}, \mathrm{VL}, \mathrm{V})$ & $1(\mathrm{~L}, \mathrm{VL}, \mathrm{V})$ & Mix. \\
\hline SPB.2 & $\mathrm{M}=2 \mathrm{phM}$ & 1..n $(\mathrm{L}, \mathrm{VL}, \mathrm{V})$ & $1(\mathrm{~L}, \mathrm{VL}, \mathrm{V})$ & Mix. \\
\hline SPB.3 & $\mathrm{M}=\mathrm{R}$ & $1 . . \mathrm{n}(\mathrm{L}, \mathrm{VL}, \mathrm{V})$ & $1(\mathrm{~L}, \mathrm{VL}, \mathrm{V})$ & Mix.+React. \\
\hline SPB.4 & $\mathrm{M}=\mathrm{H}$ & 1..n $(\mathrm{L}, \mathrm{VL}, \mathrm{V})$ & $1(\mathrm{~L}, \mathrm{VL}, \mathrm{V})$ & Mix.+Heat. \\
\hline SPB.5 & $\mathrm{M}=\mathrm{C}$ & $1 . . \mathrm{n}(\mathrm{L}, \mathrm{VL}, \mathrm{V})$ & $1(\mathrm{~L}, \mathrm{VL}, \mathrm{V})$ & Mix.+Cool. \\
\hline SPB.6 & $\mathrm{M}=\mathrm{R}=\mathrm{H}$ & 1..n $(\mathrm{L}, \mathrm{VL}, \mathrm{V})$ & $1(\mathrm{~L}, \mathrm{VL}, \mathrm{V})$ & React.+Heat. \\
\hline SPB.7 & $\mathrm{M}=\mathrm{R}=\mathrm{C}$ & 1..n(L,VL,V) & $1(\mathrm{~L}, \mathrm{VL}, \mathrm{V})$ & React.+Cool. \\
\hline SPB.8 & $\mathrm{M}=\mathrm{R}=\mathrm{H}=\mathrm{PC}(\mathrm{VL})=\mathrm{PT}(\mathrm{VL})$ & 1..n $(\mathrm{L}, \mathrm{VL}, \mathrm{V})$ & $1(\mathrm{~L}, \mathrm{VL}, \mathrm{V})$ & React.+Heat. \\
\hline SPB.9 & $\mathrm{M}=\mathrm{R}=\mathrm{C}=\mathrm{PC}(\mathrm{VL})=\mathrm{PT}(\mathrm{VL})$ & 1..n $(\mathrm{L}, \mathrm{VL}, \mathrm{V})$ & $1(\mathrm{~L}, \mathrm{VL}, \mathrm{V})$ & React. + Cool. \\
\hline SPB.10 & $\mathrm{M}=\mathrm{R}=2 \mathrm{phM}=\mathrm{PC}(\mathrm{VL})=\mathrm{PT}(\mathrm{VL})$ & $1 . . \mathrm{n}(\mathrm{L}, \mathrm{VL})$ & $2(\mathrm{~V} / \mathrm{L})$ & React.+Sep. \\
\hline SPB.11 & $\mathrm{M}=\mathrm{R}=2 \mathrm{phM}=\mathrm{PC}(\mathrm{VL})=\mathrm{PT}(\mathrm{VL})=\mathrm{PS}(\mathrm{VL})$ & 1..n(L,VL) & $2(\mathrm{~V} ; \mathrm{L})$ & React.+Sep. \\
\hline SPB.12 & $\mathrm{M}=\mathrm{R}=2 \mathrm{phM}=\mathrm{PC}(\mathrm{VL})=\mathrm{PT}(\mathrm{PVL})=\mathrm{PS}(\mathrm{VL})$ & 1..n(L,VL) & $2(\mathrm{~V} ; \mathrm{L})$ & React. + Sep. \\
\hline SPB.13 & $\mathrm{M}=\mathrm{R}=\mathrm{H}=2 \mathrm{phM}=\mathrm{PC}(\mathrm{VL})=\mathrm{PT}(\mathrm{PVL})=\mathrm{PS}(\mathrm{VL})$ & 1..n(L,VL) & $2(\mathrm{~V} ; \mathrm{L})$ & React. + Sep. \\
\hline SPB.14 & $\mathrm{M}=\mathrm{R}=\mathrm{C}=2 \mathrm{phM}=\mathrm{PC}(\mathrm{VL})=\mathrm{PT}(\mathrm{PVL})=\mathrm{PS}(\mathrm{VL})$ & $1 . . \mathrm{n}(\mathrm{L}, \mathrm{VL})$ & $2(\mathrm{~V} ; \mathrm{L})$ & React.+Sep. \\
\hline SPB.15 & $\mathrm{M}=2 \mathrm{phM}=\mathrm{PC}(\mathrm{VL})=\mathrm{PT}(\mathrm{VL})$ & $1 . . \mathrm{n}(\mathrm{L}, \mathrm{VL})$ & $2(\mathrm{~V} ; \mathrm{L})$ & Mix.+Ph. Cr \\
\hline SPB.16 & $\mathrm{M}=2 \mathrm{phM}=\mathrm{C}=\mathrm{PC}(\mathrm{VL})=\mathrm{PT}(\mathrm{VL})$ & 1..n(L,VL) & $2(\mathrm{~V} ; \mathrm{L})$ & Mix.+Ph. Cr. \\
\hline SPB.17 & $\mathrm{M}=2 \mathrm{phM}=\mathrm{H}=\mathrm{PC}(\mathrm{VL})=\mathrm{PT}(\mathrm{VL})$ & 1..n(L,VL) & $2(\mathrm{~V} ; \mathrm{L})$ & Mix.+Ph. Cr. \\
\hline SPB.18 & $\mathrm{M}=2 \mathrm{phM}=\mathrm{PC}(\mathrm{VL})=\mathrm{PT}(\mathrm{VL})=\mathrm{PS}(\mathrm{VL})$ & $1 . . \mathrm{n}(\mathrm{L}, \mathrm{VL})$ & $2(\mathrm{~V} ; \mathrm{L})$ & Mix.+Sep. \\
\hline SPB.19 & $\mathrm{M}=\mathrm{C}=2 \mathrm{phM}=\mathrm{PC}(\mathrm{VL})=\mathrm{PT}(\mathrm{VL})=\mathrm{PS}(\mathrm{VL})$ & 1..n(L,VL) & $2(\mathrm{~V} ; \mathrm{L})$ & Cool.+Sep. \\
\hline SPB.20 & $\mathrm{M}=\mathrm{H}=2 \mathrm{phM}=\mathrm{PC}(\mathrm{VL})=\mathrm{PT}(\mathrm{VL})=\mathrm{PS}(\mathrm{VL})$ & $1 . . \mathrm{n}(\mathrm{VL})$ & $2(\mathrm{~V} ; \mathrm{L})$ & Heat.+Sep. \\
\hline SPB.21 & $\mathrm{M}=2 \mathrm{phM}=\mathrm{PC}(\mathrm{VL})=\mathrm{PT}(\mathrm{PVL})=\mathrm{PS}(\mathrm{VL})$ & 1..n(VL) & $2(\mathrm{~V} ; \mathrm{L})$ & Mix.+Sep. \\
\hline SPB.22 & $\mathrm{M}=2 \mathrm{phM}=\mathrm{PC}(\mathrm{VL})=\mathrm{PT}(\mathrm{VV})=\mathrm{PS}(\mathrm{VV})$ & $1 . . \mathrm{n}(\mathrm{L}, \mathrm{VL}, \mathrm{V})$ & $2(\mathrm{~V} ; \mathrm{V})$ & Mix.+Sep. \\
\hline SPB.23 & $\mathrm{M}=2 \mathrm{phM}=\mathrm{PT}(\mathrm{VV})=\mathrm{PS}(\mathrm{VV})$ & $1 . . \mathrm{n}(\mathrm{V})$ & $2(\mathrm{~V} ; \mathrm{V})$ & Mix.+Sep. \\
\hline SPB... & $\ldots$ & $\ldots$ & $\ldots$ & $\ldots$ \\
\hline SPB.70 & $\mathrm{D}$ & $1(\mathrm{~L} ; \mathrm{VL}, \mathrm{V})$ & $\begin{array}{l}1 . . \mathrm{n}(\mathrm{L} ; \mathrm{V} ; \\
\mathrm{VL})\end{array}$ & Stream Div. \\
\hline
\end{tabular}

Action 2: The generated task based superstructure is shown in Figure 6-17. The concept for the task-based superstructure has already been presented in section 6.1.10. 


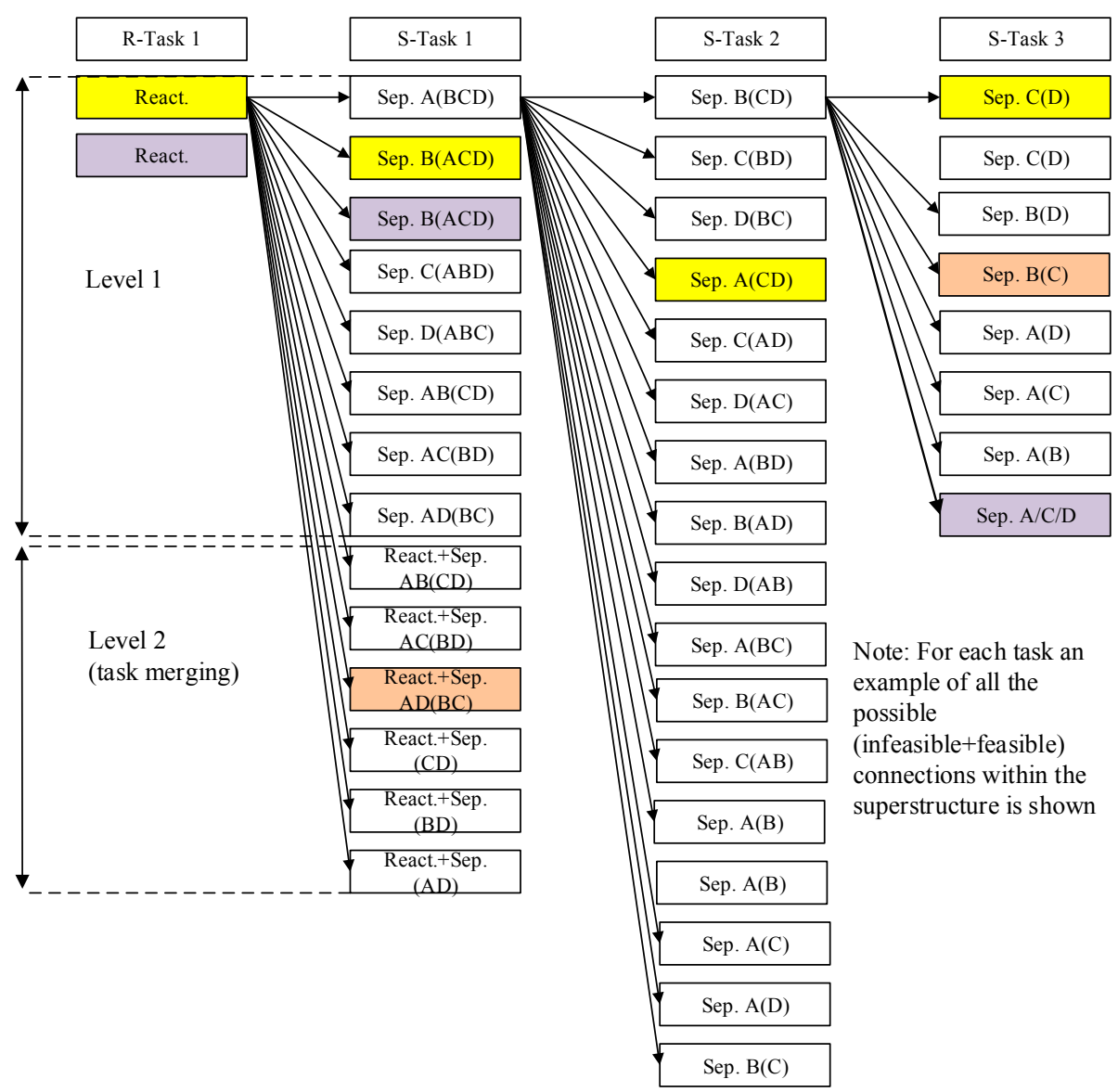

Figure 6-17: Task-based superstructure for the production of DMC. Task-based superstructure including task-merging. Flowsheet alternative 3 (highlighted in yellow), Flowsheet alternative 5 (highlighted in purple) and Flowsheet alternative 9 (highlighted in orange). A-PC, B-MeOH, C-DMC, D-PG

Action 4: Table 6-8 gives the identified basic structures that perform reaction and separation tasks. 
Table 6-19: Identified basic structures that perform single or multiple tasks for conversion of $\mathrm{PC}$ and $\mathrm{MeOH}$ to DMC and PG. Note each binary pair that represent the inlet to a task represent the two key compounds under consideration

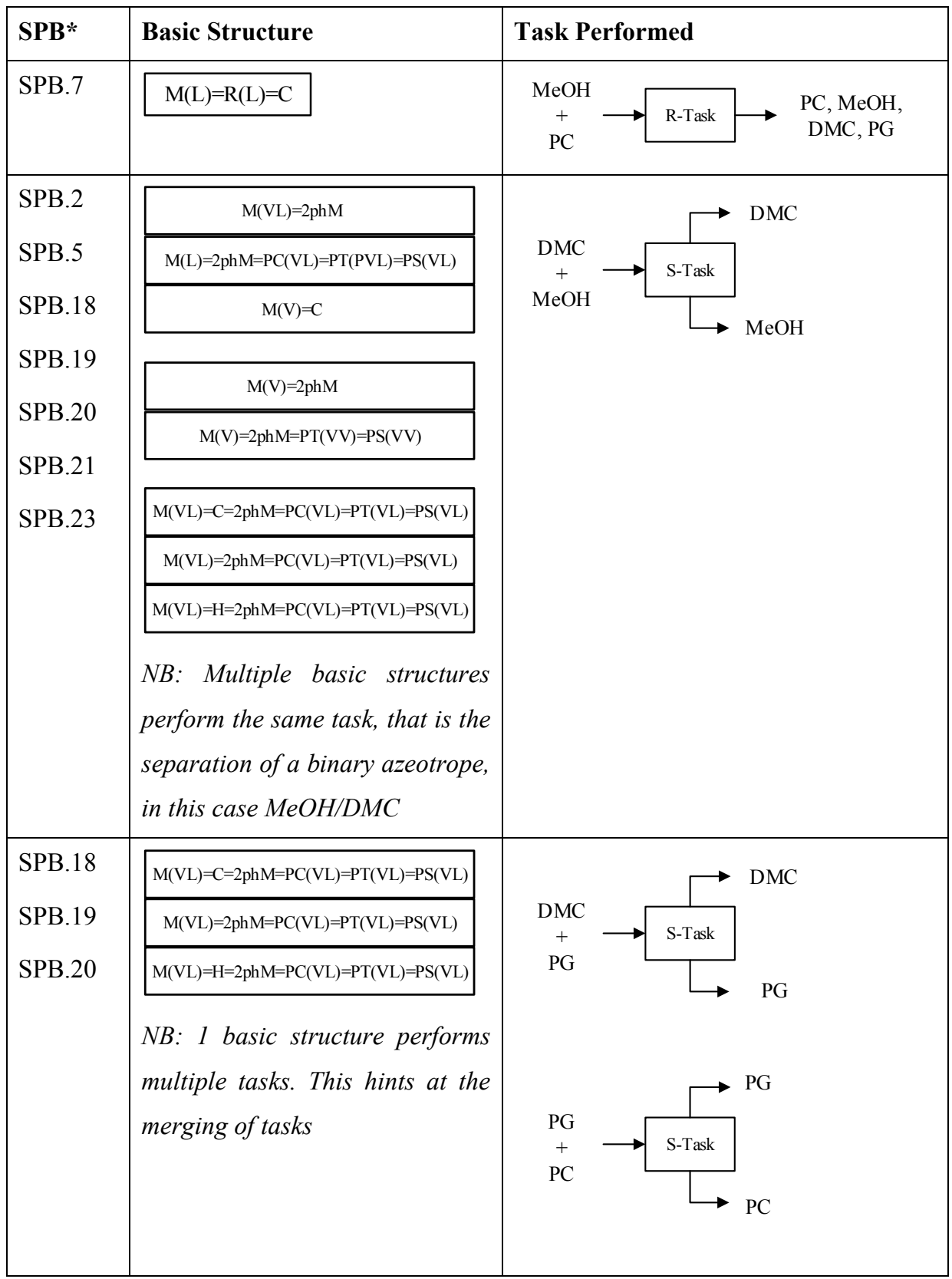

*The SPB number corresponds to the SPB given in Table 6-18. Note: For combined basic structures, only the SPBs present in the combined basic structure are presented 
Action 5: The identified task based flowsheets highlighted in level 1 and level 2 of the task based superstructure shown in Figure 6-17 is explained as follows: Level 1Flowsheet alternative 2-3, highlighted yellow in Figure 6-17:

- Flowsheet alternative 1-Not shown due to confidential agreements.

- Flowsheet alternative 2-3: A reactor feed (as in the base case) of a 5:1 mole ratio of $\mathrm{MeOH}$ to $\mathrm{PG}$ is used. It is generated as follows. The reaction is a reversible liquid phase reaction, therefore, the reactor outlet contains a mixture of raw materials and products. A basic structure containing a $\mathrm{R}(\mathrm{L}) \mathrm{PBB}$ is selected to perform the reaction task.

Based on the mixture analysis, 1 minimum boiling, pressure dependent azeotrope is present. From the basic structures identified in Table 6-19, a basic structure containing a $\mathrm{PT}(\mathrm{PVL})$ or $\mathrm{PT}(\mathrm{VV}) \mathrm{PBB}$ is selected to separate $\mathrm{MeOH}$ from $\mathrm{DMC}, \mathrm{PG}$ and PC

The stream from S-Task 1, contains DMC, PG and PC. No azeotropes are present. From the basic structures identified in Table 6-19, 1 basic structure is feasible to perform the S-Task 1 and S-Task 2. At this point all recovered unreacted raw materials are recycled thereby closing the task based flowsheet.

Level 2: Flowsheet alternative 3-4, highlighted purple and orange in Figure 6-17: 
- Flowsheet alternative 4-5-In level 2 the merging of tasks is considered which is feasible because the same basic structure performs the same task. Note: This is not to be confused with the combination of PBBs for example reactionseparation, which also provides the feasibility for merging of tasks.

The concept of merging tasks also reduces the overall number of tasks that must be performed in meeting a desired design target. Therefore the merging of the STask 1 and S-Task 2 is considered. The tasks are merged based on the system properties: (1) Distinct boiling points between the compounds to be separated DMC, PG and PC and (2) no azeotropes present. This is given in Table 6-20.

Table 6-20: Identified basic structures for flowsheet alternatives 3 . Note each binary pair that represent the inlet to a task represent the two key compounds under consideration

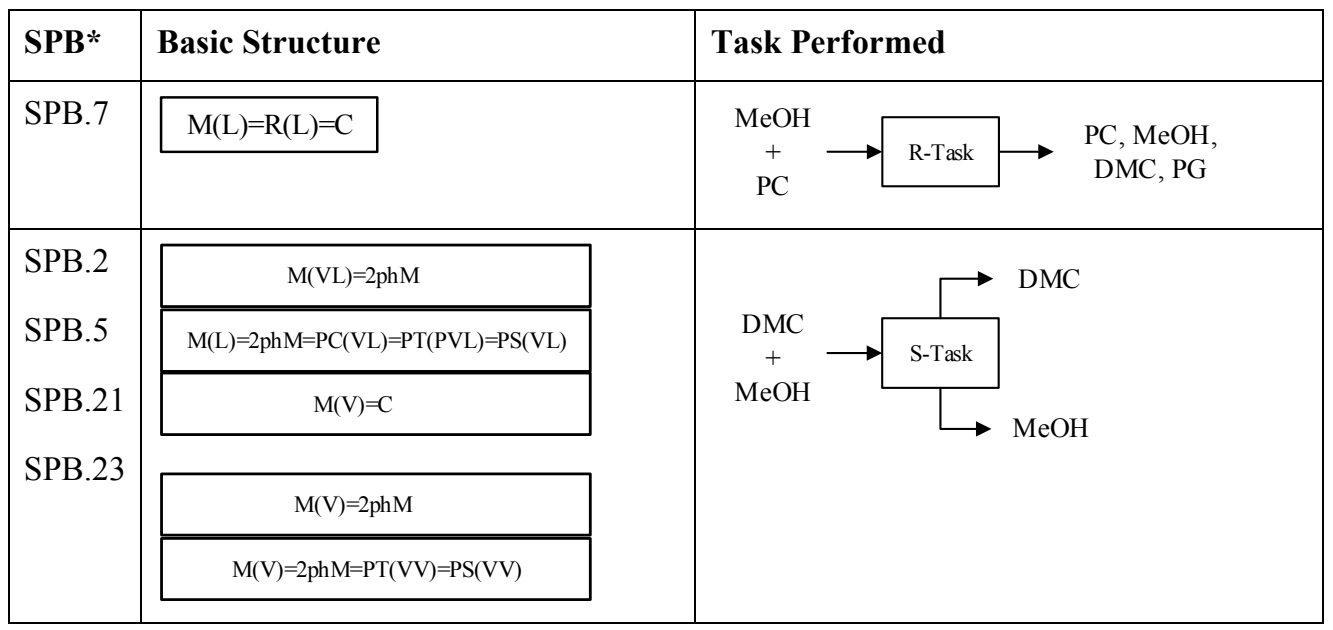




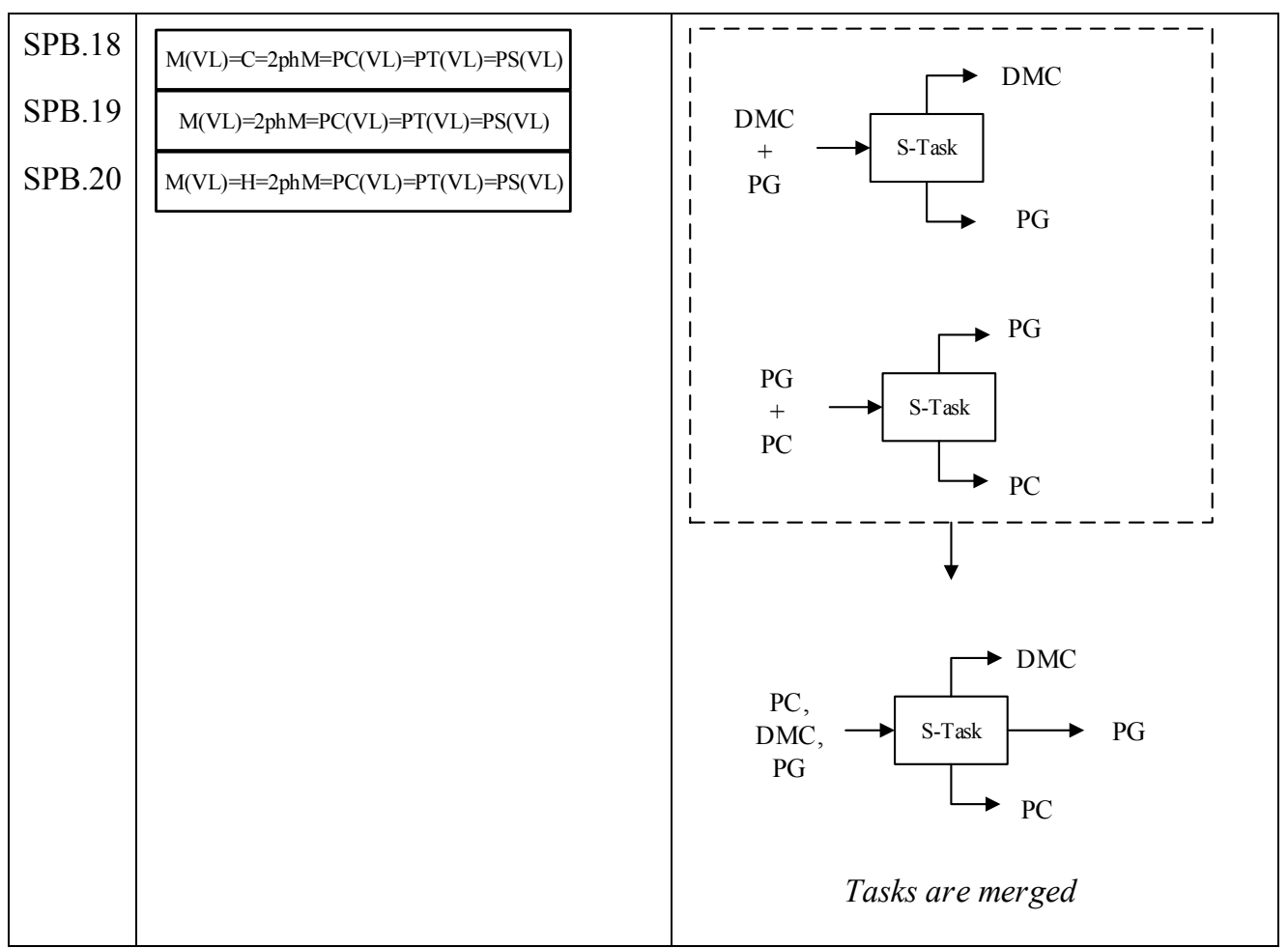

Note: *The SPB number corresponds to the SPB given in Table 6-18. For combined basic structures, only the SPBs present in the combined basic structure are presented 
- Flowsheet alternative 6-9-The merging of tasks is further considered which is feasible because PBBs can be combined that perform reaction and separation together. The merging of R-Task, S-Task 1, S-Task 2 and S-Task 3 is considered. This is possible based on the system properties: (1) esterification reaction (2) an azeotrope is present and (3) the reaction is in the liquid phase. Therefore the basic structures can be combined in order to perform the $\mathrm{R}=\mathrm{S}$ Task together and this is given in Table 6-21. Different configurations of such a structure exist that is only reaction, reaction and separation with single or double inlet feed.

Table 6-21: Identified basic structures for flowsheet alternatives 6-9

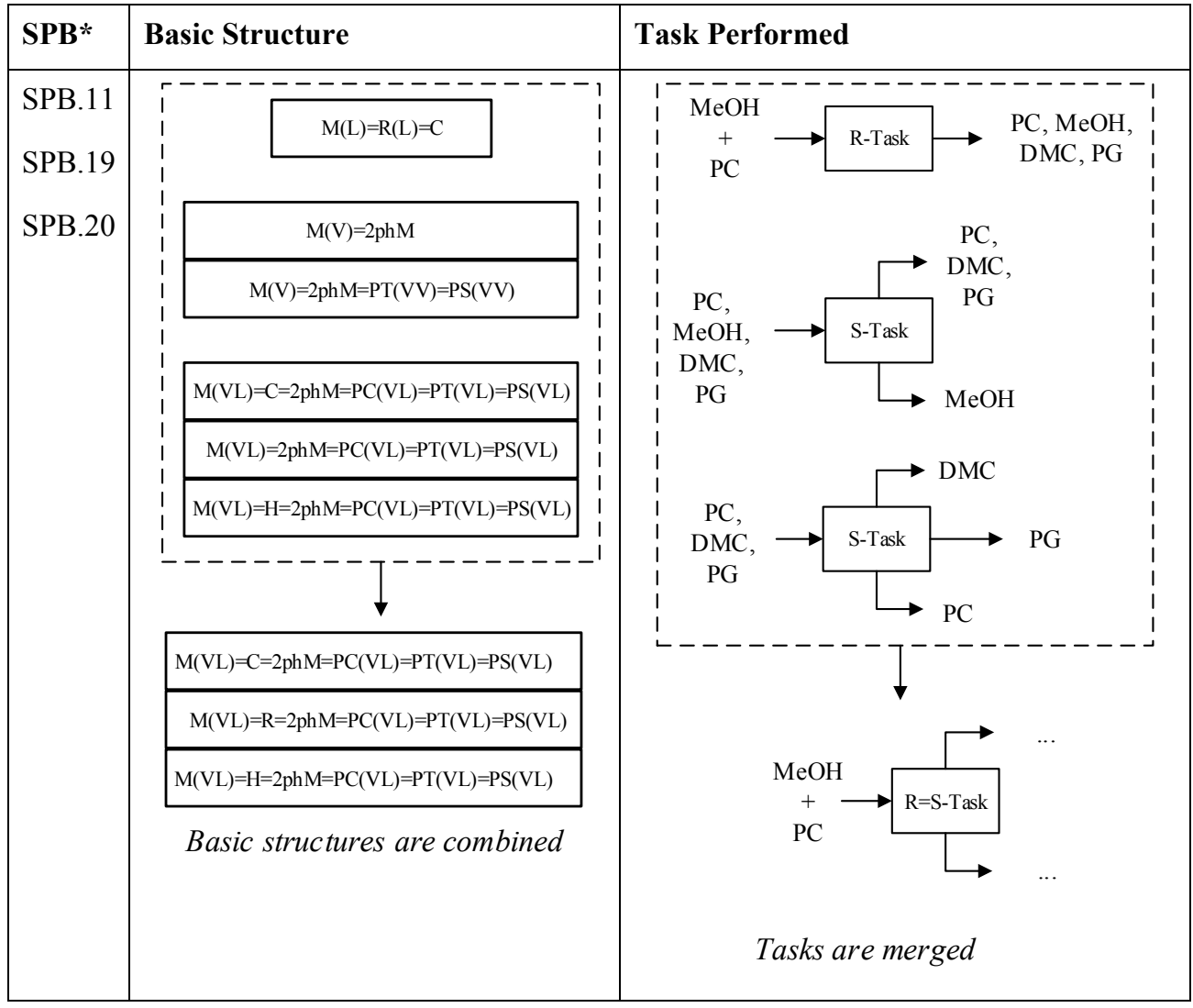

*The SPB number corresponds to the SPB given in Table 6-21. Note: For combined basic structures, only the SPBs present in the combined basic structure are presented Action 6: The basic structures that perform the different identified tasks are translated into unit operations. The final flowsheet alternatives are presented in Figure 6-18: 


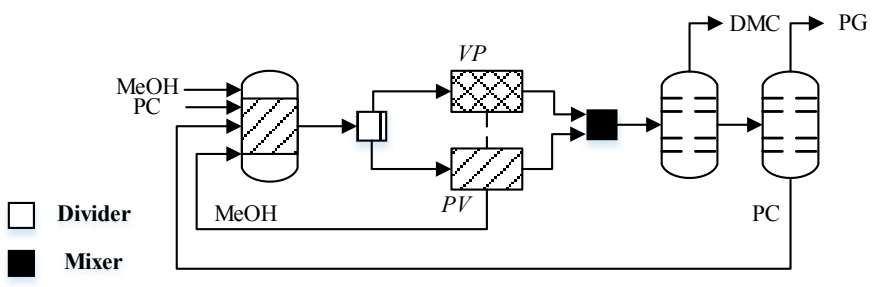

Figure 6-18 (a)

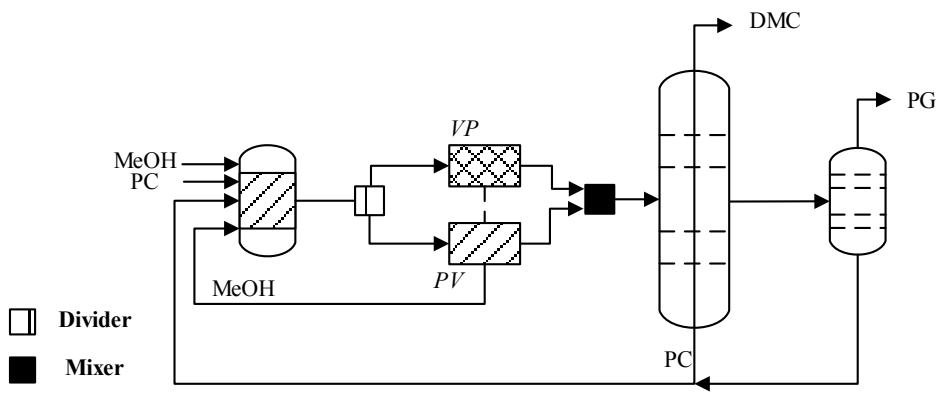

Figure 6-18 (b)*

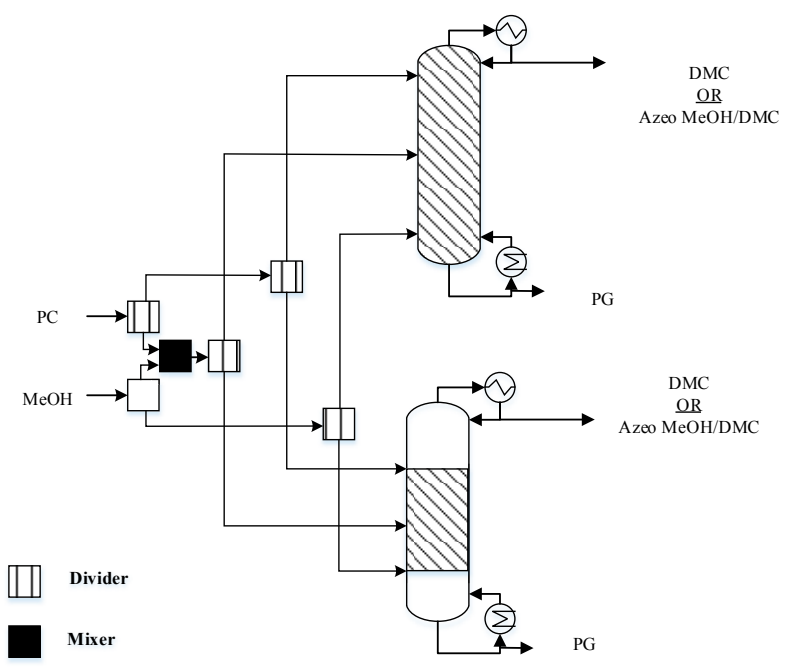

Figure 6-18 (c) 


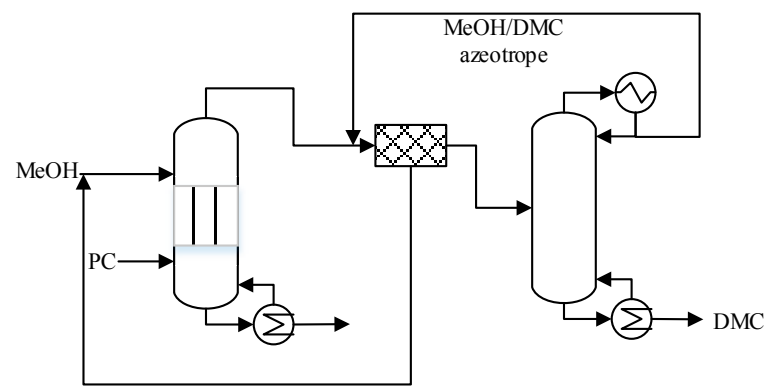

Figure 6-18 (c)**

Figure 6-18: The generated flowsheet alternatives for the production of DMC. *Final dividing wall configuration. **Final reactive distillation configuration. VP-vapor permeation membrane, PV-pervaporation membrane

Action 7: The flowsheet alternatives are analyzed and screened in order to select the feasible alternatives for IT-PBS.4.

1. The flowsheet alternatives are analyzed using the following models while maintaining the following logical $\left(\underline{\theta_{1}}\right)$ and operational constraints $\left(\underline{\theta_{3}}\right)$ defined in step 2, $\theta_{1}$-The product purity of DMC is defined is $\geq 99 \mathrm{~mol} \%, \underline{\theta_{3}}$-Production target of DMC is set at $1700 \mathrm{~kg} / \mathrm{hr}$ :

- Flowsheet alternatives 2-6-Based on the availability of data (Holtbruegge et al., 2013 (c)) and the system properties, a vapor permeation membrane was selected. In principle since the reactor outlet is liquid, a pervaporation membrane would be a better choice for selection, however the limitation is the availability of data for such a membrane. For the investigation of the dividing wall column, the method of Rangaiah et al. (2009) and the method of Halvorsen and Skogestad (2011) was used.

- Flowsheet alternatives 6-9-Reactive distillation model. This investigation was carried out by Holtbruegge et al. (2013(a), 2014). It was found that the best configuration was a double feed $\mathrm{RD}$ with both reactive and nonreactive stages. The top composition consists of the MeOH/DMC mixture and the bottoms PG. Since the top of the column is already in vapor form, it is fed to a vapor permutation membrane where $\mathrm{MeOH}$ is removed until the composition is on the side of the azeotrope where DMC can be recovered by VL separation. 
2. The screening of the flowsheet alternatives is given in Figure 6-19.

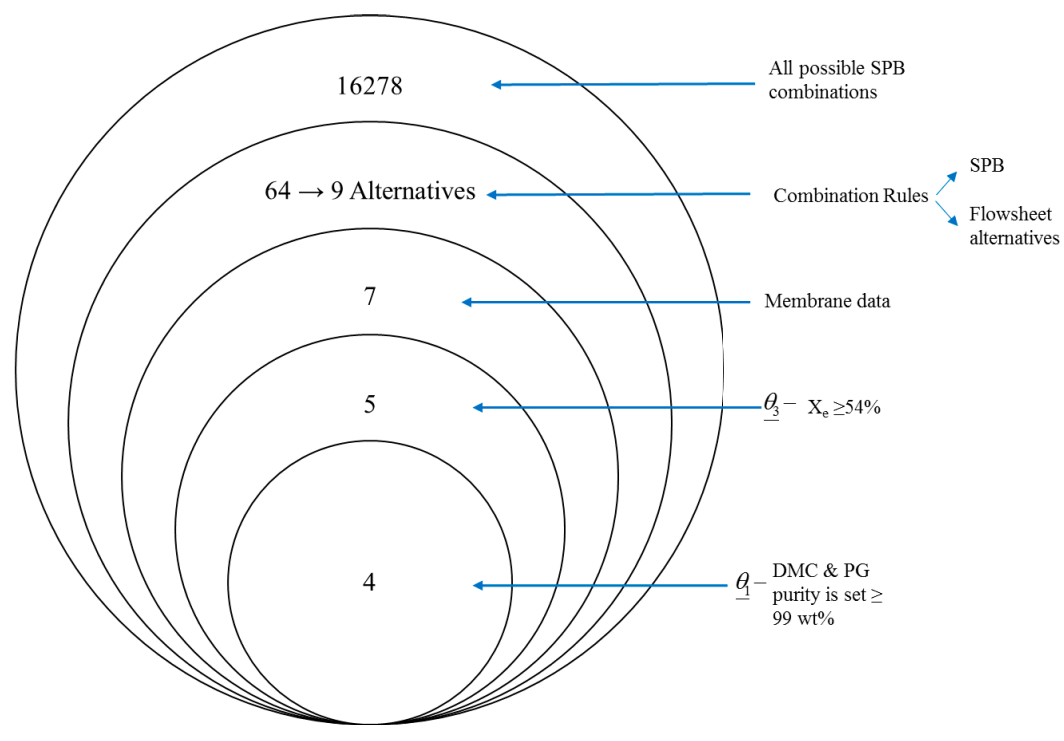

Figure 6-19: Screening of the SPBs and generated flowsheet alternatives

The 4 feasible flowsheet alternatives selected for further analysis in IT-PBS 4 are flowsheet alternative 1 (not shown), flowsheet alternative 3 (see Figure 6-18(a), with vapor permeation membrane), flowsheet alternative 5 (see Figure 6-18(b)*, with vapor permeation membrane) and flowsheet alternative 9 (see Figure 6-18(c)**, double feed RD column with both reactive and non-reactive stages). 


\subsubsection{IT-PBS.4-Comparision and Section of the Best Flowsheet Alternatives}

The results of the economic, sustainability and LCA analysis for the 4 feasible alternatives are given in Table 6-11. The prices used for different utilities are: cooling water at $0.35 \$ / G J$, LP Steam at 7.78 \$/GJ and electricity at $16.80 \$ / G J$ (Peters, Timmerhaus, West, 2003).

Table 6-22: Economic, sustainability and LCA analysis for the 4 feasible flowsheet alternatives generated for the production of DMC

\begin{tabular}{|c|c|c|c|c|c|c|}
\hline \multirow{8}{*}{ 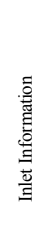 } & Measures of Comparison (units) & Base Case & Alternative 1 & Alternative 3 & Alternative 5 & Alternative 9 \\
\hline & Feed Mole Ratio & 5 to 1 & 2 to 1 & 5 to 1 & 5 to 1 & 12.5 to 1 \\
\hline & Mole Feed to reactor $(\mathrm{kmol} / \mathrm{hr})$ & $177: 35$ & $70: 35$ & $38: 19$ & $38: 19$ & $237: 19$ \\
\hline & Mole Feed Make-up (kmol/hr) & $38: 19$ & $38: 19$ & & & $38: 19$ \\
\hline & PC conversion & 0.54 & 0.535 & 0.54 & 0.54 & 99.5 \\
\hline & Input-MeOH (kg/h) & 1215.65 & 1212.329 & 1211.614 & 1211.614 & 1214.45694 \\
\hline & Input-PC $(\mathrm{kg} / \mathrm{h})$ & 1936.6 & 1937.97 & 1949.66 & 1953.859 & 1934.69658 \\
\hline & Input-Total $(\mathrm{kg} / \mathrm{h})$ & 3152.25 & 3150.299 & 3161.274 & 3165.473 & 3149.15352 \\
\hline \multirow{7}{*}{ 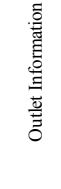 } & DMC product $(\mathrm{kg} / \mathrm{h})$ & 1698 & 1698 & 1702 & 1699 & 1698 \\
\hline & Operating Days & 300 & 300 & 300 & 300 & 300 \\
\hline & Product purity (DMC,\%) & 99.9 & 99.9 & 99.92 & 98.9 & 99.9 \\
\hline & By-product purity (PG,\%) & 99 & 99.1 & 98.6 & 98.1 & 99 \\
\hline & Raw Material loss-MeOH (kg/hr) & 4.86 & 0.72 & 0.00 & 0.00 & 6.24 \\
\hline & Raw Material loss-PC (kg/hr) & 7.74 & 7.79 & 0.19 & 23.70 & 9.95 \\
\hline & Raw Material loss-Total (kg/hr) & 12.59 & 8.51 & 0.19 & 23.70 & 16.19 \\
\hline \multirow{4}{*}{ 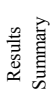 } & Energy usage (MJ/hr) & 133,563 & 28,424 & 17,818 & 17,734 & 64,816 \\
\hline & Utility Cost (\$/year) & $4,393,537$ & 979,301 & 906,474 & 593,541 & $2,011,964$ \\
\hline & Raw Material Cost $(\$ / \mathrm{yr})$ & $24,853,986$ & $24,858,022$ & $24,981,958$ & $24,820,352$ & $24,829,564$ \\
\hline & Operating Cost (\$/year) & $29,247,523$ & $25,837,323$ & $25,888,432$ & $25,413,893$ & $26,841,528$ \\
\hline \multirow{9}{*}{ 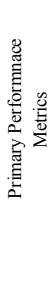 } & Raw Material usage (kg Raw Material/kg DMC Product) & 1.86 & 1.85 & 1.86 & 1.86 & 1.85 \\
\hline & Energy usage per kg of product ( $\mathrm{MJ} / \mathrm{kg}$ of DMC product) & 78.65 & 16.74 & 10.47 & 10.44 & 38.17 \\
\hline & Raw Material Cost per kg of product ( $\$ / \mathrm{kg}$ of DMC product) & 2.03 & 2.03 & 2.04 & 2.03 & 2.03 \\
\hline & Utility Cost per kg of product ( $\$ / \mathrm{kg}$ of DMC product) & 0.36 & 0.08 & 0.07 & 0.05 & 0.16 \\
\hline & Operational Cost ( $\$ / \mathrm{kg}$ of DMC product)-min & 2.39 & 2.11 & 2.11 & 2.08 & 2.20 \\
\hline & Product Sale $(\$ / y r)$ & $32,580,433$ & $32,415,861$ & $32,672,416$ & $32,538,792$ & $32,550,111$ \\
\hline & Product Sale per kg of product ( $\$ / \mathrm{kg}$ of DMC product) & 2.66 & 2.65 & 2.67 & 2.66 & 2.66 \\
\hline & Profit (\$/kg of DMC product)-max & 0.27 & 0.54 & 0.55 & 0.58 & 0.47 \\
\hline & Fobj-TAC ( $\$ / \mathrm{kg}$ of DMC product)-min & 0.36 & 0.08 & 0.09 & 0.06 & 0.18 \\
\hline \multirow{5}{*}{ 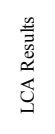 } & Total Carbon Footprint (kg CO2/kg of DMC product) & 2.08 & 0.46 & 0.31 & 0.31 & 0.98 \\
\hline & HTPI (1/LD 50) & $2.83 \mathrm{E}-04$ & $2.76 \mathrm{E}-04$ & $2.75 \mathrm{E}-04$ & $6.08 \mathrm{E}-05$ & $2.78 \mathrm{E}-04$ \\
\hline & GWP (CO2 eq.) & $6.15 \mathrm{E}+00$ & $4.53 \mathrm{E}+00$ & $4.37 \mathrm{E}+00$ & $3.70 \mathrm{E}+00$ & $5.05 \mathrm{E}+00$ \\
\hline & HTC (kg benzen eq) & $4.68 \mathrm{E}-03$ & $4.01 \mathrm{E}-03$ & $3.94 \mathrm{E}-03$ & $3.80 \mathrm{E}-03$ & $4.20 \mathrm{E}-03$ \\
\hline & HTNC (kg toluen eq.) & $6.84 \mathrm{E}-02$ & $6.68 \mathrm{E}-02$ & $6.65 \mathrm{E}-02$ & $6.63 \mathrm{E}-02$ & $6.73 \mathrm{E}-02$ \\
\hline
\end{tabular}

The results of the objective function (Equation 6.27) is given in Table 6-22. Flowsheet alternative 1 and flowsheet alternative 5 show the best values of the objective function. These two alternatives also have the lowest carbon footprint (see LCA results in Table 6-22). However 4 feasible alternatives have been generated which have a minimum improvement when compared to the base case of $50 \%$ (alternative 9 ). 
The results presented in Table 6-22 are represented in terms of a radar plot. Therefore from Figure 6-20 it can be seen that for all the considered criteria, the alternatives are better than the base case design.

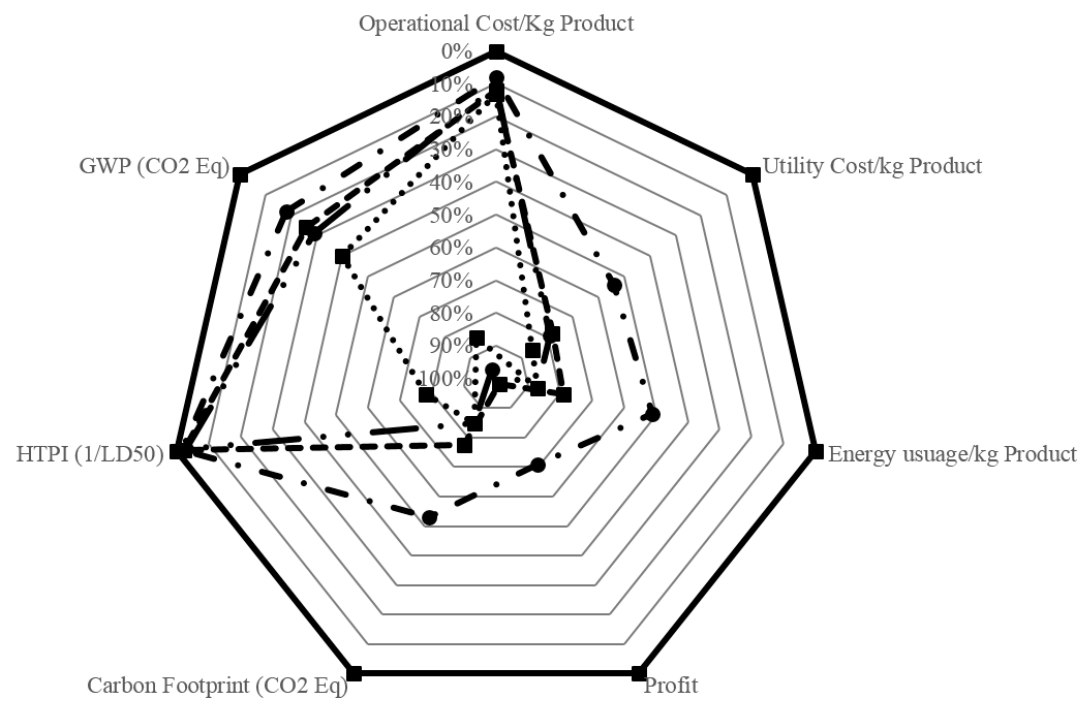

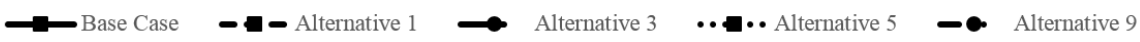

Figure 6-20: Economic and LCA improvements relative to the base case design. HTPIHuman Toxicity Potential by Ingestion, GWP- Global Warming Potential.

From the results presented in Table 6-22 and the design targets set in step 8 the following can be concluded:

1. Reduce energy consumption-yes

2. Reduce utility cost-yes

3. Improvements in LCA/Sustainability indicators-yes, all variables within Figure 6-20

4. Unit operations reduction-yes, 5 (base case), 4 (flowsheet alternative 3, see Figure 6-18(a), with vapor permeation membrane), 4 (flowsheet alternative 5 , see Figure 6-18(b)*, with vapor permeation membrane), 3 (flowsheet alternative 9, see Figure 6-18(c)**)

5. Product purity (kept as the base case)-yes

6. Production target (kept as the base case)-yes

7. Reduce operational cost-yes

8. Waste minimization (raw material)-yes 


\subsection{Production of Biodiesel}

\subsubsection{Step 1-Need Identification}

Action 1: Biodiesel (FAME) is a feasible alternative to conventional petroleum based diesel because it reduces most emissions (except NOx) for example hydro-carbons and carbon monoxide (CO) (Lin et al., 2009) and can be used in conventional diesel engines, which is not the same for conventional diesel.

Action 2: The total production per year of biodiesel according to the biodiesel board in the US, is $5.9 \times 10^{6}$ tons/year (Simasatitkul et al., 2013). Therefore the specified production target is $42690 \mathrm{~kg} / \mathrm{hr}$ (Mansouri et al., 2013). The purity of the product and byproduct should be greater than or equal to $99.9 \mathrm{wt} \%$ and $99 \mathrm{wt} \%$, for FAME and glycerol respectively.

\subsubsection{Step 2-Problem definition}

Action 1: Problem statement: Identification of process flowsheet alternatives using intensified unit operations for the production of FAME subject to constraints and performance criteria.

Action 2: The objective function is defined in terms of minimizing the operational cost, Equation 6.29 subject to constraints and performance criteria:

$$
\operatorname{Min} F_{o b j}=\frac{C_{R M, i}+E_{j} C_{U t}}{m_{\text {prod }}}
$$

Action 3: The constraints considered are given in Table 6-23. 
Table 6-23: Defined constraints for process synthesis-intensification of FAME production

\begin{tabular}{|c|c|c|c|c|}
\hline \multirow{2}{*}{ Objective } & \multicolumn{3}{|c|}{ Constraint } & \multirow{2}{*}{$\begin{array}{l}\text { Performance } \\
\text { Criteria }(\underline{\varphi})\end{array}$} \\
\hline & $\underline{\theta_{1}}$ & $\underline{\theta_{2}}$ & $\underline{\theta_{3}}$ & \\
\hline Flowsheet structure: reaction + separation & $*$ & & & \\
\hline Reaction occurs in the first unit operation & $*$ & & & \\
\hline $\begin{array}{l}\text { The product purity of FAME and Glycerol } \\
\text { is defined is } \geq 99 \mathrm{~mol} \%\end{array}$ & $*$ & & & \\
\hline $\begin{array}{l}\text { PBBs are connected to form SPBs based } \\
\text { on combination rules }\end{array}$ & & $*$ & & \\
\hline $\begin{array}{l}\text { SPBs are connected to form Basic Struc- } \\
\text { tures based on combination rules }\end{array}$ & & * & & \\
\hline $\begin{array}{l}\text { Do not use mass separating agents for re- } \\
\text { action/separation }\end{array}$ & & * & & \\
\hline Recycle un-reacted raw materials & & * & & \\
\hline $\begin{array}{l}\text { Do not use recycle streams if not neces- } \\
\text { sary }\end{array}$ & & * & & \\
\hline $\begin{array}{l}\text { Raw materials, methanol and acetic acid } \\
\text { are assumed to be in their pure state }\end{array}$ & & & $*$ & \\
\hline $\begin{array}{l}\text { Production target of FAME is set at } \\
350 \times 10^{3} \text { tons/year }\end{array}$ & & & * & \\
\hline $\begin{array}{l}\text { PI screening criteria for basic structures to } \\
\text { unit operations: Novel equipment feasible }\end{array}$ & & & & * \\
\hline Increase $\mathrm{MeOH}$ conversion is explored & & & & * \\
\hline $\begin{array}{l}\text { Minimization/reduction in energy con- } \\
\text { sumption }\end{array}$ & & & & $*$ \\
\hline Inclusion of intensified equipment & & & & $*$ \\
\hline Reduction in the number of unit operations & & & & $*$ \\
\hline Waste minimization & & & & $*$ \\
\hline $\begin{array}{l}\text { Sustainability and LCA factors must be the } \\
\text { same or better }\end{array}$ & & & & $*$ \\
\hline
\end{tabular}




\subsubsection{Step 3-Reaction Identification/Selection}

Action 1: The raw materials are methanol $(\mathrm{MeOH})$ and waste cooking vegetable oil $(\mathrm{WcVo})$ and are in the liquid phase for the reaction. The reaction is catalyzed using a homogenous of heterogeneous catalyst (Simasatitkul et al., 2013). The WcVo is a complex mixture consisting of fatty alkyl acids (FAA) and tri-glycerides. The FAME mixture consists of methyl esters. The compounds present in both $\mathrm{WcVo}$ and FAME before and during the reaction that are considered are given in Table 6-24. Multiple reactions occur for the production of FAME based on the FAA's and glycerides. A list of the reactions considered, their conversion and enthalpy of reaction is given in Table 6-25. The overall heat of reaction is $-4.77 \times 10^{4} \mathrm{~kJ} / \mathrm{mol}$. FAME and $\mathrm{WcVo}$ are made up of a number of compounds and these are given in Table 6-26 and Table 6-27.

Table 6-24: Compounds present in FAME and WcVo before and during the reaction

\begin{tabular}{|c|c|c|c|c|c|}
\hline & Compound & Chemical formula & & Compound & Chemical formula \\
\hline \multirow{10}{*}{ 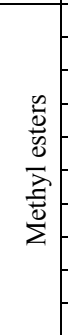 } & Methanol & $\mathrm{CH}_{3} \mathrm{OH}$ & \multirow{7}{*}{ 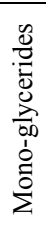 } & Monolaurin & $\mathrm{H}_{3} \mathrm{C}\left(\mathrm{CH}_{2}\right)_{10} \mathrm{COOCH}_{2} \mathrm{CH}(\mathrm{OH}) \mathrm{CH}_{2} \mathrm{OH}$ \\
\hline & Water & $\mathrm{H}_{2} \mathrm{O}$ & & Monomyristin & $\mathrm{H}_{3} \mathrm{C}\left(\mathrm{CH}_{2}\right)_{12} \mathrm{COOCH}_{2} \mathrm{CH}(\mathrm{OH}) \mathrm{CH}_{2} \mathrm{OH}$ \\
\hline & Glycerol & $\mathrm{C}_{3} \mathrm{H}_{8} \mathrm{O}_{3}$ & & Monopalmitin & $\mathrm{HOCH}_{2} \mathrm{CH}(\mathrm{OH}) \mathrm{CH}_{2} \mathrm{OCO}\left(\mathrm{CH}_{2}\right)_{14} \mathrm{CH}_{3}$ \\
\hline & Methyl laurate & $\mathrm{CH}_{3}\left(\mathrm{CH}_{2}\right)_{10} \mathrm{CO}_{2} \mathrm{CH}_{3}$ & & Monostearin & $\mathrm{CH}_{3}\left(\mathrm{CH}_{2}\right)_{16} \mathrm{COOCH}_{2} \mathrm{CH}(\mathrm{OH}) \mathrm{CH}_{2} \mathrm{OH}$ \\
\hline & Methyl myristate & $\mathrm{CH}_{3}\left(\mathrm{CH}_{2}\right)_{12} \mathrm{COOCH}_{3}$ & & Monoolein & $\mathrm{CH}_{3}(\mathrm{CH} 2)_{7} \mathrm{CH}=\mathrm{CH}\left(\mathrm{CH}_{2}\right)_{7} \mathrm{COOCH}_{2} \mathrm{CHOHCH}_{2} \mathrm{OH}$ \\
\hline & Methyl palmitate & $\mathrm{CH}_{3}\left(\mathrm{CH}_{2}\right)_{14} \mathrm{CO}_{2} \mathrm{CH}_{3}$ & & Monolinolein & $\mathrm{C}_{21} \mathrm{H}_{38} \mathrm{O}_{4}$ \\
\hline & Methyl stearate & $\mathrm{CH}_{3}\left(\mathrm{CH}_{2}\right)_{16} \mathrm{CO}_{2} \mathrm{CH}_{3}$ & & Monolinolenin & $\mathrm{C}_{21} \mathrm{H}_{36} \mathrm{O}_{4}$ \\
\hline & Methyl oleate & $\mathrm{CH}_{3}\left(\mathrm{CH}_{2}\right)_{7} \mathrm{CH}=\mathrm{CH}\left(\mathrm{CH}_{2}\right)_{7} \mathrm{CO}_{2} \mathrm{CH}_{3}$ & \multirow{9}{*}{ 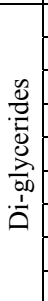 } & Dilaurin & $\mathrm{C}_{27} \mathrm{H}_{52} \mathrm{O}_{5}$ \\
\hline & Methyl linoleate & $\mathrm{CH}_{3}\left(\mathrm{CH}_{2}\right)_{3}\left(\mathrm{CH}_{2} \mathrm{CH}=\mathrm{CH}\right)_{2}\left(\mathrm{CH}_{2}\right)_{7} \mathrm{CO}_{2} \mathrm{CH}_{3}$ & & Dimyristin & $\mathrm{C}_{31} \mathrm{H}_{60} \mathrm{O}_{5}$ \\
\hline & Methyllinol & - & & Dipalmitin & $\mathrm{C}_{35} \mathrm{H}_{68} \mathrm{O}_{5}$ \\
\hline \multirow{6}{*}{ 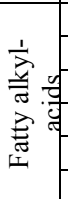 } & Lauric acid & $\mathrm{CH}_{3}\left(\mathrm{CH}_{2}\right)_{10} \mathrm{COOH}$ & & Distearin & $\mathrm{C}_{39} \mathrm{H}_{76} \mathrm{O}_{5}$ \\
\hline & Myristic acid & $\mathrm{CH}_{3}\left(\mathrm{CH}_{2}\right)_{12} \mathrm{COOH}$ & & Diolein & $\mathrm{C}_{39} \mathrm{H}_{72} \mathrm{O}_{5}$ \\
\hline & Palmitic acid & $\mathrm{CH}_{3}\left(\mathrm{CH}_{2}\right)_{14} \mathrm{COOH}$ & & Dilinolein & $\mathrm{C}_{39} \mathrm{H}_{68} \mathrm{O}_{5}$ \\
\hline & Stearic acid & $\mathrm{CH}_{3}\left(\mathrm{CH}_{2}\right)_{16} \mathrm{COOH}$ & & Dilinolenin & $\mathrm{C}_{39} \mathrm{H}_{64} \mathrm{O}_{5}$ \\
\hline & Oleic acid & $\mathrm{CH}_{3}\left(\mathrm{CH}_{2}\right)_{7} \mathrm{CH}=\mathrm{CH}\left(\mathrm{CH}_{2}\right)_{7} \mathrm{COOH}$ & & & \\
\hline & Linoleic acid & $\mathrm{CH}_{3}\left(\mathrm{CH}_{2}\right)_{4} \mathrm{CH}=\mathrm{CHCH}_{2} \mathrm{CH}=\mathrm{CH}\left(\mathrm{CH}_{2}\right)_{7} \mathrm{CO}_{2} \mathrm{H}$ & & & \\
\hline \multicolumn{6}{|c|}{ Tri-glycerides } \\
\hline & Trilaurin & {$\left[\mathrm{CH}_{3}\left(\mathrm{CH}_{2}\right)_{10} \mathrm{COOCH}_{2}\right]_{2} \mathrm{CHOCO}\left(\mathrm{CH}_{2}\right)_{10} \mathrm{CH}_{3}$} & & Triolein & $\mathrm{C}_{57} \mathrm{H}_{104} \mathrm{O}_{6}$ \\
\hline & Trimyristin & {$\left[\mathrm{CH}_{3}\left(\mathrm{CH}_{2}\right)_{12} \mathrm{COOCH}_{2}\right]_{2} \mathrm{CHOCO}\left(\mathrm{CH}_{2}\right)_{12} \mathrm{CH}_{3}$} & & Trilinolein & $\mathrm{C}_{57} \mathrm{H}_{98} \mathrm{O}_{6}$ \\
\hline & Tripalmitin & {$\left[\mathrm{CH}_{3}\left(\mathrm{CH}_{2}\right)_{14} \mathrm{COOCH}_{2}\right]_{2} \mathrm{CHOCO}\left(\mathrm{CH}_{2}\right)_{14} \mathrm{CH}_{3}$} & & Trilinolenin & $\mathrm{C}_{57} \mathrm{H}_{92 \mathrm{O}_{6}}$ \\
\hline & Tristearin & $\left(\mathrm{C}_{17} \mathrm{H}_{33} \mathrm{COOCH}_{2}\right)_{2} \mathrm{CHOCOC}_{17} \mathrm{H}_{33}$ & & & \\
\hline & Trilaurin & {$\left[\mathrm{CH}_{3}\left(\mathrm{CH}_{2}\right)_{10} \mathrm{COOCH}_{2}\right]_{2} \mathrm{CHOCO}\left(\mathrm{CH}_{2}\right)_{10} \mathrm{CH}_{3}$} & & & \\
\hline
\end{tabular}


Table 6-25: The reactions involved in FAME production from $\mathrm{WcVo}$

\begin{tabular}{|c|c|c|c|}
\hline Number & Reaction & $\begin{array}{c}\text { Conversion } \\
\text { (\%) }\end{array}$ & $\begin{array}{c}\Delta H \\
(\mathrm{~kJ} / \mathrm{kmol})\end{array}$ \\
\hline R.1 & Lauric acid + Methanol $\rightarrow$ Methyl laurate + Water & 94.0 & $-1.0 \mathrm{E}+04$ \\
\hline R.2 & Linoleic acid + Methanol $\rightarrow$ Methyl linoleate + Water & 94.0 & $-1.6 \mathrm{E}+05$ \\
\hline R.3 & Linoleic acid+Methanol $\rightarrow$ Methyllinol+Water & 94.0 & $-3.6 \mathrm{E}+04$ \\
\hline R.4 & Myristic acid + Methanol $\rightarrow$ Methyl myristate + Water & 94.0 & $-2.7 \mathrm{E}+04$ \\
\hline R.5 & Oleic acid + Methanol $\rightarrow$ Methyl oleate + Water & 94.0 & $6.3 \mathrm{E}+03$ \\
\hline R.6 & Stearic acid + Methanol $\rightarrow$ Methyl stearate + Water & 94.0 & $-1.1 \mathrm{E}+04$ \\
\hline R.7 & Palmitic acid + Methanol $\rightarrow$ Methyl palmitate + Water & 94.0 & $-1.4 \mathrm{E}+04$ \\
\hline R.8 & Trilaurin+Methanol $\rightarrow$ Methyl laurate+Dilaurin & 99.0 & $5.6 \mathrm{E}+05$ \\
\hline R.9 & Trilinolein+Methanol $\rightarrow$ Dilinolein + Methyl linoleate & 99.0 & $-7.8 \mathrm{E}+04$ \\
\hline R.10 & Trilinolenin+Methanol $\rightarrow$ Methyllinol+Dilinolenin & 99.0 & $2.8 \mathrm{E}+05$ \\
\hline R.11 & Trimyristin+Methanol $\rightarrow$ Methyl myristate+Dimyristin & 99.0 & $5.2 \mathrm{E}+05$ \\
\hline R.12 & Triolein + Methanol $\rightarrow$ Diolein + Methyl oleate & 99.0 & $2.7 \mathrm{E}+05$ \\
\hline R.13 & Tripalmitin+Methanol $\rightarrow$ )Methyl palmitate+Dipalmitin & 99.0 & $5.0 \mathrm{E}+05$ \\
\hline R.14 & Tristearin+Methanol $\rightarrow$ Methyl stearate+Distearin & 99.0 & $4.8 \mathrm{E}+05$ \\
\hline R.15 & Dilaurin + Methanol $\rightarrow$ Methyl laurate + Monolauri & 99.0 & $-5.6 \mathrm{E}+05$ \\
\hline R.16 & Dilinolein+Methanol $\rightarrow$ Monolinolein+Methyl linoleate & 99.0 & $-1.7 \mathrm{E}+05$ \\
\hline R.17 & Dilinolenin+Methanol $\rightarrow$ Methyllinol+Dilinolenin & 99.0 & $2.8 \mathrm{E}+05$ \\
\hline R.18 & Dimyristin + Methanol $\rightarrow$ Methyl myristate + Monomyristin & 99.0 & $-5.5 \mathrm{E}+05$ \\
\hline R.19 & Diolein+Methanol $\rightarrow$ Monoolein+Methyl oleate & 99.0 & $-2.8 \mathrm{E}+05$ \\
\hline R.20 & Dipalmitin + Methanol $\rightarrow$ Methyl palmitate + Monopalmitin & 99.0 & $-5.3 \mathrm{E}+05$ \\
\hline R.21 & Monolinolenin+Methanol $\rightarrow$ Methyl laurate + Glycerol & 99.0 & $-1.6 \mathrm{E}+04$ \\
\hline R.22 & Distearin+Methanol $\rightarrow$ Methyl stearate + Monostearin & 99.0 & $-5.1 \mathrm{E}+05$ \\
\hline R.23 & Monolinolein+Methanol $\rightarrow$ Methyl linoleate+Glycerol & 99.0 & $-1.4 \mathrm{E}+05$ \\
\hline R.24 & $\square($ Monolinolenin+Methanol $\rightarrow$ Methyllinol+Glycerol & 99.0 & $-1.4 \mathrm{E}+05$ \\
\hline R.25 & Monomyristin+Methano $\rightarrow$ Methyl myristate+Glycerol & 99.0 & $-3.3 \mathrm{E}+04$ \\
\hline R.26 & Monoolein + Methanol $\rightarrow$ Methyl oleate + Glycerol & 99.0 & $-2.3 \mathrm{E}+4$ \\
\hline R.27 & Monopalmitin + Methanol $\rightarrow$ Methyl palmitate + Glycerol & 99.0 & $-3.3 \mathrm{E}+04$ \\
\hline R.28 & Monostearin + Methanol $\rightarrow$ Methyl stearate + Glycerol & 99.0 & $-3.3 \mathrm{E}+04$ \\
\hline
\end{tabular}


Table 6-26: FAME (biodiesel) composition in terms of mass fraction

\begin{tabular}{|l|c|}
\hline \multicolumn{1}{|c|}{ Compound } & Biodiesel \\
\hline Methyl laurate & 0.0010 \\
\hline Methyl myristate & 0.0100 \\
\hline Methyl palmitate & 0.4303 \\
\hline Methyl stearate & 0.0420 \\
\hline Methyl oleate & 0.4038 \\
\hline Methyl linoleate & 0.1013 \\
\hline Methyllinol & 0.0075 \\
\hline Total & 1.0000 \\
\hline
\end{tabular}

Table 6-27: WcVo feed composition in terms of mass

\begin{tabular}{|c|c|c|}
\hline & Compound & Biodiesel \\
\hline \multirow{7}{*}{ 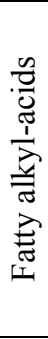 } & Lauric acid & 0.0010 \\
\hline & Myristic acid & 0.0097 \\
\hline & Palmitic acid & 0.4155 \\
\hline & Stearic acid & 0.0437 \\
\hline & Oleic acid & 0.3932 \\
\hline & Linoleic acid & 0.0981 \\
\hline & Linolenc acid & 0.0388 \\
\hline & Total & 1.0000 \\
\hline \multirow{8}{*}{ 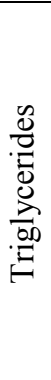 } & Trilaurin & 0.0010 \\
\hline & Trimyristin & 0.0101 \\
\hline & Tripalmitin & 0.4306 \\
\hline & Tristearin & 0.0453 \\
\hline & Triolein & 0.4074 \\
\hline & Trilinolein & 0.1016 \\
\hline & Trilinoleni & 0.0040 \\
\hline & Total & 1.0000 \\
\hline
\end{tabular}

Action 2: State of the products and by-products from Table 6-25 are in the liquid phase. The heat of reaction for each reaction is shown in Table 6-25. The reactions are forward reactions and therefore, they are irreversible and exothermic because the overall heat of reaction, $\Delta H_{r x n}<0$.

\subsubsection{Step 4-Check for Availability-Base Case}

Action 1: From a literature survey, a known base case design (Simasatitkul et al., 2013) was pre-selected and is shown in Figure 6-12. The base case consists of 9 unit operations: 1 reactor (R1), 2 flash columns (T1 and T5), 2 decanters (D1 and D2) and 4 distillation columns (T2, T3, T4 and T6). 
A brief description about the process: The raw materials are fed at a mole ratio of 9:1, with $\mathrm{MeOH}$ in excess, to the reactor where, esterification and trans-esterification reactions occur to produce FAME and mainly $\mathrm{H} 2 \mathrm{O}$. The reactions associated to the FFAs are esterification reactions and the reactions associated with the glycerides are transesterification reactions. The reactor effluent consist of a mixture of $\mathrm{MeOH}, \mathrm{WcVo}$ and $\mathrm{H} 2 \mathrm{O}$. The first column (T1) is a flash separation and separates $\mathrm{MeOH}$ and $\mathrm{H} 2 \mathrm{O}$ (top of T1) from the reactor effluent with WcVo, FAME, glycerol and $\mathrm{H} 2 \mathrm{O}$ (bottom of T1). The separation is not perfect so some $\mathrm{WcVo}$ and glycerol are found at the top of T1 and $\mathrm{H} 2 \mathrm{O}$ and $\mathrm{MeOH}$ are found in the bottom of T1. The top of $\mathrm{T} 1$ contains $\mathrm{MeOH}$ and $\mathrm{H} 2 \mathrm{O}$ (mainly) and $\mathrm{WcVo}$ and glycerol. In D1 (decanter) $\mathrm{MeOH}$ and $\mathrm{H} 2 \mathrm{O}$ are separated and the other compounds obtained at the bottom are referred to in the diagram as heavy liquids (HL). In T2, MeOH is separated from $\mathrm{H} 2 \mathrm{O}$ and the unreacted $\mathrm{MeOH}$ is recycled to the reactor.

In $\mathrm{D} 2 \mathrm{MeOH}$, glycerol and $\mathrm{H} 2 \mathrm{O}$ are separated from WcVo and FAME. In T5, a flash separation occurs which separates glycerol from $\mathrm{MeOH}$ and $\mathrm{H} 2 \mathrm{O}$. In $\mathrm{T} 6 \mathrm{MeOH}$ is separated from $\mathrm{H} 2 \mathrm{O}$ and the unreacted $\mathrm{MeOH}$ is recycled to the reactor. The $\mathrm{D} 2 \mathrm{MeOH}$ is present in both phases with glycerol and, WcVo and FAME. In T3, MeOH is separated from $\mathrm{WcVo}$, and FAME and in T4, FAME is separated from $\mathrm{WcVo}$.

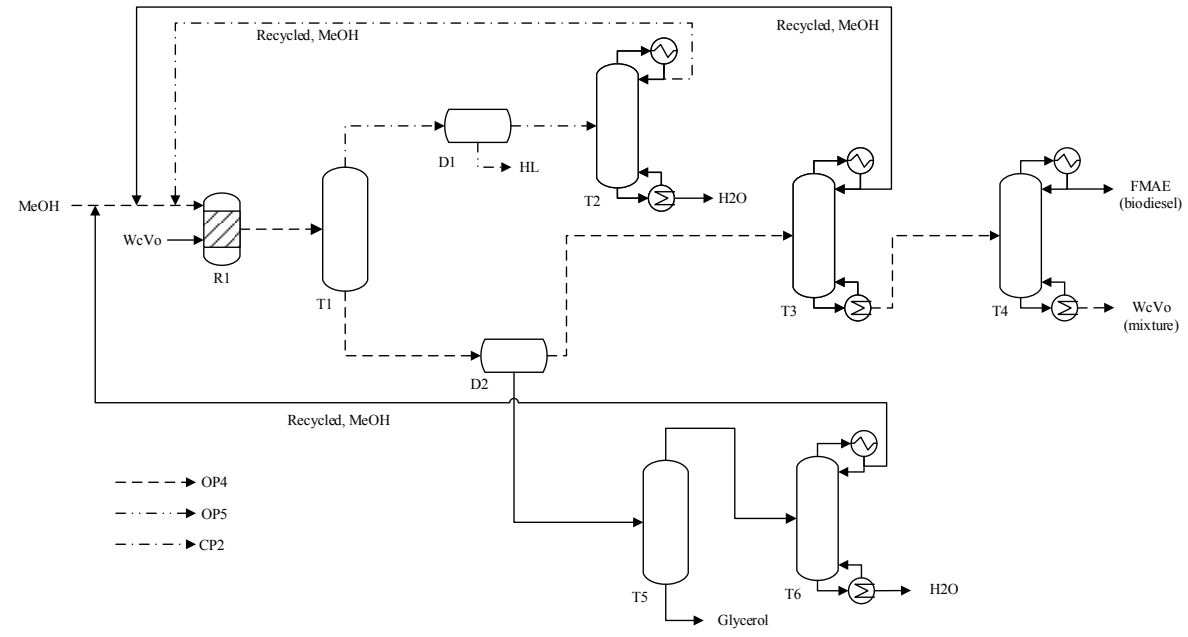

Figure 6-21: Base case design for the production of FAME (biodiesel). The open and closed paths (OP, CP) are also highlighted which is the output of Step 8

\subsubsection{Step 5-Check for Base Case Feasibility}

The pre-selected base design is verified using the process synthesis method of Douglas (1985) in order to verify if it is feasible to be used as a base case design. From the analysis the pre-selected design satisfied the synthesis method of Douglas (1985), therefore, it is selected to be used as a feasible design. 


\subsubsection{Step 7-Perform Rigorous Simulation}

Action 1: The selected thermodynamic model is the UNIQUAC using Figure 3-2 and data from Simasatitkul et al. (2013). The base case design is rigorously using equilibrium based models for the reactor and separators using Aspen HYSYS. $\mathrm{MeOH}$ is fed in excess in order to achieve close to the equilibrium conversion. An overview of the simulation results is given in Table 6-28.

Table 6-28: Highlighted results from the simulation of the base case design

\begin{tabular}{|l|l|}
\hline & Value \\
\hline Feed Mole ratio (MeOH:WcVo) & $9: 1$ \\
\hline DMC product (kg/hr) & 42,690 \\
\hline Energy usage (MJ/ hr) & 119,163 \\
\hline Utility Cost (\$/yr) & $7,790,000$ \\
\hline
\end{tabular}

Action 2: The detailed mass and energy balance data, number of streams and unit operations of the base case based on the rigorous simulation is retrieved, which is to be used for the analyses in step 8.

\subsubsection{Step 8-Economic, Sustainability and LCA analysis}

Action 1-3: The economic, sustainability and LCA analysis are performed. The economic and LCA analysis results are shown in Figure 6-22 and the sustainability analyses is shown in Table 6-29. In Table 6-29 the most critical streams (paths) in the process are listed with the paths highlighted in Figure 6-21. 

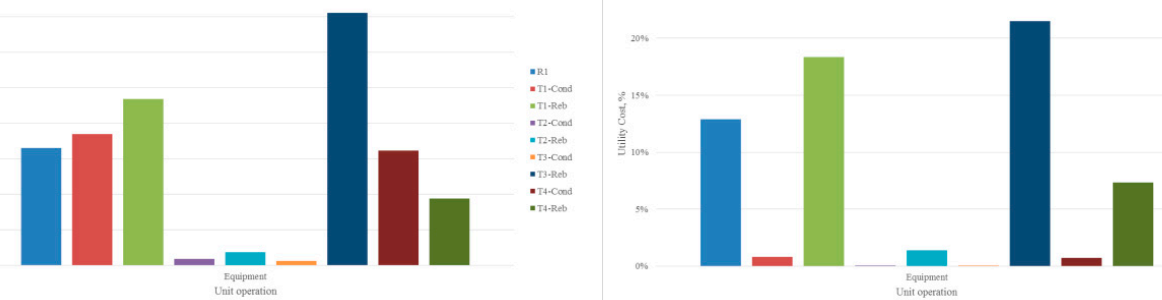

Figure 6-22: Economic analysis and LCA analysis for the base case design. Carbon footprint and Utility cost are compared. Note: $\mathrm{Cond}=$ condenser, $\mathrm{Reb}=\mathrm{reboiler}$

Table 6-29: The 3 most critical paths in the base case design that have the highest potentials for improvement. Note: OP-open path, CP-closed path

\begin{tabular}{|l|l|l|l|l|l|}
\hline Path & Compound & $\begin{array}{l}\text { Flowrate } \\
(\mathbf{k g} / \mathbf{h r})\end{array}$ & $\begin{array}{l}\text { MVA } \\
\left(\mathbf{1 0}^{\mathbf{3}} \mathbf{\$} / \mathbf{y e a r}\right)\end{array}$ & $\begin{array}{l}\text { TVA } \\
\left(\mathbf{1 0}^{\mathbf{3}} \mathbf{\$} / \text { year }\right)\end{array}$ & $\begin{array}{l}\text { EWC } \\
\left(\mathbf{1 0}^{\mathbf{3}} \mathbf{\$} / \text { year }\right)\end{array}$ \\
\hline OP4 & MeOH & 3129.80 & -14174.30 & & \\
\hline OP5 & Methyl oleate & 174.10 & -2047.20 & & \\
\hline CP2 & MeOH & 46166.60 & & & 2291.70 \\
\hline
\end{tabular}

From Table 6-29 OP4 and $\mathrm{CP} 2$ which follows the raw material $\mathrm{MeOH}$, has a high MVA and EWC respectively. This means that $\mathrm{MeOH}$ is losing its value as it exits the process through OP4, that is, raw material is being lost in this path and in CP2 a high flow of $\mathrm{MeOH}$ is being recycled resulting in high loads of energy and waste/use of utilities.

Action 4: The identified process hot-spots are given in Table 6-30.

Table 6-30: Identified process hot-spots in the base case design for the production of FAME

\begin{tabular}{|c|c|c|c|}
\hline Indicator values & $\begin{array}{l}\text { Base Case prop- } \\
\text { erty }\end{array}$ & Reason & $\begin{array}{l}\text { Identified Process } \\
\text { hot-spot }\end{array}$ \\
\hline $\begin{array}{l}\alpha_{2}=\text { Utility cost } \\
\beta_{1}=\mathrm{MVA} \\
\beta_{2}=\mathrm{EWC} \\
\gamma_{1}=\mathrm{CO} 2 \text { equiva- } \\
\text { lent } \\
\gamma_{2}=\mathrm{PEI}\end{array}$ & $\begin{array}{l}\text { Un-reacted raw } \\
\text { materials and } \\
\text { products recovery }\end{array}$ & $\begin{array}{l}\text {-Presence of azeo- } \\
\text { trope(s) } \\
\text {-High energy usage- } \\
\text { heating and/or cool- } \\
\text { ing }\end{array}$ & $\begin{array}{l}\text {-Azeotrope } \\
\text {-Difficult separation: } \\
\text { low driving force } \\
\text {-High energy con- } \\
\text { sumption and/or de- } \\
\text { mand }\end{array}$ \\
\hline
\end{tabular}

Action 5: Using Table 3-3, the design targets to be set/met are:

1. Reduce energy consumption

2. Reduce utility cost 
3. Improvements in LCA/Sustainability indicators

4. Unit operations reduction

5. Product purity (kept as the base case)

6. Production target (kept as the base case)

7. Reduce operational cost

\subsubsection{IT-PBS.1-Process Analysis}

Action 1: The task based flowsheet of the base case design is shown in Figure 6-23.

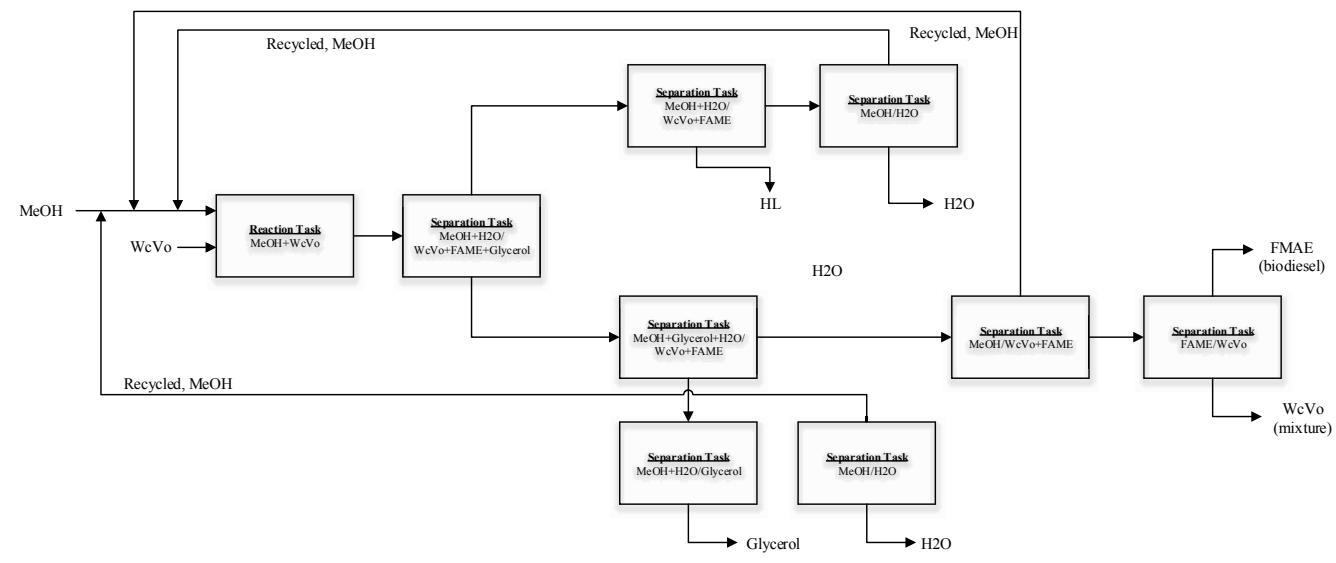

Figure 6-23: Task based flowsheet of the base case design 
Action 2: The phenomena based flowsheet of the base case design is shown in Figure 6-24. The identified PBBs are:

- Reaction task: M, R, C

- Separation task:

○ VL-M, 2phM, C/H, PC(VL), PT(VL), PS(VL)

○ LL-M, PC(LL), PS(LL)

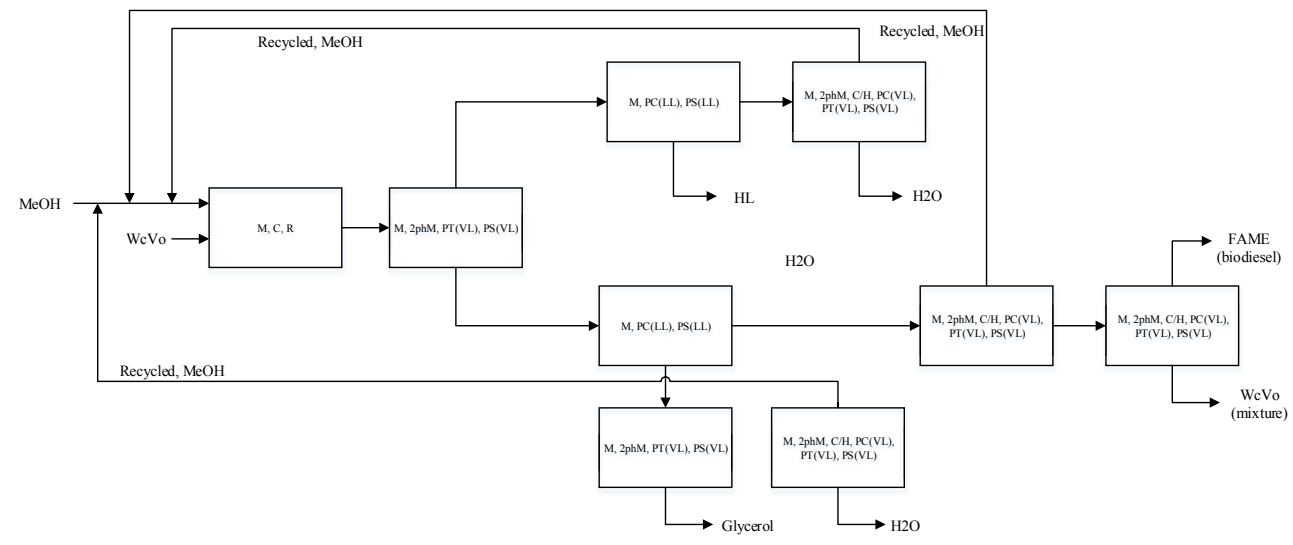

Figure 6-24: Phenomena based flowsheet of the base case design

Action 3: The binary ratio matrix (highlighted results) is given in presented in Table 6-31. Due to the number of compounds present in the system, the total number of binary pairs is 666. Therefore the binary pairs shown in Table 6-31 are those of the main compounds of $\mathrm{WcVo}$ and FAME. 
Table 6-31: Binary ratio matrix for a selected set of properties. MW- molecular weight, Tb- normal boiling point, RG- radius of gyration, Tm- normal melting point, VM- molar volume, SolPar- solubility parameter, VDW- Van der Waals volume, NA- not available

\begin{tabular}{|l|l|l|l|l|l|l|l|}
\hline rij & Mw & Tm & Tb & RG & SolPar & VdW & VM \\
\hline $\mathrm{MeOH} / \mathrm{H} 2 \mathrm{O}$ & 1.78 & 1.56 & 1.1 & 2.52 & 1.62 & 1.76 & 2.25 \\
\hline $\mathrm{MeOH} /$ Glycerol & 2.85 & 1.67 & 1.59 & 2.27 & 1.17 & 2.38 & 1.75 \\
\hline $\mathrm{MeOH}$ Tripalmitin & 25.23 & 2.38 & 2.42 & 6.73 & 2.32 & NA & 22.15 \\
\hline $\mathrm{MeOH/Triolein}$ & 27.86 & 2.48 & 2.49 & 6.90 & 2.43 & NA & 24.28 \\
\hline $\begin{array}{l}\text { Methyl Palmitate/ } \\
\text { Tripalmitin }\end{array}$ & 2.99 & 1.38 & 1.36 & 1.53 & 1.39 & NA & 2.91 \\
\hline $\begin{array}{l}\text { Methyl Palmitate/ } \\
\text { Triolein }\end{array}$ & 3.30 & 1.43 & 1.40 & 1.56 & 1.45 & NA & 3.19 \\
\hline $\begin{array}{l}\text { Methyl oleate/ } \\
\text { Tripalmitin }\end{array}$ & 2.72 & 1.43 & 1.33 & 1.00 & 1.38 & NA & 2.65 \\
\hline $\begin{array}{l}\text { Methyl oleate / } \\
\text { Triolein }\end{array}$ & 3.00 & 1.48 & 1.36 & 1.02 & 1.44 & NA & 2.91 \\
\hline
\end{tabular}

According to Simasatitkul et al. (2013), an azeotrope exists between methyl laureate and glycerol. However the composition of methyl laureate is small and therefore, the presence of this azeotrope for separation of FAME from glycerol is not considered.

The octanol/water partition coefficient and water solubility coefficient for the main compounds in FAME and the tri glycerides (in $\mathrm{WcVo}$ ) (see Table 6-26 and Table 6-27) is given in Table 6-32. It can be seen that based on the value of the binary ratio for the octanol/water partition coefficient and water solubility coefficient, a phase split between glycerol and, FAME and WcVo is possible. It has been shown by Doungsri et al. (2011) that FAME and methanol, and glycerol and methanol, are completely mutually soluble, but glycerol and FAME are partially soluble in each other. 
Table 6-32: Miscibility calculations based on pure component properties for glycerol, FAME and Triglycerides

\begin{tabular}{|l|l|l|l|l|}
\hline $\begin{array}{l}\text { Compound in } \\
\text { either FAME of } \\
\text { WcVo }\end{array}$ & $\log (\mathrm{Kow})$ & $\log (\mathrm{Ws})$ & \multicolumn{2}{|l|}{$\begin{array}{l}\text { Binary ratio with Glycerol: } \\
\log (\mathrm{Kow}) \text { and Log (Ws) }\end{array}$} \\
\hline $\begin{array}{l}\text { Methyl palmitate } \\
\text { (FAME) }\end{array}$ & 6.46 & 0.65 & -4.25 & 7.72 \\
\hline $\begin{array}{l}\text { Methyl oleate } \\
\text { (FAME) }\end{array}$ & 7.21 & -0.07 & -4.74 & -71.71 \\
\hline $\begin{array}{l}\text { Tripalmitin } \\
\text { (WcVo) }\end{array}$ & 18.86 & -8.46 & -12.41 & -1.69 \\
\hline Triolein (WcVo) & 21.11 & -10.62 & -13.89 & -2.12 \\
\hline
\end{tabular}

\subsubsection{IT-PBS.2-Identification of Desirable Tasks and Phenomena}

Action 1: The additional PBBs selected are PT(PVL), PT(VV), and PS(VV). Therefore the total list of PBBs are: R, M, 2phM, C, H, PT(LL), PT(VL), PT(PVL), PT(VV), PC(VL), PS(VL), PS(LL), PS(VV), D

Action 2: The remaining PBBs from applying the constraints defined in step 2 are R, M (assuming four types: ideal liquid, flow, rectangular, ideal vapor), 2phM, C, H, PT(LL), PT(VL), PT(PVL), PT(VV), PC(VL), PS(LL), PS(VL), PS(VV), D

Action 3: The operating window for each $\mathrm{PBB}$ is given in Table 6-33 
Table 6-33: Operating window of the identified PBBs in the base case design. All concentrations are below the dew point line and above the bubble point line.

\begin{tabular}{|c|c|}
\hline \multirow{2}{*}{ Phenomena } & Operating Window \\
\hline \multirow{2}{*}{$\mathrm{R}$} & $\mathrm{T}_{\text {low }}=175.15 \mathrm{~K}$ (Lowest Melter) \\
\cline { 2 - 2 } & $\begin{array}{c}\mathrm{T}_{\text {high }}=326.6 \mathrm{~K} \text { (Maximum T for reactor } \\
\text { operation) }\end{array}$ \\
\hline \multirow{2}{*}{$M_{\mathrm{V}}$} & $\mathrm{T}_{\text {low }}=337.70 \mathrm{~K}$ (Lowest boiler) \\
\cline { 2 - 2 } $\mathrm{M}_{\mathrm{ld}}$ & $\mathrm{T}_{\text {high }}=838.82 \mathrm{~K}$ (Highest Boiler) \\
\cline { 2 - 2 } $\mathrm{M}_{\mathrm{V}}, 2 \mathrm{phM}$ & $\mathrm{T}_{\text {low }}=175.15 \mathrm{~K}$ (Lowest Melter) \\
\hline PC(VL) & $\mathrm{T}_{\text {high }}=838.82 \mathrm{~K}$ (Highest Boiler) \\
\hline PC(LL) & $\mathrm{T}_{\text {low }}=337.70 \mathrm{~K}$ (Lowest boiler) \\
\hline \multirow{2}{*}{ PT(VL) } & V-L present \\
\hline PS(VL) & $\mathrm{T}_{\text {low }}=337.70 \mathrm{~K}$ (Lowest boiler) \\
\hline PS(LL) & $\mathrm{T}_{\text {high }}=838.82 \mathrm{~K}$ (Highest Boiler) \\
\hline PT(PVL) & V-L present \\
\hline PT(VV) & L-L present \\
\hline PS(VV) & Component affinity - \\
\hline H & Component affinity \\
\hline C & present (all compounds in the va- \\
\hline D & pour phase) \\
\hline
\end{tabular}

\subsubsection{IT-PBS.3-Generation of Feasible Flowsheet Alternatives}

Action 1: The maximum number of phenomena that can be combined to form an SPB, $\mathrm{n}_{\text {PBB,Max }}$, is calculated to be 13 (Equation 4.22). The total number of SPBs that can be generated, having a maximum of $13 \mathrm{SPBs}$ is 3903817 (Equation 4.23). A list of feasible SPBs is presented in Table 6-34 assuming three types of mixing for each SPB in the liquid phase that is ideal liquid, flow and rectangular. 
Table 6-34: Partial list of feasible SPBs. Mix.-mixing, Cool.-cooling, Heat.-heating, React.-reaction, Sep.-Separation, Ph. Cr.-phase creation, Div.-dividing

\begin{tabular}{|c|c|c|c|c|}
\hline SPB & Connected PBB & In & Out & $\begin{array}{l}\text { Task they } \\
\text { may per- } \\
\text { form }\end{array}$ \\
\hline SPB.1 & $\mathrm{M}$ & $1 . . \mathrm{n}(\mathrm{L}, \mathrm{VL}, \mathrm{V})$ & $1(\mathrm{~L}, \mathrm{VL}, \mathrm{V})$ & Mix. \\
\hline SPB.2 & $\mathrm{M}=2 \mathrm{phM}$ & $1 . . \mathrm{n}(\mathrm{L}, \mathrm{VL}, \mathrm{V})$ & $1(\mathrm{~L}, \mathrm{VL}, \mathrm{V})$ & Mix. \\
\hline SPB.3 & $\mathrm{M}=\mathrm{R}$ & $1 . . \mathrm{n}(\mathrm{L}, \mathrm{VL}, \mathrm{V})$ & $1(\mathrm{~L}, \mathrm{VL}, \mathrm{V})$ & Mix.+React. \\
\hline SPB.4 & $\mathrm{M}=\mathrm{H}$ & 1..n $(\mathrm{L}, \mathrm{VL}, \mathrm{V})$ & $1(\mathrm{~L}, \mathrm{VL}, \mathrm{V})$ & Mix.+Heat. \\
\hline SPB.5 & $\mathrm{M}=\mathrm{C}$ & 1..n $(\mathrm{L}, \mathrm{VL}, \mathrm{V})$ & $1(\mathrm{~L}, \mathrm{VL}, \mathrm{V})$ & Mix.+Cool. \\
\hline SPB.6 & $\mathrm{M}=\mathrm{R}=\mathrm{H}$ & $1 . . \mathrm{n}(\mathrm{L}, \mathrm{VL}, \mathrm{V})$ & $1(\mathrm{~L}, \mathrm{VL}, \mathrm{V})$ & React. + Heat. \\
\hline SPB.7 & $\mathrm{M}=\mathrm{R}=\mathrm{C}$ & $1 . . \mathrm{n}(\mathrm{L}, \mathrm{VL}, \mathrm{V})$ & $1(\mathrm{~L}, \mathrm{VL}, \mathrm{V})$ & React.+Cool. \\
\hline SPB.8 & $\mathrm{M}=\mathrm{R}=\mathrm{H}=\mathrm{PC}(\mathrm{VL})=\mathrm{PT}(\mathrm{VL})$ & $1 . . \mathrm{n}(\mathrm{L}, \mathrm{VL}, \mathrm{V})$ & $1(\mathrm{~L}, \mathrm{VL}, \mathrm{V})$ & React.+Heat. \\
\hline SPB.9 & $\mathrm{M}=\mathrm{R}=\mathrm{C}=\mathrm{PC}(\mathrm{VL})=\mathrm{PT}(\mathrm{VL})$ & $1 . . \mathrm{n}(\mathrm{L}, \mathrm{VL}, \mathrm{V})$ & $1(\mathrm{~L}, \mathrm{VL}, \mathrm{V})$ & React. + Cool. \\
\hline SPB.10 & $\mathrm{M}=\mathrm{R}=2 \mathrm{phM}=\mathrm{PC}(\mathrm{VL})=\mathrm{PT}(\mathrm{VL})$ & $1 . . \mathrm{n}(\mathrm{L}, \mathrm{VL})$ & $2(\mathrm{~V} / \mathrm{L})$ & React.+Sep. \\
\hline SPB.11 & $\mathrm{M}=\mathrm{R}=2 \mathrm{phM}=\mathrm{PC}(\mathrm{VL})=\mathrm{PT}(\mathrm{VL})=\mathrm{PS}(\mathrm{VL})$ & 1..n(L,VL) & $2(\mathrm{~V} ; \mathrm{L})$ & React. + Sep. \\
\hline SPB.12 & $\mathrm{M}=\mathrm{R}=2 \mathrm{phM}=\mathrm{PC}(\mathrm{VL})=\mathrm{PT}(\mathrm{PVL})=\mathrm{PS}(\mathrm{VL})$ & 1..n(L,VL) & $2(\mathrm{~V} ; \mathrm{L})$ & React.+Sep. \\
\hline SPB.13 & $\mathrm{M}=\mathrm{R}=\mathrm{H}=2 \mathrm{phM}=\mathrm{PC}(\mathrm{VL})=\mathrm{PT}(\mathrm{PVL})=\mathrm{PS}(\mathrm{VL})$ & 1..n(L,VL) & $2(\mathrm{~V} ; \mathrm{L})$ & React. + Sep. \\
\hline SPB.14 & $\mathrm{M}=\mathrm{R}=\mathrm{C}=2 \mathrm{phM}=\mathrm{PC}(\mathrm{VL})=\mathrm{PT}(\mathrm{PVL})=\mathrm{PS}(\mathrm{VL})$ & 1..n(L,VL) & $2(\mathrm{~V} ; \mathrm{L})$ & React.+Sep. \\
\hline SPB.15 & $\mathrm{M}=\mathrm{R}=2 \mathrm{phM}=\mathrm{PT}(\mathrm{VV})=\mathrm{PS}(\mathrm{VV})$ & 1..n(L,VL) & $2(\mathrm{~V} ; \mathrm{V})$ & React. + Sep. \\
\hline SPB.16 & $\mathrm{M}=\mathrm{R}=\mathrm{H}=2 \mathrm{phM}=\mathrm{PT}(\mathrm{VV})=\mathrm{PS}(\mathrm{VV})$ & 1...n(L,VL) & $2(\mathrm{~V} ; \mathrm{V})$ & React. + Sep. \\
\hline SPB.17 & $\mathrm{M}=\mathrm{R}=2 \mathrm{phM}=\mathrm{PC}(\mathrm{LL})=\mathrm{PS}(\mathrm{LL})$ & 1..n(L,VL,V,LL) & 1(VL,LL,V) & React. + Sep. \\
\hline SPB.18 & $\mathrm{M}=\mathrm{R}=\mathrm{H}=2 \mathrm{phM}=\mathrm{PC}(\mathrm{LL})=\mathrm{PS}(\mathrm{LL})$ & 1..n(L,VL,V,LL) & $1(\mathrm{VL}, \mathrm{LL}, \mathrm{V})$ & React. + Sep. \\
\hline SPB.19 & $\mathrm{M}=\mathrm{R}=\mathrm{C}=2 \mathrm{phM}=\mathrm{PC}(\mathrm{LL})=\mathrm{PS}(\mathrm{LL})$ & 1..n(L,VL,V,LL) & $1(\mathrm{VL}, \mathrm{LL}, \mathrm{V})$ & React.+Sep. \\
\hline SPB.20 & $\mathrm{M}=2 \mathrm{phM}=\mathrm{PC}(\mathrm{VL})=\mathrm{PT}(\mathrm{VL})$ & $1 . . \mathrm{n}(\mathrm{L}, \mathrm{VL})$ & $2(\mathrm{~V} ; \mathrm{L})$ & Mix.+Ph. Cr \\
\hline SPB.21 & $\mathrm{M}=2 \mathrm{phM}=\mathrm{C}=\mathrm{PC}(\mathrm{VL})=\mathrm{PT}(\mathrm{VL})$ & $1 . . \mathrm{n}(\mathrm{L}, \mathrm{VL})$ & $2(\mathrm{~V} ; \mathrm{L})$ & Mix.+Ph. Cr. \\
\hline SPB.22 & $\mathrm{M}=2 \mathrm{phM}=\mathrm{H}=\mathrm{PC}(\mathrm{VL})=\mathrm{PT}(\mathrm{VL})$ & 1..n(L,VL) & $2(\mathrm{~V} ; \mathrm{L})$ & Mix.+Ph. Cr. \\
\hline SPB.23 & $\mathrm{M}=2 \mathrm{phM}=\mathrm{PC}(\mathrm{VL})=\mathrm{PT}(\mathrm{VL})=\mathrm{PS}(\mathrm{VL})$ & 1..n(L,VL) & $2(\mathrm{~V} ; \mathrm{L})$ & Mix.+Sep. \\
\hline SPB.24 & $\mathrm{M}=\mathrm{C}=2 \mathrm{phM}=\mathrm{PC}(\mathrm{VL})=\mathrm{PT}(\mathrm{VL})=\mathrm{PS}(\mathrm{VL})$ & 1..n(L,VL) & $2(\mathrm{~V} ; \mathrm{L})$ & Cool.+Sep. \\
\hline SPB.25 & $\mathrm{M}=\mathrm{H}=2 \mathrm{phM}=\mathrm{PC}(\mathrm{VL})=\mathrm{PT}(\mathrm{VL})=\mathrm{PS}(\mathrm{VL})$ & $1 . . \mathrm{n}(\mathrm{VL})$ & $2(\mathrm{~V} ; \mathrm{L})$ & Heat.+Sep. \\
\hline SPB.26 & $\mathrm{M}=2 \mathrm{phM}=\mathrm{PC}(\mathrm{VL})=\mathrm{PT}(\mathrm{PVL})=\mathrm{PS}(\mathrm{VL})$ & $1 . . \mathrm{n}(\mathrm{VL})$ & $2(\mathrm{~V} ; \mathrm{L})$ & Mix.+Sep. \\
\hline SPB.27 & $\mathrm{M}=2 \mathrm{phM}=\mathrm{PC}(\mathrm{VL})=\mathrm{PT}(\mathrm{VV})=\mathrm{PS}(\mathrm{VV})$ & 1..n $(\mathrm{L}, \mathrm{VL}, \mathrm{V})$ & $2(\mathrm{~V} ; \mathrm{V})$ & Mix.+Sep. \\
\hline SPB.28 & $\mathrm{M}=2 \mathrm{phM}=\mathrm{PT}(\mathrm{VV})=\mathrm{PS}(\mathrm{VV})$ & $1 . . \mathrm{n}(\mathrm{V})$ & $2(\mathrm{~V} ; \mathrm{V})$ & Mix.+Sep. \\
\hline SPB.29 & $\mathrm{M}=2 \mathrm{phM}=\mathrm{PC}(\mathrm{LL})=\mathrm{PS}(\mathrm{LL})$ & 1..n(LL) & $2(\mathrm{~L} ; \mathrm{L})$ & Mix.+Sep. \\
\hline SPB... & $\ldots$ & $\ldots$ & $\ldots$ & $\ldots$ \\
\hline SPB.88 & $\mathrm{D}$ & $1(\mathrm{~L} ; \mathrm{VL}, \mathrm{V})$ & 1..n(L;V;VL) & Stream Div. \\
\hline
\end{tabular}

Action 2: An excerpt of the generated task based superstructure is shown in Figure 6-25. The concept for the task-based superstructure has already been presented in section 6.1.10. 


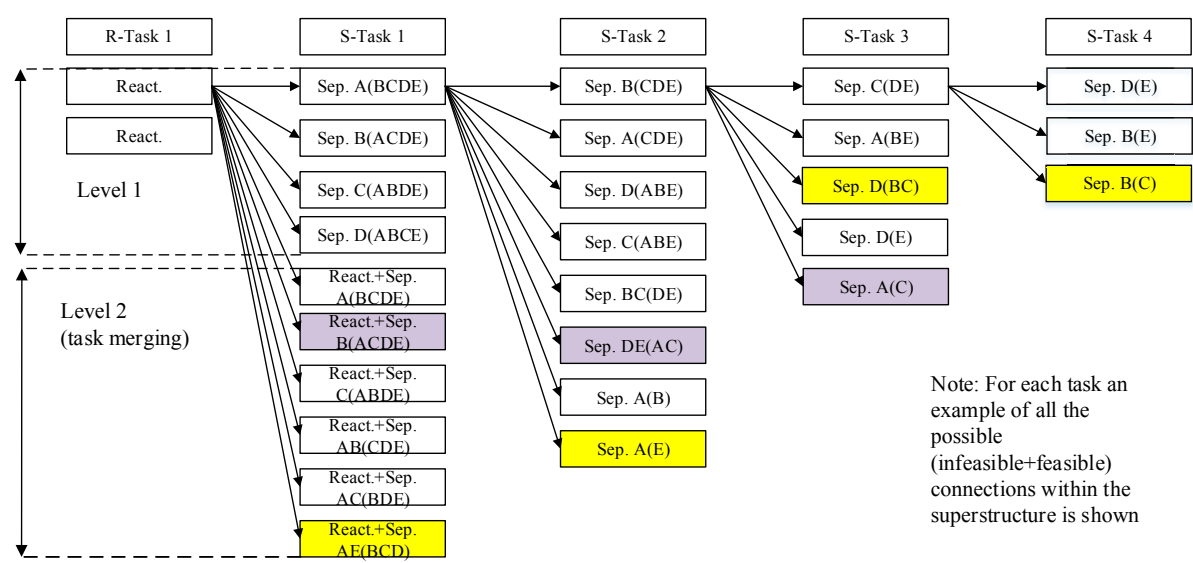

Figure 6-25: Excerpt of the task-based superstructure for the production of FAME. Task-based superstructure including task-merging. Flowsheet alternative 1 (highlighted in yellow) and Flowsheet alternative 2 (highlighted in purple) A-MeOH, B-WcVo, CFAME, D-Glycerol, E-H2O

Action 4: Table 6-35 gives the identified basic strictures that perform reaction and separation tasks. 
Table 6-35: Identified basic structures that perform single or multiple tasks for conversion of $\mathrm{MeOH}$ and $\mathrm{WcVo}$ to FAME, Glycerol and H2O. Note each binary pair that represent the inlet to a task represent the two key compounds under consideration

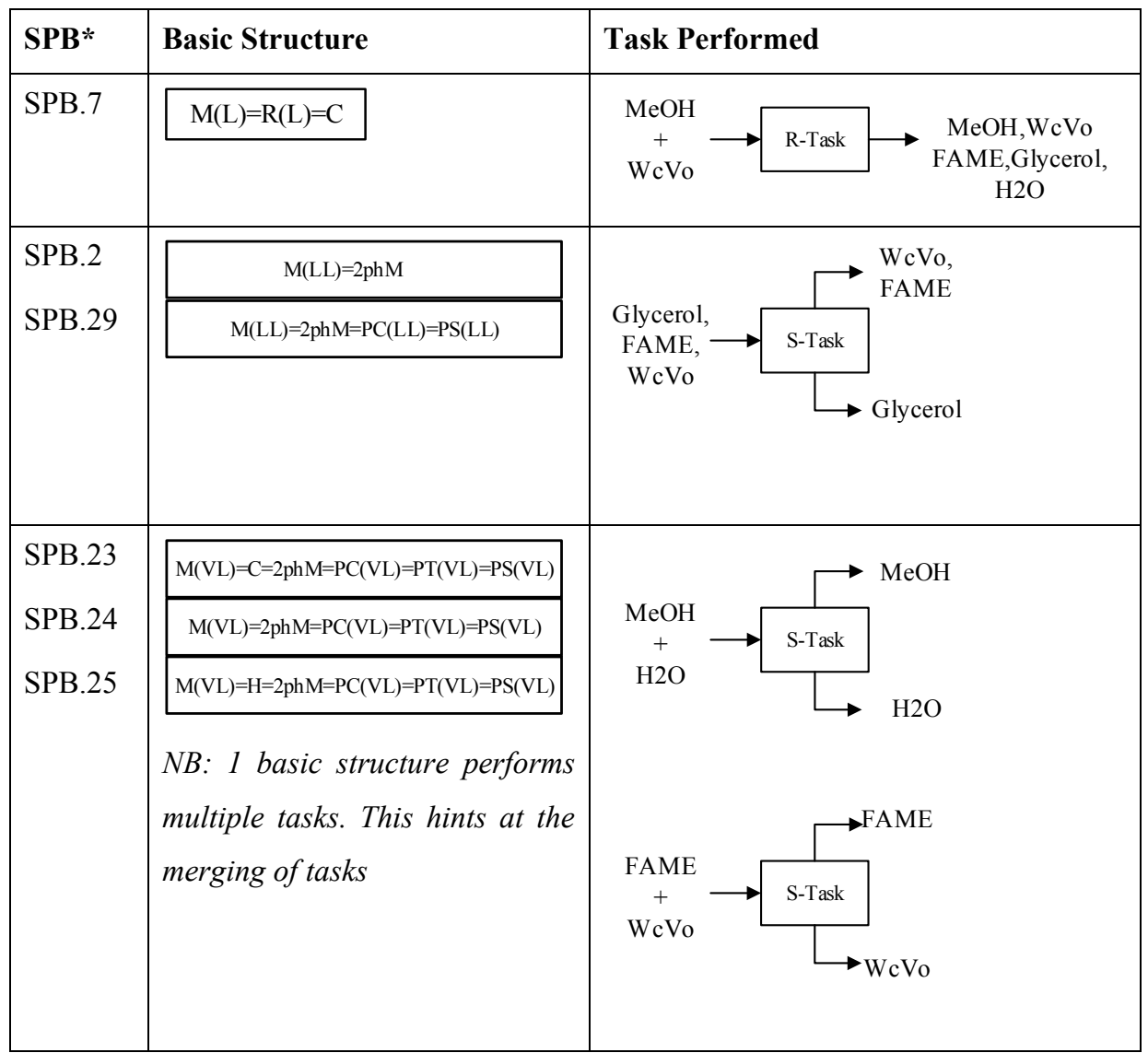

Note: ${ }^{*}$ The SPB number corresponds to the SPB given in Table 6-34. For combined basic structures, only the SPBs present in the combined basic structure are presented

The identified task based flowsheets highlighted in level 1 and level 2 of the task based superstructure shown in Figure 6-25 is explained as follows: Level 2-Flowsheet alternative 1, highlighted yellow and flowsheet alternative 2 highlighted purple in Figure 6-25:

- Flowsheet alternative 1: A reactor feed (similar to the base case) of a 10:1 mole ratio of $\mathrm{MeOH}$ to $\mathrm{WcVo}$ is used. It is generated as follows. The reactions are irreversible liquid phase reactions that does not go to full completion, therefore, the reactor outlet contains a mixture of raw materials and products. A basic structure containing a $\mathrm{R}(\mathrm{L}) \mathrm{PBB}$ is selected to perform the reaction task.

Based on the mixture analysis, a miscibility gap exist between glycerol and, FAME and WcVo. Also it has been observed experimentally Dube et al. (2007) that the 
mixture in the reactor is an emulsification, where the $\mathrm{WcVo}$ (tri-glycerides) is surrounded by FAME, glycerol, $\mathrm{MeOH}$ and $\mathrm{H} 2 \mathrm{O}$ (see Figure 6-26). Therefore a merging of R-Task and S-Task 1 is considered because PBBs can be combined that perform reaction-separation together. This is possible based on the system properties: (1) esterification reaction, (2) mixture structure and (3) the reaction is in the liquid phase. A basic structure having R(L) and PT(PVL) is selected.

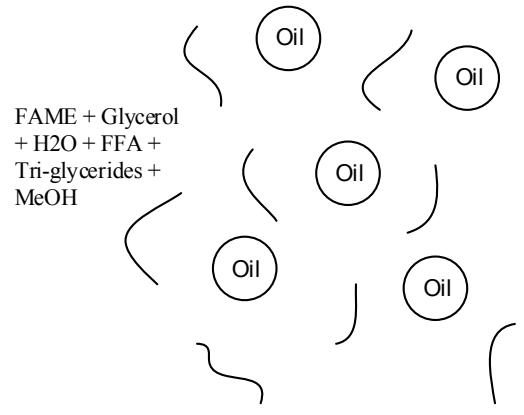

Figure 6-26: Experimental observation of the reacting mixture

The stream from this merged task contains FAME, glycerol, $\mathrm{H} 2 \mathrm{O}, \mathrm{WcVo}$ (FFA) and $\mathrm{MeOH}$. Due to the presence of the miscibility gap between glycerol and, FAME and $\mathrm{WcVo}$, glycerol is separated from FAME and $\mathrm{WcVo}$. $\mathrm{MeOH}$ and $\mathrm{H} 2 \mathrm{O}$ are assumed present in both phases. For the separation of the remaining mixtures, no azeotropes are present. From the basic structures identified in Table 6-35, 1 basic structure is feasible to perform the S-Task 2, S-Task 3 and S-Task 4 . The identified basic structures are given in Table 6-36. 
Table 6-36: Identified basic structures for flowsheet alternatives 3 . Note each binary pair that represent the inlet to a task represent the two key compounds under consideration

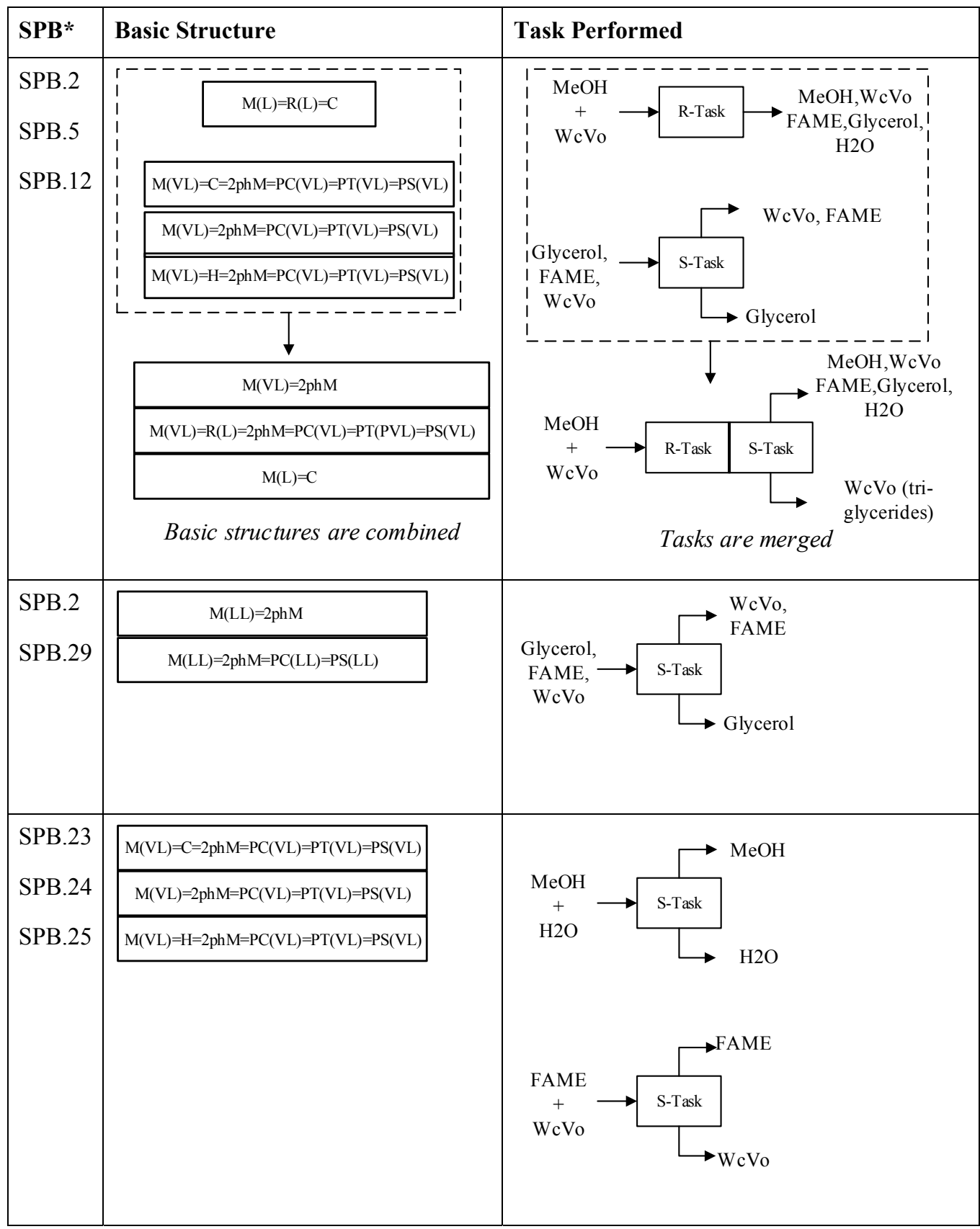


Note: *The SPB number corresponds to the SPB given in Table 6-34. For combined basic structures, only the SPBs present in the combined basic structure are presented

- Flowsheet alternative 3-The merging of tasks is further considered that is the merging of R-Task and S-Task 1 is merged in a different way. Again, this is possible based on the system properties. Therefore the basic structures can be combined in order to perform the $\mathrm{R}=\mathrm{S}$ Task together and this is given in Table 6-37. Different configurations of such a structure exist as shown for the previous case studies however only reaction and separation with single inlet feed is considered. 
Table 6-37: Identified basic structures for flowsheet alternatives 3

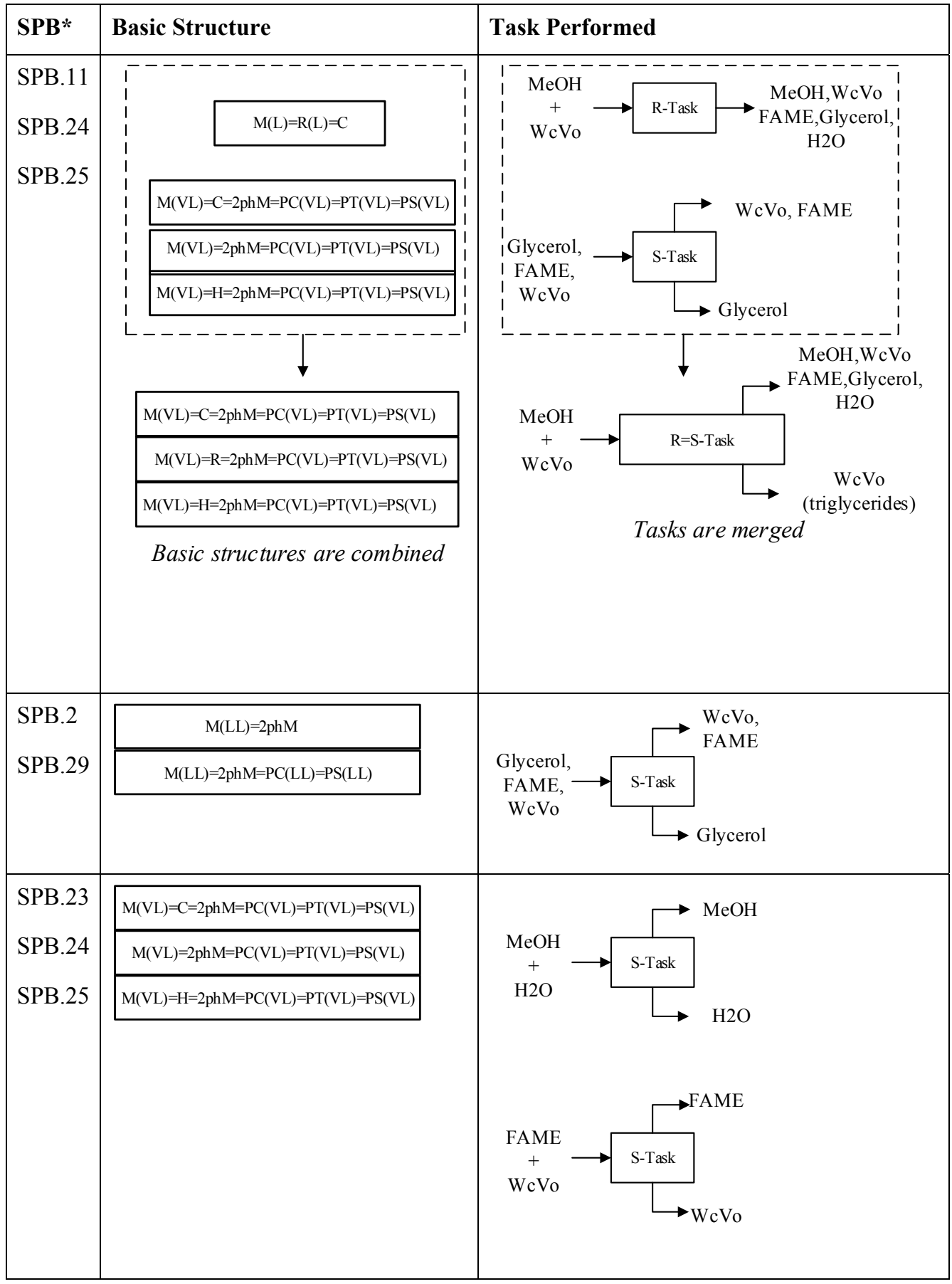


Note: *The SPB number corresponds to the SPB given in Table 6-34. For combined basic structures, only the SPBs present in the combined basic structure are presented

Action 6: The basic structures that perform the different identified tasks are translated into unit operations. The final flowsheet alternatives are presented in Figure 6-27.

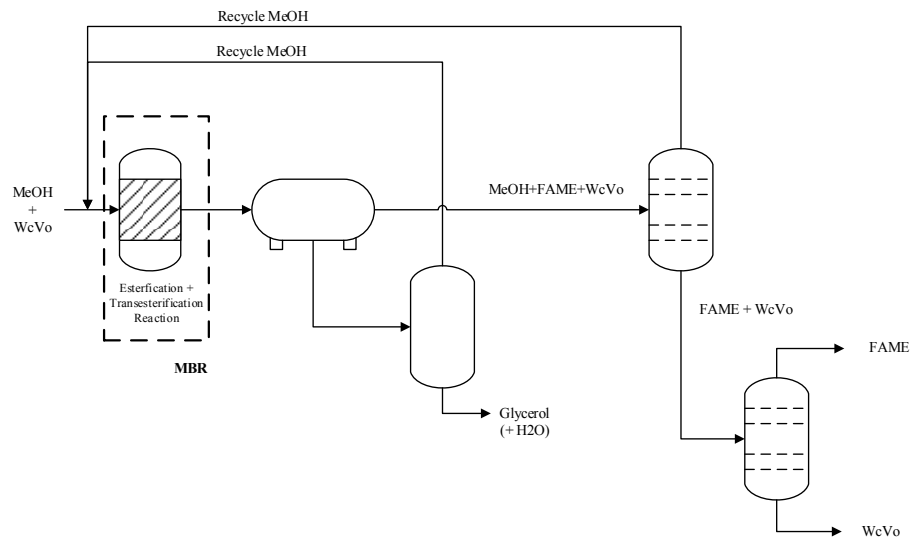

Figure 6-27 (a)

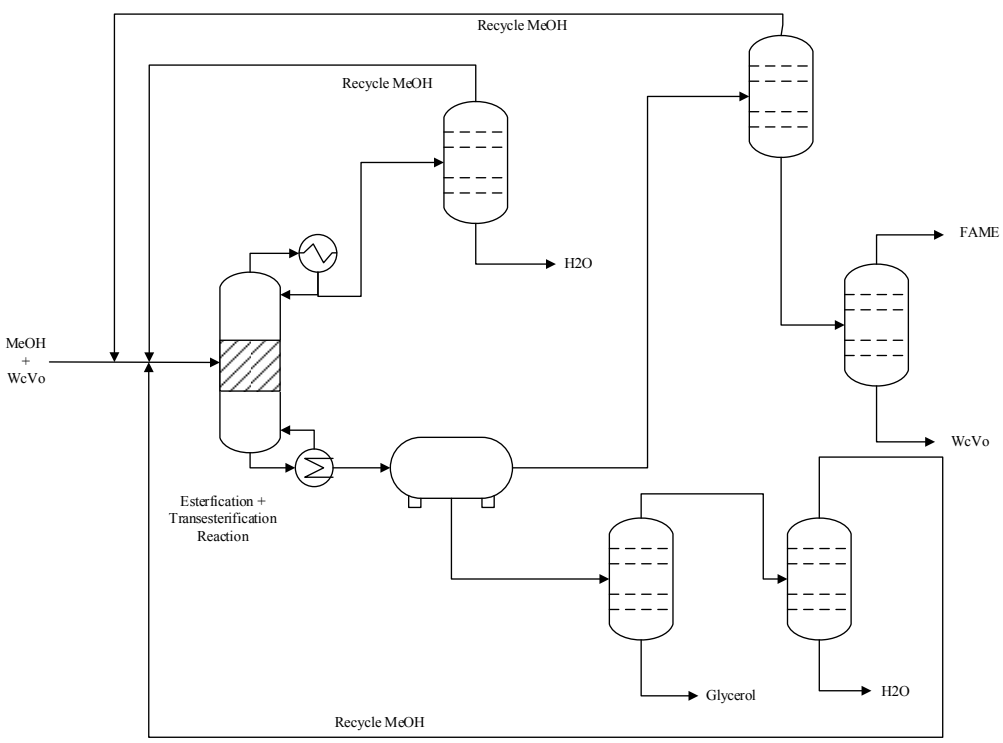

Figure 6-27 (b)

Figure 6-27: The generated flowsheet alternatives for the production of FAME. MBRmembrane reactor 
Action 7: The flowsheet alternatives are analyzed and both are selected as feasible alternatives for IT-PBS.4.

\subsubsection{IT-PBS.4-Comparision and Selection of the Best Flow- sheet Alternatives}

The results of the economic, sustainability and LCA analysis for the 2 feasible alternatives are given in Table 6-38. The prices used for different utilities are: cooling water at $0.35 \$ / G J$, LP Steam at 7.78 \$/GJ and electricity at $16.80 \$ / G J$ (Peters, Timmerhaus, West, 2003).

Table 6-38: Economic, sustainability and LCA analysis for the 2 feasible flowsheet alternatives generated for the production of FAME

\begin{tabular}{|c|c|c|c|c|}
\hline \multirow{8}{*}{ 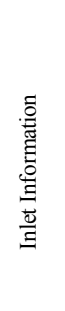 } & Measures of Comparison (units) & Base Case & Alternative 1 & Alternative 2 \\
\hline & Feed Mole Ratio & 9 to 1 & 10 to 1 & 2 to 1 \\
\hline & Mole Feed to reactor $(\mathrm{kmol} / \mathrm{hr})$ & & & \\
\hline & Mole Feed Make-up (kmol/hr) & & & \\
\hline & PC conversion & $>94 \%$ & $>94 \%$ & $>94 \%$ \\
\hline & Input-MeOH $(\mathrm{kg} / \mathrm{h})$ & 5502 & 14510 & 5031 \\
\hline & Input-FFA+TriGl $(\mathrm{kg} / \mathrm{h})$ & 43630 & 48060 & 43630 \\
\hline & Input-Total $(\mathrm{kg} / \mathrm{h})$ & 49132 & 5502 & 48661 \\
\hline \multirow{7}{*}{ 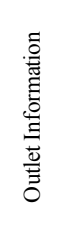 } & Biodiesel product $(\mathrm{kg} / \mathrm{h})$ & 42690 & 43110 & 43050 \\
\hline & Operating Days & 340 & 340 & 340 \\
\hline & Product purity (Biodiesel,\%) & 99.5 & 99.5 & 99.5 \\
\hline & By-product purity (Glycerol,\%) & 99.5 & 99.5 & 99.5 \\
\hline & Raw Material loss-MeOH (kg/hr) & 638.00 & 178.94 & 267.84 \\
\hline & Raw Material loss-FFA+TriGl (kg/hr) & 0.00 & 0.00 & 0.00 \\
\hline & Raw Material loss-Total (kg/hr) & 638.00 & 178.94 & 267.84 \\
\hline \multirow{4}{*}{ 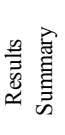 } & Energy usage $(\mathrm{MJ} / \mathrm{hr})$ & 119,163 & 65,639 & 73,104 \\
\hline & Utility Cost (\$/year) & $7,790,000$ & $3,949,269$ & $4,660,000$ \\
\hline & Raw Material Cost (\$/yr) & $20,203,344$ & $20,203,344$ & $18,473,832$ \\
\hline & Operating Cost (\$/year) & $27,993,344$ & $24,152,613$ & $23,133,832$ \\
\hline \multirow{8}{*}{ 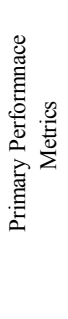 } & Raw Material usage (kg Raw Material/kg FAME Product) & 0.13 & 0.23 & 0.12 \\
\hline & Energy usage per kg of product (MJ/ kg of FAME product) & 2.79 & 1.52 & 1.70 \\
\hline & Raw Material Cost per kg of product ( $\$ / \mathrm{kg}$ of FAME product) & 0.06 & 0.06 & 0.05 \\
\hline & Utility Cost per kg of product ( $\$ / \mathrm{kg}$ of FAME product) & 0.02 & 0.01 & 0.01 \\
\hline & Product Sale (\$/yr) & $278,680,320$ & $281,422,080$ & $281,030,400$ \\
\hline & Product Sale per kg of product (\$/kg of DMC product) & 0.80 & 0.80 & 0.80 \\
\hline & Profit (\$/kg of DMC product)-max & 0.78 & 0.79 & 0.79 \\
\hline & Fobj-Operaing cost ( $\$ / \mathrm{kg}$ of FAME product)-min & 0.1 & 0.1 & 0.1 \\
\hline \multirow{5}{*}{ 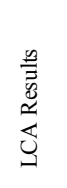 } & \begin{tabular}{|l|} 
Total Carbon Footprint ( $\mathrm{kg} \mathrm{CO} 2 / \mathrm{kg}$ of FAME product) \\
\end{tabular} & 0.18 & 0.12 & 0.14 \\
\hline & GWP (CO2 eq.) & $5.52 \mathrm{E}-01$ & $3.83 \mathrm{E}-01$ & $5.52 \mathrm{E}-01$ \\
\hline & ODP (CFC-11 eq.) & $5.18 \mathrm{E}-09$ & $4.60 \mathrm{E}-09$ & $5.18 \mathrm{E}-09$ \\
\hline & $\mathrm{AP}(\mathrm{H}+$ eq. $)$ & $1.00 \mathrm{E}-04$ & $9.23 \mathrm{E}-05$ & $1.00 \mathrm{E}-04$ \\
\hline & ET (kg 2,4-D eq) & $5.25 \mathrm{E}-03$ & $4.95 \mathrm{E}-03$ & $4.90 \mathrm{E}-03$ \\
\hline
\end{tabular}


The results of the objective function (Equation 6.29) is given in Table 6-38. Flowsheet alternative 1 and flowsheet alternative 2, consisting of a membrane reactor and reactive distillation column respectively, show the same values of the objective function compared to the base case design. This shows that the by-products (for example glycerol) of biodiesel should be considered for production of value-added chemicals/products in the concept of bio-refinery for enhancing the viability of the process. However, these two alternatives have the lowest carbon footprint (see LCA results in Table 6-38). The main drawback is the raw material cost of $\mathrm{MeOH}$, however, if the utility cost is used as the objective, the two alternatives show improvement compared to the base case design.

The results presented in Table 6-38 are represented in terms of a radar plot. Therefore, from Figure 6-28 it can be seen that for all the considered criteria, the alternatives are better that the base case design.

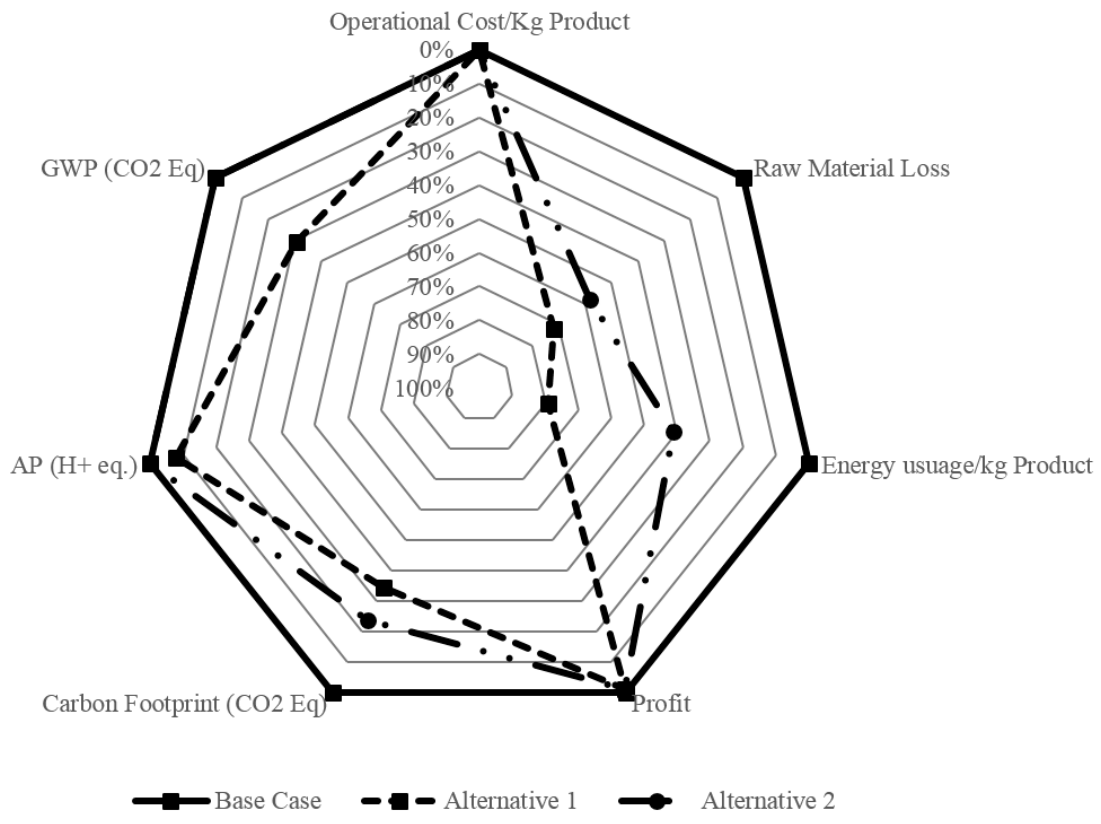

Figure 6-28: Economic and LCA improvements relative to the base case design. GWPGlobal Warming Potential, AP- Acidification Potential (H+ eq.)

From the results presented in Table 6-38 and the design targets set in step 8 the following can be concluded:

1. Reduce energy consumption-yes

2. Reduce utility cost-yes

3. Improvements in LCA/Sustainability indicators-yes, all variables within Figure 6-28. Note different impacts have been considered since biodiesel is considered as a renewable energy resource 
4. Unit operations reduction-yes, 9 (base case), 7 (flowsheet alternative 2, see Figure 6-27(a)), 5 (flowsheet alternative 1, see Figure 6-27(b))

5. Product purity (kept as the base case)-yes

6. Production target (kept as the base case)-yes

7. Reduce operational cost-no, same as the base case

\subsection{Conclusion}

In this chapter the application of the framework to 3 case studies has been presented, the production of methyl acetate, di-methyl carbonate and biodiesel. For the production of methyl acetate, the objective function (profit) was to be maximized and 9 flowsheet alternatives were generated of which, 4 were found to be feasible. It was found that another flowsheet alternative exist compared to the well-known alternative using a reactive distillation column.

For the production of di-methyl carbonate, the objective function (total annualized cost) was to be minimized and 9 flowsheet alternatives were also generated, of which, 4 were found to be feasible. It was found that all alternatives had at least a $50 \%$ improvement of the objective function.

For the production of biodiesel, the objective function (operating cost) was to be minimized and 2 flowsheet alternatives were generated and were found to be feasible. It was found that process intensification can provide a means by which the utility cost can be further reduced for a bio-based process. 


\section{CONCLUSION AND FUTURE PERSPECTIVES}

Process synthesis-intensification involves a complex MINLP problem to solve and it can be categorized into three main stages: synthesis, design and sustainable design (see Figure 7-1). Each stage has an input from which an output is obtained and is hierarchal, that is, the output of each stage is the input to the next. The problem can be solved in many ways, the most common being a simultaneous solution approach or by using a decomposition based approach. In this thesis, the process synthesis-intensification problem for achieving more sustainable designs has been solved using the decomposition based approach, where in order to manage the complexity associated with the problem, it is decomposed into a set of sub-problems. Traditionally, the approach employed for solving the synthesis-intensification problem has been a sequential approach where, process synthesis (and design) followed by process intensification is performed. However, in this thesis, a simultaneous approach is employed and recommended, where process intensification concepts are considered during process synthesis.

Therefore, to solve the synthesis-intensification problem, there is a need for the development of a systematic, flexible and efficient framework that covers a wide range of applications. In this thesis, a computer-aided, multi-level, multi-scale framework for performing process synthesis-intensification has been developed which is systematic, that is, it is hierarchal in structure. The framework is flexible because it has the ability to handle a large range of problems and efficient because it solves the synthesisintensification problem through the use of reliable numerical methods.

The developed framework consist of 8 steps (step 1 to step 8) and 4 integrated taskphenomena based synthesis steps (IT-PBS.1 to IT-PBS.4). Steps 1 to step 8 operate from at the unit operations scale and task scale and IT-PBS.1 to IT-PBS.4 operate at the phenomena scale, task scale and unit operations scale, generating sustainable flowsheet alternatives (inclusive of hybrid/intensified unit operations) using a phenomena-based synthesis method. Phenomena-based synthesis is analogous to CAMD because both methods operate at lower scales, thereby expanding the search space of flowsheet alternatives/compounds that can be found/generated.

A first version of the phenomena based synthesis method, within the framework, was first proposed by Lutze (2012). This thesis has further developed/expanded this work through the method by which process hot-spots, which are to be eliminated, are identified and the systematization of the generation of flowsheet alternatives using an integrated task-phenomena based approach. 
The framework was found useful in its application to these three case studies related to chemical processes and a bioprocess. First the problem was defined and the objective function stated. The base case designs were obtained and analysed using economic, sustainability and LCA analyses. The process hot-spots for each base case design could then be identified from the comprehensive analysis related to economic and sustainability. The process hot-spots related to each base case were then translated into design targets that, if satisfied, would generate sustainable feasible flowsheet alternatives for each process. The base case designs were further analysed in terms of thermodynamic insights and mixture property analyses and these proposed desirable tasks that were translated into phenomena building blocks.

Using the proposed combination rules for combining phenomena building blocks to basic structures that perform tasks, multiple basic structures were identified for performing a task, thereby increasing the search space of unit operations (well-known or hybrid/intensified) or a basic structure was identified that fulfil a set of tasks, thereby reducing the number of unit operations in a final flowsheet alternative. Since the combination of phenomena building blocks to basic structures is rule based, this provided the opportunity to generate multiple basic structures thereby, creating a database a priori that can be used for identifying a basic structure that fulfils a task or set of tasks. The basic structures were then translated into unit operations for generating flowsheet alternatives that eliminate the process hot-spots and fulfil the design targets, necessary for conversion of the raw materials to the final products and recovery of un-reacted raw materials (for recycle) and products. In principle generating flowsheet alternatives from the combination of phenomena building blocks leads to a large number of possible combinations. The framework has sought to manage this complexity through the use of combination rules for combining phenomena building blocks to simultaneous phenomena building blocks and then into basic structures. It should be noted that a global optimal design is not guaranteed.

The generated flowsheet alternatives were then screened based on the constraints set in the definition of the objective function and the remaining feasible alternatives were further analysed using the recommended economic and sustainability analyses in order to identify the more sustainable flowsheet deigns. The more sustainable designs satisfies the set design targets, show improvements in economic and sustainability/LCA factors, reduces the number of unit operations in the process and employs (where feasible) intensified/hybrid equipment.

For the production of methyl acetate and dimethyl carbonate, it was found that nine flowsheet alternatives could be generated for each process, from which four were found to be feasible for each process. For the feasible flowsheet alternatives for either case study, non-trade off flowsheet alternatives compared to the base case design were found.

For the production of biodiesel, two feasible flowsheet alternatives were generated. It was found that the alternatives compared to the base design did show improvements 
related to economics and sustainability/LCA factors, however the improvement economically was marginal compared to the base case design. From a synthesis, design and sustainable design perspective this shows that the by-products (for example glycerol) of biodiesel should be considered for production of value-added chemicals/products in the concept of bio-refinery.

In conclusion, the overall concept of sustainable process synthesis-intensification achieved through the developed framework in this thesis is shown in Figure 7-1.

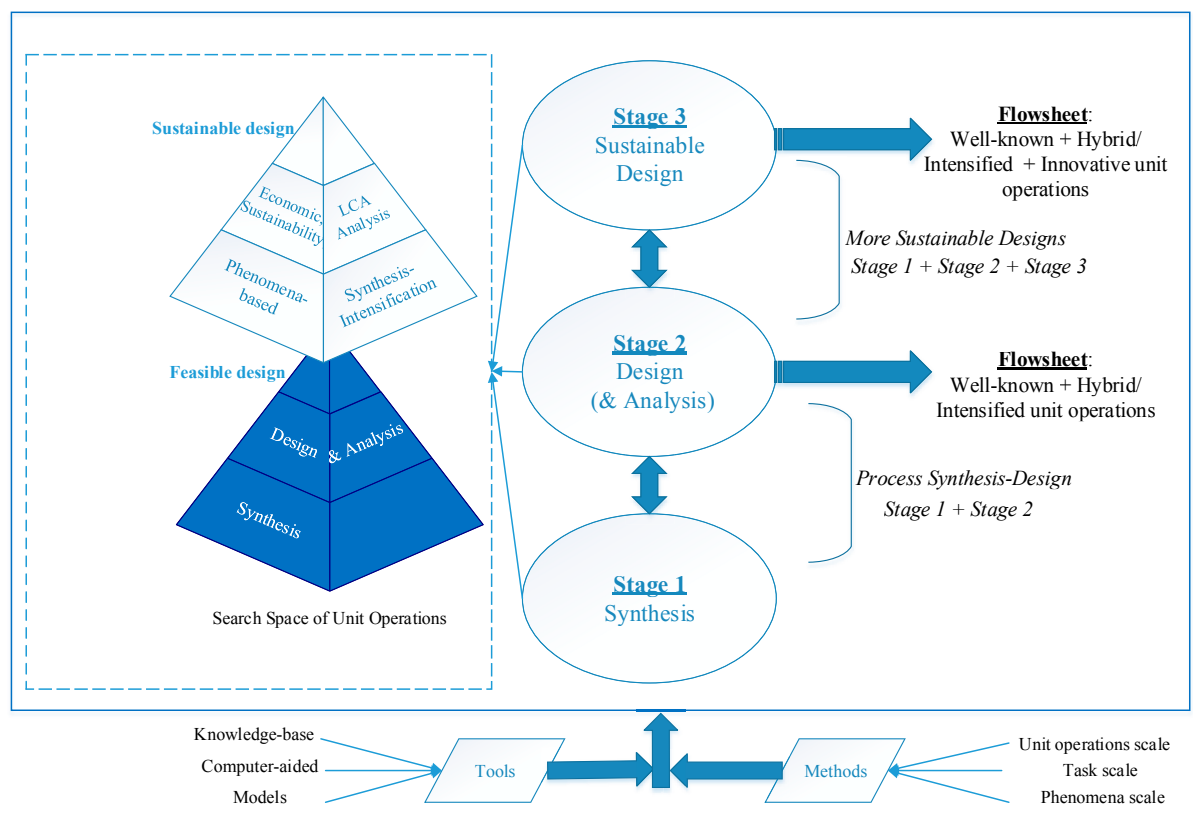

Figure 7-1: Achieving more sustainable design through process intensification

As shown in Figure 7-1, more sustainable designs are achieved through a three stage process. In stage 1 , process synthesis is performed for generating a large number of alternatives. In stage 2 the generated (feasible) alternatives are designed for selecting the best flowsheet alternative. If a design is selected at stage 2 then it consists of wellknown (and possibly hybrid/intensified) unit operations. If stage 3 is entered, then the design from stage 2 is analyzed in terms of economics and sustainability for identifying process hot-spots that are translated into design targets, that is, if satisfied, eliminates the process hot-spots and generates sustainable flowsheet alternatives. The search space of unit operations is expanded during phenomena-based synthesis because at this scale the opportunity to innovate is provided.

\section{Proposed Future Work}

In the application of the sustainable process synthesis-intensification framework, one of the main defining steps is the reaction step. If the reaction step can be improved, then the separation design can, in principle, be simplified, as shown with the use of a mem- 
brane reactor for case study 1 and 3 and, the use of a membrane after the reactor, in case study 2. However, the improvement of the reaction step is affected by external effects, for example, the use of a membrane. It would be beneficial if the reaction can be improved using chemical effects, among others (Özkan et al., 2012), for example, the use of a solvent, therefore, a method for generating reaction alternatives should be embedded within the framework, for example, Chen et al. (2012), Hersi (2013) and Bertran (2014).

In generation of the flowsheet alternatives, some of the alternatives must be rigorously simulated and then evaluated using the defined constraints (for example, operational constraints) in order to, screen out infeasible alternatives. It would be beneficial if shortcut models for hybrid/intensified unit operations are developed, in order to, quickly screen alternatives having hybrid/intensified unit operations, for example, if a reactive distillation superstructure is generated as a possible alternative, then a model that quickly and quantitatively allows, the evaluation of different configurations would be beneficial in selection of the best configuration for rigorous simulation compared to rigorous simulation of the entire superstructure followed by the evaluation of the superstructure. In principle, the former is less time consuming than the latter.

Finally, since the framework is systematic, hierarchal and consists of steps/rules and knowledgebase/databases, parts of it can be automated into a process synthesisintensification tool for achieving more sustainable design. Such a tool would be interactive because it will require human intervention, however, the solution time of the sustainable synthesis-intensification problem will be improved. A first version of such a tool has been proposed by Lutze (2012) and a tool is being developed by Tula et al. (2014) that will incorporate synthesis-intensification. 


\section{ABBREVIATIONS AND NOMENCLATURE}

\section{Abbreviations}

2phM- Two Phase Mixing

A1- Algorithm I

A2- Algorithm II

AP- Acidification Potential

C- Cooling

CAMD- Computer-Aided Molecular Design

$\mathrm{CO} 2$ eq- Carbon Dioxide Equivalent per kilogram of product

CP- Closed Path

D- Dividing

DBSS- Decomposition-based Solution Strategy

Div.- Dividing

DMC- Di-methyl Carbonate

DMSO- Di-methyl Sulfoxide

EthOAc- Ethyl Acetate

ET Fresh water ecotoxicity

EWC- Energy to Waste Cost

FFA- Free Fatty Acid

FAME- Fatty-Acid Methyl Ester

GWP-Global Warming Potential

H- Heating

H2O- Water

$\mathrm{H}_{\mathrm{F}}$ - heat of Formation

Hk- Heavy Key Compound

HOAc- Acetic Acid

hr- Hour

GfSPB- Generation of feasible Simultaneous Phenomena Building Blocks

GTbS- Generate Task-based Superstructure

I- Initiator

IAT- Identifying Alternative Tasks

ICAS- Integrated Computer-Aided System

ITP- Identify main Tasks to be Performed

IT-PBS- Integrated Task-Phenomena based Synthesis

K- Kelvin 
kg- Kilogram

lk- Light Key Compound

L- Liquid

LCA- Life Cycle Assessment

LL- Liquid-Liquid

M- Mixing

MeOAc- Methyl Acetate

$\mathrm{MeOH}-$ Methanol

Mix.- Mixing

Mfl- Flow mixing

Mid- ideal Mixing

MINLP- Mixed Integer Non-linear Programming

Min- Minimize

MJ- Mega Joule

MoT- Modelling Testbed

Mrect- Rectangular mixing

MSA- Mass Separating Agent

Mv- Vapor mixing

MV- Molar Volume

MVA-Mass value Added

n- Final number in a summation or series

$\mathrm{N}-\mathrm{No}$

NA- Not applicable

NC- Number of Compounds

NLP- Non-linear programming

ODP-Ozone Depletion Potential

OP- Open Path

ProPred- Property Prediction

PEI- Potential Environmental Impacts

PBB- Phenomena Building Block

PC- Phase Contact/Propylene Carbonate

PDS- Process Design Studio

PG- Propylene Glycol

PI- Process Intensification

PS- Phase Separation

PT- Phase Transition

PVL- Separation by permeability/affinity

$\mathrm{r}_{\mathrm{ij}}$ - Binary ratio

R- Reaction

R-Task- Reaction Task

RG- Radius of Gyration 
R-S Task- Reaction-Separation Task

S-Task- Separation Task

Sep.- Separation

SL- Solid-Liquid

SolPar- Solubility Parameter

SPB-Simultaneous Phenomena Building Block

SoPBB- Selection of Phenomena Building Blocks

T- Terminator/Temperature/Tower

Tb- Normal boiling point

TBF- Task-based Flowsheet

TBsUo- Translation of Basic structures into Unit operations

TVA- Total Value Added

V- Vapor

VdW- van der Waals Volume

VL- Vapor-Liquid

VP- vapor permeation

VV- Vapor-vapor

wt- Weight

WcVo- Waste Cooking Vegetable Oil

Y-Yes

Yr- Year

\section{Nomenclature}

$C_{\mathrm{Pr} o d}$ - Cost of Products

$C_{R M}$ - Cost of Raw materials

$C_{U t}$-Utility Cost

$\underline{d}$ - Set of equipment variables

$E_{j}$-Energy Flowrate

$m_{j}$ - Mass flowrate

nPBB- Total number of Phenomena Building Blocks

nPBBE- Total number of Energy Transfer Phenomena Building Blocks

nPBBD- Total number of Dividing Phenomena Building Blocks

nPBBM- Total number of mixing Phenomena Building Blocks

nPBB,max- Maximum number within a Simultaneous Phenomena Building Block

$\mathrm{N}_{\mathrm{ST}}$ - Minimum number of separation tasks

NSPBmax- Maximum number of SPB combinations

$\mathrm{p}_{\mathrm{ij}}$ - Binary Ratio

p- Number of Binary Pairs

$t_{\text {proj }}$-Set project lifetime 
$\underline{X}$ - Design/optimization variable

$\underline{Y}$ - Decision integer variables

$\underline{z}$ - Set of thermodynamic variables

Greek Symbols

$\underline{\theta}$ - Process (and product) specifications

$\underline{\theta_{1}}$ - Logical Constraints

$\theta_{2}$ - Structural Constraints

$\underline{\theta_{3}}$ - Operational Constraints

$\varphi$ - Performance Criteria

$v$ - Stoichiometric coefficient

$\Delta H_{r x n}$ - Heat of Reaction

$\alpha$ - Economic Analysis results

$\beta$ - Sustainability Analysis results

$\gamma$ - LCA Analysis results 


\section{REFERENCES}

Agreda, V. H., Partin, L. R., \& Heise, W. H. (1990). High-Purity Methyl Acetate via Reactive Distillation. Chemical Engineering Progress, 40-46.

Amte, V. (2011). 21st European Symposium on Computer Aided Process Engineering. Computer Aided Chemical Engineering (Vol. 29, pp. 718-722). Elsevier. doi:10.1016/B978-0-444-53711-9.50144-9

Assabumrungrat, S., Phongpatthanapanich, J., Praserthdam, P., Tagawa, T., \& Goto, S. (2003). Theoretical study on the synthesis of methyl acetate from methanol and acetic acid in pervaporation membrane reactors: effect of continuous-flow modes. Chemical Engineering Journal, 95(1-3), 57-65. doi:10.1016/S1385-8947(03)00084-6

Babi, D. K., \& Gani, R. (2014). Hybrid Distillation Schemes: Design, Analysis, and Application. In A. Gorak \& E. Sorensen (Eds.), Distillation (pp. 357-381). London: Elsevier. doi:10.1016/B978-0-12-386547-2.00009-0.

Babi, D. K., Holtbruegge, J., Lutze, P., Górak, A., Woodley, J. M., \& Gani, R. (2014). Sustainable Process Synthesis-Intensification. Computer Aided Chemical Engineering, 34, 255-260. doi:10.1016/B978-0-444-63433-7.50027-4 (a)

Babi, D. K., Lutze, P., Woodley, J. M., \& Gani, R. (2014). A Process SynthesisIntensification Framework for the Development of Sustainable Membrane-based Operations. Chemical Engineering and Processing: Process Intensification, 86, 173-195. doi:10.1016/j.cep.2014.07.001 (b)

Babi, D. K., Woodley, J. M., \& Gani, R. (2014). Achieving More Sustainable Designs through a Process Synthesis-Intensification Framework. Computer Aided Chemical Engineering, 33, 31-36. doi:10.1016/B978-0-444-63456-6.50006-5 (c)

Baliban, R. C., Elia, J. A., Misener, R., \& Floudas, C. A. (2012). Global optimization of a MINLP process synthesis model for thermochemical based conversion of hybrid coal, biomass, and natural gas to liquid fuels. Computers \& Chemical Engineering, 42, 6486. doi:10.1016/j.compchemeng.2012.03.008 
Barnicki, S. D., \& Siirola, J. J. (2004). Process synthesis prospective. Computers \& Chemical Engineering, 28(4), 441-446. doi:10.1016/j.compchemeng.2003.09.030

Bayer, B., Schneider, R., \& Marquardt, W. (2000). Integration of data models for process design - first steps and experiences. Computers \& Chemical Engineering, 24(27), 599-605. doi:10.1016/S0098-1354(00)80002-2

Bedenik, N. I., Pahor, B., \& Kravanja, Z. (2004). An integrated strategy for the hierarchical multilevel MINLP synthesis of overall process flowsheets using the combined synthesis/analysis approach. Computers \& Chemical Engineering, 28(5), 693-706. doi:10.1016/j.compchemeng.2004.02.011

Bertran, M.-O. (2014). Chemical Processing Routes Based on Reaction Pathways. Technical University of Denmark.

Bessling, B., Schembecker, G., \& Simmrock, K. H. (1997). Design of Processes with Reactive Distillation Line Diagrams $\uparrow$. Industrial \& Engineering Chemistry Research, 36(8), 3032-3042. doi:10.1021/ie960727p

Biegler, L. T., Grossmann, I. E., \& Westerberg, A. W. (1997). Systematic Methods of Chemical Process Design. (N. R. Amundson, Ed.). New Jersey: Prentice Hall. Retrieved from http:/www.pearsonhighered.com/educator/product/Systematic-Methods-ofChemical-Process-Design/9780134924229.page

Bilde, M., Møgelberg, T. E., Sehested, J., Nielsen, O. J., Wallington, T. J., Hurley, M. D., Kurylo, M. J. (1997). Atmospheric Chemistry of Dimethyl Carbonate: Reaction with $\mathrm{OH}$ Radicals, UV Spectra of $\mathrm{CH} 3 \mathrm{OC}(\mathrm{O}) \mathrm{OCH} 2$ and $\mathrm{CH} 3 \mathrm{OC}(\mathrm{O}) \mathrm{OCH} 2 \mathrm{O} 2$ Radicals, Reactions of $\mathrm{CH} 3 \mathrm{OC}(\mathrm{O}) \mathrm{OCH} 2 \mathrm{O} 2$ with $\mathrm{NO}$ and $\mathrm{NO} 2$, and Fate of $\mathrm{CH} 3 \mathrm{OC}(\mathrm{O}) \mathrm{OCH} 2 \mathrm{O}$ Radicals. The Journal of Physical Chemistry A, 101(19), 3514-3525. doi:10.1021/jp961664r

Brandt, S. C., Morbach, J., Miatidis, M., Theißen, M., Jarke, M., \& Marquardt, W. (2008). An ontology-based approach to knowledge management in design processes. Computers \& Chemical Engineering, 32(1-2), 320-342. doi:10.1016/j.compchemeng.2007.04.013

Caballero, J. A., \& Grossmann, I. E. (2004). Design of distillation sequences: from conventional to fully thermally coupled distillation systems. Computers \& Chemical Engineering, 28(11), 2307-2329. doi:10.1016/j.compchemeng.2004.04.010 
Carvalho, A., Matos, H. A., \& Gani, R. (2009). Design of batch operations: Systematic methodology for generation and analysis of sustainable alternatives. Computers \& Chemical Engineering, 33(12), 2075-2090. doi:10.1016/j.compchemeng.2009.06.015

Carvalho, A., Matos, H. A., \& Gani, R. (2013). SustainPro-A tool for systematic process analysis, generation and evaluation of sustainable design alternatives. Computers \& Chemical Engineering, 50, 8-27. doi:10.1016/j.compchemeng.2012.11.007

CEFIC. (2008). Propylene-glycol. Brochure. Retrieved from http://www.propyleneglycol.com/uploads/PropyleneGlycolAdvocacybrochure.pdf

Chen, L., Chen, L., Ye, Y., Qi, Z., Freund, H., \& Sundmacher, K. (2012). Co-solvent intensification effect on aromatic alcohol oxidation. Catalysis Communications, 28, 143-146. doi:10.1016/j.catcom.2012.08.029

Chemicals, W. of. (2012). Ube forms dimethyl carbonate JV in China. News. Retrieved from http://www.worldofchemicals.com/media/ube-forms-dimethyl-carbonate-jv-inchina/2995.html

D'Anterroches, L. (2006). Integrated Process/Product Synthesis and Design Through a Reverse Modelling Approach. Technical University of Denmark. Retrieved from http://orbit.dtu.dk/en/projects/integrated-processproduct-synthesis-and-design-througha-reverse-modelling-approach(561d051c-f1ff-4a71-8f0f-a55bd2368b33).html

Daza, O. S., Pérez-Cisneros, E. S., Bek-Pedersen, E., \& Gani, R. (2003). Graphical and stage-to-stage methods for reactive distillation column design. AIChE Journal, 49(11), 2822-2841. doi:10.1002/aic.690491115

Douglas, J. M. (1985). A hierarchical decision procedure for process synthesis. AIChE Journal, 31(3), 353-362. doi:10.1002/aic.690310302

Doungsri, S., \& Terasut, S. (2011). Solubility curves of FAME + Methanol + Glycerol. In TIChE International Conference 2011. Songkhla, Thailand: Faculty of Engineering, Prince of Songkla University (PSU). Retrieved from http://www.chem.eng.psu.ac.th/tiche2011/TCHE/data/paper/thai/tfc/oral/tfc005.pdf

Dubé, M. A., Tremblay, A. Y., \& Liu, J. (2007). Biodiesel production using a membrane reactor. Bioresource Technology, 98(3), 639-47. doi:10.1016/j.biortech.2006.02.019 
Fedorova, M., Sin, G., \& Gani, R. (2014). 24th European Symposium on Computer Aided Process Engineering. Computer Aided Chemical Engineering (Vol. 33, pp. 817822). Elsevier. doi:10.1016/B978-0-444-63456-6.50137-X

Fernandez, E. B. (2012). Separation of azeotropic mixtures. Technical University of Denmark.

Gani, R. (2010). Selection of a thermodynamic model. Retrieved from http://www.kurser.dtu.dk/28350.aspx?menulanguage=en-gb

Gani, R. (2004). Chemical product design: challenges and opportunities. Computers \& Chemical Engineering, 28(12), 2441-2457. doi:10.1016/j.compchemeng.2004.08.010

Gani, R., \& Babi, D. K. (2014). Systematic Computer Aided Framework for Process Synthesis, Design and Intensification. In T. Letcher, J. Scott, \& P. A. Darrell (Eds.), Chemical Processes for a Sustainable Future (pp. 698-752). Cambridge: Royal Chemical Society.

Gani, R., Hytoft, G., Jaksland, C., \& Jensen, A. K. (1997). An integrated computer aided system for integrated design of chemical processes. Computers \& Chemical Engineering, 21(10), 1135-1146. doi:10.1016/S0098-1354(96)00324-9

Gernaey, K. V., \& Gani, R. (2010). A model-based systems approach to pharmaceutical product-process design and analysis. Chemical Engineering Science, 65(21), 57575769. doi:10.1016/j.ces.2010.05.003

Grossmann, I. E. (2012). Advances in mathematical programming models for enterprise-wide optimization. Computers \& Chemical Engineering, 47, 2-18. doi:10.1016/j.compchemeng.2012.06.038

Halvorsen, I. J., \& Skogestad, S. (2011). Energy efficient distillation. Journal of Natural Gas Science and Engineering, 3(4), 571-580. doi:10.1016/j.jngse.2011.06.002

Harmsen, J. (2010). Process intensification in the petrochemicals industry: Drivers and hurdles for commercial implementation. Chemical Engineering and Processing: Process Intensification, 49(1), 70-73. doi:10.1016/j.cep.2009.11.009

Harper, P. M., \& Gani, R. (2000). A multi-step and multi-level approach for computer aided molecular design. Computers \& Chemical Engineering, 24(2-7), 677-683. doi:10.1016/S0098-1354(00)00410-5 
Hersi, R. M. (2013). Process Intensification Case Studies: Hydroformylation of Higher Olefins. Technical University of Denmark.

Holtbruegge, J., Heile, S., Lutze, P., \& Górak, A. (2013). Synthesis of dimethyl carbonate and propylene glycol in a pilot-scale reactive distillation column: Experimental investigation, modeling and process analysis. Chemical Engineering Journal, 234, 448463. doi:10.1016/j.cej.2013.08.054 (a)

Holtbruegge, J., Kuhlmann, H., \& Lutze, P. (2014). Process analysis and economic optimization of intensified process alternatives for simultaneous industrial scale production of dimethyl carbonate and propylene glycol. Chemical Engineering Research and Design. doi:10.1016/j.cherd.2014.05.002

Holtbruegge, J., Leimbrink, M., Lutze, P., \& Górak, A. (2013). Synthesis of dimethyl carbonate and propylene glycol by transesterification of propylene carbonate with methanol: Catalyst screening, chemical equilibrium and reaction kinetics. Chemical Engineering Science, 104, 347-360. doi:10.1016/j.ces.2013.09.007 (b)

Holtbruegge, J., Wierschem, M., Steinruecken, S., Voss, D., Parhomenko, L., \& Lutze, P. (2013). Experimental investigation, modeling and scale-up of hydrophilic vapor permeation membranes: Separation of azeotropic dimethyl carbonate/methanol mixtures. Separation and Purification Technology, 118, 862-878. doi:10.1016/j.seppur.2013.08.025 (c)

Hunan Xiangwei Co., L. (2005). Methyl-acetate. Product Inofrmation-Methyl-acetate. Retrieved from http://www.hhxw.chemchina.com/hnxwen/cpyfw/ppysb/tztl/B31030204web_1.htm

Huss, R. S., Chen, F., Malone, M. F., \& Doherty, M. F. (2003). Reactive distillation for methyl acetate production. Computers \& Chemical Engineering, 27(12), 1855-1866. doi:10.1016/S0098-1354(03)00156-X

Inoue, T., Nagase, T., Hasegawa, Y., Kiyozumi, Y., Sato, K., Nishioka, M., ... Mizukami, F. (2007). Stoichiometric Ester Condensation Reaction Processes by Pervaporative Water Removal via Acid-Tolerant Zeolite Membranes. Industrial \& Engineering Chemistry Research, 46(11), 3743-3750. doi:10.1021/ie0615178

Jaksland, C. A., Gani, R., \& Lien, K. M. (1995). Separation process design and synthesis based on thermodynamic insights. Chemical Engineering Science, 50(3), 511-530. doi:10.1016/0009-2509(94)00216-E 
Kalakul, S., Malakul, P., Siemanond, K., \& Gani, R. (2014). Integration of life cycle assessment software with tools for economic and sustainability analyses and process simulation for sustainable process design. Journal of Cleaner Production, 71, 98-109. doi:10.1016/j.jclepro.2014.01.022

Karunanithi, A. T., Achenie, L. E. K., \& Gani, R. (2005). A New Decomposition-Based Computer-Aided Molecular/Mixture Design Methodology for the Design of Optimal Solvents and Solvent Mixtures. Industrial \& Engineering Chemistry Research, 44(13), 4785-4797. doi:10.1021/ie049328h

Kiss, A., Pragt, H., \& van Strien, C. (2007). 17th European Symposium on Computer Aided Process Engineering. Computer Aided Chemical Engineering (Vol. 24, pp. 467472). Elsevier. doi:10.1016/S1570-7946(07)80101-5

Kobus, A., Kuppinger, F.-F., Meier, R., Düssel, R., Tuchlenski, A., \& Nordhoff, S. (2001). Improvement of Conventional Unit Operations by Hybrid Separation Technologies - A Review of Industrial Applications. Chemie Ingenieur Technik, 73(6), 714. doi:10.1002/1522-2640(200106)73:6<714::AID-CITE7142222>3.0.CO;2-S

Kongpanna, P., Pavarajarn, V., Gani, R., \& Assabumrungrat, S. (2014). Technoeconomic evaluation of different $\mathrm{CO} 2$-based processes for dimethyl carbonate production. Chemical Engineering Research and Design. doi:10.1016/j.cherd.2014.07.013

Li, L.-J., Zhou, R.-J., Dong, H.-G., \& Grossmann, I. E. (2011). Separation network design with mass and energy separating agents. Computers \& Chemical Engineering, 35(10), 2005-2016. doi:10.1016/j.compchemeng.2010.10.013

Lin, B.-F., Huang, J.-H., \& Huang, D.-Y. (2009). Experimental study of the effects of vegetable oil methyl ester on DI diesel engine performance characteristics and pollutant emissions. Fuel, 88(9), 1779-1785. doi:10.1016/j.fuel.2009.04.006

Lutze, P. (2012). An Innovative Synthesis Methodology for Process Intensification. Technical University of Denmark. Retrieved from http://orbit.dtu.dk/en/publications/aninnovative-synthesis-methodology-for-process-intensification(56b93a7d-2ecc-46209990-4f9272b15d8e).html

Lutze, P., Babi, D. K., Woodley, J. M., \& Gani, R. (2013). Phenomena Based Methodology for Process Synthesis Incorporating Process Intensification. Industrial \& Engineering Chemistry Research, 52(22), 7127-7144. doi:10.1021/ie302513y 
Lutze, P., Gani, R., \& Woodley, J. M. (2010). Process intensification: A perspective on process synthesis. Chemical Engineering and Processing: Process Intensification, 49(6), 547-558. doi:10.1016/j.cep.2010.05.002

Lutze, P., \& Gorak, A. (2013). Reactive and membrane-assisted distillation: Recent developments and perspective. Chemical Engineering Research and Design, 91(10), 1978-1997. doi:10.1016/j.cherd.2013.07.011

Marrero, J., \& Gani, R. (2001). Group-contribution based estimation of pure component properties. Fluid Phase Equilibria, 183-184, 183-208. doi:10.1016/S03783812(01)00431-9

Moulijn, J. A., Stankiewicz, A., Grievink, J., \& Górak, A. (2008). Process intensification and process systems engineering: A friendly symbiosis. Computers \& Chemical Engineering, 32(1-2), 3-11. doi:10.1016/j.compchemeng.2007.05.014

Özkan, L., Backx, T., Van Gerven, T., \& Stankiewicz, A. I. (2012). Towards Perfect Reactors: Gaining full control of chemical transformations at molecular level. Chemical Engineering and Processing: Process Intensification, 51, 109-116. doi:10.1016/j.cep.2011.09.013

Papalexandri, K. P., \& Pistikopoulos, E. N. (1994). A multiperiod MINLP model for the synthesis of flexible heat and mass exchange networks. Computers \& Chemical Engineering, 18(11-12), 1125-1139. doi:10.1016/0098-1354(94)E0022-F

Papoulias, S. A., \& Grossmann, I. E. (1983). A structural optimization approach in process synthesis-I. Computers \& Chemical Engineering, 7(6), 695-706. doi:10.1016/0098-1354(83)85022-4

Peschel, A., Jörke, A., Freund, H., \& Sundmacher, K. (2012). Model-based development of optimal reaction concepts for plant wide process intensification. Computer Aided Chemical Engineering,. 31, 150-154. doi:10.1016/B978-0-444-59507-2.50022-6

Peters, M. S., Timmerhaus, K. D., \& West, R. E. (2003). sign and Economics for Chemical Engineers. (M. S. Peters, K. D. Timmerhaus, \& R. E. West, Eds.) (5th ed.). New York: Mc Graw Hill. Retrieved http://catalogs.mhhe.com/mhhe/viewProductDetails.do?isbn=0072392665

Pöpken, T., Götze, L., \& Gmehling, J. (2000). Reaction Kinetics and Chemical Equilibrium of Homogeneously and Heterogeneously Catalyzed Acetic Acid Esterification with Methanol and Methyl Acetate Hydrolysis. Industrial \& Engineering Chemistry Research, 39(7), 2601-2611. doi:10.1021/ie000063q 
Quaglia, A., Gargalo, C. L., Chairakwongsa, S., Sin, G., \& Gani, R. (2014). Systematic network synthesis and design: Problem formulation, superstructure generation, data management and solution. Computers \& Chemical Engineering. doi:10.1016/j.compchemeng.2014.03.007

Quaglia, A., Sarup, B., Sin, G., \& Gani, R. (2012). Integrated business and engineering framework for synthesis and design of enterprise-wide processing networks. Computers \& Chemical Engineering, 38, 213-223. doi:10.1016/j.compchemeng.2011.12.011

Rangaiah, G. P., Ooi, E. L., \& Premkumar, R. (2009). A Simplified Procedure for Quick Design of Dividing-Wall Columns for Industrial Applications. Chemical Product and Process Modelling, 4(1). doi:10.2202/1934-2659.1265

Rohm and Haas. (2003). AMBERLYST(TM) 15WET Industrail Grade Strong Acidic Catalyst. For Catalysis and Separation Technologies. Retrieved from http://www.dow.com/assets/attachments/business/process_chemicals/amberlyst/amberly st_15wet/tds/amberlyst_15wet.pdf

Rong, B.-G., Kolehmainen, E., \& Turunen, I. (2008). Methodology of conceptual process synthesis for process intensification. Computer Aided Chemical Engineering, 25, 283-288. doi:10.1016/S1570-7946(08)80052-1

Rong, B.-G., Kolehmainen, E., Turunen, I., \& Hurme, M. (2004). European Symposium on Computer-Aided Process Engineering-14, 37th European Symposium of the Working Party on Computer-Aided Process Engineering. Computer Aided Chemical Engineering (Vol. 18, pp. 481-486). Elsevier. doi:10.1016/S1570-7946(04)80146-9

Rudd, D. F., \& Watson, C. C. (1968). Strategy of Process Engineering. (D. F. Rudd \& C. C. Watson, Eds.). New York: John Wiley \& Sons, Inc.

Seifert, T., Sievers, S., Bramsiepe, C., \& Schembecker, G. (2012). Small scale, modular and continuous: A new approach in plant design. Chemical Engineering and Processing: Process Intensification, 52, 140-150. doi:10.1016/j.cep.2011.10.007

Schlosberg, R. H., Buchanan, S. J., Santiesteban, J. G., Jiang, Z., \& Weber, W. A. (2002). Low corrosive integrated process for preparing dialkyl carbonates. US. Retrieved from http://www.freepatentsonline.com/y2003/0023109.html 
Siirola, J. J. (1996). Strategic process synthesis: Advances in the hierarchical approach. Computers \& Chemical Engineering, 20, S1637-S1643. doi:10.1016/00981354(96)85982-5

Siirola, J. J., Powers, G. J., \& Rudd, D. F. (1971). Synthesis of system designs: III. Toward a process concept generator. AIChE Journal, 17(3), 677-682. doi:10.1002/aic.690170334

Simasatitkul, L., Arpornwichanop, A., \& Gani, R. (2013). Design methodology for biobased processing: Biodiesel and fatty alcohol production. Computers \& Chemical Engineering, 57, 48-62. doi:10.1016/j.compchemeng.2013.01.018

Singh, R., Gernaey, K. V., \& Gani, R. (2010). An ontological knowledge-based system for the selection of process monitoring and analysis tools. Computers \& Chemical Engineering, 34(7), 1137-1154. doi:10.1016/j.compchemeng.2010.04.011

Song, W., Venimadhavan, G., Manning, J. M., Malone, M. F., \& Doherty, M. F. (1998). Measurement of Residue Curve Maps and Heterogeneous Kinetics in Methyl Acetate Synthesis. Industrial \& Engineering Chemistry Research, 37(5), 1917-1928. doi:10.1021/ie9708790

Tula, A. K., \& Gani, R. (2014). Proceedings of the 8th International Conference on Foundations of Computer-Aided Process Design. Computer Aided Chemical Engineering (Vol. 34, pp. 453-458). Elsevier. doi:10.1016/B978-0-444-63433-7.50060-2

Urselmann, M., Barkmann, S., Sand, G., \& Engell, S. (2011). Optimization-based design of reactive distillation columns using a memetic algorithm. Computers \& Chemical Engineering, 35(5), 787-805. doi:10.1016/j.compchemeng.2011.01.038

Van Baelen, D., Van der Bruggen, B., Van den Dungen, K., Degreve, J., \& Vandecasteele, C. (2005). Pervaporation of water-alcohol mixtures and acetic acidwater mixtures. Chemical Engineering Science, 60(6), 1583-1590. doi:10.1016/j.ces.2004.10.030

Westerberg, A. W. (2004). A retrospective on design and process synthesis. Computers \& Chemical Engineering, 28(4), 447-458. doi:10.1016/j.compchemeng.2003.09.029 
APPENDICES 


\section{Appendix A-Classification of Basic Structures}

In section 2.3.4, the concept of basic structures is presented. In order to generate basic structures which is the combination of simultaneous phenomena building blocks, using rules. Simultaneous phenomena building blocks are categorized into initiators, intermediates and terminators, given in Table 0-1. Note, initiator simultaneous phenomena building blocks are also feasible intermediate simultaneous phenomena building blocks.

Table 0-1 is explained as follows, each simultaneous phenomena building block is categorized as either an initiator, intermediate or terminator. Once the category is selected then the class of the simultaneous phenomena building block is selected. The generated basic structures from the application of algorithm II.4, consists of initiator, intermediate and terminator simultaneous phenomena building blocks. 


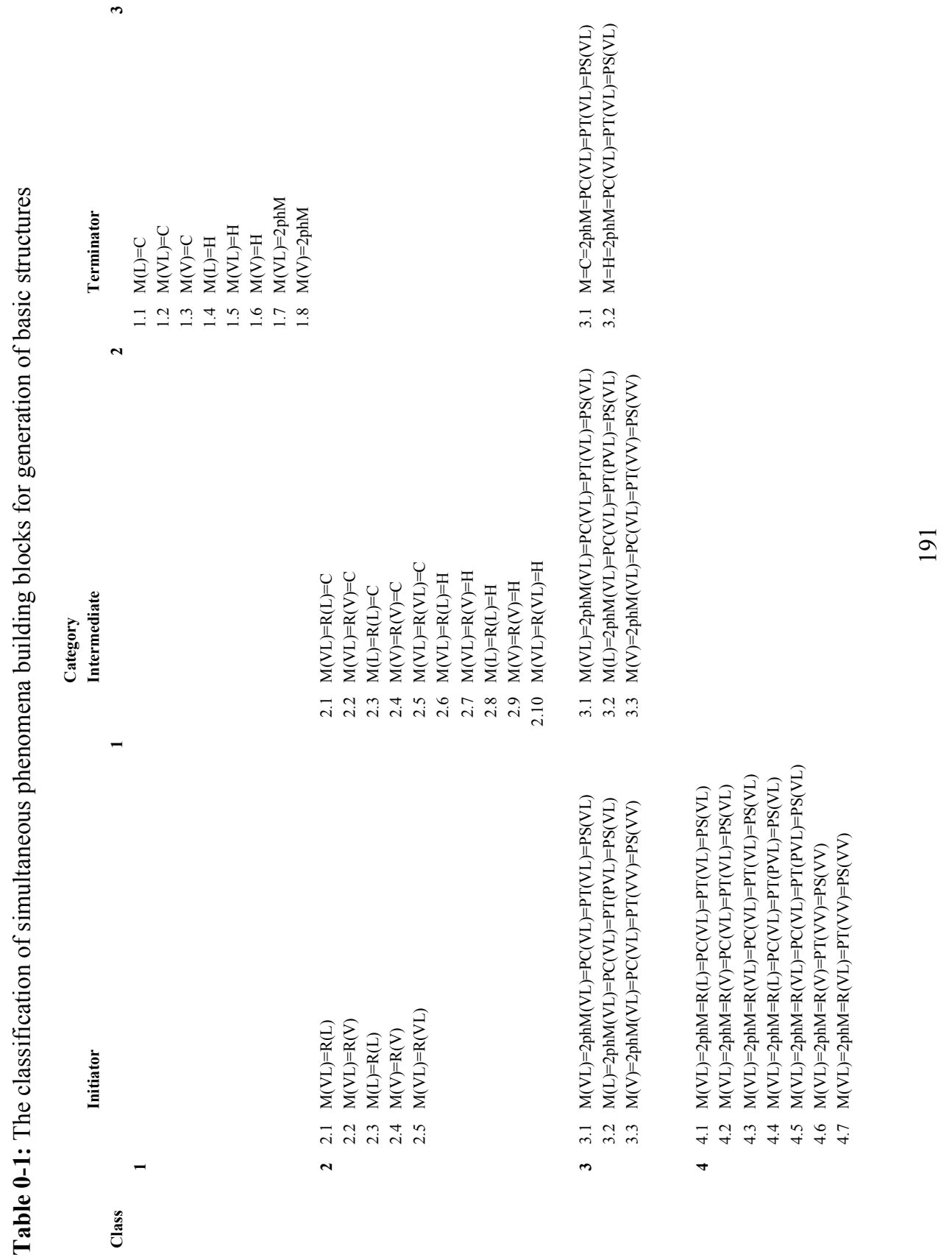




\section{Appendix B-Identification of Phenomena Building Blocks}

In section 2.3, the concept of phenomena building blocks (PBBs) is explained and in algorithm I.2 the PBBs for performing a task must be identified. A knowledge base tool was expanded (Lutze, 2012) and shown in Table 0-2 


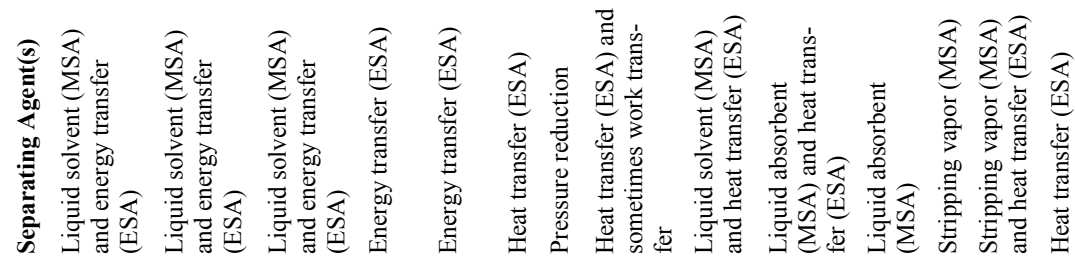

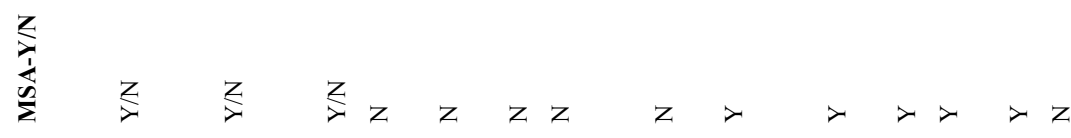

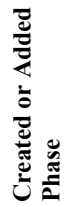

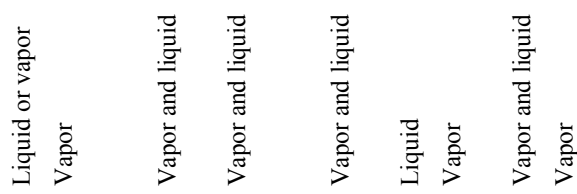

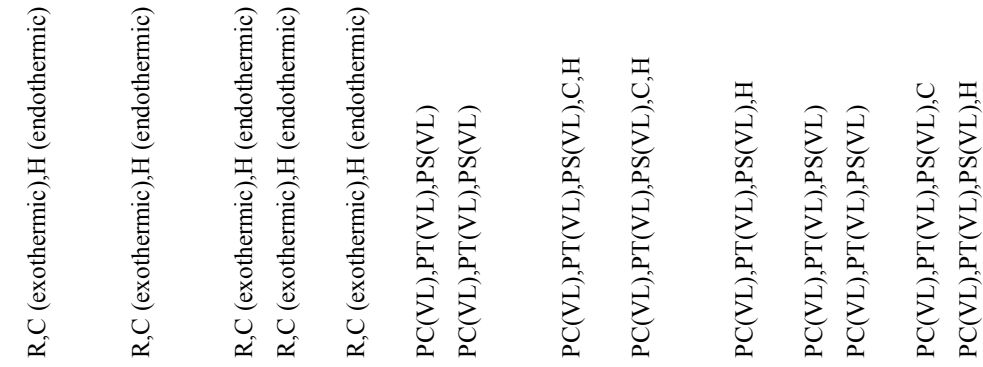
ฐ

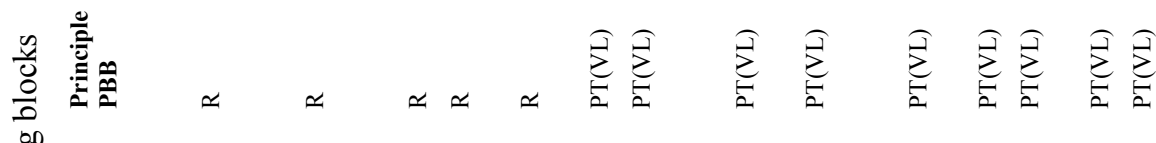
:

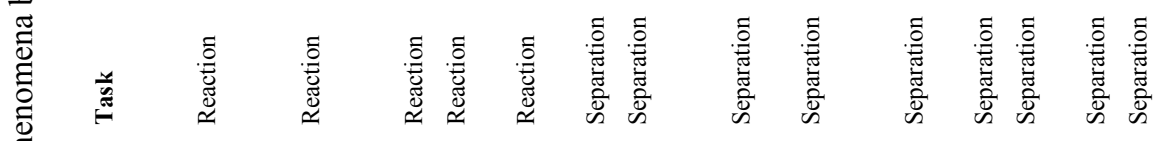

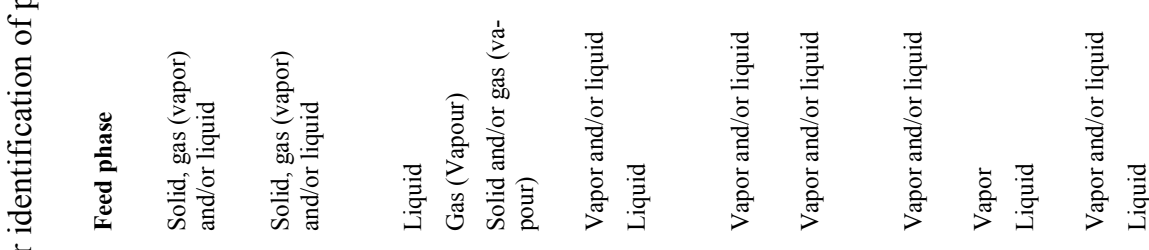

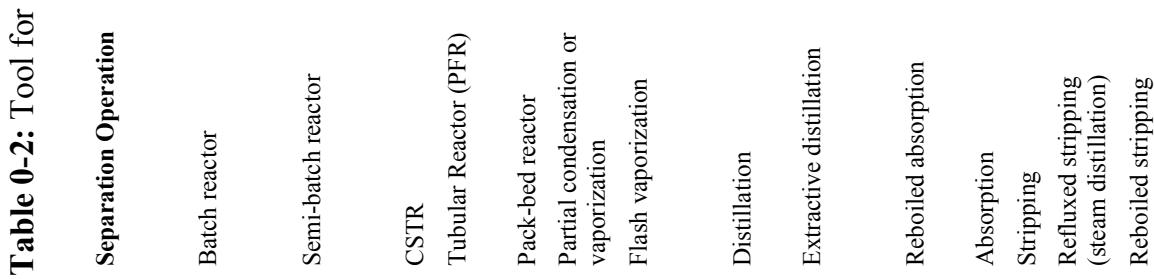




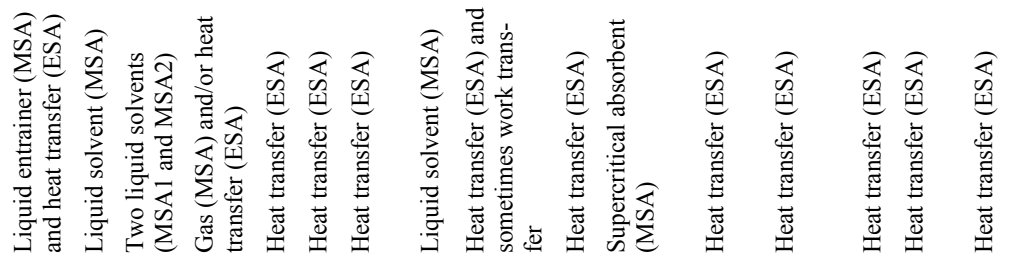

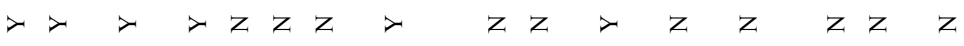

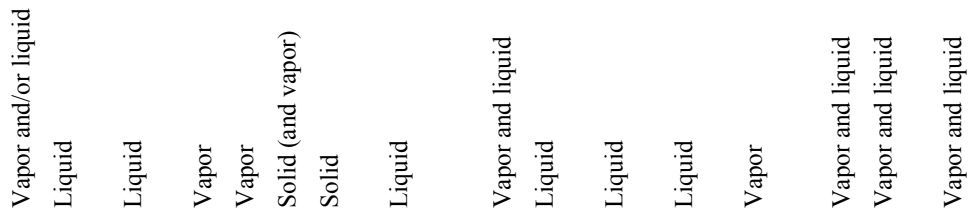

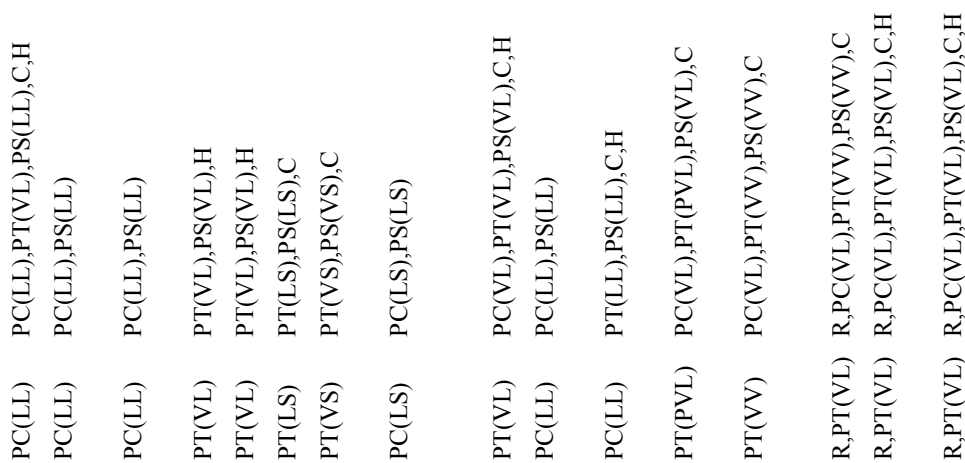

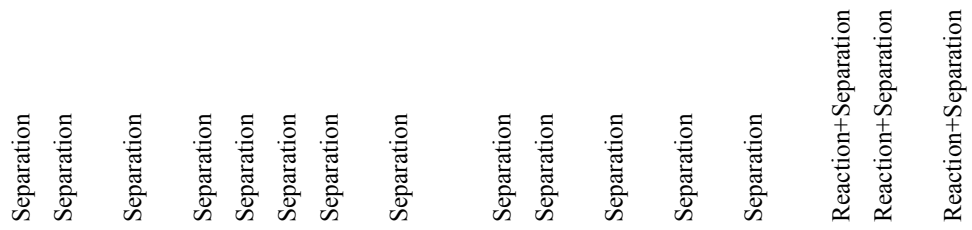

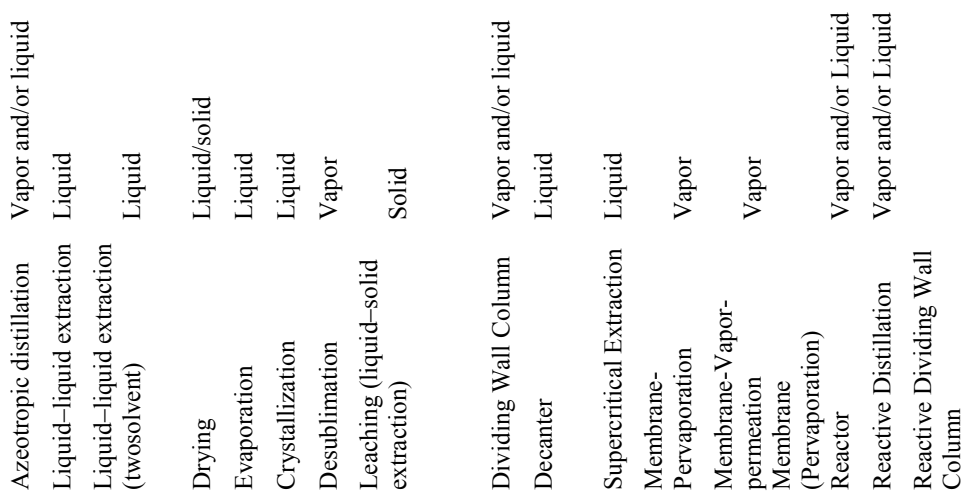




\section{Appendix C-Identification of Desirable Task and Phenome- na Building Blocks}

In algorithm I.3 alternative tasks and phenomena building blocks (PBBs) which are beneficial to the generation of more sustainable designs are identified. A knowledge base tool was expanded (Lutze, 2012) and shown in Table 0-3. 



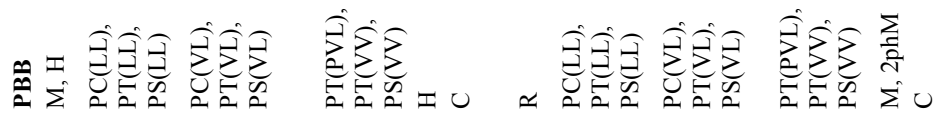

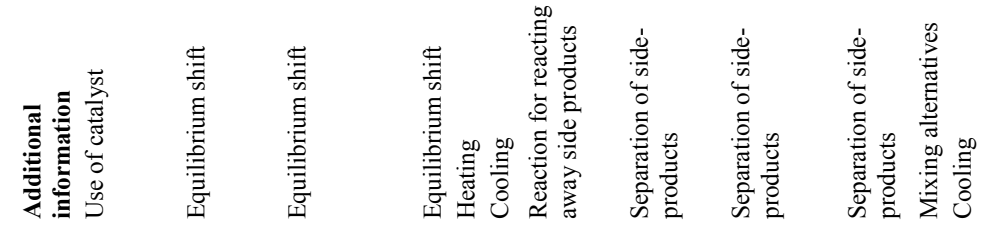

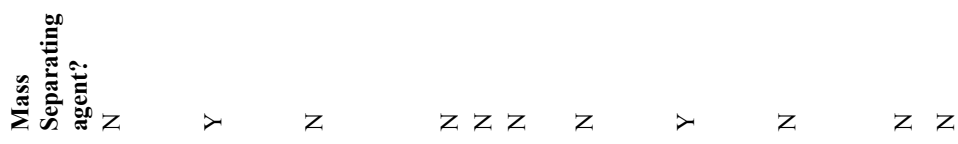

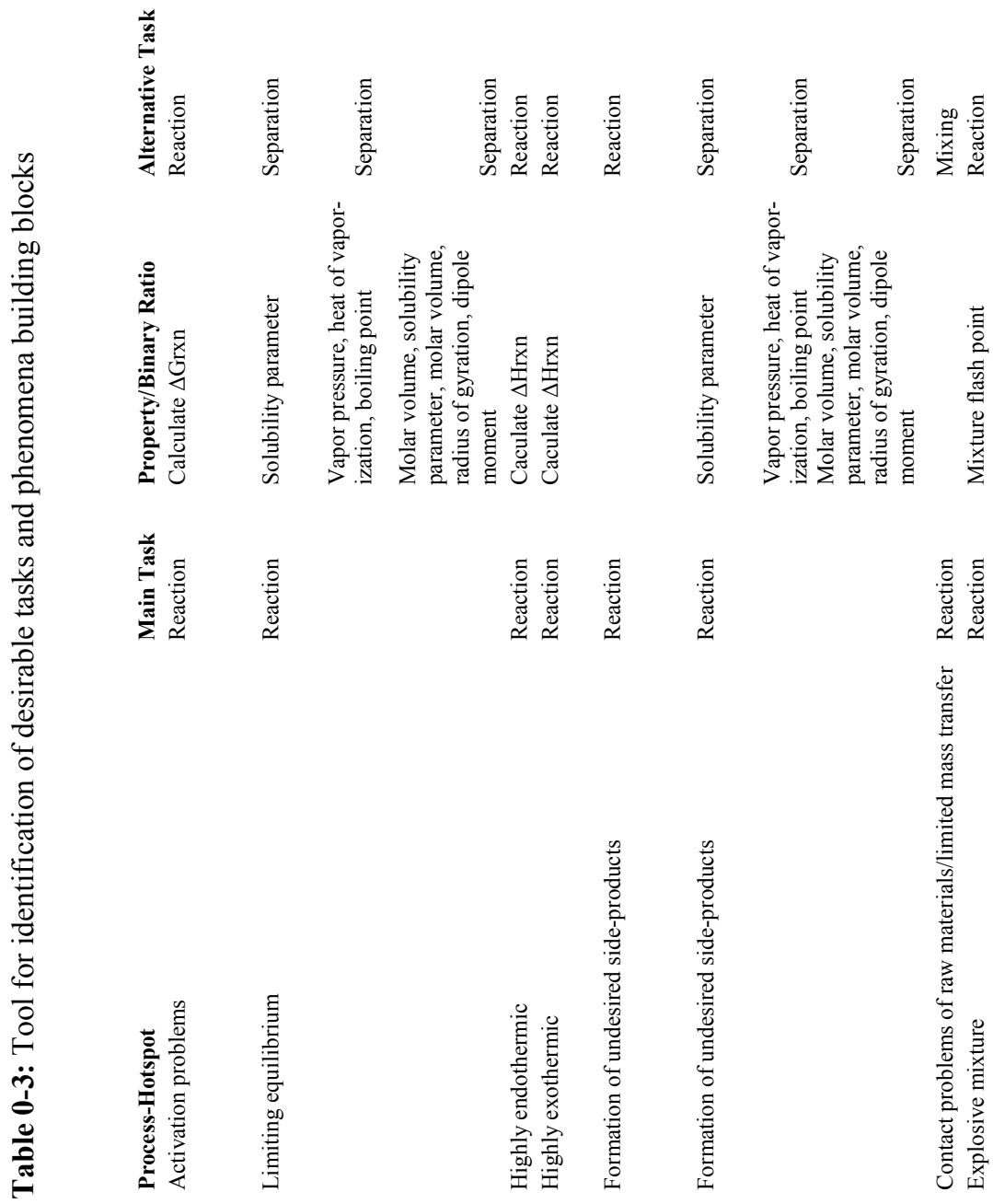




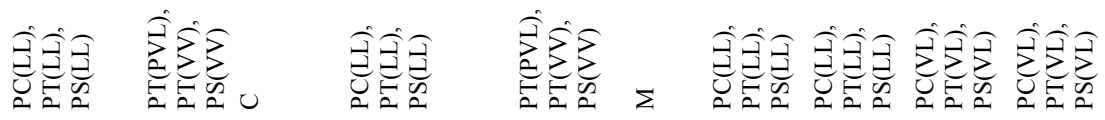

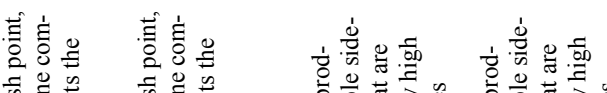

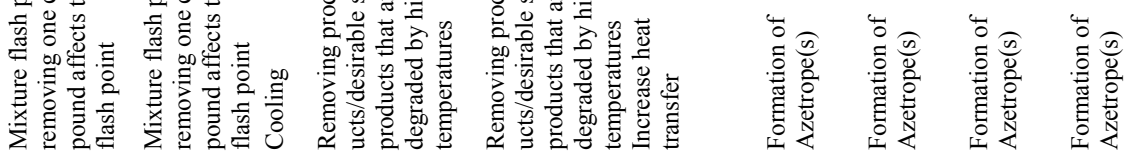
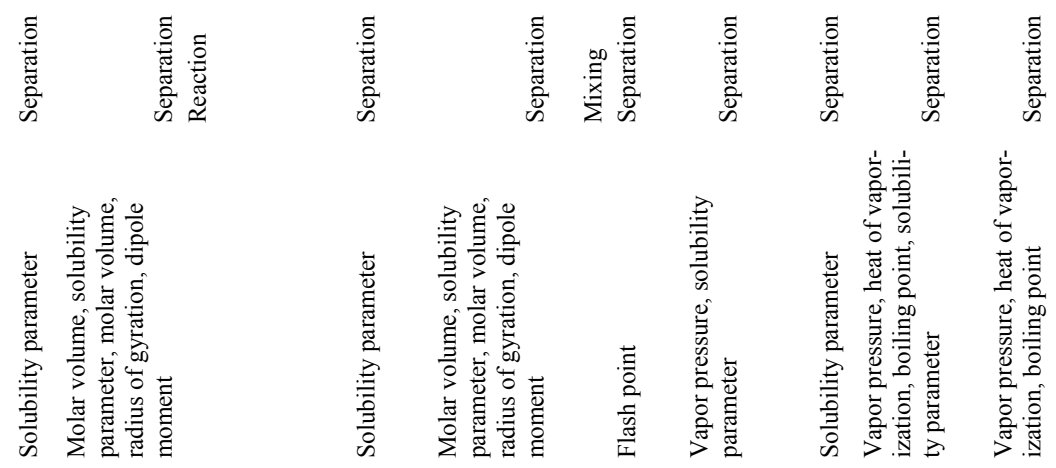

I 1 I $11 ! \mid$

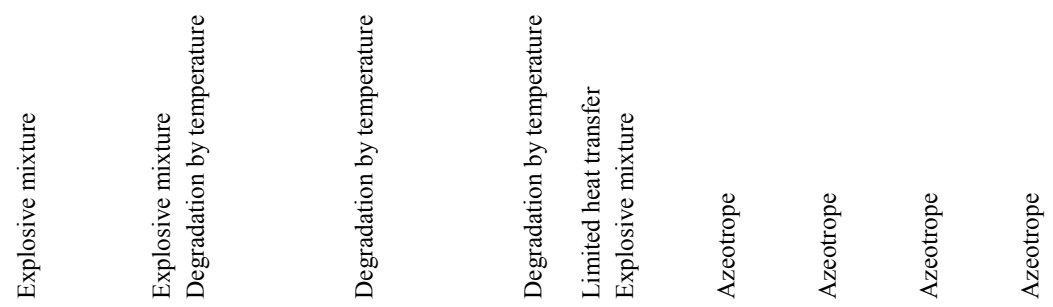




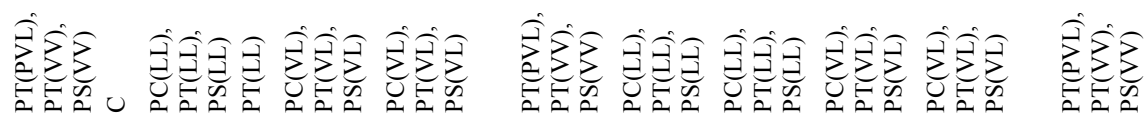

Inl

IIIIIIIII Mn

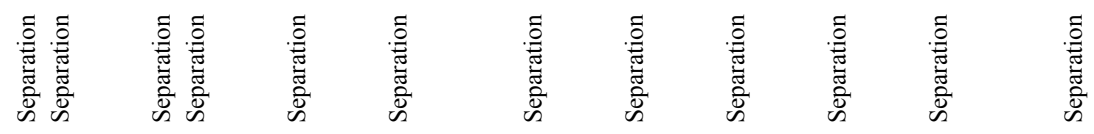

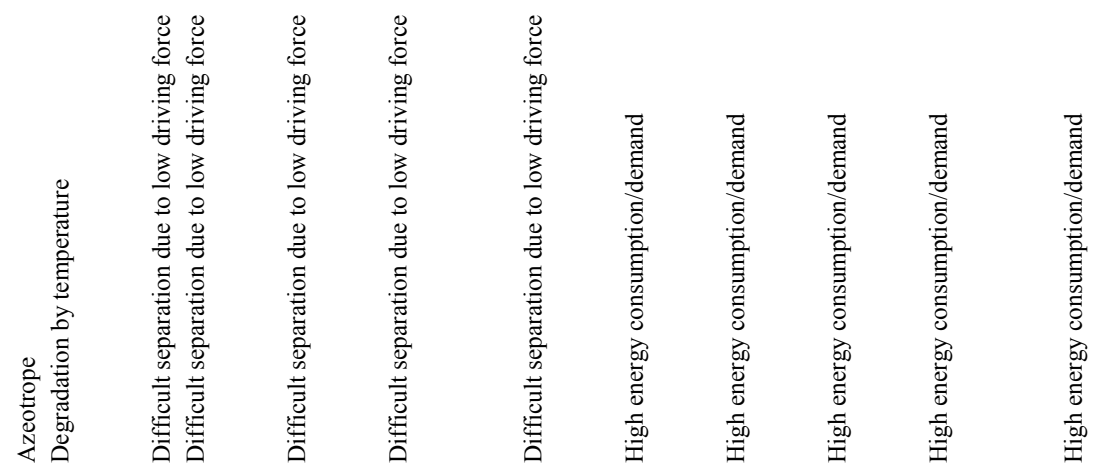




\section{Appendix D-Database of Basic Structures}

In section 2.3.4, the concept of basic structures is explained and in algorithm II.4 basic structures are identified that perform a task or set of tasks. Basic structures are generation from the combination of phenomena building blocks (PBBs) to simultaneous phenomena building blocks (SPBs), using combination rules. For different task activities basic structures can be generate $a$ priori and made readily available for use when identifying basic structures that fulfill a task or set of tasks. These basic structures are the stored a knowledge-based tool (Lutze, 2012) Table 0-4, 
Table 0-5 and Table 0-6, gives basic structures for reaction, separation and reactionseparation.

Table 0-4: Reaction basic structures

\begin{tabular}{|l|l|l|}
\hline Basic Structure & Task Activity & Task* \\
\hline
\end{tabular}




\begin{tabular}{|c|c|c|}
\hline$M(V L)=R(L)$ & \multirow{3}{*}{$\begin{array}{l}\text {-R-phase-L, } \\
\text {-R-Type-Endo. } \\
\text { (Feed Cond.-V-L) }\end{array}$} & \multirow{24}{*}{ 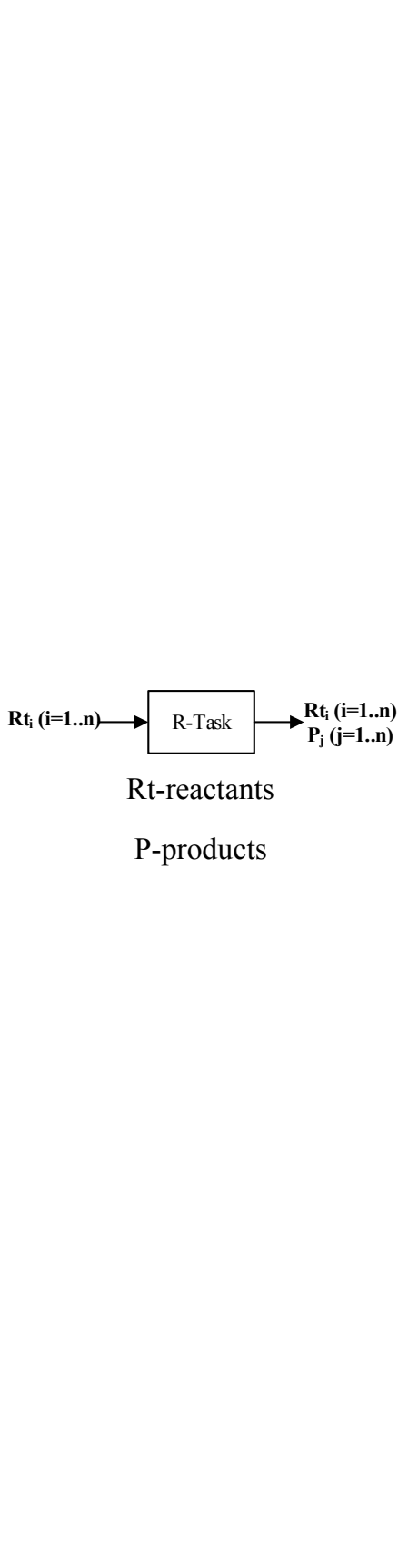 } \\
\hline \multirow[t]{2}{*}{$M(V L)=C$} & & \\
\hline & & \\
\hline$M(V L)=R(L)$ & \multirow{3}{*}{$\begin{array}{l}\text {-R-phase-L, } \\
\text {-R-Type-Exo. } \\
\text { (Feed Cond.-V-L) }\end{array}$} & \\
\hline \multirow[t]{2}{*}{$M(V L)=H$} & & \\
\hline & & \\
\hline$M(V L)=R(V)$ & \multirow{3}{*}{$\begin{array}{l}\text {-R-phase-V- } \\
\text { R-Type-Endo. } \\
\text { (Feed Cond.-V-L) }\end{array}$} & \\
\hline \multirow[t]{2}{*}{$M(V L)=C$} & & \\
\hline & & \\
\hline$M(V L)=R(V)$ & \multirow{3}{*}{$\begin{array}{l}\text {-R-phase-V,- } \\
\text {-R-Type-Exo. } \\
\text { (Feed Cond.-V-L) }\end{array}$} & \\
\hline \multirow[t]{2}{*}{$M(V L)=H$} & & \\
\hline & & \\
\hline$M(L)=R(L)$ & \multirow{3}{*}{$\begin{array}{l}\text {-R-phase-L,- } \\
\text { R-Type-Endo. } \\
\text { (Feed Cond.-L) }\end{array}$} & \\
\hline \multirow[t]{2}{*}{$M(L)=C$} & & \\
\hline & & \\
\hline$M(L)=R(L)$ & -R-phase-L, & \\
\hline \multirow[t]{2}{*}{$M(L)=H$} & -R-Туре-Ехо. & \\
\hline & (Feed Cond.-L) & \\
\hline$M(V)=R(V)$ & -R-phase-V,- & \\
\hline \multirow[t]{2}{*}{$M(V)=C$} & R-Type-Endo. & \\
\hline & (Feed Cond.-V) & \\
\hline$M(V)=R(V)$ & -R-phase-V, & \\
\hline \multirow[t]{2}{*}{$M(V)=H$} & -R-Туре-Ехо. & \\
\hline & (Feed Cond.-V) & \\
\hline
\end{tabular}




\begin{tabular}{|c|l|}
\hline$M(V L)=R(V L)$ & $\begin{array}{l}\text {-R-phase-VL, } \\
\text {-R-Type-Endo. } \\
\text { (Feed Cond.-V-L) }\end{array}$ \\
\hline$M(V L)=C$ & $\begin{array}{l}\text {-R-phase-VL, } \\
\text {-R-Type-Exo. } \\
\text { (Feed Cond.-V-L) }\end{array}$ \\
\hline$M(V L)=R(V L)$
\end{tabular}


Table 0-5: Separation basic structures. Note each binary pair that represent the inlet to a task represent the two key compounds under consideration

\begin{tabular}{|c|c|c|c|}
\hline $\begin{array}{l}\text { Basic } \\
\text { Struc- } \\
\text { ture No. }\end{array}$ & Basic Structure & Task Activity & Task* \\
\hline \multirow[t]{3}{*}{1} & $\mathrm{M}(\mathrm{VL})=\mathrm{C}=2 \mathrm{phM}=\mathrm{PC}(\mathrm{VL})=\mathrm{PT}(\mathrm{VL})=\mathrm{PS}(\mathrm{VL})$ & \multirow{3}{*}{$\begin{array}{l}\text {-S-phase-V-L, } \\
\text { Azeo-Yes/No } \\
\text { (Feed Cond.-L, } \\
\text { V-L,V) }\end{array}$} & \multirow{21}{*}{ 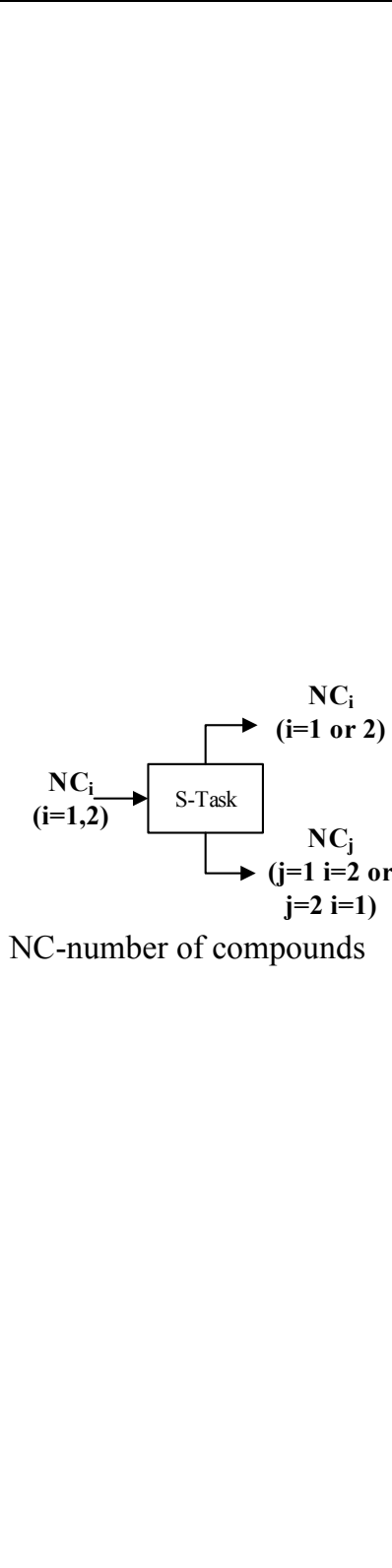 } \\
\hline & $\mathrm{M}(\mathrm{VL})=2 \mathrm{phM}=\mathrm{PC}(\mathrm{VL})=\mathrm{PT}(\mathrm{VL})=\mathrm{PS}(\mathrm{VL})$ & & \\
\hline & $\mathrm{M}(\mathrm{VL})=\mathrm{H}=2 \mathrm{phM}=\mathrm{PC}(\mathrm{VL})=\mathrm{PT}(\mathrm{VL})=\mathrm{PS}(\mathrm{VL})$ & & \\
\hline \multirow[t]{2}{*}{2} & $\mathrm{M}(\mathrm{VL})=2 \mathrm{phM}$ & \multirow{2}{*}{$\begin{array}{l}\text {-S-phase-V-L, } \\
\text { Azeo-Yes, } \\
\text { (Feed Cond.-L) }\end{array}$} & \\
\hline & $\mathrm{M}(\mathrm{L})=2 \mathrm{phM}=\mathrm{PC}(\mathrm{VL})=\mathrm{PT}(\mathrm{PVL})=\mathrm{PS}(\mathrm{VL})$ & & \\
\hline \multirow[t]{3}{*}{3} & $\mathrm{M}(\mathrm{VL})=2 \mathrm{phM}$ & \multirow{3}{*}{$\begin{array}{l}\text {-S-phase-V, } \\
\text { Azeo-Yes, } \\
\text { (Feed Cond.-V) }\end{array}$} & \\
\hline & $\mathrm{M}(\mathrm{L})=2 \mathrm{phM}=\mathrm{PC}(\mathrm{VL})=\mathrm{PT}(\mathrm{PVL})=\mathrm{PS}(\mathrm{VL})$ & & \\
\hline & $\mathrm{M}(\mathrm{V})=\mathrm{C}$ & & \\
\hline & & & \\
\hline \multirow[t]{4}{*}{4} & $\mathrm{M}(\mathrm{VL})=2 \mathrm{phM}$ & \multirow{4}{*}{$\begin{array}{l}\text {-S-phase-V, } \\
\text { Azeo-Yes, } \\
\text { (Feed Cond.-V- } \\
\text { L) }\end{array}$} & \\
\hline & $\mathrm{M}(\mathrm{L})=2 \mathrm{phM}=\mathrm{PC}(\mathrm{VL})=\mathrm{PT}(\mathrm{PVL})=\mathrm{PS}(\mathrm{VL})$ & & \\
\hline & $\mathrm{M}(\mathrm{VL})=\mathrm{C}$ & & \\
\hline & & & \\
\hline \multirow[t]{3}{*}{5} & $\mathrm{M}(\mathrm{VL})=2 \mathrm{phM}$ & \multirow{3}{*}{$\begin{array}{l}\text {-S-phase-V, } \\
\text { Azeo-Yes, } \\
\text { (Feed Cond.-V- } \\
\text { L) }\end{array}$} & \\
\hline & $\mathrm{M}(\mathrm{V})=2 \mathrm{phM}=\mathrm{PC}(\mathrm{VL})=\mathrm{PT}(\mathrm{VV})=\mathrm{PS}(\mathrm{VV})$ & & \\
\hline & & & \\
\hline \multirow[t]{2}{*}{6} & $\mathrm{M}(\mathrm{V})=2 \mathrm{phM}$ & \multirow{2}{*}{$\begin{array}{l}\text {-S-phase-V, } \\
\text { Azeo-Yes, } \\
\text { (Feed Cond.-V) }\end{array}$} & \\
\hline & $\mathrm{M}(\mathrm{V})=2 \mathrm{phM}=\mathrm{PT}(\mathrm{VV})=\mathrm{PS}(\mathrm{VV})$ & & \\
\hline \multirow[t]{3}{*}{7} & $\mathrm{M}(\mathrm{VL})=2 \mathrm{phM}$ & \multirow{3}{*}{$\begin{array}{l}\text {-S-phase-V, } \\
\text { Azeo-Yes, } \\
\text { (Feed Cond.-L) }\end{array}$} & \\
\hline & $\mathrm{M}(\mathrm{V})=2 \mathrm{phM}=\mathrm{PC}(\mathrm{VL})=\mathrm{PT}(\mathrm{VV})=\mathrm{PS}(\mathrm{VV})$ & & \\
\hline & $\mathrm{M}(\mathrm{L})=\mathrm{H}$ & & \\
\hline
\end{tabular}




\begin{tabular}{|c|c|c|c|}
\hline \multirow[t]{3}{*}{8} & $\mathrm{M}(\mathrm{VL})=2 \mathrm{phM}$ & \multirow{3}{*}{$\begin{array}{l}\text {-S-phase-V, } \\
\text { Azeo-Yes, } \\
\text { (Feed Cond.-V- } \\
\text { L) }\end{array}$} & \\
\hline & $\mathrm{M}(\mathrm{VL})=2 \mathrm{phM}=\mathrm{PC}(\mathrm{VL})=\mathrm{PT}(\mathrm{VV})=\mathrm{PS}(\mathrm{VV})$ & & \\
\hline & $\mathrm{M}(\mathrm{VL})=\mathrm{H}$ & & \\
\hline $\begin{array}{l}\text { Basic } \\
\text { Struc- } \\
\text { tures } \\
\text { in the } \\
\text { combi- } \\
\text { nation }\end{array}$ & Basic Structure & Task Activity & Task* \\
\hline \multirow[t]{4}{*}{$1+2$} & $\mathrm{M}(\mathrm{VL})=\mathrm{C}=2 \mathrm{phM}=\mathrm{PC}(\mathrm{VL})=\mathrm{PT}(\mathrm{VL})=\mathrm{PS}(\mathrm{VL})$ & \multirow{4}{*}{$\begin{array}{l}\text {-S-phase-V-L, } \\
\text { Azeo-Yes } \\
\text { (Feed Cond.-L, } \\
\text { V-L,V) }\end{array}$} & \\
\hline & $\mathrm{M}(\mathrm{VL})=2 \mathrm{phM}=\mathrm{PC}(\mathrm{VL})=\mathrm{PT}(\mathrm{VL})=\mathrm{PS}(\mathrm{VL})$ & & \\
\hline & $\mathrm{M}(\mathrm{L})=2 \mathrm{phM}=\mathrm{PC}(\mathrm{VL})=\mathrm{PT}(\mathrm{PVL})=\mathrm{PS}(\mathrm{VL})$ & & \\
\hline & $\mathrm{M}(\mathrm{VL})=2 \mathrm{phM}$ & & \\
\hline \multirow[t]{5}{*}{$1+5$} & $\mathrm{M}(\mathrm{VL})=\mathrm{C}=2 \mathrm{phM}=\mathrm{PC}(\mathrm{VL})=\mathrm{PT}(\mathrm{VL})=\mathrm{PS}(\mathrm{VL})$ & \multirow{5}{*}{$\begin{array}{l}\text {-S-phase-V-L, } \\
\text { Azeo-Yes, } \\
\text { (Feed Cond.-L, } \\
\text { V-L,V) }\end{array}$} & \\
\hline & $\mathrm{M}(\mathrm{VL})=2 \mathrm{phM}=\mathrm{PC}(\mathrm{VL})=\mathrm{PT}(\mathrm{VL})=\mathrm{PS}(\mathrm{VL})$ & & \\
\hline & $\mathrm{M}(\mathrm{V})=2 \mathrm{phM}=\mathrm{PC}(\mathrm{VL})=\mathrm{PT}(\mathrm{VV})=\mathrm{PS}(\mathrm{VV})$ & & \\
\hline & $M(L)=H$ & & \\
\hline & $\mathrm{M}(\mathrm{VL})=2 \mathrm{phM}$ & & \\
\hline \multirow[t]{4}{*}{$1+6$} & $\mathrm{M}(\mathrm{V})=2 \mathrm{phM}$ & \multirow{4}{*}{$\begin{array}{l}\text {-S-phase-V-L, } \\
\text { Azeo-Yes, } \\
\text { (Feed Cond.-L, } \\
\text { V-L,V) }\end{array}$} & \\
\hline & $\mathrm{M}(\mathrm{V})=2 \mathrm{phM}=\mathrm{PT}(\mathrm{VV})=\mathrm{PS}(\mathrm{VV})$ & & \\
\hline & $\mathrm{M}(\mathrm{VL})=2 \mathrm{phM}=\mathrm{PC}(\mathrm{VL})=\mathrm{PT}(\mathrm{VL})=\mathrm{PS}(\mathrm{VL})$ & & \\
\hline & $\mathrm{M}(\mathrm{VL})=\mathrm{H}=2 \mathrm{phM}=\mathrm{PC}(\mathrm{VL})=\mathrm{PT}(\mathrm{VL})=\mathrm{PS}(\mathrm{VL})$ & & \\
\hline
\end{tabular}




\begin{tabular}{|c|c|c|c|}
\hline \multirow[t]{5}{*}{$1+2+6$} & $\mathrm{M}(\mathrm{VL})=2 \mathrm{phM}$ & \multirow{5}{*}{$\begin{array}{l}\text {-S-phase-V-L, } \\
\text { Azeo-Yes, } \\
\text { (Feed Cond.-L, } \\
\text { V-L,V) }\end{array}$} & \\
\hline & $\mathrm{M}(\mathrm{V})=\mathrm{C}$ & & \\
\hline & $\mathrm{M}(\mathrm{L})=2 \mathrm{phM}=\mathrm{PC}(\mathrm{VL})=\mathrm{PT}(\mathrm{PVL})=\mathrm{PS}(\mathrm{VL})$ & & \\
\hline & $\mathrm{M}(\mathrm{VL})=2 \mathrm{phM}=\mathrm{PC}(\mathrm{VL})=\mathrm{PT}(\mathrm{VL})=\mathrm{PS}(\mathrm{VL})$ & & \\
\hline & $\mathrm{M}(\mathrm{VL})=\mathrm{H}=2 \mathrm{phM}=\mathrm{PC}(\mathrm{VL})=\mathrm{PT}(\mathrm{VL})=\mathrm{PS}(\mathrm{VL})$ & & \\
\hline & $\mathrm{M}(\mathrm{V})=2 \mathrm{phM}$ & \multirow{5}{*}{$\begin{array}{l}\text {-S-phase-V-L, } \\
\text { Azeo-Yes, } \\
\text { (Feed Cond.-L, } \\
\text { V-L,V) }\end{array}$} & \\
\hline & $\mathrm{M}(\mathrm{V})=2 \mathrm{phM}=\mathrm{PT}(\mathrm{VV})=\mathrm{PS}(\mathrm{VV})$ & & \\
\hline & $\mathrm{M}(\mathrm{VL})=2 \mathrm{phM}=\mathrm{PC}(\mathrm{VL})=\mathrm{PT}(\mathrm{VL})=\mathrm{PS}(\mathrm{VL})$ & & \\
\hline & $\mathrm{M}(\mathrm{L})=2 \mathrm{phM}=\mathrm{PC}(\mathrm{VL})=\mathrm{PT}(\mathrm{PVL})=\mathrm{PS}(\mathrm{VL})$ & & \\
\hline & $\mathrm{M}(\mathrm{VL})=2 \mathrm{phM}$ & & \\
\hline \multirow[t]{7}{*}{$1+3+5$} & $\mathrm{M}(\mathrm{VL})=2 \mathrm{phM}$ & \multirow{7}{*}{$\begin{array}{l}\text {-S-phase-V-L, } \\
\text { Azeo-Yes, } \\
\text { (Feed Cond.-L, } \\
\text { V-L,V) }\end{array}$} & \\
\hline & $\mathrm{M}(\mathrm{V})=\mathrm{C}$ & & \\
\hline & $\mathrm{M}(\mathrm{L})=2 \mathrm{phM}=\mathrm{PC}(\mathrm{VL})=\mathrm{PT}(\mathrm{PVL})=\mathrm{PS}(\mathrm{VL})$ & & \\
\hline & $\mathrm{M}(\mathrm{VL})=2 \mathrm{phM}=\mathrm{PC}(\mathrm{VL})=\mathrm{PT}(\mathrm{VL})=\mathrm{PS}(\mathrm{VL})$ & & \\
\hline & $\mathrm{M}(\mathrm{V})=2 \mathrm{phM}=\mathrm{PC}(\mathrm{VL})=\mathrm{PT}(\mathrm{VV})=\mathrm{PS}(\mathrm{VV})$ & & \\
\hline & $M(L)=H$ & & \\
\hline & $\mathrm{M}(\mathrm{VL})=2 \mathrm{phM}$ & & \\
\hline \multirow[t]{6}{*}{$1+2+3$} & $\mathrm{M}(\mathrm{VL})=2 \mathrm{phM}$ & \multirow{6}{*}{$\begin{array}{l}\text {-S-phase-V-L, } \\
\text { Azeo-Yes, } \\
\text { (Feed Cond.-L, } \\
\text { V-L,V) }\end{array}$} & \\
\hline & $\mathrm{M}(\mathrm{V})=\mathrm{C}$ & & \\
\hline & $\mathrm{M}(\mathrm{L})=2 \mathrm{phM}=\mathrm{PC}(\mathrm{VL})=\mathrm{PT}(\mathrm{PVL})=\mathrm{PS}(\mathrm{VL})$ & & \\
\hline & $\mathrm{M}(\mathrm{VL})=2 \mathrm{phM}=\mathrm{PC}(\mathrm{VL})=\mathrm{PT}(\mathrm{VL})=\mathrm{PS}(\mathrm{VL})$ & & \\
\hline & $\mathrm{M}(\mathrm{L})=2 \mathrm{phM}=\mathrm{PC}(\mathrm{VL})=\mathrm{PT}(\mathrm{PVL})=\mathrm{PS}(\mathrm{VL})$ & & \\
\hline & $\mathrm{M}(\mathrm{VL})=2 \mathrm{phM}$ & & \\
\hline
\end{tabular}




\begin{tabular}{|c|c|c|}
\hline \multirow[t]{6}{*}{$1+6+7$} & $\mathrm{M}(\mathrm{V})=2 \mathrm{phM}$ & \multirow{6}{*}{$\begin{array}{l}\text {-S-phase-V-L, } \\
\text { Azeo-Yes, } \\
\text { (Feed Cond.-L, } \\
\text { V-L,V) }\end{array}$} \\
\hline & $\mathrm{M}(\mathrm{V})=2 \mathrm{phM}=\mathrm{PT}(\mathrm{VV})=\mathrm{PS}(\mathrm{VV})$ & \\
\hline & $\mathrm{M}(\mathrm{VL})=2 \mathrm{phM}=\mathrm{PC}(\mathrm{VL})=\mathrm{PT}(\mathrm{VL})=\mathrm{PS}(\mathrm{VL})$ & \\
\hline & $\mathrm{M}(\mathrm{V})=2 \mathrm{phM}=\mathrm{PC}(\mathrm{VL})=\mathrm{PT}(\mathrm{VV})=\mathrm{PS}(\mathrm{VV})$ & \\
\hline & $M(L)=H$ & \\
\hline & $\mathrm{M}(\mathrm{VL})=2 \mathrm{phM}$ & \\
\hline
\end{tabular}


Table 0-6: Reaction-Separation basic structures. Note: (1) The reaction phase is assumed as the feed condition. (2) $i=\mathrm{L}, \mathrm{V}, \mathrm{V}-\mathrm{L}$, therefore, for each of the basic structures with $\mathrm{R}(i)$ there exist three of these and for representation not all three have been shown. The basic structures highlighted yellow represent basic structures that have been combined for reaction-separation

\begin{tabular}{|c|c|c|}
\hline Basic Structure & Task Activity & Task* \\
\hline $\mathrm{M}(\mathrm{VL})=\mathrm{C}=2 \mathrm{phM}=\mathrm{PC}(\mathrm{VL})=\mathrm{PT}(\mathrm{VL})=\mathrm{PS}(\mathrm{VL})$ & \multirow{5}{*}{$\begin{array}{l}\text {-R-phase-L,V,V- } \\
\text { L,S-phase-VL, } \\
\text { R-Type- } \\
\text { Exo./Endo., } \\
\text { Azeo-Yes/No } \\
\text { (Feed Cond.- } \\
\text { L,V,V-L) }\end{array}$} & \multirow{20}{*}{$\underset{(\mathbf{i}=\mathbf{1} . . . \mathbf{n})}{\mathbf{N C}_{\mathbf{i}}} \longrightarrow \mathrm{R}=\mathrm{S}$-Task } \\
\hline $\mathrm{M}(\mathrm{VL})=\mathrm{R}(i)=2 \mathrm{phM}=\mathrm{PC}(\mathrm{VL})=\mathrm{PT}(\mathrm{VL})=\mathrm{PS}(\mathrm{VL})$ & & \\
\hline $\mathrm{M}(\mathrm{VL})=\mathrm{H}=2 \mathrm{phM}=\mathrm{PC}(\mathrm{VL})=\mathrm{PT}(\mathrm{VL})=\mathrm{PS}(\mathrm{VL})$ & & \\
\hline & & \\
\hline & & \\
\hline $\mathrm{M}(\mathrm{VL})=\mathrm{C}=2 \mathrm{phM}=\mathrm{PC}(\mathrm{VL})=\mathrm{PT}(\mathrm{VL})=\mathrm{PS}(\mathrm{VL})$ & \multirow{5}{*}{$\begin{array}{l}\text {-R-phase-L,V,V- } \\
\text { L,S-phase-VL, } \\
\text { R-Type- } \\
\text { Exo./Endo., } \\
\text { Azeo-Yes/No } \\
\text { (Feed Cond.- } \\
\text { L,V,V-L) }\end{array}$} & \\
\hline $\mathrm{M}(\mathrm{VL})=\mathrm{R}(i)=2 \mathrm{phM}=\mathrm{PC}(\mathrm{VL})=\mathrm{PT}(\mathrm{VL})=\mathrm{PS}(\mathrm{VL})$ & & \\
\hline $\mathrm{M}(\mathrm{L})=2 \mathrm{phM}=\mathrm{PC}(\mathrm{VL})=\mathrm{PT}(\mathrm{PVL})=\mathrm{PS}(\mathrm{VL})$ & & \\
\hline $\mathrm{M}(\mathrm{VL})=2 \mathrm{phM}$ & & \\
\hline & & \\
\hline $\mathrm{M}(\mathrm{VL})=\mathrm{C}=2 \mathrm{phM}=\mathrm{PC}(\mathrm{VL})=\mathrm{PT}(\mathrm{VL})=\mathrm{PS}(\mathrm{VL})$ & \multirow{5}{*}{$\begin{array}{l}\text {-R-phase-L,V,V- } \\
\text { L,S-phase-VL, } \\
\text { R-Type- } \\
\text { Exo./Endo., } \\
\text { Azeo-Yes/No } \\
\text { (Feed Cond.- } \\
\text { L,V,V-L) }\end{array}$} & \\
\hline $\mathrm{M}(\mathrm{VL})=\mathrm{R}(i)=2 \mathrm{phM}=\mathrm{PC}(\mathrm{VL})=\mathrm{PT}(\mathrm{VL})=\mathrm{PS}(\mathrm{VL})$ & & \\
\hline $\mathrm{M}(\mathrm{V})=2 \mathrm{phM}=\mathrm{PC}(\mathrm{VL})=\mathrm{PT}(\mathrm{VV})=\mathrm{PS}(\mathrm{VV})$ & & \\
\hline $\mathrm{M}(\mathrm{L})=\mathrm{H}$ & & \\
\hline $\mathrm{M}(\mathrm{VL})=2 \mathrm{phM}$ & & \\
\hline $\mathrm{M}(\mathrm{V})=2 \mathrm{phM}$ & \multirow{5}{*}{$\begin{array}{l}\text {-R-phase-L,V,V- } \\
\text { L,S-phase-VL, } \\
\text { R-Type- } \\
\text { Exo./Endo., } \\
\text { Azeo-Yes/No } \\
\text { (Feed Cond.- } \\
\text { L,V,V-L) }\end{array}$} & \\
\hline $\mathrm{M}(\mathrm{V})=2 \mathrm{phM}=\mathrm{PT}(\mathrm{VV})=\mathrm{PS}(\mathrm{VV})$ & & \\
\hline $\mathrm{M}(\mathrm{VL})=\mathrm{R}(i)=2 \mathrm{phM}=\mathrm{PC}(\mathrm{VL})=\mathrm{PT}(\mathrm{VL})=\mathrm{PS}(\mathrm{VL})$ & & \\
\hline $\mathrm{M}(\mathrm{VL})=\mathrm{H}=2 \mathrm{phM}=\mathrm{PC}(\mathrm{VL})=\mathrm{PT}(\mathrm{VL})=\mathrm{PS}(\mathrm{VL})$ & & \\
\hline & & \\
\hline
\end{tabular}




\begin{tabular}{|c|c|}
\hline$M(V L)=2 p h M$ & \multirow{5}{*}{$\begin{array}{l}\text {-R-phase-L,V,V- } \\
\text { L,S-phase-VL, } \\
\text { R-Type- } \\
\text { Exo./Endo., } \\
\text { Azeo-Yes/No } \\
\text { (Feed Cond.- } \\
\text { L,V,V-L) }\end{array}$} \\
\hline $\mathrm{M}(\mathrm{V})=\mathrm{C}$ & \\
\hline $\mathrm{M}(\mathrm{L})=2 \mathrm{phM}=\mathrm{PC}(\mathrm{VL})=\mathrm{PT}(\mathrm{PVL})=\mathrm{PS}(\mathrm{VL})$ & \\
\hline $\mathrm{M}(\mathrm{VL})=\mathrm{R}(i)=2 \mathrm{phM}=\mathrm{PC}(\mathrm{VL})=\mathrm{PT}(\mathrm{VL})=\mathrm{PS}(\mathrm{VL})$ & \\
\hline $\mathrm{M}(\mathrm{VL})=\mathrm{H}=2 \mathrm{phM}=\mathrm{PC}(\mathrm{VL})=\mathrm{PT}(\mathrm{VL})=\mathrm{PS}(\mathrm{VL})$ & \\
\hline $\mathrm{M}(\mathrm{V})=2 \mathrm{phM}$ & \multirow{5}{*}{$\begin{array}{l}\text {-R-phase-L,V,V- } \\
\text { L,S-phase-VL, } \\
\text { R-Type- } \\
\text { Exo./Endo., } \\
\text { Azeo-Yes/No } \\
\text { (Feed Cond.- } \\
\text { L,V,V-L) }\end{array}$} \\
\hline $\mathrm{M}(\mathrm{V})=2 \mathrm{phM}=\mathrm{PT}(\mathrm{VV})=\mathrm{PS}(\mathrm{VV})$ & \\
\hline $\mathrm{M}(\mathrm{VL})=\mathrm{R}(i)=2 \mathrm{phM}=\mathrm{PC}(\mathrm{VL})=\mathrm{PT}(\mathrm{VL})=\mathrm{PS}(\mathrm{VL})$ & \\
\hline $\mathrm{M}(\mathrm{L})=2 \mathrm{phM}=\mathrm{PC}(\mathrm{VL})=\mathrm{PT}(\mathrm{PVL})=\mathrm{PS}(\mathrm{VL})$ & \\
\hline $\mathrm{M}(\mathrm{VL})=2 \mathrm{phM}$ & \\
\hline $\mathrm{M}(\mathrm{VL})=2 \mathrm{phM}$ & \multirow{7}{*}{$\begin{array}{l}\text {-R-phase-L,V,V- } \\
\text { L,S-phase-VL, } \\
\text { R-Type- } \\
\text { Exo./Endo., } \\
\text { Azeo-Yes/No } \\
\text { (Feed Cond.- } \\
\text { L,V,V-L) }\end{array}$} \\
\hline $\mathrm{M}(\mathrm{V})=\mathrm{C}$ & \\
\hline $\mathrm{M}(\mathrm{L})=2 \mathrm{phM}=\mathrm{PC}(\mathrm{VL})=\mathrm{PT}(\mathrm{PVL})=\mathrm{PS}(\mathrm{VL})$ & \\
\hline $\mathrm{M}(\mathrm{VL})=\mathrm{R}(i)=2 \mathrm{phM}=\mathrm{PC}(\mathrm{VL})=\mathrm{PT}(\mathrm{VL})=\mathrm{PS}(\mathrm{VL})$ & \\
\hline $\mathrm{M}(\mathrm{V})=2 \mathrm{phM}=\mathrm{PC}(\mathrm{VL})=\mathrm{PT}(\mathrm{VV})=\mathrm{PS}(\mathrm{VV})$ & \\
\hline $\mathrm{M}(\mathrm{L})=\mathrm{H}$ & \\
\hline $\mathrm{M}(\mathrm{VL})=2 \mathrm{phM}$ & \\
\hline $\mathrm{M}(\mathrm{VL})=2 \mathrm{phM}$ & \multirow{6}{*}{$\begin{array}{l}\text {-R-phase-L,V,V- } \\
\text { L,S-phase-VL, } \\
\text { R-Type- } \\
\text { Exo./Endo., } \\
\text { Azeo-Yes/No } \\
\text { (Feed Cond.- } \\
\text { L,V,V-L) }\end{array}$} \\
\hline $\mathrm{M}(\mathrm{V})=\mathrm{C}$ & \\
\hline $\mathrm{M}(\mathrm{L})=2 \mathrm{phM}=\mathrm{PC}(\mathrm{VL})=\mathrm{PT}(\mathrm{PVL})=\mathrm{PS}(\mathrm{VL})$ & \\
\hline $\mathrm{M}(\mathrm{VL})=\mathrm{R}(i)=2 \mathrm{phM}=\mathrm{PC}(\mathrm{VL})=\mathrm{PT}(\mathrm{VL})=\mathrm{PS}(\mathrm{VL})$ & \\
\hline $\mathrm{M}(\mathrm{L})=2 \mathrm{phM}=\mathrm{PC}(\mathrm{VL})=\mathrm{PT}(\mathrm{PVL})=\mathrm{PS}(\mathrm{VL})$ & \\
\hline $\mathrm{M}(\mathrm{VL})=2 \mathrm{phM}$ & \\
\hline
\end{tabular}




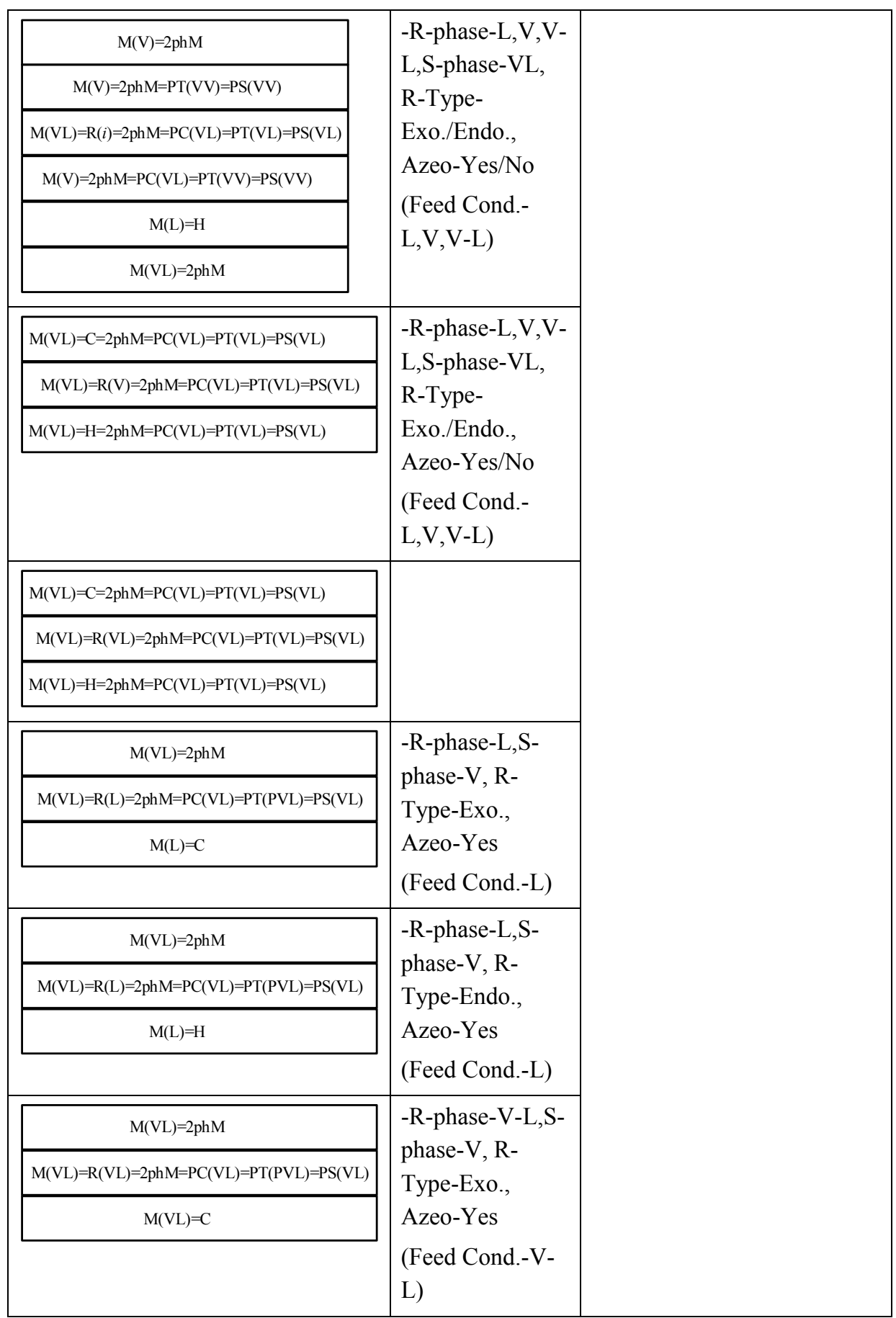




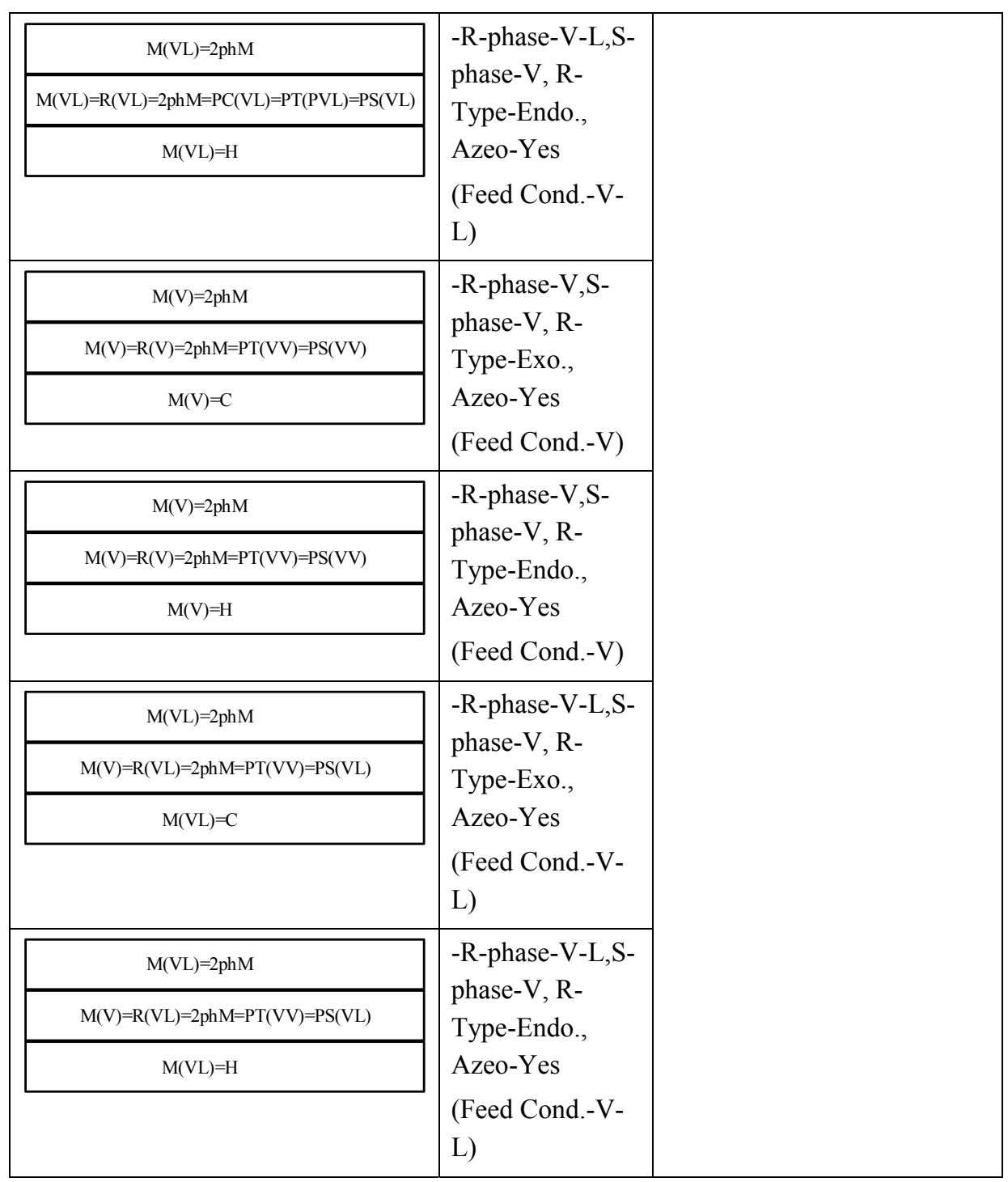




\section{Appendix E-Translation of Basic Structures into Unit Oper- ations}

In algorithm II.6 the identified basic structures that fulfill a task or set of tasks are translated into unit operations for generating the flowsheet alternatives. A knowledge base tool was expanded (Lutze, 2012) and shown in Table 0-7. 


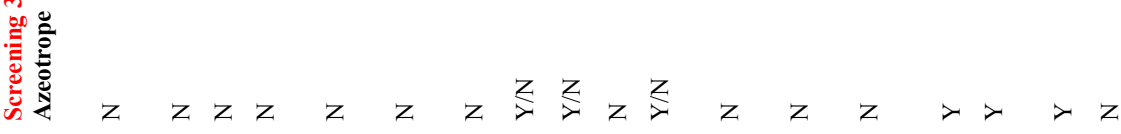

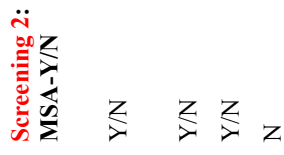

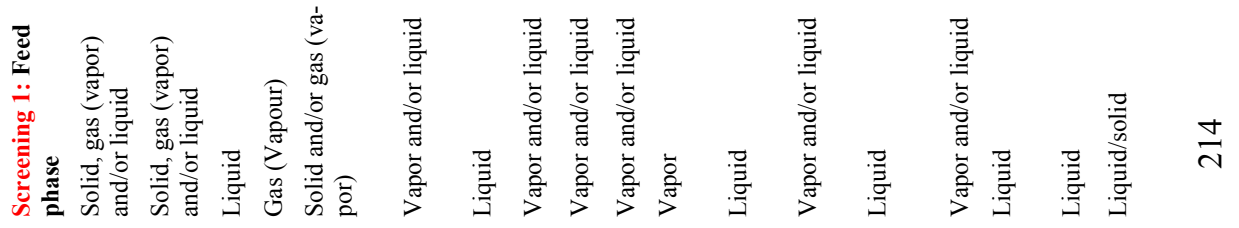

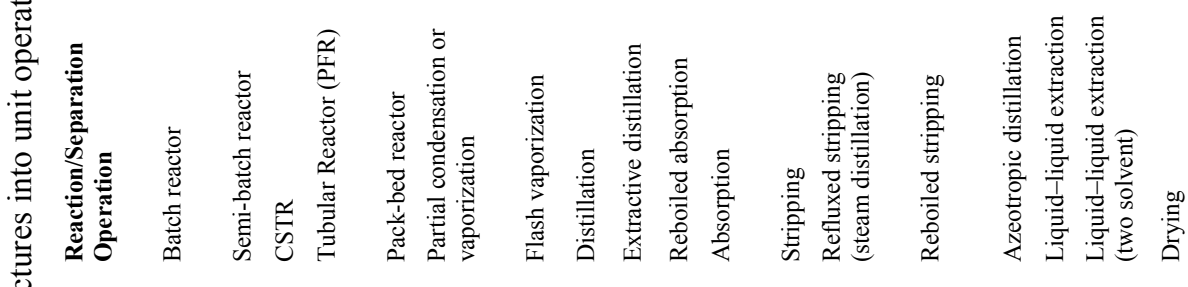
咅

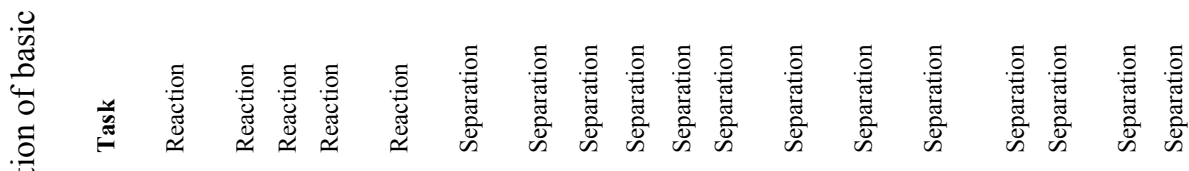

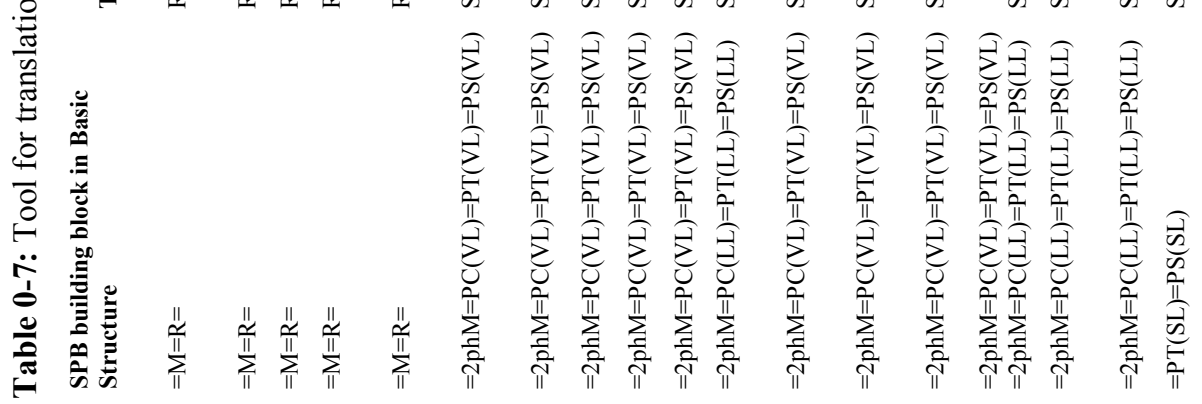


$z \stackrel{z}{z} z \quad z \quad z \stackrel{z}{z} z>>>z \underset{\nu}{z}$

$z z z>z z>z \quad z \quad z \quad z \quad z$

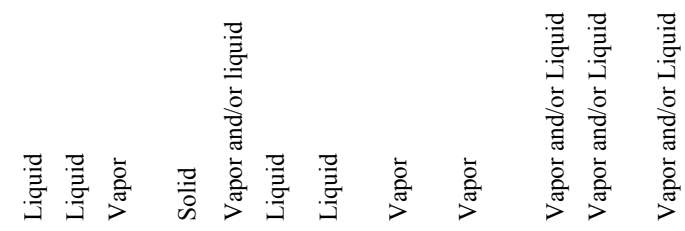

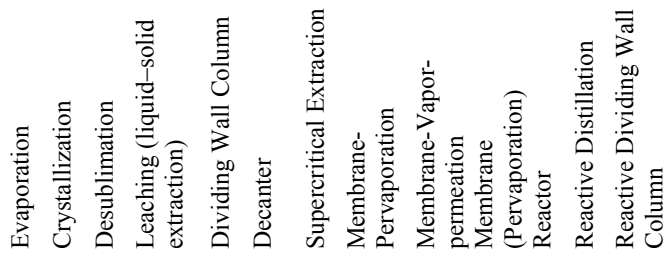

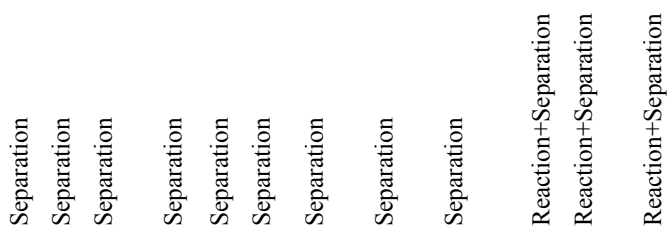

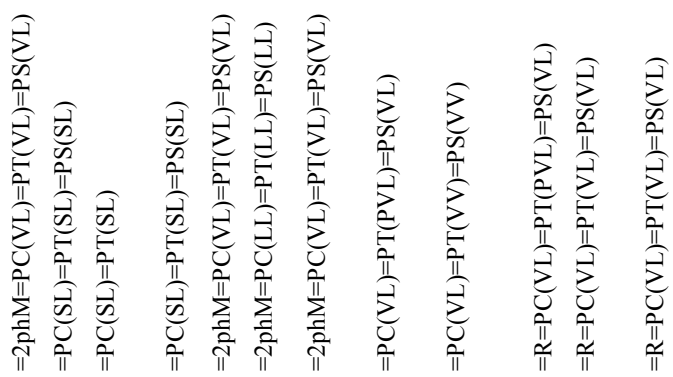




\section{Appendix F-Membrane reactor Analysis-Methyl-Acetate}

The membrane reactor which is part of flowsheet alternative 3 , flowsheet alternative 4 and flowsheet alternative 5 is analyzed using a semi-batch model (Inoue et al., 2007). The reactor model and solution results are discussed below.

The overall mass balance of the reactor excluding the membrane effects (permeation) is given in Equation 0.30. In Equation $0.30 N_{i}$ is the number of moles of the component, $v_{i}$ is the stoichiometric coefficient and $r_{i}$ is the rate of consumption/production.

$$
\frac{d N_{i}}{d t}=v_{i} r_{i}
$$

Considering the permeation effect of a species through the membrane, Equation 0.30 becomes Equation 0.31 .

$$
\frac{d N_{i}}{d t}=v_{i} r_{i}-Q_{i}
$$

In Equation 0.31, $Q_{i}$ is the permeation rate of the component through the membrane and is defined in Equation 0.32. In Equation 0.32, $A$ is the membrane area, $P_{i}$ is the permeability coefficient and $a_{i}$ is the activity of the component.

$$
Q_{i}=A P_{i} a_{i}
$$

The kinetic and UNIQUAC thermodynamic data is obtained from Pöpken e.. al. (2000) and the permeability coefficients data are obtained from Assabumrungrat et al. (2003). Therefore Equation 0.31 becomes Equation 0.33.

$$
\frac{d N_{i}}{d t}=v_{i} m_{c a t}\left(\frac{k_{1} a_{H O A c}^{\prime} a_{H O A c}^{\prime}-k_{-1} a_{M e O A c}^{\prime} a_{H 2 O}^{\prime}}{\left(a_{H O A c}^{\prime}+a_{H O A C}^{\prime}+a_{M e O A C}^{\prime}+a_{H 2 O}^{\prime}\right)^{2}}\right)-A P_{i} a_{i}
$$

For analyzing the semi-batch model, Equation 0.33 is non-dimensionalised into Equation 0.34 . In Equation $0.34 F_{H O A c}$ is the amount of HOAc fed to the reactor initially.

$$
\begin{aligned}
& \frac{d^{N_{i}} / F_{H O A c 0}}{d t}=v_{i}\left(\frac{k_{1} m_{c a t}}{F_{H O A C O}}\right)\left(\frac{a_{H O A c}^{\prime} a_{H O A c}^{\prime}-a_{M e O A c}^{\prime} a_{H 2 O}^{\prime} / K_{a}}{\left(a_{H O A C}^{\prime}+a_{H O A C}^{\prime}+a_{M e O A c}^{\prime}+a_{H 2 O}^{\prime}\right)^{2}}\right)-\left(\frac{k_{1} m_{c a t}}{F_{H O A C O}}\right)\left(\frac{P_{H 2 O} A}{k_{1} m_{c a t}}\right)\left(\frac{1}{P_{H 2 O} / P_{i}}\right) a_{i} \\
& \frac{d \overline{N_{i}}}{d t}=v_{i} D a\left(\frac{r_{i}}{k_{1}}\right)-\bar{Q}_{i}
\end{aligned}
$$

The final dimensionless form of the semi-batch model is given in Equation 0.35. In Equation 0.35 the dimensionless parameters are as follows: 
1. Damkohler number, $D a$, is the dimensionless ratio of a characteristic liquid residence time to the reaction time. High values indicate that the forward reaction is fast and low values indicate that the reaction is kinetically controlled

2. The rate ratio (Assabumrungrat et al., 2003), $\delta$ is the dimensionless ratio of the permeation rate to the reaction rate

3. The membrane selectivity, $\beta$, is the dimensionless ratio of the membrane selectivity. High values mean that the membrane is not selective to a specific component

$$
\frac{d \bar{N}_{i}}{d t}=v_{i} D a\left(\frac{a_{H O A c}^{\prime} a_{H O A c}^{\prime}-a_{M e O A c}^{\prime} a_{H 2 O}^{\prime} / K_{a}}{\left(a_{H O A C}^{\prime}+a_{H O A C}^{\prime}+a_{M e O A C}^{\prime}+a_{H 2 O}^{\prime}\right)^{2}}\right)-\frac{D a \delta a_{i}}{\beta_{i}}
$$

The reaction rate using an adsorption-based model (Pöpken et al., 2000) is expressed in Equation 0.27 . In Equation $0.27, K_{i}$ is the adsorption equilibrium constant and $M_{i}$ is the molar mass of the compound.

$$
\begin{aligned}
& r=m_{c a t}\left(\frac{a_{H O A c}^{\prime} a_{H O A c}^{\prime}-a_{M e O A c}^{\prime} a_{H 2 O}^{\prime} / K_{a}}{\left(a_{H O A c}^{\prime}+a_{H O A C}^{\prime}+a_{M e O A C}^{\prime}+a_{H 2 O}^{\prime}\right)^{2}}\right) \\
& a_{i}^{\prime}=\frac{K_{i} a_{i}}{M_{i}}
\end{aligned}
$$

The activities of the components are defined using Equation 0.37. In Equation 0.37, $x_{i}$ is the mole fraction of the compound in the liquid phase and $\gamma_{i}$ is the activity coefficient.

$$
a_{i}=x_{i} \gamma_{i}
$$

The liquid activity coefficients are calculated using the UNIQUAC thermodynamic model and are expressed as a function of temperature, binary parameters and molar fractions.

The ideal membrane should be selective to $\mathrm{H} 2 \mathrm{O}$ only, however as reported by Assabumrungrat et al., (2003), the membrane is also selective to $\mathrm{MeOH}$ and weakly selective to MeOAc. Therefore a main parameter in Equation 0.36 is the membrane selectivity, $\beta$. Therefore through the model based reactor analysis one can study the following:

1. Set and verify that a set conversion of HOAc can be achieved 
2. Propose a recommended minimum value of $\beta$, that is a design criteria of the membrane. This can be useful because it provides a measure for which the membrane can be improved

3. The effect of the dimensionless parameters of the HOAc conversion

Equation 0.36 is solved assuming the membrane is only permeable to $\mathrm{H} 2 \mathrm{O}(\beta=1)$ and $\mathrm{MeOH}$ ( $\beta=$ to be calculated). The conversion of HOAc is set at $92 \%$ that is the minimum conversion to satisfy the operational constraint for HOAc conversion. The minimum value of $\beta$ for $\mathrm{MeOH}$ is calculated using the following method:

1. Obtain the LHSV for the catalyst. This gives the value final time, $t$ to solve Equation 0.36 because it provides an estimate of the residence time for the reactor

2. Investigate the effect of Da and $\delta$ on $\beta$

3. Select the value of Da and $\delta$ and corresponding value of $\beta$ for achieving the required conversion of HOAc.

4. Investigate the effect of the Da number and $\delta$ for the selected value of $\beta$-.This shows the effect of each parameter on the conversion of the raw material considered.

Therefore Equation 0.36 is solved using the above method and the results are:

1. $\mathrm{LHSV}=5 \mathrm{hr}^{-1}$ (Rohm and Hass Company, 2003)

2. The effect of Da and $\delta$ on $\beta$ is shown in Figure 0-2 and Figure 0-3

a. Figure 0-2- Increasing the Da number decreases the membrane selectivity $(\beta \mathrm{MeOH})$ for $\mathrm{MeOH}$. This happens because the rate of reaction increases and therefore to ensure that $\mathrm{MeOH}$ is available for reacting with $\mathrm{HOAc}$, the membrane should be less selective to $\mathrm{MeOH}$. The reverse is also true that is for low values of the Da number $\mathrm{BMeOH}$ increases because the rate of reaction decreases and therefore the membrane should be least selective to $\mathrm{MeOH}$. For increasing values of the rate ratio $(\delta)$ the value of $\beta \mathrm{MeOH}$ increases for the same Da number because the membrane must be least selective to $\mathrm{MeOH}$ in order to prevent $\mathrm{MeOH}$ loss through the membrane. Therefore one does not want to be in the operating window that is circled but the operating window highlighted grey 
b. Figure 0-3- Increasing the value of the rate ratio $(\delta)$ increases the membrane selectivity $(\beta \mathrm{MeOH})$ for $\mathrm{MeOH}$. This happens because $\mathrm{MeOH}$ will be lost through the membrane and not enough $\mathrm{MeOH}$ will be present to react with HOAc. Also the Da number has no effect on the rate ratio $(\delta)$ because the Da number governs the rate at which the reaction happens and not the behavior of the membrane.

3. The selected values of $\mathrm{Da}$ and $\delta$ are 20 and 0.05 respectively with a recommended value of $\beta=9.15$ (calculated)

4. The effect of the Da number and $\delta$ for the selected (calculated) value of $\beta$ on the HOAc conversion are shown in Figure 0-2 and Figure 0-3.

a. Figure 0-4- For a set value of $\delta$, increasing the Da number increases the HOAc conversion. This happens because increasing the Da number increases the reaction residence time. For increasing values of $\delta$ and the Da number it is possible to go above the equilibrium conversion due to the increase rate of removal of $\mathrm{H} 2 \mathrm{O}$. However because the membrane is also permeable to $\mathrm{MeOH}, \mathrm{MeOH}$ is also being removed from the reactor and therefore the steady state conversion is achieved

b. Figure 0-5- For a set value of the Da number, increasing $\delta$ increases the HOAc conversion. This is because increasing $\delta$ increases the rate of removal of $\mathrm{H} 2 \mathrm{O}$ (but also $\mathrm{MeOH}$ ) thereby shifting the equilibrium. For low values of the Da number one cannot go beyond the equilibrium conversion because the reaction is kinetically controlled. 


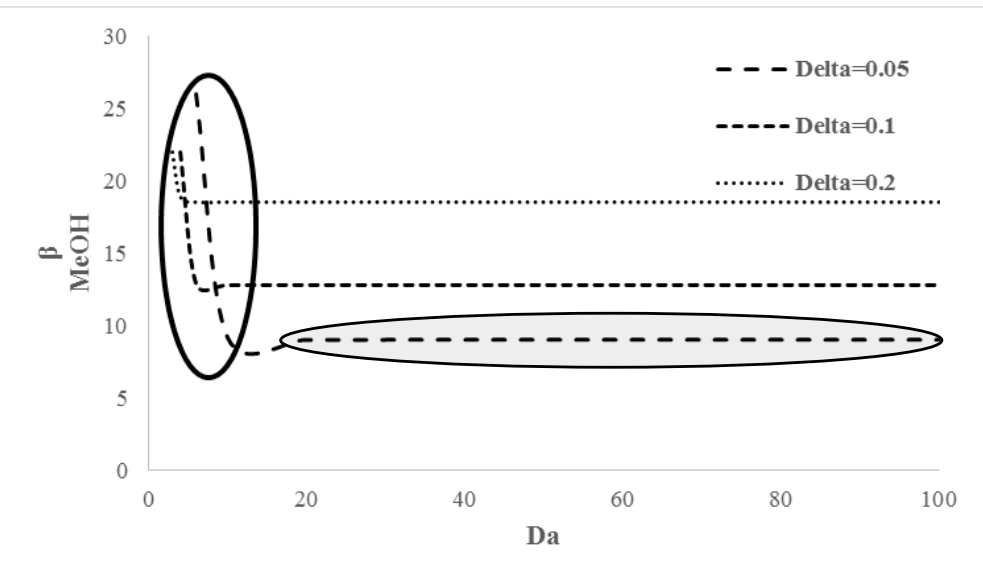

Figure 0-2: Effect of the Da number on the membrane selectivity $(\beta \mathrm{MeOH})$ for different values of the rate ratio $(\delta)$ for HOAc conversion $=0.92$

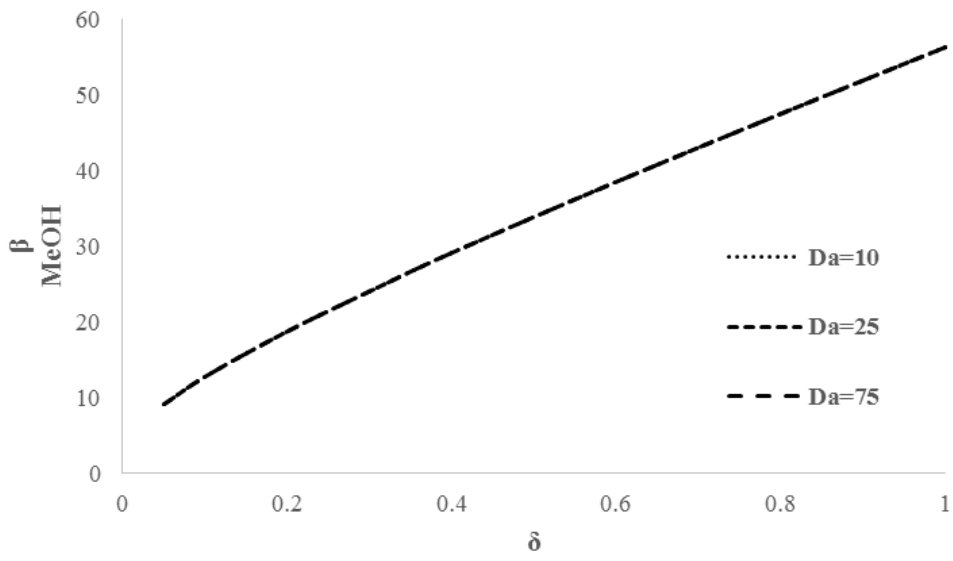

Figure 0-3: Effect of the rate ratio $(\delta)$ on the membrane selectivity $(\beta \mathrm{MeOH})$ for different values of the Da number for HOAc conversion $=0.92$ 


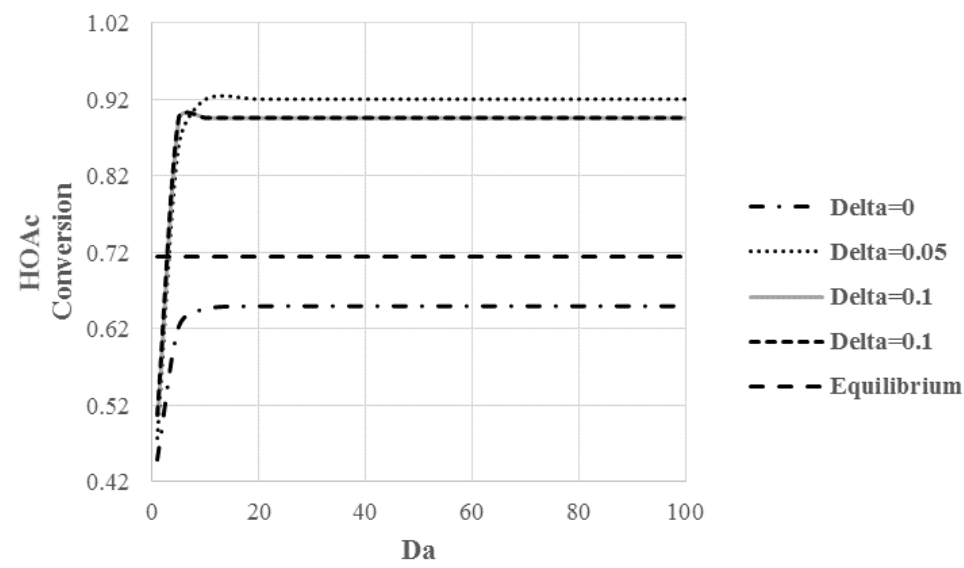

Figure 0-4: Effect of the Da number on HOAc conversion for different values of the rate ratio $(\delta)$

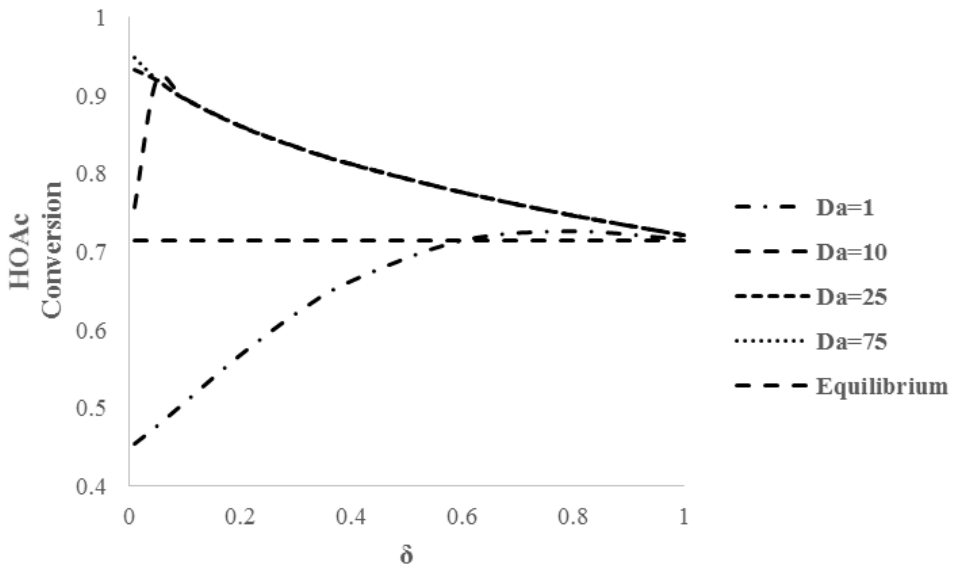

Figure 0-5: Effect of the rate ratio $(\delta)$ on HOAc conversion for different values of the Da number 
The formula matrix for the four compound system for the production of methyl acetate is given in Table 0-8. This is then used for calculation and generation of the reactive VLE phase diagram and residue curve map which is represented on a ternary diagram because the four-compound $\mathrm{MeOAc}$ system is represented by three elements. The method is based on Daza et al. (2004). This method is advantageous in generating reactive VLE phase diagrams and residue curve maps because for a multi-component system, as long as the compounds can be represented by three elements of less, these diagrams can be represented graphically for deducing useful information.

Table 0-8: Formula matrix for the MeOAc system

\begin{tabular}{|c|c|c|c|c|}
\hline $\begin{array}{c}\text { Element/ } \\
\text { Component }\end{array}$ & $\mathrm{MeOH}$ & $\mathrm{HOAc}$ & $\mathrm{MeOAc}$ & $\mathrm{H} 2 \mathrm{O}$ \\
\hline $\mathrm{A}=\mathrm{C} 2 \mathrm{H} 2 \mathrm{O}$ & 0 & 1 & 1 & 0 \\
\hline $\mathrm{B}=\mathrm{CH} 4 \mathrm{O}$ & 1 & 0 & 1 & 0 \\
\hline $\mathrm{C}=\mathrm{H} 2 \mathrm{O}$ & 0 & 1 & 0 & 1 \\
\hline
\end{tabular}

Van Baelen et al. (2005) has studied the effect of water-alcohol mixtures and H2O acidwater mixtures. According to the weight $\%$ of $\mathrm{H} 2 \mathrm{O}$ in the feed to the membrane, $\mathrm{MeOH}$ can also permeate the membrane together with H2O. Figure 0-6 is used for evaluating this, for flowsheet alternative 4 and flowsheet alternative 5 .

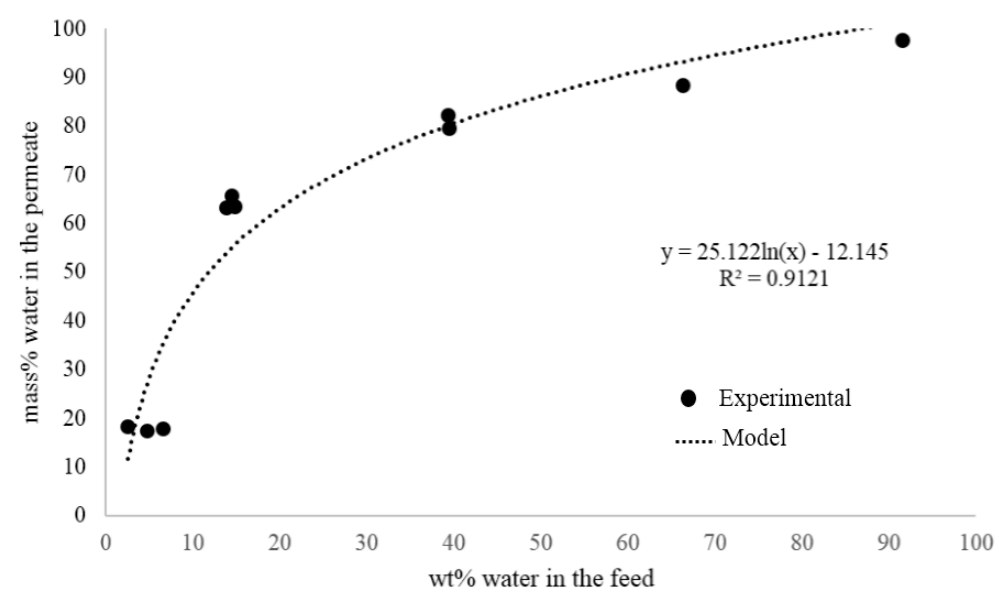

Figure 0-6: Mass\% of $\mathrm{H} 2 \mathrm{O}$ in the permeate for PERVAP 2201 


\section{www.capec.kt.dtu.dk}

Computer-Aided Process-Product Engineering Center

Department of Chemical \& Biochemical Engineering

Soltofts Plads

Building 227

DK-2800 Kgs. Lyngby

Denmark

Tel: (+45) 45252800

Fax: (+45) 45882258

E-mail: rag@kt.dtu.dk 
CAPEC-PROCESS

Computer Aided Process Engineering/

Process Engineering and Technology center

Department of Chemical and Biochemical Engineering

Technical University of Denmark

Søltofts Plads, Building 229

DK-2800 Kgs. Lyngby

Denmark

Phone: $\quad+4545252800$

Fax: $\quad+4545252906$

Web: $\quad$ www.capec-process.kt.dtu.dk 